\title{
A Nested Case-Control Study of Leukemia and Ionizing Radiation at the Portsmouth Naval Shipyard
}




\section{A Nested Case-Control Study of Leukemia and Ionizing Radiation at the Portsmouth Naval Shipyard}




\section{Disclaimer}

Mention of any company or product does not constitute endorsement by the National Institute for Occupational Safety and Health (NIOSH). In addition, citations to Web sites do not constitute NIOSH endorsement of the sponsoring organizations or their programs or products. Furthermore, NIOSH is not responsible for the content of these Web sites.

Ordering Information

To receive documents or other information about occupational safety and health topics, contact NIOSH at

NIOSH-Publications Dissemination

4676 Columbia Parkway

Cincinnati, Ohio 45226-1998

Telephone: 1-800-35-NIOSH (1-800-356-4675)

Fax: 513-533-8573

E-mail: pubstaft@cdc.gov

or visit the NIOSH Web site at www.cdc.gov/niosh 


\section{Preface}

Ionizing radiation and its sources are used every day in medical, industrial and governmental facilities around the world. Although some health risks from ionizing radiation exposures are widely recognized, the association of these exposures to specific diseases, especially various types of cancer, remains uncertain. Workers at U.S. Department of Energy (DOE) facilities have produced nuclear weapons, provided nuclear fuel materials for power reactors, and conducted a wide spectrum of research related to nuclear safety and other scientific issues. While completing this work, many of the employees have been exposed to ionizing radiation and other potentially hazardous materials.

Since 1991, the National Institute for Occupational Safety and Health (NIOSH) has conducted analytical epidemiologic studies of workers at DOE nuclear facilities, through a Memorandum of Understanding between the DOE and the U.S. Department of Health and Human Services (DHHS). The agreement occurred in response to recommendations to the Secretary of Energy in 1989 by the independent Secretarial Panel for the Evaluation of Epidemiologic Research Activities (SPEERA).

This technical report, entitled A Nested Case-Control Study of Leukemia and Ionizing Radiation at the Portsmouth Naval Shipyard, is one several products of the NIOSH Occupational Energy Research Program that are being published as a series. Most of these studies include detailed historical exposure assessments for radiation and other potentially hazardous agents so the health risks at different levels of exposure can be accurately estimated. Each of these studies contributes to the knowledge required to ensure that workers are adequately protected from chronic disease over their working lifetimes.

Distribution of this final report addresses the recommendation of the SPEERA panel to make reports of study results more readily available to workers and the interested public. Additional information about the NIOSH epidemiologic research program of occupational health studies involving the DOE nuclear weapons workforce may be obtained by contacting NIOSH toll free at 1-800-35-NIOSH (1-800-356-4674) or by visiting the NIOSH website for the Occupational Energy Research Program at http://www.cdc.gov/niosh/2001-133.html 


\section{Authors}

Kubale TL ${ }^{1}$, Daniels RD ${ }^{1}$, Yiin, $\mathrm{JH}^{1}$, Kinnes $\mathrm{GM}^{1}$, Couch $\mathrm{J}^{2}$, Schubauer-Berigan $\mathrm{MK}^{1}$, Silver $\mathrm{SR}^{1}$, Nowlin $\mathrm{SJ}^{1}$, Chen $\mathrm{PH}^{1}$

${ }^{1}$ Division of Surveillance, Hazard Evaluations, and Field Studies, National Institute for Occupational Safety and Health

${ }^{2}$ Westat Inc.

\section{Acknowledgments}

Funding for this study was provided through an agreement between the U.S. DOE and the U.S. DHHS. This technical report resulted from the cooperation and support of the U.S. Navy, DOE, and their employees and contractors. Employees from the Portsmouth Naval Shipyard (PNS) provided numerous sources of information that were required to complete this complex study. The PNS professional staff answered many telephone calls and e-mails as source information was interpreted. This study particularly benefited from the assistance of the Jeff Brann, Jim Braun, and the shipyard Human Resources staff.

Ms. Barbara Bauman and Ms. Sondra Wisdom of the National Public Record Center facility provided invaluable assistance locating critical medical record files, enabling an analysis of work-related medical X-ray exposure.

Current and former staff at DOE headquarters, including Marsha Lawn, Gerry Petersen, and Heather Stockwell, provided ongoing encouragement for completion of the study.

Former NIOSH scientists Robert Rinsky, William Murray, and Tim Jiggins carried out initial epidemiological, health physics, and industrial hygiene work on the study. We are grateful to the many current and former government and contract staff working with NIOSH who have provided essential services for the collection, compilation, and validation of records and data used in this study. These include Dennis Zaebst, David Back, Kevin Hubbard, Dianne Reeder, Melissa Tolson, Kim Collins, Susan Freking, and Donna Pfirman, who was instrumental in the preparation of this report.

The quality of this report was substantially improved as a result of technical reviews that were provided by colleagues within NIOSH, including David Utterback, James Deadens, Dennis Zaebst, and Erin Wickliff, as well as scientific peers outside of NIOSH, Rick Hornung and Robert Rinsky.

Finally, Drs. Buncher, Lockey, Rice, Rinsky, and Spitz from the Department of Environmental Health at the University of Cincinnati provided invaluable review, advice, and guidance to the study team. 


\section{Abstract}

\section{Objective}

To determine if there is an association between occupational exposure to external ionizing radiation and leukemia mortality among civilian Portsmouth Naval Shipyard workers after potential confounders and effect modifiers such as solvent exposure, and time since exposure are considered.

\section{Methods}

This study employs a nested case-control design and includes 115 leukemia cases and 460 controls. Among the cases and controls, 201 (35\%) were monitored for radiation exposure. Badge doses and exposures to work-required medical x-rays were included in the analysis. Benzene and carbon tetrachloride exposure was assessed using workers' job information and industrial hygiene records. Conditional logistic regression was used to analyze the exposure-response relationship between external ionizing radiation exposure and leukemia mortality.

\section{Results}

A significant positive association was found between leukemia mortality and external ionizing whole-body radiation exposure $(\mathrm{OR}=1.08$ at $10 \mathrm{mSv} ; 95 \% \mathrm{CI}=1.01,1.16)$ adjusting for gender, radiation worker status and solvent exposure duration. The latter factor $(\mathrm{OR}=1.03$ at one year of exposure; $95 \% \mathrm{CI}=1.01,1.06)$ was also significantly associated with leukemia mortality. The incorporation of estimated doses from workrelated medical x-ray exposures did not change the leukemia risk estimate.

Significantly different exposure-response trends were observed in the $2.5-5$ years since last exposure category compared to the $>10$ years since last exposure category. The choice of categories for time since last (radiation) exposure (TSLE) classification did not greatly alter these findings.

In this study the results using a linear ERR model estimate an excess relative risk of $23 \%$ $(95 \% \mathrm{CI}=3 \%, 88 \%)$ per $10 \mathrm{mSv}$ of external radiation exposure from occupational sources after potential confounders were considered in the analysis. The excess relative risk has previously been estimated at between $-4.1 \%$ and $19.0 \%$ at $10 \mathrm{mSv}$ in other epidemiologic studies of workers exposed to penetrating ionizing radiation (Fraser et al., 1993) and approximately 4\% for individuals in the Japanese Life Span Study who were simultaneously exposed at various ages and developed diseases at different times after exposure (BEIR V,1990; Schubauer-Berigan and Wenzl, 2001). 


\section{Conclusion}

We observed a positive association between leukemia mortality and increasing external whole-body ionizing radiation exposure, adjusting for radiation worker status and solvent exposure duration. A significant exposure response between leukemia mortality and the duration of time workers were employed in job categories where solvent exposures were probable was also observed. However, solvent exposure was not a confounder of the association between radiation exposure and leukemia risk. 


\section{Table of Contents}

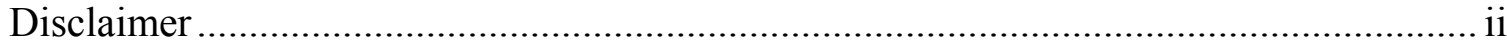

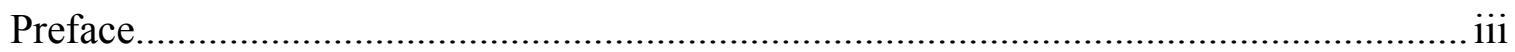

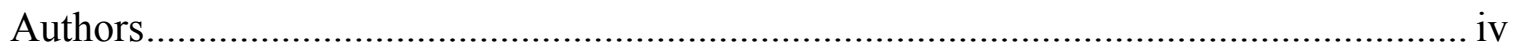

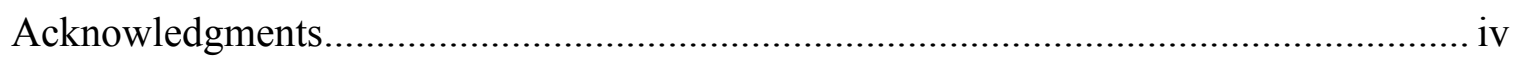

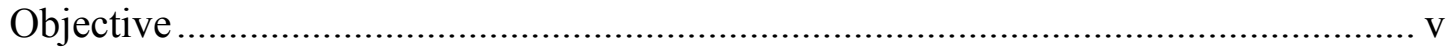

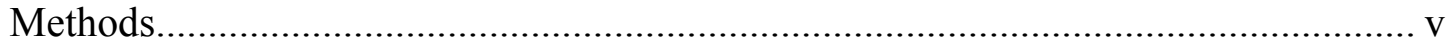

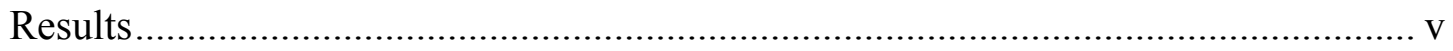

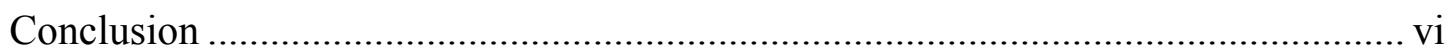

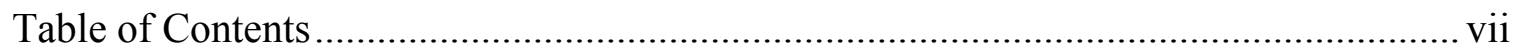

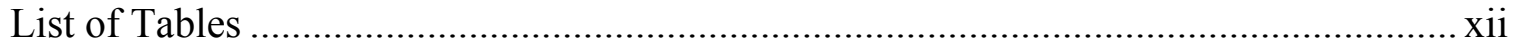

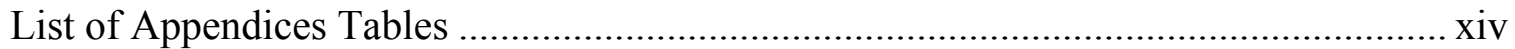

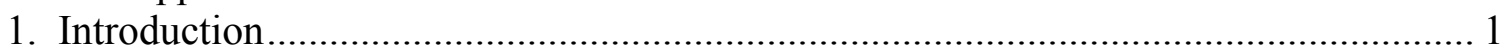

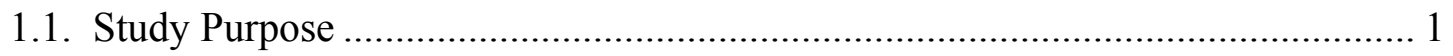

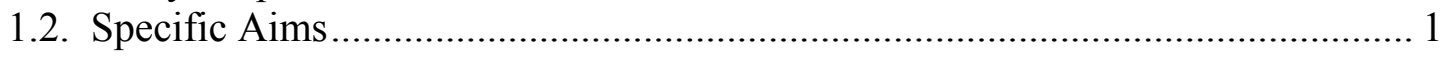

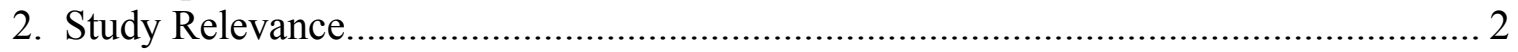

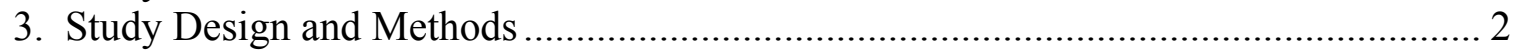

3.1. Brief History of the Portsmouth Naval Shipyard............................................ 2

3.1.1. Previous occupational studies conducted at PNS ................................... 3

3.2. Study Design —Leukemia Case-Control Study ............................................ 4

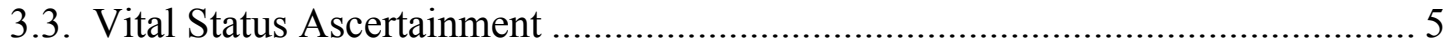

3.4. Method of Case and Control Selection ............................................................. 5

3.4.1. Selection of cases .......................................................................... 5

3.4.2. Selection of controls ............................................................................. 5

3.5. Description of the Primary Radiological and Chemical PNS Exposures ............. 6

3.5.1. Overview of PNS work organization ................................................. 6

3.5.2. Radiation exposure during overhaul, repair, and refueling activities....... 6

3.5.3. Radiation exposure from fission products ....................................... 7

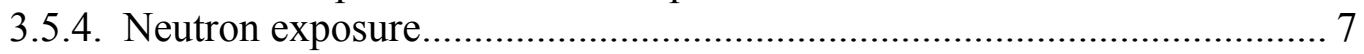

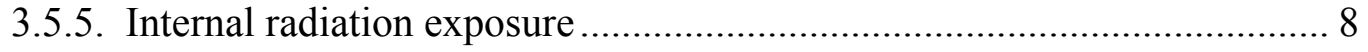

3.5.6. Work-related medical $x$-ray exposure .................................................... 8

3.5.7. Types of chest $\mathrm{x}$-ray techniques used at PNS ........................................ 9

3.5.8. Method for estimating dose equivalent to the active bone marrow from occupational work-related medical x-rays......................................... 10

3.6. Radiation Exposure Assessment .................................................................... 11

3.6.1. Devices used to monitor external ionizing radiation exposure at PNS ... 11

3.6.2. Evaluation of missed radiation exposure due to the sensitivity of dosimetry devices ...................................................................... 11

3.6.3. Evaluation of occupational radiation exposures that have occurred while workers were previously employed at a facility other than PNS .......... 11 
3.6.4. PNS methods of recording external ionizing radiation exposure............ 12

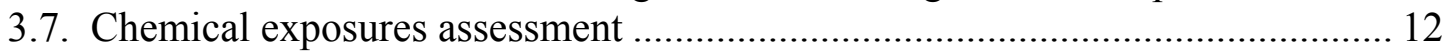

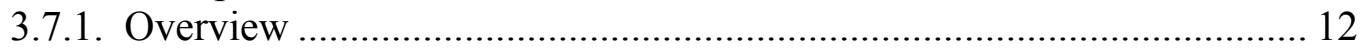

3.7.2. PNS industrial hygiene program ................................................... 12

3.7.3. Identification of jobs and shops with the greatest potential exposure to benzene and carbon tetrachloride ...................................................... 13

3.7.4. Identification of job and shop assignments for cases and controls ......... 15

3.7.5. Standardization and grouping of job titles............................................ 15

3.7.6. Analysis of benzene and carbon tetrachloride exposure ....................... 16

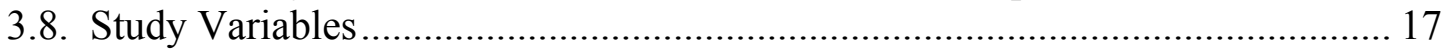

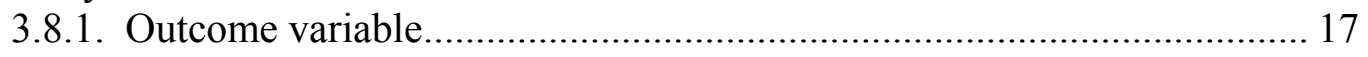

3.8.2. Radiation dose metrics ................................................................... 18

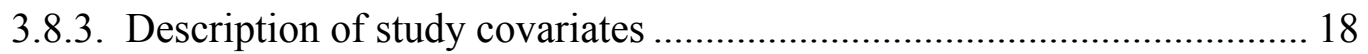

3.8.4. Covariates not included in the analysis .............................................. 20

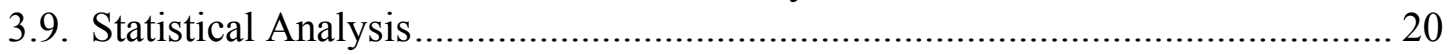

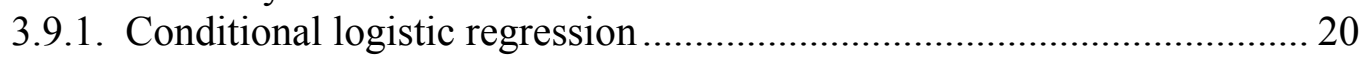

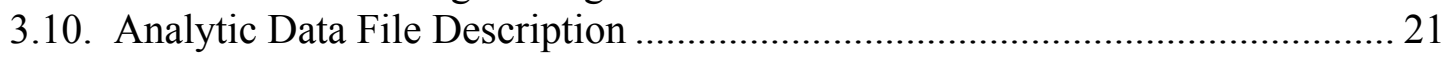

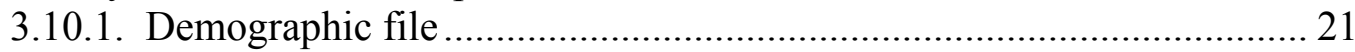

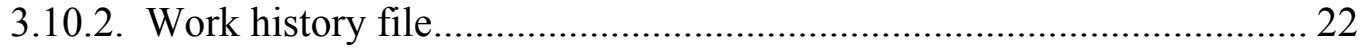

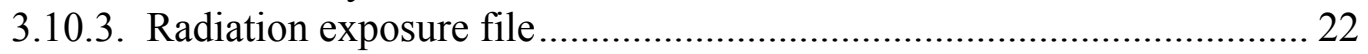

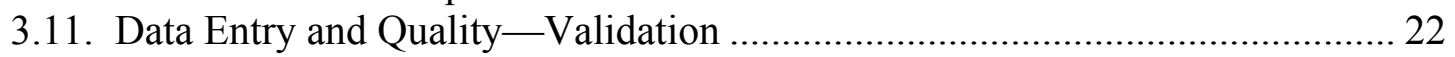

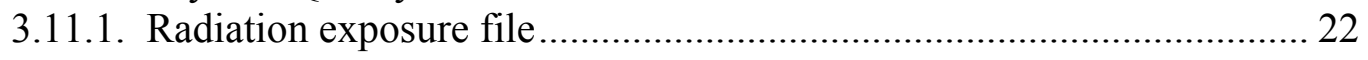

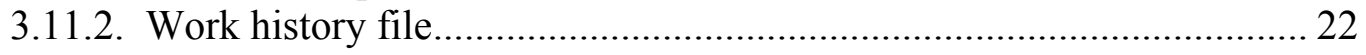

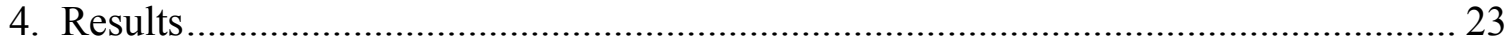

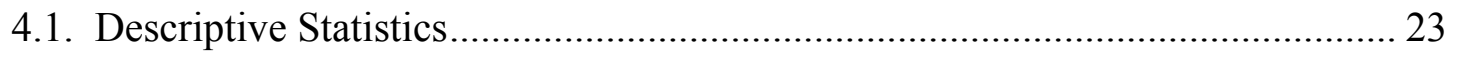

4.1.1. Cause of death information for the cases ........................................... 23

4.1.2. Temporal variables — cases and controls ......................................... 23

4.2 Radiation Exposure Descriptive Statistics ..................................................... 24

4.2.1. Radiation exposure from occupational sources .................................... 24

4.2.2. Radiation exposure from offsite sources .......................................... 26

4.2.3. Estimated missed radiation exposure ................................................. 26

4.3. Cumulative Bone Marrow Dose Descriptive Statistics .................................... 26

4.3.1. Bone marrow dose estimates from occupational sources...................... 26

4.3.2. Bone marrow dose estimates from work-related medical x-ray exams .. 27

4.3.3. Cumulative bone marrow dose from onsite occupational sources and work-related medical x-rays combined ........................................... 30

4.4. Solvent Exposure Duration Descriptive Statistics ......................................... 31

4.5. Results of Conditional Logistic Regression Analysis....................................... 32

4.5.1. Determination of lag period - primary exposure variable - cumulative radiation badge exposure. 
4.5.2. Assessment of interactions with the primary exposure metriccumulative radiation badge exposure ................................................... 33

4.5.3. Final regression model — occupational badge exposure ........................ 36

4.5.4. Final regression model using bone marrow dose ................................ 37 4.5.4.1. Final log-linear regression model - primary exposure variablebone marrow dose from occupational sources ......................... 37

4.5.4.2. Final regression model — primary exposure variableoccupational bone marrow dose combined with medical x-ray bone marrow dose............................................................... 38

4.5.5. Sensitivity analysis — badge exposure and time since last exposure variable interaction ........................................................................ 39

4.5.6. Sensitivity analysis - occupational and work-related medical $\mathrm{x}$-ray bone marrow dose combined and time since last exposure variable interaction ........................................................................... 42

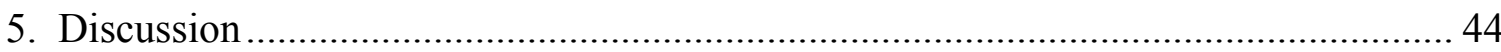

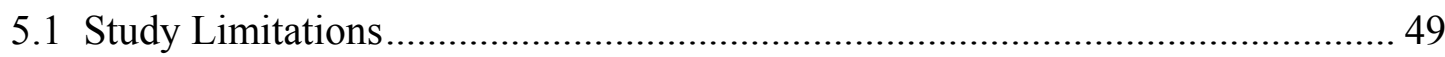

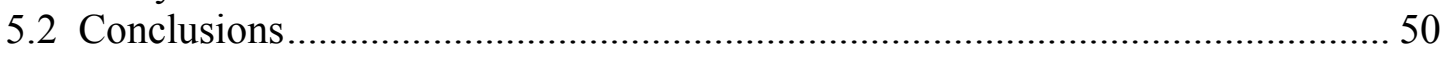

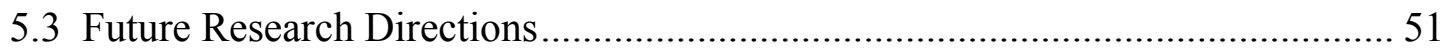

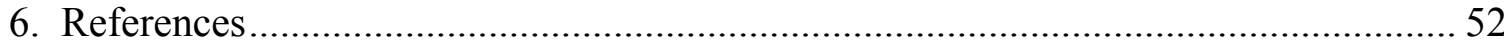

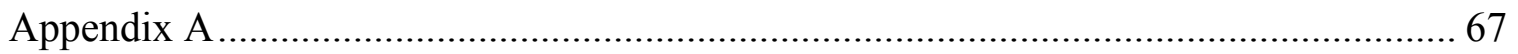

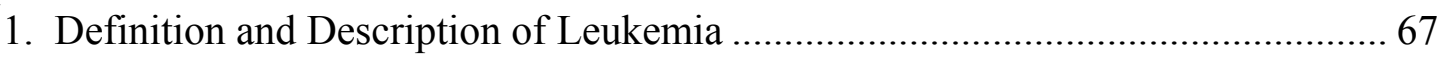

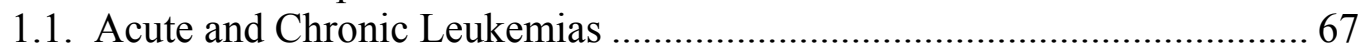

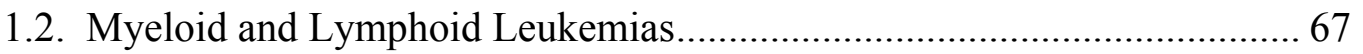

2. Identification of Leukemia as a Clinical Entity_A Brief History .........................6 68

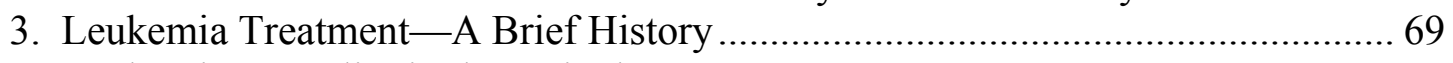

4. Leukemia Mortality in the United States ....................................................... 70

4.1. Mortality from All Leukemia Types Combined-Trends for Males and Females, All Races ............................................................. 70

4.2. Mortality from All Leukemia Types Combined-Trends for Males of All Races .................................................................................. 70

4.3. Mortality from All Leukemia Types Combined-Trends for Females of All Races ....................................................................................... 70

4.4. Mortality from All Leukemia Types Combined-Trends for White Males and Females ......................................................................... 70

4.5. Leukemia Mortality for All Leukemia Types Combined-Black Males and Females ..................................................................... 71

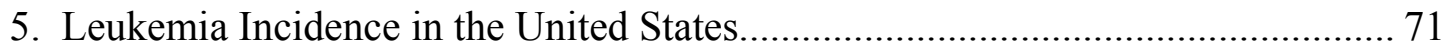

5.1. Incidence of All Leukemia Types Combined.......................................... 71

5.2. Incidence of All Leukemia Types Combined-Trends for White Males and Females 
5.3. Incidence of All Leukemia Types Combined-Trends for Black

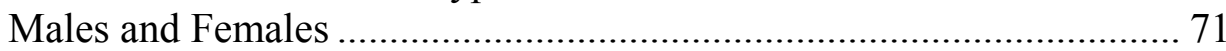

5.4. Survival Rates for All Leukemia Types Combined-Both

Males and Females 72

6. The Four Major Leukemia Subtypes - Incidence, Mortality, and Five-Year

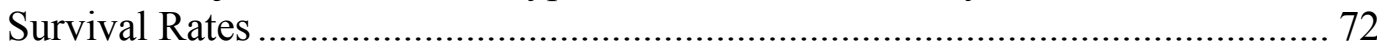

6.1. Acute Myeloid Leukemia (AML) ............................................................. 72

6.2. Chronic Lymphocytic Leukemia (CLL) ……………………………...... 72

6.3. Chronic Myeloid Leukemia (CML) ………………………………......... 73

6.4. Acute Lymphocytic Leukemia (ALL) ..................................................... 73

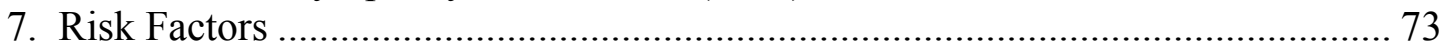

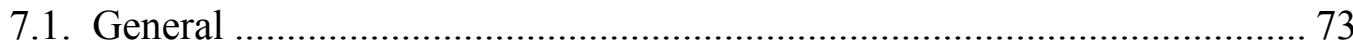

7.2. Familial and Genetic Factors.................................................................. 73

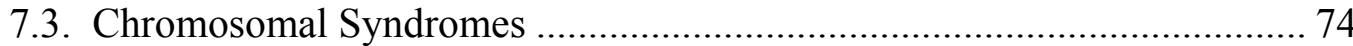

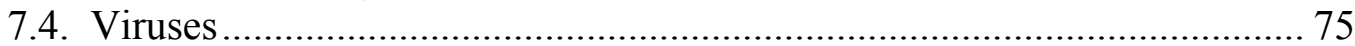

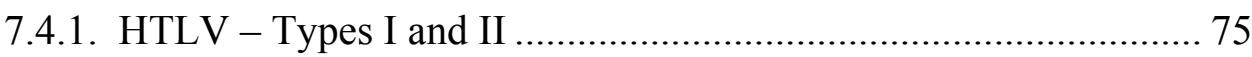

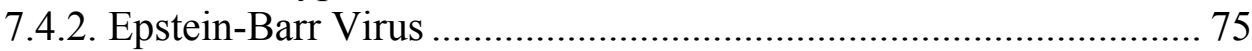

7.4.3. Hepatitis B Virus................................................................................ 75

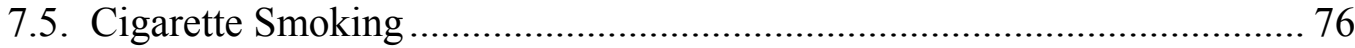

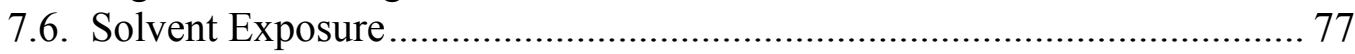

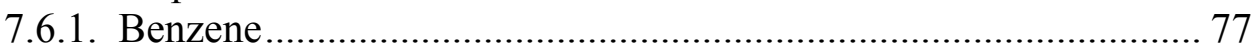

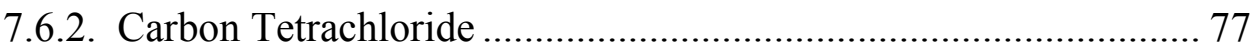

7.6.3. Ethylene Glycol .................................................................... 78

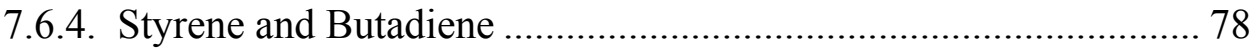

7.7. Ionizing Radiation —Atomic Bomb Exposures......................................... 79

7.7.1. Japanese Atomic Bomb Survivors ................................................ 79

7.7.2. Military Personnel Present During Nuclear Weapons Testing ...... 79

7.8. Ionizing Radiation - Occupational Studies of United States, British,

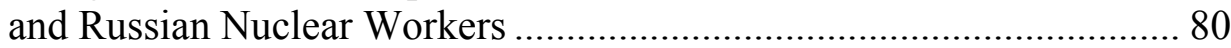

7.8.1. The United States Department of Energy Hanford Facility........... 80

7.8.2. The United States Department of Energy Savannah River

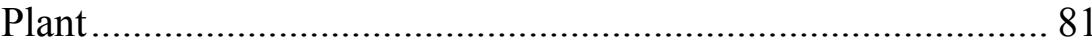

7.8.3. The United States Department of Energy Oak Ridge National Laboratory (ORNL) ................................................................... 81

7.8.4. The Department of Energy Los Alamos National Laboratory....... 82

7.8.5. The Mallinckrodt Chemical Works …………………………...... 82

7.8.6. British Nuclear Worker Studies - The Sellafield Plant ................. 82

7.8.7. The United Kingdom's National Registry for Radiation

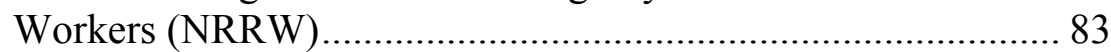

7.8.8. Russian Nuclear Workers- The Mayac Production Complex ..... 83

7.8.9. The Chernobyl Clean-Up Workers ................................................. 84 
7.9. Exposures from Medical X-Ray Treatment ............................................. 84

7.9.1. Ankylosing Spondylitis........................................................ 84

7.9.2. Cervical and Uterine Cancer Treatment ....................................... 84

7.9.3. Breast Cancer ............................................................................... 85

8. Occupations Associated with Increased Risk of Leukemia ................................ 85

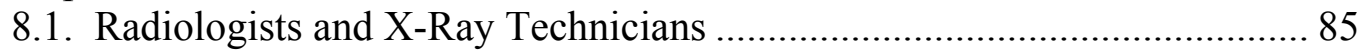

8.2. Garage and Transportation Maintenance Workers.................................... 85

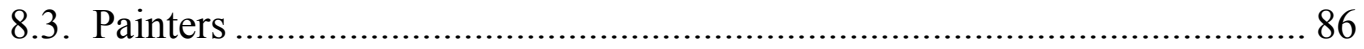

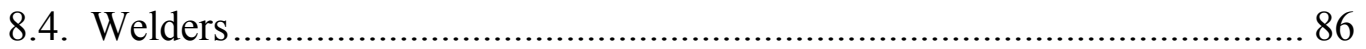

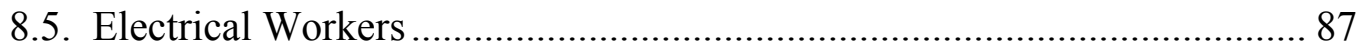

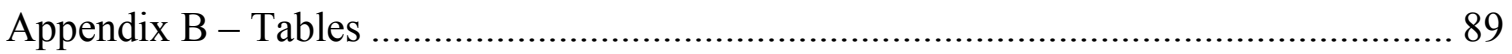

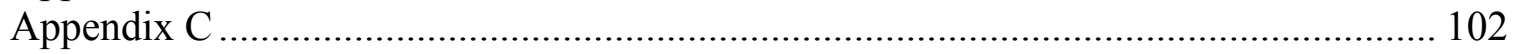

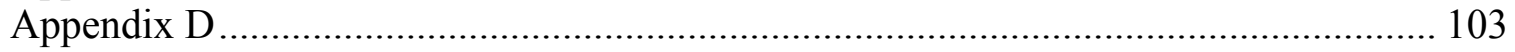

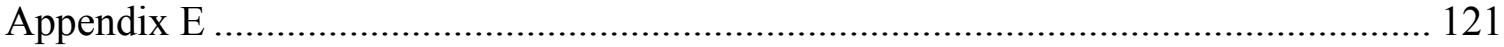

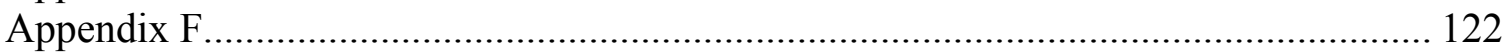

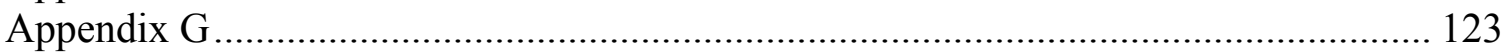

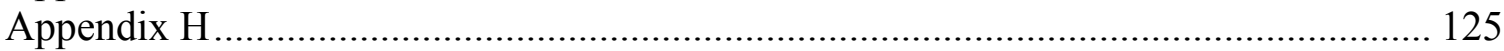

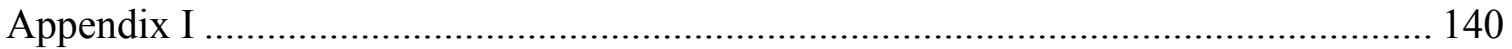

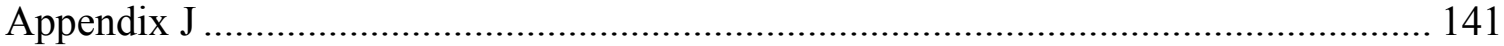

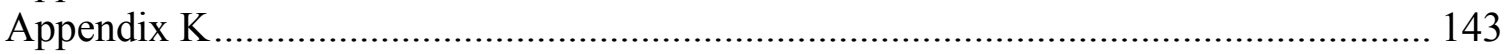




\section{List of Tables}

Table 3.5.6. $\quad$ Frequency and Type of Actual Work-Related Medical X-Ray Examinations Given at PNS to the Cases and Controls ......................... 8

Table 3.7.3. Job/Shops Solvent Exposures-Including Benzene and Carbon Tetrachloride ..................................................................................... 14

Table 3.8.1. ICD Code Revisions .................................................................... 17

Table 3.8.3. List of Study Variables ........................................................................... 19

Table 4.1.1. Frequency of Cases By ICD Code Revisions ...................................... 23

Table 4.1.2. Temporal Variables For All Leukemia Cases, And Matched Controls: Portsmouth Naval Shipyard, Kittery, Me, January 1, 1952 to

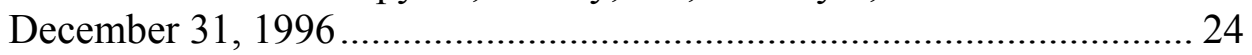

Table 4.2.1.A. Radiation Monitoring Status for Cases and Controls ............................ 25

Table 4.2.1.B. Summary of Cumulative Radiation Exposure from Onsite Occupational Sources ..................................................................... 25

Table 4.2.3. Missed Badge Cumulative External Radiation Exposure....................... 26

Table 4.3.1. Cumulative Bone Marrow Dose from Onsite Sources Radiation Monitored Cases and Controls.

Table 4.3.2.A. Frequency By Type of Medical Examination that Included A WorkRelated Medical X-Ray For All Cases, All Controls and RadiationMonitored and Non-Monitored Cases and Controls.

Table 4.3.2.B. Cumulative Bone Marrow Dose from Work-Related Medical X-Rays Given at PNS - Radiation Monitored and Non-Monitored Cases and Controls Separately.....

Table 4.3.2.C. Cumulative Bone Marrow Dose from Work-Related Medical X-Rays Given At PNS-Radiation Monitored Cases And Controls Combined With Non-Radiation Monitored Cases and Controls

Table 4.3.3.A. Cumulative Bone Marrow Dose From Work-Related Medical X-Rays and Occupational Dose Combined-Radiation Monitored Cases and Controls

Table 4.3.3.B. Cumulative Bone Marrow Dose from Onsite Occupational Sources and Work-Related Medical X-Rays Combined.

Table 4.4. Frequency of Cases and Controls By Job/Shop With Likely Solvent Exposure Including Benzene and Carbon Tetrachloride ........................ 32

Table 4.5.1. Occupational Badge Exposure Variable With Zero, Two, Five, and Seven Year Lags. 
Table 4.5.2.A. Model Fit Statistics - Two-Year Lag................................................ 34

Table 4.5.2.B. Main Effects Model-Two-Year Lag ................................................... 35

Table 4.5.3. Final Model (Log Linear)_Occupational Badge ExposureTwo-Year Lag................................................................................ 37

Table 4.5.4.1. Final Regression Model—Occupational Bone Marrow Dose Only Two-Year Lag..

Table 4.5.4.2. Final Regression Model-Occupational Bone Marrow Dose Combined With Work-Related Medical X-Ray Dose-Two Year Lag ....

Table 4.5.5.A. Cumulative Badge Exposure Variable — No Lag — and Four TSLE Category Variable Interactions (1 Msv)*

Table 4.5.5.B. Cumulative Badge Exposure Variable—No Lag—and Four TSLE Category Variable Interactions (10 Msv)*

Table 4.5.5.C. Cumulative Badge Exposure Variable-No Lag-and Three TSLE Category Variable Interactions*

Table 4.5.5.D. Cumulative Badge Exposure Variable-No Lag — and Three TSLE Category Variable Interactions*....

Table 4.5.6.A. Cumulative Bone Marrow Dose from Occupational Sources and Work-Related Medical X-Rays - No Lag - and Four TSLE Category Variable Interactions*. 


\section{List of Appendices Tables}

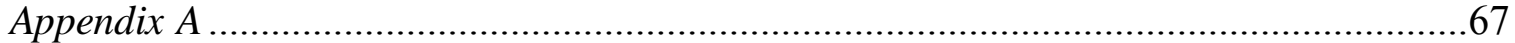

1. Definition and Description of Leukemia ……………......................................67

1.1. Acute and Chronic Leukemias.................................................................67

1.2. My eloid and Ly mphoid Leukemias ...................................................67

2. Identification of Leuk emia as a Clinical Entity - A Brief History ..........................68

3. Leukemia Treatment-A Brief History ...................................................................69

4. Leukemia Mortality in the United States...............................................................

4.1. Mortality from All Leukemia Types Combined-Trends for Males and Females, All Races ............................................................................ 70

4.2. Mortality from All Leukemia Types Combined-Trends for Males of All Races ....................................................................................

4.3. Mortality from All Leukemia Typ es Combined-Trends for Females of

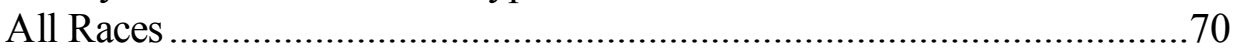

4.4. Mortality from All Leukemia Types Combined—Trends for White Males

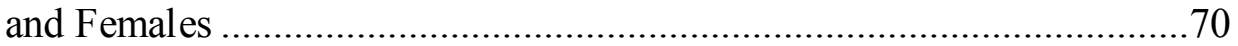

4.5. Leukemia Mortality for All Leukemia Types Combined-Black Males

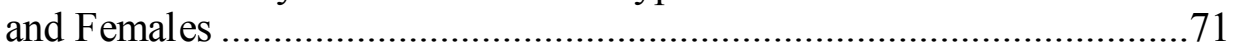

5. Leukemia Incidence in the United States............................................................

5.1. Incidence of All Leukemia Types Combined .................................................71

5.2. Incidence of All Leukemia Types Combined - Trends for White Males and Females .................................................................................... 71

5.3. Incidence of All Leukemia Types Combined - Trends for Black Males

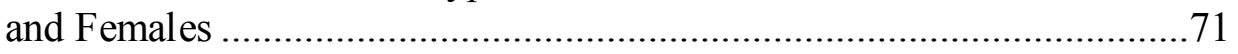

5.4. Survival Rates for All Leukemia Types Combined—Both Males and

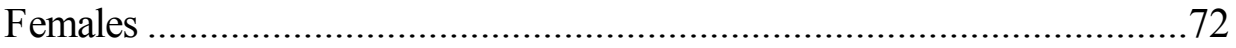

6. The Four Major Leukemia Subtypes - Incidence, Mortality, and Five-Year

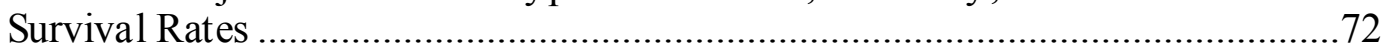

6.1. Acute Myeloid Leukemia (AML) ...............................................................72

6.2. Chronic Lymphocytic Leukemia (CLL) ………….....................................72

6.3. Chronic Myeloid Leukemia (CML)..........................................................73

6.4. Acute Lymphocytic Leukemia (ALL) …………………............................73

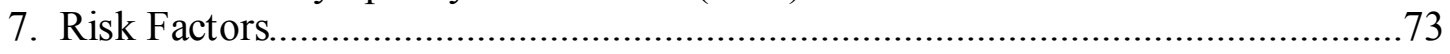

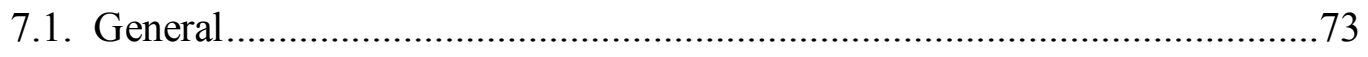

7.2. Familial and Genetic Factors ................................................................73

7.3. Chromosomal Sy ndromes.....................................................................

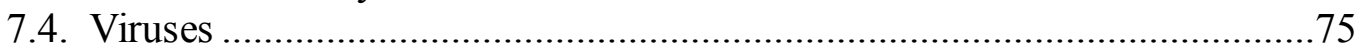

7.4.1. HTLV - Types I and II ..........................................................

7.4.2. Ep stein-Barr Virus ........................................................................75

7.4.3. Hep atitis B Virus......................................................................... 


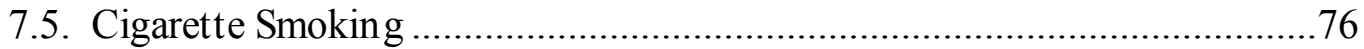

7.6. Solvent Exposure.................................................................................... 77

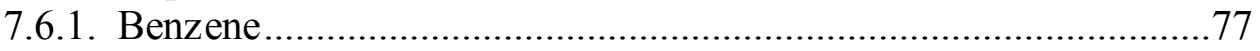

7.6.2. Carbon Tetrachloride .................................................................... 77

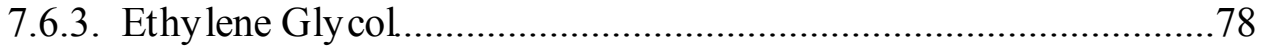

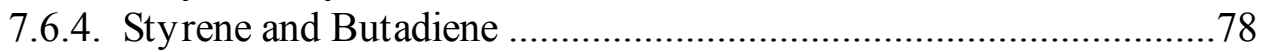

7.7. Ionizing Radiation-Atomic Bomb Exposures .........................................79

7.7.1. Japanese Atomic Bomb Survivors ..............................................79

7.7.2. Military Personnel Present During Nuclear Weapons Testing.......79

7.8. Ionizing Radiation-Occupational Studies of United States, British, and

Russian Nuclear Workers .....................................................................80

7.8.1. The United States Department of Energy Hanford Facility............80

7.8.2. The United States Department of Energy Savannah River Plant....81

7.8.3. The United States Department of Energy Oak Ridge National

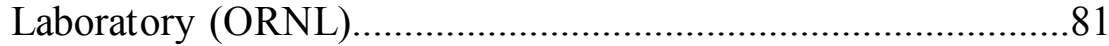

7.8.4. The Department of Energy Los Alamos National Laboratory........82

7.8.5. The Mallinckrodt Chemical Works..............................................8 82

7.8.6. British Nuclear Worker Studies-The Sellafield Plant .................8 82

7.8.7. The United Kingdom's National Registry for Radiation Workers

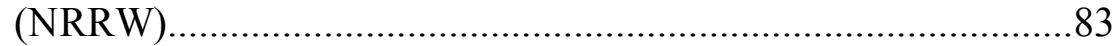

7.8.8. Russian Nuclear Work ers - The Mayac Production Complex......83

7.8.9. The Chernobyl Clean-Up Workers ............................................8 84

7.9. Exposures from Medical X-Ray Treatment........................................... 84

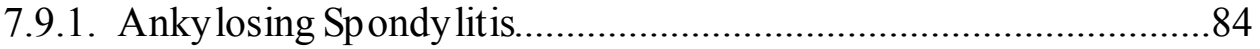

7.9.2. Cervical and Uterine Can cer Treatment......................................84

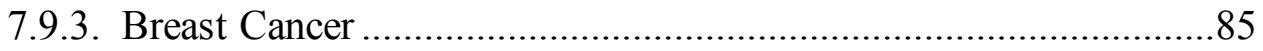

8. Occupations Associated with Increased Risk of Leukemia .................................85

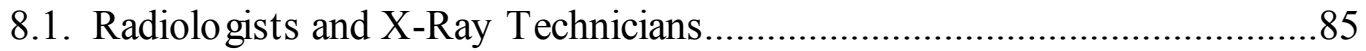

8.2. Garage and Transp ortation Maintenance Workers ..................................85

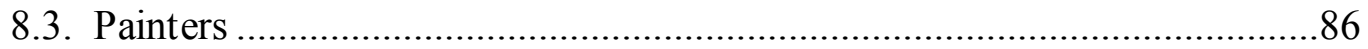

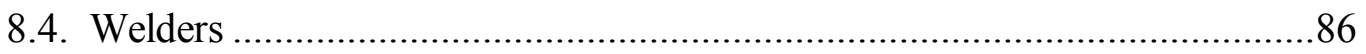

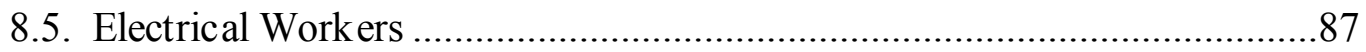

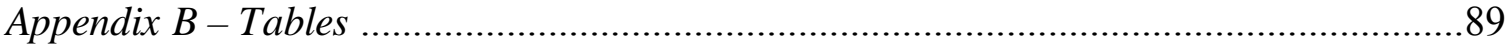

Table 1: Cancer Mortality in the United States (Males) 1950-91.................................89

Table 2: Cancer Morality in the United States (Females) 1950-91 ...............................91

Table 3: M ortality —All Leukemia Types Combined - Males ....................................92

Table 4: Mortality—All Leukemia Types Combined—Females..................................93

Table 5: SEER Incidence and Mortality Rates - 1973 - 1999 ....................................94

Table 6: Acute My eloid Leukemia-Incid ence-1973-1999 ......................................95

Table 7: Acute My eloid Leukemia-Mortality-1969-1999......................................96

Table 8: Chronic Lymphocytic Leukemia-Incidence-1973-1999 ............................97 
Table 9: Chronic Lymphocytic Leukemia-Mortality - 1969-1999..........................98

Table 10: Chronic Myeloid Leukemia_-Incidence-1973-1999 .................................99

Table 11: Chronic Myeloid Leukemia-Mortality - 1969-1999...................................100

Table 12: Acute Lymphocytic Leukemia—Incidence - 1973-1999 .............................101

Table 13: Acute Ly mphocytic Leukemia-Mortality - 1969-1999 .............................102

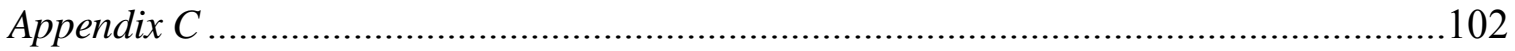

Number of Civilian Employ ees Working at the PNS by Fiscal Year ............................102

Appendix D........................................................................................................... 103

List of Construction, Overhauls, and Scheduled Maintenance October 1, 1955, to

December 11, 2002 ........................................................................... 103

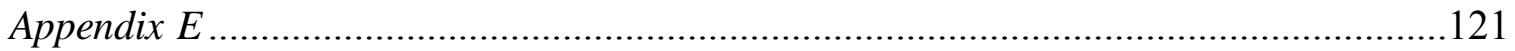

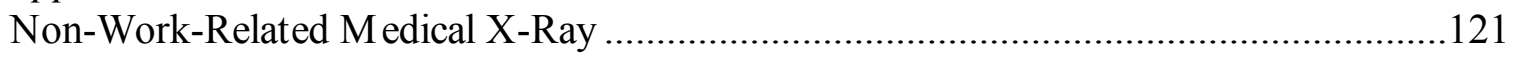

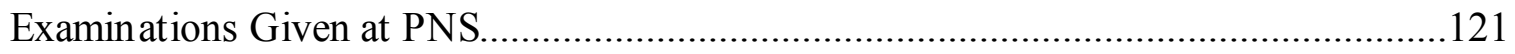

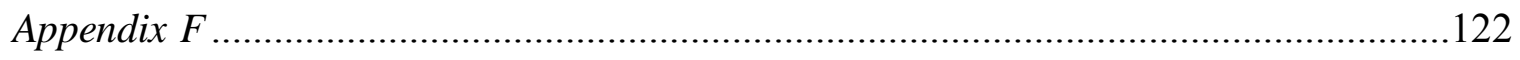

Actual and Estimated Routine and Diagnostic Medical X-Rays Combined

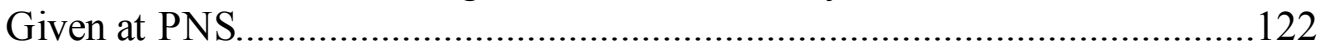

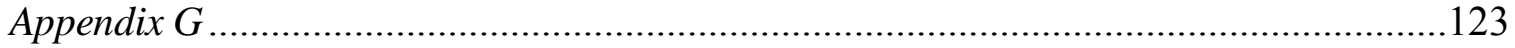

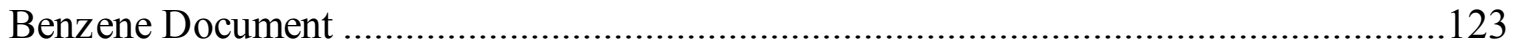

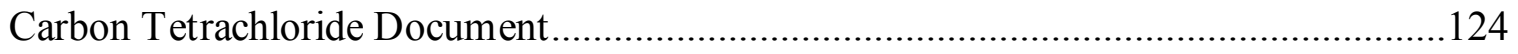

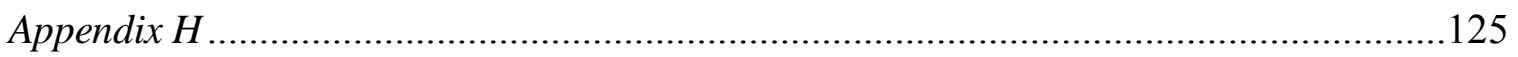

Table 1: Illustration of Shop/Job Title Collap se Using Painters.................................125

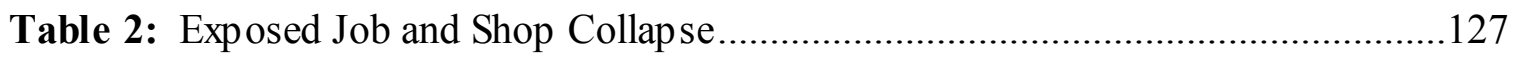

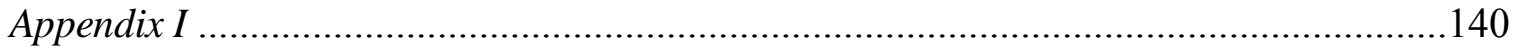

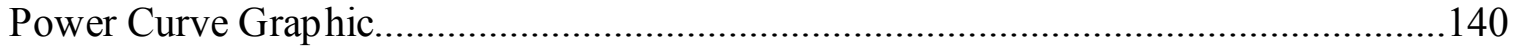

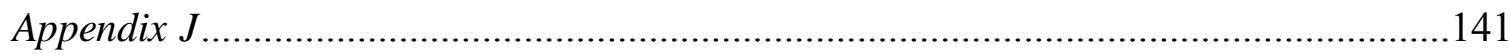

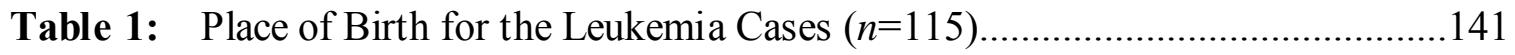

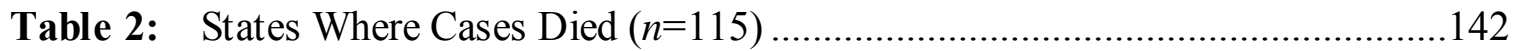

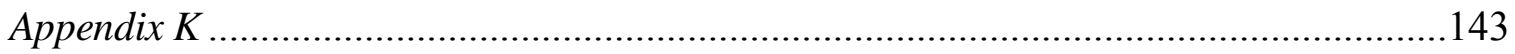

Table 1: Cumulative Bone Marrow Dose from Offsite Sources ..................................143

Table 2: Estimated $M$ issed Cumulative Bone Marrow Dose.......................................144

Table 3: Full Model with 2-Way Interactions and Main Effects-Badge ExposureTwo Year Lag ....................................................................................145

Table 4: Reduced Model—2-way Exposure Interaction and Main Effects—Badge Exposure - Two Year Lag .................................................................146

Table 5: Percent Change in the Radiation Exposure Variable When Other Main Effect Variables are Excluded. 
Table 6: Pearson Correlation Coefficients ( $p$-value) - Main Effects ModelTwo-Year Lag. 148

Table 7: Final Regression Model—On-Site Badge Exposure Only (Estimated Missed Exposure and Exposure from Off-Site Sources Excluded) Two Year Lag

Table 8: Occupational Bone Marrow Dose Variable Only with Zero, Two, Five, and Seven Year Lags

Table 9: Occupational Bone Marrow Dose Variable Combined with Work-Related Medical X-Ray Dose with Zero, Two, Five, and Seven Year Lags

Table 10: Model Fit Statistics - Occupational Bone Marrow Dose Only

Table 11: Model A-Full model with 2-Way, Interactions and Main EffectsOccupational Bone Marrow Dose Only - Two Year Lag

Table 12: Model B-Reduced Model with 2-Way Dose Interactions and Main Effects-Occupational Bone Marrow Dose Only-Two Year Lag....

Table 13: Model C-Model with Main Effects Only-Occupational Bone Marrow Dose Only - Two Year Lag

Table 14: Model Fit Statistics-Occup ational Bone Marrow Dose Combined with Bone Marrow Dose from Medical X-Ray Examinations

Table 15: Model A-Full Model with 2-Way, and 3-Way, Interactions and Main Effects-Occupational Bone Marrow Dose Combined with Work-Related Medical X-Ray Dose-Two Year Lag

Table 16: Model B-Reduced Model with 2-Way Exposure Interactions and Main Effects - Occupational Bone Marrow Dose Combined with WorkRelated Medical X-Ray Dose-Two Year Lag....

Table 17: Model C Main Effects Only - Occupational Bone Marrow Dose Combined with Work-Related Medical X-Ray BMD-Two Year Lag ...

Table 18: Final Regression Model—On-Site BMD Only + Medical BMD—

Two Year Lag.

Table 19: Amount of Collective Cumulative Bone Marrow Dose and Whole Body Exposure Received from Estimated Missed Exposure, Onsite, and Offsite Sources for the 201 Radiation Monitored Cases and Controls 160

Table 20: Formula for the Computation of Odds Ratio and 95\% Confidence Intervals for the Radiation Exposure * Time Since Last Exposed (TSLE) Category ...161

Table 21: Variance Covariance Matrix-Categories ( $\geq 10$ yrs TSLE; $\geq 5-<10$ yrs TSLE; $\geq 2.5-<5$ yrs TSLE; $\geq 0-<2.5$ yrs TSLE)

Table 22: Variance Covariance Matrix-Categories $(\geq 0-\leq 3$ yrs TSLE; $>3-\leq 7$ yrs TSLE; $>7$ yrs TSLE) 
Table 23: Variance Covariance Matrix - Categories ( $\geq 10$ yrs. TSLE; $\geq 5-<10$ yrs TSLE; $\geq 2.5-<5$ yrs TSLE; $\geq 0-<2.5$ yrs TSLE) .................................. 164

Table 24: Variance Covariance Matrix - Categories ( $>7$ yrs TSLE; $\geq 0-\leq 3$ yrs TSLE; $>3-\leq 7$ yrs TSLE)...

Table 25: Model Fit Statistics — Badge Exposure with TSLE as a Continuous Variable 166

Table 26: Model A - Full model with 2-Way Interactions and Main EffectsBadge Exposure - Two Year Lag — with TSLE as a Continuous Variable.. 167

Table 27: Model B-2-Way Exposure Interaction and Main Effects-Badge Exposure-Two Year Lag-TSLE Included as a Continuous Variable 168

Table 28: Mode C-Main Effects_-Badge Exposure-Two Year Lag-TSLE Included as a Continuous Variable 169

Table 29: Time Windows of Exposure Analysis 169

Table 30: Description of all Radiation Dose Metrics Used in the Regression Analysis in Order of Appearance or Reference in Report ...................................... 170

Table 31: Dose Distribution Radiation Monitored Cases .......................................... 173

Table 32: Dose Distribution Radiation Monitored Controls....................................... 174

Table 33: Distribution of Solvent Duration (yrs) Radiation Monitored Cases ............. 175

Table 34: Distribution of Solvent Duration (yrs) Non-Radiation Monitored Cases..... 176

Table 35: Distribution of Solvent Duration (yrs) Radiation Monitored Controls......... 177

Table 36: Distribution of Solvent Duration (yrs) Non-Radiation Monitored Controls 178

Table 37: OR by Dose Category Onsite, Offsite, and Missed Badge Dose Lagged Two Years ( $\mathrm{n}=201$ Radiation Monitored Workers). 


\section{Introduction}

\subsection{Study Purpose}

This is a nested case-control study investigating associations between external ionizing radiation exposure and leukemia mortality among civilian workers employed for at least one day between January 1, 1952 and December 31, 1992 at the Portsmouth Naval Shipyard (PNS). The nested case-control study design offers the opportunity for a more in-depth examination of exposures from solvents (particularly benzene and carbon tetrachloride) and work-related medical x-rays and their relation to leukemia risk than has been possible in previous cohort mortality studies of PNS workers.

No previous PNS studies have been able to assess solvent exposure as a confounder or effect modifier because coded work history information was not available for non-radiationmonitored workers. Because the case-control study design allows for increased efficiency in the collection of information, it was feasible to code detailed work history information for all cases and controls and include this information in the analysis. The work histories identified the job and shop assignments for all the study subjects throughout their work history at PNS. Using industrial hygiene information from the shipyard with the coded work history information, it was possible to develop a qualitative chemical exposure assessment based on job and shop combinations that were most likely to have workers exposed to solvents (primarily benzene and carbon-tetrachloride). Employment duration in these exposed jobs and shops was used to estimate magnitude of cumulative exposure.

NIOSH research published in 2002 suggests that work-related medical x-ray exposures can add substantially to a worker's cumulative occupational dose and should be considered when estimating the effects from low-level radiation exposures (Cardarelli, 2002). No previous studies of PNS workers examining the effects of external ionizing radiation exposure have assessed the impact of work-related medical chest x-ray exposures on a worker's cumulative exposure. Because of the availability of the worker medical records containing information about the number and type of work-related medical x-rays for PNS civilian employees, this study provides a unique opportunity to account for this additional source of exposure to ionizing radiation.

\subsection{Specific Aims}

This study has three specific aims:

1. To conduct a nested case-control study that investigates the relationship between the dose from external occupational radiation exposure and leukemia mortality.

2. To utilize uniquely available radiation dosimetry and medical records to estimate dose from occupational sources and work-related medical x-rays. 
3. To conduct a dose response analysis to detect any relationship that might be present.

\section{Study Relevance}

Previous studies of PNS workers did not include exposure to work-related medical x-rays as one of the sources of external occupational ionizing radiation exposure, making it possible that doses for some workers were underestimated. This study will provide an opportunity to study the effects of chronic low-dose external radiation exposures, including doses resulting from workrelated medical x-rays.

The proposed study includes a population of workers whose primary exposure is likely to have been external ionizing radiation. There are relatively complete and accurate dosimetry and workrelated medical x-ray exposure data available for each worker and there has been sufficient length of follow-up to study mortality from cancers, such as leukemia, that have relatively short latency and morbidity periods. This research study, because it utilizes a nested case-control design, offers an opportunity to provide less biased results than those derived from the full PNS cohort analysis.

\section{Study Design and Methods}

This section describes the type of work performed by civilian workers at PNS, summarizes results of previous occupational studies and the choice of exposure measurements, temporal, and demographic variables used in this new analysis. Sources of occupational radiation exposure and the methods used at the shipyard to monitor and record radiation and chemical exposures are also described. Finally, the analytical and statistical methods used in the analysis are discussed.

\subsection{Brief History of the Portsmouth Naval Shipyard}

The Portsmouth Naval Shipyard (PNS) was established in 1800 as a United States Naval Facility and has been involved in the design, construction, and repair of all types of warships, from those powered by sail to nuclear-powered submarines. PNS built what has been called the first United States submarine, the L-8, which was commissioned in 1917, and established the record for building the greatest number of submarines during a calendar year-31 in 1944. From 1917 to 1971, the shipyard constructed a total of 137 submarines (McDonough, 1978).

In 1950, PNS instituted a radiation dosimetry program to monitor primarily industrial radiographers and individuals responsible for the calibration of various types of x-ray machines. The shipyard Radiological Health Branch was established within the existing shipyard medical department in 1955 with the initiation of employee training to overhaul and construct nuclear powered submarines. From 1955 to 1971, a fleet of 100 nuclear-powered submarines was constructed by Portsmouth and Mare Island (California) Naval shipyards and three private shipyards. Ten of these submarines were constructed at the Portsmouth Naval shipyard. The PNS constructed the USS Swordfish, which was commissioned on September 15, 1958, and was the 
first nuclear submarine built in a United States Government shipyard. The nuclear-powered USS Sand Lance (SSN 660), commissioned on September 25, 1971, was the last submarine built at the PNS (McDonough, 1978).

In the late 1950s and early 1960s, as more nuclear-powered submarines entered the U.S. naval fleet, the need for shipyards to overhaul and maintain nuclear submarines increased. In June 1959, PNS began its first overhaul, repair, and refueling of a nuclear submarine, the USS Nautilus. From 1959 through 2002, the shipyard performed 221 nuclear-powered submarine overhauls, repairs, and refuelings (Appendix D).

The Portsmouth Naval Shipyard is a large industrial complex employing workers from a variety of trades including welding, insulating, electronics, woodworking, foundry, rubber working, pipefitting, painting, engineering, rigging, steel fabrication, and machining. Potential sources of ionizing radiation exposure include activated cobalt-60 in the stainless steel tubing used in the nuclear reactor cooling system and industrial radiography and medical surveillance involving $\mathrm{x}$ rays. PNS workers were also potentially exposed to organic solvents including benzene and carbon tetrachloride (Stern et al., 1986). Historically, the number of civilian workers employed at the shipyard has increased dramatically during times of war, such as in 1918, when civilian employment was 5,500; in 1943, when civilian employment was 20,466; and in 1952 during the cold war and Korean conflict, when civilian employment reached 10,559. Currently there are 4,083 civilian workers employed at PNS (Appendix C).

\subsubsection{Previous occupational studies conducted at PNS}

In 1978, Najarian and Colton reported the results of a proportional mortality ratio analysis of workers hired during 1959 through 1977 at PNS. The study was conducted after Najarian treated a 63-year-old former PNS employee with hairy-cell leukemia who reported that he knew of several younger nuclear workers at the facility who had died of leukemia. Najarian and Colton reported a five-fold increase in proportional mortality due to leukemia and a two-fold increase in mortality due to all cancers combined among workers exposed to low levels of ionizing radiation at PNS. No increased mortality for leukemia was observed for PNS workers not monitored for ionizing radiation (Najarian and Colton, 1978).

In response to the findings reported by Najarian and Colton, The United States Congressional Subcommittee on Health and the Environment held public hearings to discuss workplace safety at PNS. A primary request from the committee was that the National Institute for Occupational Safety and Health (NIOSH) conduct a study to further evaluate the reported excess risk of leukemia. NIOSH responded by conducting a cohort mortality study that included 24,545 PNS civilian workers (white males only) employed from January 1, 1952, through August 15, 1977. The primary exposure examined in the study was external ionizing radiation. The cohort was divided into three subcohorts based on radiation exposure: Subcohort I included 7,615 workers who had a recorded lifetime cumulative radiation exposure history of at least 0.001 rem. 
Subcohort II included 15,585 workers who were never assigned work involving occupational exposure to radiation. Subcohort III included 1,345 workers who were monitored for radiation exposure but whose total lifetime cumulative dose was recorded as 0.000 rem (Rinsky et al., 1981).

In 1981, NIOSH published the results of the mortality study (Rinsky et al., 1981), which, unlike the Najarian and Colton study, reported no increase in leukemia or overall cancer mortality. The standardized mortality rate (SMR) for leukemia among the radiation-exposed workers with at least 0.001 rem of lifetime cumulative dose (Subcohort I) was 0.84 (95\% CI 0.34, 1.74). The SMR for leukemia among the non-radiation workers (Subcohort II) was 1.06 (95\% CI 0.72, 1.51) (Rinsky et al., 1981).

In 1985, NIOSH conducted a leukemia case-control study of PNS workers including all white male PNS civilian workers ever employed between January 1, 1952 and December 31, 1980. The study, which included 53 leukemia cases, revealed no statistically significant positive association between leukemia and exposure to external radiation or possible exposure to organic solvents, which could have included benzene, xylene, toluene, and carbon tetrachloride. However, elevated leukemia risk was seen in workers with a total recorded cumulative external ionizing radiation exposure of least $1 \mathrm{rem}$, with no lagging of exposure assignment (Stern et al., 1986).

In 2003, a NIOSH analysis of mortality of an expanded PNS cohort was completed (Silver et al., 2004). The updated mortality study population includes 37,853 male and female workers hired before January 1, 1993 with vital status follow-up through 1996. In the full cohort, leukemia mortality was as expected based on U.S. population rates $(\mathrm{SMR}=1.01,95 \% \mathrm{CI}=0.84,1.22)$. The SMR showed a non-statistically significant elevation among non-radiation-monitored workers $(\mathrm{SMR}=1.08,95 \% \mathrm{CI}=0.86,1.35)$, and for radiation exposed workers the SMR was below expectation. However, dose-response analysis revealed a non-statistically significant elevation in leukemia mortality among radiation workers who had an exposure between $1-9.9$ $\mathrm{mSv}$ (Standardized Rate Ratio [SRR] $=2.06,95 \% \mathrm{CI}=0.77,5.50)$ when compared to workers in the baseline group $(0-0.9 \mathrm{mSv})$ and statistically significant increases among workers receiving an exposure between $10-49.9 \mathrm{mSv}(\mathrm{SRR}=2.94,95 \% \mathrm{CI}=1.10,7.86)$ and greater than or equal to $50 \mathrm{mSv}(\mathrm{SRR}=5.08,95 \% \mathrm{CI}=1.35,19.20)$ (Silver et al., 2004). No evaluation of potential confounding by solvent exposure was conducted.

\subsection{Study Design-Leukemia Case-Control Study}

This study employed a nested case-control design to analyze the association between occupational external ionizing radiation exposure and leukemia, while controlling for confounding and evaluating effect modifiers. The study population from which the cases and controls were selected has been described in the NIOSH cohort mortality study of civilian workers employed at the Portsmouth Naval Shipyard (Silver et al., 2004), and consists of 37,853 civilian workers employed between 1/1/52 and 12/31/92 whose vital status and cause of death were obtained through 12/31/96. At the end of vital status follow-up (12/31/96), approximately 
two-thirds $(25,460)$ of the workers in the study population were classified as alive and one-third $(12,393)$ as deceased. Personal radiation monitoring was conducted for personnel meeting the training and physical requirements (i.e. radiation qualified workers) required to enter designated radiological areas. There were 13,468 workers in the total cohort of 37,853 that were monitored for external ionizing radiation. Of these 13,468 radiation-monitored workers $11,791(88 \%)$ had a recorded exposure greater than zero and 1,677 (12\%) had a recorded exposure of zero.

\subsection{Vital Status Ascertainment}

The vital status of the PNS cohort of 37,853 from which the cases and controls were selected was determined through December 31, 1996. For the cohort of workers employed through August 15, 1977, vital status through that date was assessed by active follow-up and death certificates obtained from the states. Members of the cohort who were not known to be deceased were submitted to the National Death Index (NDI) service of the National Center for Health Statistics. NDI Plus returns coded causes for deaths occurring in 1979 or later. The full cohort was also submitted to the Social Security Administration for a "presumed living" search. This search provides date-of-death information both before and after 1979, and also confirms alive status for those paying social security taxes or receiving social security benefits. It does not provide the cause of death for deceased individuals, nor does it identify individuals who are not actively paying into or receiving Social Security benefits. Death certificates were sought from the state in which death occurred for all persons who were determined to be dead from the SSA results, but who had not been found on the NDI search. The certificates were coded by a qualified nosologist to the ICD (International Classification of Diseases) revision in effect at time of death, for consistency with the 1981 PNS mortality study by Rinsky et al. (Silver et al., 2004).

\subsection{Method of Case and Control Selection}

\subsubsection{Selection of cases}

All leukemia deaths that occurred between 1/1/52 and 12/31/96 among the entire PNS cohort of 37,853 civilian workers were selected as cases. All of the leukemia cases have an underlying cause of death classified to leukemia under the revision of the International Classification of Diseases in effect at the time of death (Table 3.8.1).

\subsubsection{Selection of controls}

For each case, risk sets were defined from the entire cohort of PNS civilian workers first employed between 1/1/52 and 12/31/92 (Beaumont et al., 1989; Checkoway et al., 1989). Four controls per case were randomly selected from each risk set. Selection was done by a computer program developed by NIOSH to perform incidence density sampling of potential controls for nested case-control studies (Beaumont et al., 1989). The program considers each case and selects controls from the cohort who are at risk of an observed failure (dying from leukemia) at the time the case fails (dies from leukemia). The risk set is made up of all controls who were under observation and who lived to an age equal to or greater than the age of the index case at the time 
of failure. Time is defined as the length of life (attained age) of the case; the cases and controls are matched on attained age because it is a strong predictor of leukemia mortality and therefore an important potential confounder of the associations of interest in these analyses.

To illustrate how controls were selected, consider a PNS worker who dies of leukemia at age 62. Potential controls were all PNS workers who were "at risk" [workers who were employed by PNS at or earlier than age 62 and were still alive at age 62]. A control's exposure was considered only up to the age at which the corresponding case died.

A power curve was developed based on the following assumptions: 1) that $40 \%$ of the cases and controls were monitored for external ionizing radiation; 2) an alpha level of 0.05 using a twotailed test; 3 ) a power of 0.80 . A ratio of four controls to each case was found to provide power of $45 \%$ for detection of an odds ratio of 1.9 at $150 \mathrm{mSv}$ (Appendix I) (Egret-Siz, 1997). Power was increased very little with the addition of more controls per case (i.e., power is case-limited).

\subsection{Description of the Primary Radiological and Chemical PNS Exposures}

\subsubsection{Overview of PNS work organization}

All PNS employees are assigned to trade-specific occupational groups called shops, and each shop is responsible for specific tasks in submarine construction, overhaul, refueling, or in general support of the shipyard. All workers within each shop are assigned job titles that further describe their specific functions. Personnel records kept by the shipyard document all job and shop assignments with dates for all workers throughout their working careers at the shipyard (Rinsky et al., 1981).

In addition to shop and job designations, workers who were "radiation-qualified" are also identified in the shipyard records. Since the establishment of the film dosimetry program on July 1, 1950, workers who have been selected and trained for work in radiation-controlled areas on the basis of their expertise in a particular trade have been radiation- qualified and a record of their dosimetry established and retained. Unlike chemical exposures, for which there are few records directly describing the types and extent of individual exposure, individual radiationmonitoring records were maintained for all qualified radiation workers at the shipyard (Daniels et al., 2004a; Murray and Terpilak, 1983; PNS Report RC-105-1, 1980).

\subsubsection{Radiation exposure during overhaul, repair, and refueling activities}

The propulsion plants of nuclear-powered submarines primarily use highly purified water to generate steam for propulsion and auxiliary machinery. These propulsion plants are closed-loop pressurized heat transfer systems with a primary system that includes the nuclear reactor, pumps to re-circulate cooling water in pipes through the reactor, and steam generators. Steam generators transfer heat from the primary system to a secondary system that drives turbine generators to 
supply the ship with electricity and for propulsion. Both the primary and secondary systems are closed-loop systems, meaning that the water is re-circulated and either stays inside the core or outside the core. The nuclear reactor core, primary coolant pipes, and steam generators are located in a shielded compartment that is not accessible during operation (Federation of American Scientists, 2000).

Trace amounts of impurities are formed from the corrosion of surfaces of metal pipes used in the primary coolant system and steam generators. Some of the impurities eventually become suspended in the circulating coolant, and enter the reactor core where they become radioactive by neutron activation. [Activation is the process by which the nucleus of a non-radioactive substance becomes radioactive after absorbing one of the neutrons produced in the fission of nuclear fuel in the reactor (Borders, 1991)]. Much of the activated corrosion products in the coolant are removed by the water purification system; however, some of the activation products are created within the walls of stainless steel pipes throughout the primary coolant system, steam generator, and other parts of the reactor. Exposures to radiation emitted from these activation products occur primarily during maintenance, repair, and refueling operations, when workers enter the reactor compartment (Rice and Kindley, 1980; Murray and Terpilak, 1983; Daniels et al., 2004a). According to shipyard radiological personnel (Brann, 1998), approximately 95\% of the total radiation dose to the entire PNS cohort is from external exposure to radiation emitted by activation products.

Within 24 hours following reactor shutdown, the long-lived activated corrosion products become the dominant source of radiation exposure, and typically more than $50 \%$ of total activity deposited in the reactor system pipes results from the long-lived cobalt-60, which has a half-life of 5.3 years. Other radionuclides and their half-lives include: nickel-63 (100.1 years), manganese-54 (312.3 days), and chromium-51 (27.7 days) (Murray and Terpilak, 1983).

\subsubsection{Radiation exposure from fission products}

The enriched uranium nuclear fuel is clad with a zirconium metal alloy to retain virtually all of the fission products including gaseous radioisotopes such as Krypton-85, Xenon-133, and Iodine-131 (Murray and Terpilak, 1983). The fuel is installed in the reactor core that is sealed inside a thick-wall pressure vessel that provides additional shielding from radiation associated with fission and activated corrosion products. This design is the primary reason that exposures from fission products are low during operation of the submarine. Work near the reactor in the first few weeks following shutdown may result in some radiation exposure from high-energy fission products remaining in the reactor core; however, this exposure is estimated to be less than $5 \%$ of the total cumulative shipyard dose (Daniels et al., 2004a).

\subsubsection{Neutron exposure}

Significant neutron exposure is possible only during reactor operations, when access to the reactor compartment is prohibited. Therefore, occupational exposure to neutrons is confined to 
personnel who were on-board during power operations (e.g., special testing, sea trials) or worked with neutron calibration sources. Only twelve of the 575 cases and controls in this study had recorded neutron exposure. The mean exposure for these 12 workers was $0.16 \mathrm{mSv}$, the median was $0.15 \mathrm{mSv}$, and the maximum recorded exposure for one worker was $0.44 \mathrm{mSv}$. The exposure of $0.44 \mathrm{mSv}$ accounted for only 0.29 percent of the worker's cumulative occupational exposure. The cumulative neutron exposure for the 12 workers accounted for 0.04 percent of the cumulative occupational exposure recorded for all cases and controls. Because of the small amount of the total occupational exposure due to neutrons and the small number of workers exposed, neutron exposure was not included in the analysis.

\subsubsection{Internal radiation exposure}

While external radiation exposure, particularly during overhaul, repair, and refueling activities, is the primary type of shipyard exposure, internal exposure to ionizing radiation has been recorded by the shipyard radiological department. Internal exposures occurred when parts of the reactor system were cut open during overhaul or maintenance activities and primarily involved machinists and radiation technicians. However, none of the 575 cases and controls had any records of detectable internal radiation exposure.

\subsubsection{Work-related medical $x$-ray exposure}

PNS workers were also exposed to external ionizing radiation as a result of work-related medical x-rays that were performed as part of the shipyard occupational medical monitoring programs. Work-related medical x-ray examinations are defined as those x-ray examinations performed at PNS as a condition of shipyard employment such as; annual radiation qualification examinations, pre-employment screening, separation and/or disability physical examinations, and mass tuberculosis screening performed in 1948, 1951, 1952, and 1956. For this study, NIOSH researchers located and reviewed all of the available medical records for each of the cases and controls for medical x-ray information. A total of 3,162 records of actual medical xray examinations were performed at PNS between 1941 and 1995. This represented 511 cases $(89 \%)$ of the 575 cases and controls identified and extracted from the physical examination records. It was determined that $2,449(77 \%)$ of the $x$-ray examinations were work-related and $713(23 \%)$ were non-work-related. Of the work-related medical x-rays, $2,444(99.8 \%)$ were of the chest and five were of the lumbar-sacral spine (Table 3.5.6).

\begin{tabular}{|ccrc||}
\hline \begin{tabular}{|c} 
Table 3.5.6. Frequency and Type of Actual \\
Work-Related Medical X-Ray \\
Examinations Given at PNS to the \\
Cases and Controls
\end{tabular} \\
\hline \multicolumn{4}{c}{} \\
\hline Body Location & Frequency & Percent & $\begin{array}{c}\text { Cumulative } \\
\text { Frequency }\end{array}$ \\
\hline Chest & 2444 & 99.80 & 2444 \\
Lumbar-Sacral Spine & 5 & 0.20 & 2449 \\
\hline
\end{tabular}

Non-work-related medical

$\mathrm{x}$-ray examinations are defined as those $\mathrm{x}$-ray examinations performed due to an injury or illness or as follow-up to a work-related x-ray procedure. Because it was not clear from the medical 
records if the non-work-related examinations were the result of a job related illness or injury, they were separated from the work-related examinations for the analysis. Of the 713 non-workrelated x-rays, 196 (28\%) were chest x-rays (Appendix E).

\subsubsection{Types of chest $x$-ray techniques used at PNS}

For this study, chest x-ray techniques were categorized as photofluorographic or direct radiographic. When the direct radiographic $\mathrm{x}$-ray technique is employed, the $\mathrm{x}$-ray film is directly exposed by the x-rays passing through the chest. The photofluorographic technique is a method in which a fluorescent screen placed next to the patients' chest produces an image of the internal structure of the chest. This image is then photographed, providing a miniature x-ray image similar to the large picture obtained in direct radiography. Photofluorography was used when large numbers of individuals needed exams because it was less expensive than direct radiography. However, radiation exposures from the photofluorographic technique are much greater than those received from direct radiographic techniques (Daniels et al., 2004b).

The PNS medical records indicate that photofluorographic techniques using either $70 \mathrm{~mm}$ film or $35 \mathrm{~mm}$ film were used for nearly all work-related chest x-ray examinations conducted at PNS prior to May 1966. Of the 2,444 work-related chest x-ray examinations given to the cases and controls, 1,578 (65\%) used photofluorographic techniques.

All photofluorographic exams are assumed to be single exposure posterior-anterior (PA) views of the chest. There is no evidence in the records that stereographic imagery was used in conjunction with photofluorographic equipment. In instances where abnormal results were indicated by a photofluorographic image, the PNS medical records indicate that a retake was performed using the direct radiographic technique. Available medical records indicate that nonwork-related chest x-ray examinations also used the direct radiographic technique. Therefore, in this study all retakes and non-work-related chest examinations are assumed to employ direct radiographic techniques only (Daniels et al., 2004b).

Because medical records were not available for $48(9 \%)$ of the 551 cases and controls with workrelated medical x-ray exposure, the following assumptions were adopted from the information that was available for the 503 cases and controls with records (Daniels et al., 2004b). These assumptions were used to estimate $\mathrm{x}$-ray doses for the 48 workers who had no medical x-ray records.

- All work-related medical x-rays were a single (PA) view of the chest, and that there was $1.5 \mathrm{mSv}$ of dose for each chest $\mathrm{x}$-ray using photofluorographic techniques and $0.04 \mathrm{mSv}$ for each chest $\mathrm{x}$-ray using direct radiography techniques. 
- All routine x-ray examinations performed prior to 5/1/1966 used photofluorographic techniques. After May 1966, all work-related chest x-ray examinations were assumed to have been produced by direct radiography techniques.

- All workers hired between 1/1/1948 and 12/31/1956 received one pre-employment medical examination (during the year hired) that included a chest $\mathrm{x}$-ray.

- Radiation-qualified workers who worked between $1 / 1 / 1958$ and 12/31/1962 received one baseline medical examination that included a chest $\mathrm{x}$-ray.

- Radiation workers employed between $1 / 1 / 1963$ and 12/31/1968 received a medical examination that included a chest $\mathrm{x}$-ray each year that at least one occupational dose is recorded.

- Any person employed in 1948, 1951, 1952, and/or 1956 received an annual photofluorographic chest examination for mass tuberculosis screening (Daniels et al., 2004b). The frequency of work-related and non-work-related x-ray examinations by examination type is shown in Appendix F.

\subsubsection{Method for estimating dose equivalent to the active bone marrow from occupational work-related medical $x$-rays}

Estimates of the bone marrow absorbed dose from x-ray exposure for PNS workers was obtained by mathematical modeling of x-ray photon interactions in tissue using a Monte Carlo simulation program developed by the Finnish Center for Radiation and Nuclear Safety. The program input parameters included information about the PNS x-ray procedures and equipment, exposure geometry, and photon energies (Daniels et al., 2004b). The bone marrow was chosen as the target organ because it is the malignant transformation of cells in this organ that possibly cause leukemia, and it is believed that the probability of such malignant transformation is related to the dose delivered to the organ. (UNSCEAR, 2000; Jorde, 1999; Mitus \& Rosenthal, 1995).

A radiation weighting factor of unity is assumed to convert absorbed dose (mGy) to dose equivalent (mSv) (ICRP, 1974). Dose conversion factors were calculated using the methods described by the ICRP Publication 74 to estimate doses to the active bone marrow from results of occupational whole-body external radiation exposure measured using the personal dosimeter for all cases and controls (International Commission on Radiological Protection [ICRP], 1974). These dose conversion factors accommodated differences in dosimeter calibration, spatial response, and incident photon energies at the PNS that occur over time (Daniels et al., 2004b).

It is important to note that, other than using individual dosimetry results and limited x-ray examination data, bone marrow dose estimates were not performed on an individual basis. Rather, many generalizations were required to develop the dose conversion factors that were 
applied to the study group as a whole. Large uncertainties exist in estimating a particular worker's bone marrow dose, given the variability of several critical parameters over the period of the study. These parameters include but are not limited to x-ray procedures and equipment, exposure geometry, incident photon energies, and worker age, sex and anatomy (Daniels et al., 2004b).

\subsection{Radiation Exposure Assessment}

\subsubsection{Devices used to monitor external ionizing radiation exposure at PNS}

Monitoring of external radiation exposure began in the summer of 1950 with the introduction of a film badge program for industrial radiography personnel, and expanded in 1958 with the beginning of the naval nuclear propulsion program. The detection threshold for gamma radiation for the film badge prior to 1957 is reported to be $0.2 \mathrm{mSv}$ per monitoring period (Brann 1998).

Design improvements in the film badge made in 1969 reduced the detection threshold for gamma radiation to $0.1 \mathrm{mSv}$ per monitoring period (Brann, 1998; Daniels et al., 2004a). Film badges were used until October 1974, when the calcium fluoride thermoluminescent dosimeter (TLD) was introduced as the official monitor for PNS personnel. The minimum detection level of the TLD is reported by the shipyard to be $0.01 \mathrm{mSv}$ (Brann, 1998). The calcium fluoride TLD continues to be the primary personal dosimeter for the shipyard (Daniels et al., 2004a). Badge readings were recorded bi-weekly through 1959 and monthly after 1960 by PNS. Cumulative external radiation exposure was calculated for each case and control by summing all of the recorded dosimeter badge results.

\subsubsection{Evaluation of missed radiation exposure due to the sensitivity of dosimetry devices}

The combination of the limited sensitivity of the personal radiation dosimeter and greater dosimeter exchange frequency can lead to underestimation of occupational radiation exposure in very low dose-rate work environments. Dosimeters worn for longer periods of time could more readily detect low dose-rate exposures (Strom, 1986). The methods used to estimate the missed exposures for the cases and controls with at least one recorded exposure of zero prior to the introduction of TLDs in 1974 are described by Daniels et al. (2004b).

\subsubsection{Evaluation of occupational radiation exposures that have occurred while workers were previously employed at a facility other than PNS}

The shipyard kept records of radiation exposures that radiation-qualified workers received prior to their beginning work at PNS. These workers received radiation exposure while employees of the Department of Defense (Army, Air Force, Navy, and Marines), the Department of Energy, and commercial nuclear companies. Some of the workers received prior exposure while employed as medical support staff (e.g., x-ray technicians and radiologists), or because of participation in atomic weapons testing. Three individuals in the study reported offsite radiation 
exposure prior to beginning work at PNS. Actual exposure data from the previous employer was available for two of the individuals. For the third individual, NIOSH health-physics staff calculated a yearly exposure estimate using National Council on Radiation Protection (NCRP Report No. 101) for Department of Defense personnel. None of the offsite exposure recorded by the three individuals was the result of nuclear weapons testing (Daniels et al., 2004a).

\subsubsection{PNS methods of recording external ionizing radiation exposure}

Radiation-monitoring film badges were processed every two weeks prior to 1960, and monthly after 1960. All individual badge results were entered monthly onto the form DD 1141, Record of Occupational Exposure to Ionizing Radiation, which became the official dose of record for the monitored individual. The DD 1141 record contains the worker's name, social security number, date of employment, and monthly and life-time cumulative radiation exposure information. The cumulative onsite badge exposure variable used in the study analysis is based on radiation monitoring results recorded by PNS dosimetry on the form DD 1141, as the sum of gamma (penetrating), x-ray, and neutron results for each monitoring interval.

\subsection{Chemical exposures assessment}

\subsubsection{Overview}

Shipyard jobs have always included insulating, pipefitting, mechanical repair and maintenance, electrical and instrument work, rigging, welding, painting, chipping, caulking, abrasive blasting, and metal work. These jobs were performed on both moored and dry-docked submarines and in buildings housing various shops on the shipyard. Work performed on-board the submarines is frequently done in confined spaces that require ventilation which, if not performed properly, can fail to adequately control chemical exposures. Also, because of the confined work environment, indirect exposures can occur from contaminants generated by adjacent workers performing different tasks as well as direct exposures from contaminants generated by the individual task being performed. These cross-contaminating exposures were likely to be more frequent onboard the submarines than in other locations in the shipyard because unlike some of the shop areas on land it was not possible to segregate work areas by job type on the submarine.

\subsubsection{PNS industrial hygiene program}

The PNS medical clinic and, beginning in the early 1980s, the industrial hygiene (IH) department kept records providing information about some types and amounts of chemical and material products used during construction, overhaul, and maintenance activities. This information includes various manufacturing process descriptions, production flow charts, plant production inventories, and routine inspection and accident reports. The IH department also kept records of the results of environmental monitoring that was conducted to detect the presence of airborne contaminants within the shipyard complex. 
Additional information useful for the evaluation of chemical exposures kept by the shipyard IH department includes records detailing work practices and process improvements. The work practice records describe the use of personal protective equipment during sand blasting, welding and painting activities, and local exhaust ventilation used while working in confined spaces. The shipyard reduced potential exposures by replacing toxic chemicals with less toxic substitutes when possible. For example, in 1948 the shipyard began phasing out the use of the solvent carbon tetrachloride (Appendix G). Also, the shipyard substantially decreased the use of benzene by discontinuing the purchase of 100\% benzene by February of 1958 (Appendix G); however, it remained as a contaminant in petroleum distillates $(2-5 \%)$ such as gasoline and in some solvents (11-15\%) such as toluene, xylene, and naphthas. Records detailing new construction, refueling, and overhaul at the shipyard were also kept by the IH and Public Affairs offices. These records identify specific periods of time during which either significant increases or decreases in work activity occurred at the shipyard (Appendices B and C). For example, following World War II and until 1958, few diesel submarines were constructed and, because of this decline in activity, exposure frequency and duration to various chemicals (benzene in petrol distillates and diesel fuel) and aerosols were probably somewhat lower in those years than during the World War II period. In the late 1950s and through the 1960s, both new construction and overhaul increased significantly, which probably increased the frequency and duration of these exposures.

\subsubsection{Identification of jobs and shops with the greatest potential exposure to benzene and carbon tetrachloride}

Documents from the shipyard and NIOSH industrial hygiene surveys of 17 PNS shops conducted in 1979 and 1980 were reviewed to determine which jobs and shops had the greatest potential for benzene, and carbon tetrachloride. These documents provided information such as functional descriptions of various shops, manufacturing process descriptions, production flow charts, plant production inventories, inspection and accident reports, work practice and process improvements, occupational illness reports, and organizational charts. Limited sample data were available confirming exposure to the chemicals/chemical families listed by shop in Table 3.7.3. For example, the woodworking employees used benzene and carbon tetrachloride for cleaning tasks and were often assigned to shops where rubber manufacturing processes that tend to use larger quantities of solvents were located. Welders used carbon tetrachloride for multiple tasks and petroleum distillates containing benzene were present in the transportation shop. Solvents which contained benzene, toluene, and xylene (BTX) and carbon tetrachloride were used by employees in the painting shop (Table 3.7.3). 


\begin{tabular}{|c|c|}
\hline \multirow{2}{*}{\multicolumn{2}{|c|}{\begin{tabular}{|ll} 
Table 3.7.3. & Job/Shops Solvent Exposures-Including Benzene and \\
Carbon Tetrachloride
\end{tabular}}} \\
\hline & \\
\hline Total Chlorinated Hydrocarbons & Benzene \\
\hline Trichlorotrifluoroethane & Carbon Tetrachloride \\
\hline \multirow{2}{*}{\multicolumn{2}{|c|}{ Trichloroethylene }} \\
\hline & Welding \\
\hline Total Chlorinated Hydrocarbons & Carbon Tetrachloride \\
\hline \multicolumn{2}{|l|}{ Naphthas } \\
\hline \multicolumn{2}{|c|}{ Machining } \\
\hline Trichloroethylene & Acetone \\
\hline Trichlorortrifluoroethane & Petroleum distillates \\
\hline \multicolumn{2}{|l|}{ Machining Oils } \\
\hline \multicolumn{2}{|c|}{ Electrical } \\
\hline Toluene Diisocyanate & $\begin{array}{l}\text { 4,4'-Methylenebis (2-chloroaniline) } \\
\text { (MBOCA) }\end{array}$ \\
\hline Naphtha & Carbon Tetrachloride \\
\hline \multicolumn{2}{|c|}{ Woodworking } \\
\hline Butyl Alcohol & Trimellitic Anhydride \\
\hline Toluene Diisocyanate & Amines \\
\hline Benzene & Monostyrene \\
\hline Toluene & Methylene Chloride \\
\hline Vinyl Chloride & Hydrogen Chloride \\
\hline Aromatic Hydrocarbon & Hydrogen Sulfide \\
\hline \multirow[t]{3}{*}{ Ethyl Alcohol } & Isopropyl Alcohol \\
\hline & Petroleum Distillates \\
\hline & Inting \\
\hline \multicolumn{2}{|l|}{ Xylene } \\
\hline BTX (Benzene/Toluene/Xylene) & Isophorone \\
\hline Butyl Alcohol & Ethanol \\
\hline Toluene & Epichlorohydrin \\
\hline Acetone & Cyclohexanone \\
\hline Methyl Ethyl Ketone (MEK) & 2-Butoxyethanol \\
\hline Isobutanol & Monoethanolamine \\
\hline 2-Ethoxyethanol & Methyl Isobutyl Ketone \\
\hline n-Butyl Glycidyl Ether & Carbon Tetrachloride \\
\hline
\end{tabular}


A precise estimation of job-specific solvent exposures is complicated and difficult to achieve because of two main characteristics of the work performed at the shipyard. First, much of the work occurred in enclosed spaces designed to be air and watertight; workers of different occupational trades typically must work side-by-side in such spaces, each contributing to the others' exposures. Second, while an employee is usually assigned to a single shop, primarily for pay purposes, individual day-to-day work assignments can and often do vary considerably. For example, an individual assigned to a shop may be given either shipboard or non-shipboard tasks to perform and may also perform tasks in a different shop. Both of these characteristics can contribute to variability in the types and magnitude of exposures associated with any particular job. Due to the variability of day-to-day work assignments and the limited availability of shop and job specific industrial hygiene monitoring data for potential leukemogens, a qualitative chemical exposure assessment was developed based on the duration of employment in jobs and shops and time periods when exposure to solvents such as benzene and carbon tetrachloride were most likely to have occurred.

\subsubsection{Identification of job and shop assignments for cases and controls}

Job and shop assignments for each case and control throughout their employment at PNS were identified. This detailed job history information was collected from the United States Navy Standard Form 7 (SF-7) work history record. Each SF-7 work history record contained the worker's name, social security number, and the beginning and ending dates of employment. Any change in shop or job assignment and the date of each new assignment was recorded in the SF-7 according to standard operating procedure for each case and control. In addition, each job title and shop assignment was used by NIOSH to generate a four-digit code number - the first two digits identified the shop assignment and the last two the job title for each worker. A total of 1,372 job title and shop combinations were abstracted from the SF-7 for the study subjects.

\subsubsection{Standardization and grouping of job titles}

Variations and abbreviations of job titles from the shipyard records were standardized. Next, exposure potentials were grouped into several categories based on job titles and shops. Shops were grouped by: 1) function of the shop (i.e., production, administrative, support, etc.); 2) types of chemicals and materials utilized; and 3) whether employees assigned to the shop were responsible for performing work on-board submarines. The job titles were grouped by: 1) type of work tasks performed, and 2) type of potential chemical exposures.

The following examples illustrate the process followed to group job titles within a shop. First, consider the following job titles: Painter, Painter-helper, and Painter-apprentice. These job titles were all collapsed into the same job title-Painter-because they have the same or very similar benzene and carbon tetrachloride exposure potential and perform the same or very similar tasks throughout the study period. Therefore, three job titles are collapsed into one. Next the assigned shop was taken into account to determine each Painter's benzene and carbon tetrachloride exposure potential. For example, a painter assigned to a production paint shop that performs 
work on-board submarines and across the shipyard is thought to have benzene and carbon tetrachloride exposure potential and is assigned to the exposed category. However, a painter assigned to a Planning and Estimating Shop, which is an administrative shop that performs planning tasks primarily in an office setting, is thought to have little benzene and carbon tetrachloride exposure potential and is therefore assigned to the non-exposed category (Appendix $\mathrm{H}$, Table 1). A final review of the job shop collapse was conducted by NIOSH and shipyard Industrial Hygiene staff.

\subsubsection{Analysis of benzene and carbon tetrachloride exposure}

Because of limited chemical usage and exposure monitoring information available from the shipyard, the intensity and extent of potential exposures associated with each shop and job was not quantified. In this study, the employment duration was used as a surrogate for cumulative exposure magnitude for each worker who was ever employed in any of the a priori jobs or shop categories classified to be associated with exposure was calculated from individual work histories.

Based on the available chemical exposure information, job/shop titles that were of a priori interest because of their potential for exposure to benzene and carbon tetrachloride were collapsed into one of six exposure groups. These included the painting, welding, machining, wood working, electrician, and transportation groups. A description of the job collapse for these benzene and carbon tetrachloride exposed groups is included in Appendix H, Table 2.

The welding group consisted of all the welder job titles except welder superintendent and welder supervisory because these two job titles were considered to have only managerial or administrative responsibilities. The welding group also included other related job titles such as flamer cutter, gas cutter/burner, gas plant operator, learner mechanic, acetylene operator, shielding installer, and structural shop general foreman.

The woodworking group consisted of workers with job titles such as joiner, woodworker, and patternmaker. However, job titles commonly associated with carpentry such as carpenters or lofters (construct wooden scale templates) were excluded from this group because these job titles involved mainly construction utilizing wood materials and were not as likely to be exposed to solvents.

The machining group was the largest of the six exposure groups and consisted of job titles that related to occupations involved with both setting up and operating machine tools and the general maintenance, installation, and repair of industrial and marine machinery, tools, and equipment. Job titles in this group included occupations such as machinists, equipment mechanics, machinery workers, maintenance machinists, marine machinists, marine equipment mechanics, marine machinery mechanics, and maintenance mechanics. 
The transportation group included workers with job titles that were considered likely to have been exposed to benzene as a contaminant in solvents and petroleum distillates such as gasoline or other fuels. Automotive mechanics, truck drivers, motor vehicle operators, enginemen, crane operators, liquid fuel pump operators, and equipment cleaners are examples of the job titles in this group.

Since individuals at the shipyard were assigned to various organizational shops with various functions, the function of the assigned shop also had to be considered when determining the potential for exposure to benzene and carbon tetrachloride. For example, a painter who was assigned to a production shop would be performing tasks where exposure to these solvents was likely, while a painter assigned to an administrative shop would not be performing tasks with potential exposure. Therefore, shops where the primary function was either production or support of production were considered the shops with benzene and carbon tetrachloride exposure potential. Shops with primarily administrative functions were not considered to have any benzene and carbon tetrachloride exposure potential (Appendix $\mathrm{H}$, Table 1). Individuals who worked in any of the exposed job groups and were assigned to a production or support shop were considered to have experienced potential exposure to benzene and carbon tetrachloride.

This study also incorporated information about the temporal aspects of benzene exposure. Because environmental monitoring for benzene performed in the late 1970s and early 1980s as part of the NIOSH industrial hygiene surveys did not reveal any benzene exposure above current limits, an exposure cut-off date of December 31, 1980 was assigned to all of the exposure job groups except the transportation group. The transportation job group was still considered to have potential benzene exposures until January 1, 1990, when benzene in gasoline was reduced to below $1 \%$ in response to requirements enacted by the U.S. Environmental Protection Agency (Kirk et al., 1991). Therefore, a worker employed in the Transportation group would not accumulate exposure time after January 1, 1990, and all other worker's exposure time contribution was considered to have ceased after December 31, 1980.

\subsection{Study Variables}

\subsubsection{Outcome variable}

The outcome variable for the study is death from leukemia (all types included) among PNS civilian workers, as defined using the International Classification of Diseases (ICD) revision in effect

\begin{tabular}{|ccc||}
\hline \multicolumn{3}{|c|}{ Table 3.8.1. ICD Code Revisions } \\
\hline $\begin{array}{c}\text { ICD } \\
\text { Revision }\end{array}$ & Years & $\begin{array}{c}\text { Leukemia } \\
\text { Codes }\end{array}$ \\
\hline 9th & 1979 to 1999 & $204.0-208.9$ \\
8th & 1968 to 1978 & $204.0-207.9$ \\
6th and 7th & 1949 to 1967 & $204.0-204.4$ \\
\hline
\end{tabular}
at the time of death (Table 3.8.1.). The outcome variable is coded as a dichotomous (yes/no) outcome (Table 3.8.3.). 


\subsubsection{Radiation dose metrics}

Three radiation dose metrics were calculated. First, cumulative whole body dose for each case and control was calculated by summing measured doses from each monitoring period recorded in shipyard dosimetry records. This cumulative whole body dose was a result of traditional occupational sources of external ionizing radiation as measured by personal radiation dosimeters. Second, the cumulative whole body dose from occupational sources was converted to bone marrow dose using the methods described in section 3.5.8. Third, the cumulative bone marrow dose from all work-related medical x-rays was calculated using methods described in section 3.5.8 and combined with the cumulative bone marrow dose from traditional occupational sources. Radiation doses were truncated for each control when they attained the age at death of their matched case for the three dose metrics.

\subsubsection{Description of study covariates}

The analysis includes the following covariates, based on the occupational radiation research literature.

1) Gender is included as a study confounder in the analysis because males have a higher risk of leukemia than females [The American Cancer Society, 2002] and males are expected to have higher doses than females. The analysis of this variable is limited because the PNS cohort is predominately male. Of the 115 leukemia deaths, three $(2.6 \%)$ are female.

2) Solvent exposure duration is included in the analysis because of the possibility of increased risk of leukemia among workers exposed to chemical solvents, particularly benzene and carbon tetrachloride, while employed in certain jobs and shops at the shipyard (See Section 3.8). The duration of employment for each worker in any of these job/shop categories was calculated from individual work histories. Solvent exposure was truncated for each control when they attained the age at death for their matched case.

3) Time since last occupational radiation exposure (TSLE) is included in the analysis because studies have suggested that the level of leukemia risk varies with time since exposure. For example, the Japanese Life Span Study provides evidence that leukemia risk after radiation exposure initially increases for about ten years after exposure, then decreases and largely disappears after 20 years (Darby et al., 1985; Finkelstein, 2000). Also occupational studies examining the temporal patterns of leukemia risk after the end of exposure to benzene report that leukemia risk decreases with the length of time beyond the cessation of exposure, and that this time dependency is similar to those individuals exposed to ionizing radiation (Finkelstein, 2000; Hoel, 1985; Hornung and Meinhardt, 1987; Silver et al., 2002).

TSLE was evaluated first as a continuous variable and then as a categorical variable in the analysis. The categorical analysis includes four categories: category 1 ( $\geq 5$ and $<10$ years TSLE), category 2 ( $\geq 2.5$ and $<5$ years TSLE), and category 3 ( $\geq 0$ years and $<2.5$ years 
TSLE). Each of these three categories is compared to the category of $\geq 10$ years of time since last exposure.

For radiation-monitored workers, time since last exposure is the time between the date at which the last exposure occurred and the cutoff date (death from leukemia or date corresponding to matched case's age at death). For non-radiation workers - time since last exposure - is the time between the date last employed and the cutoff date. When radiation doses from work-related medical x-rays are included in the analysis, the time since last exposure variable for all workers is defined as the time between either the date of the last medical x-ray examination or last monitoring date (which ever is later) and the cutoff date.

4) The radiation monitoring status of each worker is included as a dichotomous study variable in the analysis. This variable is included because the PNS cohort study analysis (Silver et al., 2004) reported that leukemia mortality among workers not ever monitored for radiation exposure $(\mathrm{SMR}=1.08,95 \% \mathrm{CI} 0.86,1.35)$ differs from radiation-monitored workers who had a recorded exposure $(\mathrm{SMR}=0.90,95 \% \mathrm{CI} 0.60,1.29)$ and radiation-monitored workers who had no recorded exposure $(\mathrm{SMR}=0.79,95 \%$ CI $0.25,1.95)$.

\begin{tabular}{|c|c|c|}
\hline \multicolumn{3}{|c|}{ Table 3.8.3. List of Study Variables } \\
\hline Variable & Tуре & Comments \\
\hline $\begin{array}{l}\text { Dependent: Leukemia } \\
\text { death (underlying } \\
\text { cause) }\end{array}$ & $\begin{array}{l}\text { Dichotomous } \\
\text { Yes/No }\end{array}$ & $\begin{array}{l}\text { Leukemia death }=1 \text { (case) } \\
\text { No leukemia death }=0 \text { (control) }\end{array}$ \\
\hline $\begin{array}{l}\text { Primary Exposure } \\
\text { Variable: Exposure to } \\
\text { external ionizing } \\
\text { radiation (From } \\
\text { occupational \& medical } \\
\text { x-ray sources) }\end{array}$ & Continuous & $\begin{array}{l}\text { The analysis of the exposure metric will be conducted } \\
\text { three ways: 1) Occupational radiation-badge } \\
\text { exposure only 2) Occupational radiation-bone } \\
\text { marrow dose only 3) Bone marrow dose from both } \\
\text { occupational and work-related medical x-rays } \\
\text { combined. Quantitative measurements are in mSv. }\end{array}$ \\
\hline \multicolumn{3}{|c|}{ Possible Effect Modifiers and Confounders } \\
\hline Variable & Type & $\begin{array}{ll}\text { Comments } \\
\end{array}$ \\
\hline Sex & Categorical & Male $=1$, Female $=2$ \\
\hline Solvent exposure & Continuous & $\begin{array}{l}\text { Never Employed = 0, Employed = 1; in any of the } \\
\text { following job/shop categories (Transportation, } \\
\text { Welding, Machining, Electrical, Woodworking, } \\
\text { Painting and Miscellaneous). Duration of } \\
\text { employment was calculated for all workers employed } \\
\text { in the seven categories. }\end{array}$ \\
\hline & & Category $1: \geq 5$ and $<10$ years TSLE \\
\hline Time since last & Continuous \& & Category $2: \geq 2.5$ and $<5$ years TSLE \\
\hline exposure & Categorical & Category $3: \geq 0$ and 2.5 years TSLE \\
\hline $\begin{array}{l}\text { Radiation Monitoring } \\
\text { Status }\end{array}$ & Categorical & $\begin{array}{l}\text { The worker was radiation-monitored (1) or was not } \\
\text { radiation-monitored }(0) \text {. }\end{array}$ \\
\hline
\end{tabular}




\subsubsection{Covariates not included in the analysis}

1) Race was considered for inclusion in the study analysis because leukemia incidence and mortality is different and generally lower among African-American males than white males (Appendix A, Section 4 and 5). However, race is not included as a study variable for analysis because after reviewing the shipyard medical records for each case and control a determination of race was able to be made for only $444(77 \%)$ of the cases and controls. Because all but four of these 444 cases and controls with known race were white all cases and controls in the study are considered to be white.

2) Smoking has not generally been considered a major risk factor for leukemia; however, increasing evidence suggests that certain forms of adult leukemia, myeloid and acute nonlymphocytic varieties may be associated with cigarette smoking (Austin and Cole, 1986; Williams and Horm, 1977). Smoking is not included as a study variable in the analysis because of the lack of readily available individual smoking information in the PNS medical records.

\subsection{Statistical Analysis}

\subsubsection{Conditional logistic regression}

Conditional logistic regression was used to analyze the study hypothesis and evaluate any exposure-response relationship between external ionizing exposure and leukemia mortality. This type of multivariable analysis is frequently used in matched case-control studies and provides a method to analyze the relationship between a dichotomous outcome and a set of risk variables while controlling for confounding and evaluating effect modification. Conditional logistic regression with incidence density sampling, approximates Cox Proportional Hazards regression (Kleinbaum and Klein, 2002; Szklo and Nieto, 1999).

The initial full conditional logistical regression model is a log-linear model that was parameterized as follows: $\operatorname{Ln}[\mathrm{P}(\mathrm{x}) /(1-\mathrm{P}(\mathrm{x}))]=\alpha+\beta 1(\mathrm{Cum} \operatorname{Rad} \operatorname{Exp})+\beta 2$ (Radiation Monitoring Status) $+\beta 3$ (Sex) $+\beta 4$ (Solvent Duration) $+\beta 5$ (Time Since Last Radiation Exposure or Date Last Employed).

Odds ratios and the corresponding 95\% confidence intervals are derived from the parameter estimates and the associated standard errors of the conditional logistic regression model. A twotailed test of significance with an $\alpha$ level of 0.05 is used to determine statistical significance of the odds ratios and exposure-response relationships.

Because the induction period (period of time from exposure to the development of disease and subsequent death) for leukemia induced by radiation is suspected to be as short as several years (BEIR V, 1990), a separate analysis was conducted in which radiation doses received by cases and controls at zero, two, five, and seven years prior to the date of death of the case are 
discounted. As discussed above, all analyses were repeated with the incorporation of medical xray dose with occupational dose.

An assessment of possible multiplicative interactions between radiation exposure variables (cumulative badge exposure, cumulative occupational bone marrow dose, and cumulative occupational bone marrow dose combined with work-related medical x-rays) and most of the study covariates (gender, solvent exposure duration, and radiation worker status) was done using a hierarchically formulated approach (Kleinbaum and Klein, 2002). The initial full model (A) included two-way and three-way interactions between the radiation exposure variable and the covariates, and among each of the main effect covariates. It was not possible to evaluate both 2way or 3-way interactions involving gender and most interactions involving radiation worker status because among the study subjects only males were radiation workers and received a badge exposure. Solvent duration and radiation worker status was the only interaction involving radiation worker status that could be evaluated. The reduced model (B) included all two-way interactions between the radiation exposure variable and the covariates and the main effect covariates; the final reduced model (C) included only the main effects. Statistical testing of interaction terms was performed using a single chunk test for all of the interaction terms in both the full and reduced models (Kleinbaum and Klein, 2002). That is, model C is fully nested within model B, which is fully nested within model A. The statistical test procedure involved first determining the difference between the $-2 \log$ likelihood scores and degrees of freedom between the full and reduced models and then between the reduced model and main effects model. The time since last exposure variable was evaluated differently; because it was of $a$ priori interest as an effect modifier, its interaction with radiation dose is explored in detail in a sensitivity analysis-Section 4.5.5.

A variable is considered a possible confounder if it is both a leukemia risk factor and associated with radiation dose. The correlations between radiation dose and other covariates are presented in Appendix K, Table 6. Variables that are not considered confounders and cause a greater than $10 \%$ change in the parameter estimate of the radiation badge dose metric are kept in the model. Because solvent duration is an occupational exposure of interest it is also retained in the model.

\subsection{Analytic Data File Description}

\subsubsection{Demographic file}

The final analytic file for the study includes collected and coded information from three separate files: the demographic file, the work history file, and the radiation exposure file.

The demographic file includes all of the study cases and controls and information such as the worker's name, Social Security Number, date of birth, sex, race (not recorded for all individuals), date of death, ICD-code, and first and last dates employed. This file also assigns a unique identification code for each case and control, which allows for the accurate merger of the three separate files. 


\subsubsection{Work history file}

The United States Navy provided NIOSH with access to the personnel records (United States Government Standard Form 7) of all PNS employees working between January 1, 1952 and December 31, 1996, which were microfilmed and abstracted to the work history database file. This file includes a listing of all the jobs and shops ever assigned to each study subject for the time worked at the shipyard during the study period. Also included are the first and last dates employed in each job and shop assigned.

\subsubsection{Radiation exposure file}

The occupational radiation exposure records maintained at the shipyard and in individual medical records were collected for each of the radiation-monitored workers. These records contained exposure information from each monitoring period and summaries of monthly, annual, and lifetime exposures. The records also included documentation of prior exposures at locations outside of PNS. The exposure information was abstracted to a dosimetry history file created by NIOSH personnel.

Medical x-ray exposure information was extracted from the medical records for all study subjects and coded into the radiation exposure file. The medical x-ray exposure file includes information such as the x-ray examination date, examination reason (i.e., diagnostic or routine), type of projection (i.e., body part and orientation), and imaging equipment used (i.e., photofluorographic or direct radiographic).

\subsection{Data Entry and Quality-Validation}

\subsubsection{Radiation exposure file}

The radiation exposure file was created by blind double coding of the interval exposure information abstracted from the exposure records into a Microsoft Access data base. Cumulative doses were determined (section 3.5.8) from the coded data and compared to the cumulative doses reported by a separate dosimetry file from a previous NIOSH study (Rinsky et al., 1981). Seven individuals had cumulative dose discrepancies of $0.1 \mathrm{mSv}$ or greater, the largest being $2.64 \mathrm{mSv}$. These discrepancies were investigated further to facilitate the appropriate correction to the final dose file (Daniels et al., 2004a). Based on this analysis, it was determined that the electronic dosimetry file for the study was reasonably correct and was adequate for use in the study analysis.

\subsubsection{Work history file}

A sample of the hard copy-SF-7 work histories was randomly selected and compared with the electronic work history developed by NIOSH. The sample consisted of the complete work history file for $10 \%$ (58 study subjects). There were 1,573 separate entries for the sample, and 6 coding errors were found for an error rate of $0.4 \%$. It was determined that the work history file for the study is reasonably correct and adequate for use in the study analysis. 


\section{Results}

\subsection{Descriptive Statistics}

A total of 115 persons were identified in the Portsmouth Naval Shipyard cohort of 37,853 as having died from leukemia. For each case, four controls were selected for a total of 460, five of which were selected twice. The majority of the cases (82\%) were born in Maine (40 cases), New Hampshire (34 cases), or Massachusetts (20 cases) (Appendix J, Table 1). Also, the majority of the cases (85\%) died in the same three states: New Hampshire (43 cases), Maine (36 cases), and Massachusetts (19 cases) (Appendix J, Table 2).

Among the 115 cases, 34 (30\%) were monitored for radiation exposure and $81(70 \%)$ were not monitored. All 34 radiation-monitored cases were male. Of the 81 non-radiation-monitored cases, 78 were males and three were female. Among the 460 controls, 167 (36\%) were radiation-monitored (all male) and 293 (63\%) were not monitored (253 males and 40 females).

\subsubsection{Cause of death information for the cases}

The majority (87\%) of the 115 leukemia cases were coded in the eighth or ninth revision of the World Health Organization's International Classification of Diseases (ICD).

Fifteen $(13 \%)$ of the leukemia cases were coded in the ICD version 6 or 7 (Table 4.1.1.).

Prior to 1968 with publication of the $8^{\text {th }}$ revision to ICD, leukemia subtypes were not separately coded. Of the 115 leukemia cases, 54 (47\%) were assigned an ICD code of "unspecified" leukemia, and it was

\begin{tabular}{|c|c|c|c|}
\hline \multicolumn{4}{|c|}{$\begin{array}{l}\text { Table 4.1.1. Frequency of Cases by ICD Code } \\
\text { Revisions }\end{array}$} \\
\hline $\begin{array}{c}\text { ICD } \\
\text { Revision }\end{array}$ & Years & $\begin{array}{l}\text { Leukemia } \\
\text { Codes }\end{array}$ & $\begin{array}{l}\text { Number } \\
\text { of Cases } \\
(n=115)\end{array}$ \\
\hline 9 th & 1979 to 1999 & $204.0-208.9$ & 65 \\
\hline 8th & 1968 to 1978 & $204.0-207.9$ & 35 \\
\hline 6th and 7th & 1949 to 1967 & $204.0-204.4$ & 15 \\
\hline
\end{tabular}
possible to determine from the death certificates that $22(41 \%)$ of the 54 were not chronic lymphocytic leukemia (CLL). Among the remaining 61 specified cases, $28(46 \%)$ were coded as acute monocytic or myeloid leukemia, 14 $(23 \%)$ were coded as chronic lymphoid leukemia, $11(18 \%)$ were coded as chronic myeloid leukemia, and three (5\%) were coded as acute lymphoid leukemia. Three $(5 \%)$ cases were coded in ICD-6 as "myeloid leukemia" and two (3\%) cases were coded in ICD-7 as "lymphoid leukemia.

\subsubsection{Temporal variables - cases and controls}

The following temporal variables were determined for the cases and controls: the mean year of birth, the mean age at date first employed, mean duration of employment, the mean year first 
employed, the mean year last employed, the percent employed for at least five years, the mean time since last employed, and the mean age at the cutoff date (Table 4.1.2.). All temporal values were computed as of the cutoff date for each case/control pair.

\begin{tabular}{|llll|}
\hline $\begin{array}{l}\text { Table 4.1.2. Temporal variables for all leukemia cases, and matched } \\
\text { controls: Portsmouth Naval Shipyard, Kittery, ME, } \\
\text { January 1, 1952 to December 31, 1996 }\end{array}$ \\
\hline & $\begin{array}{l}\text { Cases } \\
(\boldsymbol{n}=\mathbf{1 1 5})\end{array}$ & $\begin{array}{l}\text { Controls } \\
(\boldsymbol{n}=\mathbf{4 6 0})\end{array}$ & $\boldsymbol{p}$-value \\
\hline & 1912 & 1914 & 0.24 \\
Temporal Variables & 34.2 yrs. & 35.3 yrs. & 0.30 \\
\hline Year of Birth (Mean) & 19.6 yrs. & 17.6 yrs. & 0.13 \\
Age at Date First Employed (Mean) & 1947 & 1949 & 0.06 \\
Mean Duration of Employment (years) & 1966 & 1967 & 0.46 \\
Mean Year First Employed & $79 \%$ & $76 \%$ & 0.52 \\
Mean Year Last Employed & 13.6 yrs. & 14.5 yrs. & 0.47 \\
Percent Employed at least 5 years & 67.5 yrs. & 67.4 yrs. & 0.98 \\
\hline Mean Time Since Last Employed (years) & & & \\
Mean Age at Cutoff Date & &
\end{tabular}

There was a year or less difference in the means between the cases and controls for four of the temporal variables. The mean age at date first employed was slightly younger for the cases $(34.2$ years) than for the controls (35.3 years), and the mean year last employed was one year less for the cases (1966) than for the controls (1967). The mean time since last employed was slightly longer for the controls (14.5 years) than for the cases (13.6 years).

The cases and controls were similar in the percentage of workers employed at least five years ( $79 \%$ for the cases, $76 \%$ for the controls) and in mean age at the cutoff date (67.5 years for the cases and 67.4 years for the controls).

In three of the temporal variables, the difference in the means between the cases and controls was greater than a year. The mean year of birth was two years earlier for the cases (1912) than for the controls (1914), the mean year first employed was two years earlier for the cases (1947) than for the controls (1949), and the mean duration of employment was two years longer for the cases (19.6 years) than for the controls (17.6 years). There were no statistically significant differences (Student's $t$ test) in the temporal variables between the cases and controls.

\subsection{Radiation Exposure Descriptive Statistics}

\subsubsection{Radiation exposure from occupational sources}

Workers who had at least one radiation monitoring period during their employment at the shipyard were classified as radiation-monitored workers. Of the 575 cases and controls, 201 (35\%) 
were radiation-monitored; $173(87 \%)$ of the radiation-monitored cases and controls had a recorded badge exposure greater than zero and $28(13 \%)$ had zero recorded exposure. Thirty-four (30\%) of the 115 leukemia cases and 167 (36\%) of the 460 controls were monitored for radiation exposure during their employment at PNS. Five radiation-monitored cases $(15 \%)$ and 23 radiation-monitored controls (14\%) had zero recorded exposure (Table 4.2.1.A.).

\begin{tabular}{|c|c|c|c|c|}
\hline \multirow{2}{*}{$\begin{array}{l}\text { The mean and } \\
\text { median } \\
\text { cumulative }\end{array}$} & \multicolumn{4}{|c|}{ Table 4.2.1.A. Radiation Monitoring Status for Cases and Controls } \\
\hline & Radiation-Monitoring Status & $\begin{array}{c}\text { Case } \\
(n=115)\end{array}$ & $\begin{array}{l}\text { Controls } \\
(n=460)\end{array}$ & $\begin{array}{c}\text { Total } \\
(n=575)\end{array}$ \\
\hline $\begin{array}{l}\text { occupational } \\
\text { badge exposure }\end{array}$ & $\begin{array}{l}\text { Radiation-Monitored-Recorded } \\
\text { Exposure greater than zero }\end{array}$ & $29(85 \%)$ & $144(86 \%)$ & $173(86 \%)$ \\
\hline $\begin{array}{l}\text { (results reported } \\
\text { by PNS } \\
\text { dosimetry }\end{array}$ & $\begin{array}{l}\text { Radiation-Monitored- } \\
\text { Recorded Exposure equal to } \\
\text { zero }\end{array}$ & $5(15 \%)$ & $23(14 \%)$ & $28(14 \%)$ \\
\hline without & Radiation-Monitored-Total & $34(30 \%)$ & $167(36 \%)$ & $201(35 \%)$ \\
\hline modification & Non-Radiation Monitored & $81(70 \%)$ & $293(64 \%)$ & $374(65 \%)$ \\
\hline
\end{tabular}

conversion to SI units) through the cutoff date from onsite (PNS) sources for all radiationmonitored cases and controls combined are $23.17 \mathrm{mSv}$ and $4.52 \mathrm{mSv}$, respectively. The mean onsite exposure for the cases $(38.97 \mathrm{mSv})$ is almost twice as high as that $(19.96 \mathrm{mSv})$ for the controls. Similarly, the median exposure for the cases $(10.44 \mathrm{mSv})$ is about 2.5 times as great as that $(3.82 \mathrm{mSv})$ for the controls.

The distribution of total cumulative occupational badge exposure is skewed, to the right; the medians of the exposures are smaller than the means due to the number of cases and controls with very low or zero recorded exposures. The collective cumulative occupational badge exposure is 1,325 person $\mathrm{mSv}$ for the cases and 3,333 person $\mathrm{mSv}$ for the controls. The collective cumulative occupational badge exposure for the cases and controls combined is 4,658 person $\mathrm{mSv}$ (Table 4.2.1.B.).

\begin{tabular}{|c|c|c|c|c|c|}
\hline \multicolumn{6}{|c|}{$\begin{array}{l}\text { Table 4.2.1.B. Summary of Cumulative Radiation Exposure from Onsite } \\
\text { Occupational Sources }\end{array}$} \\
\hline \multicolumn{6}{|c|}{ Cumulative Onsite Badge Exposure } \\
\hline $\begin{array}{c}\text { Number of } \\
\text { Cases and } \\
\text { Controls } \\
\end{array}$ & $\begin{array}{l}\text { Mean } \\
(\mathrm{mSv})\end{array}$ & $\begin{array}{l}\text { Median } \\
(\mathbf{m S v})\end{array}$ & $\begin{array}{l}\text { Min } \\
(\mathbf{m S v})\end{array}$ & $\begin{array}{c}\operatorname{Max} \\
(\mathbf{m S v})\end{array}$ & $\begin{array}{c}\text { Collective Badge } \\
\text { Exposure } \\
\text { (person-mSv) }\end{array}$ \\
\hline $\begin{array}{l}201 \text { (Cases \& } \\
\text { Controls) }\end{array}$ & 23.17 & 4.52 & 0 & 297.5 & 4658 \\
\hline 34 (Cases) & 38.97 & 10.44 & 0 & 190.4 & 1325 \\
\hline 167(Controls) & 19.96 & $3.82,25$ & 0 & 297.5 & 3333 \\
\hline
\end{tabular}




\subsubsection{Radiation exposure from offsite sources}

Three of the 460 controls had recorded offsite radiation exposure. The mean offsite cumulative badge exposure for these three controls is $3.64 \mathrm{mSv}$ and the median cumulative offsite exposure is $4.83 \mathrm{mSv}$. There was actual exposure information from previous employers for two of the three controls, accounting for $10.03 \mathrm{mSv}$ or $92 \%$ of the offsite exposure. The maximum offsite exposure was $5.20 \mathrm{mSv}$ and the minimum was $0.89 \mathrm{mSv}$. The offsite exposure accounted for $0.23 \%$ of the total cumulative badge exposure from missed, offsite, and occupational onsite sources combined for the cases and controls.

\subsubsection{Estimated missed radiation exposure}

Badge exposures were estimated for 175 cases and controls to account for actual exposures that may have been missed due to the variation in measurement sensitivity of the different dosimetry devices. The estimated mean cumulative missed exposure for the 175 cases and controls combined is $0.50 \mathrm{mSv}$ and the median is $0.23 \mathrm{mSv}$ (Daniels et al., 2004b).

The mean estimated missed exposure for the controls $(0.49 \mathrm{mSv})$ is very close to that for the cases $(0.54 \mathrm{mSv})$. The median estimated missed exposure for the cases $(0.21 \mathrm{mSv})$ and controls $(0.23 \mathrm{mSv})$ is also similar. Collective missed exposures totaled 87.6 person $\mathrm{mSv}$, which is $1.84 \%$ of the total cumulative badge exposure from missed, offsite, and occupational onsite sources combined for the cases and controls (Table 4.2.3.).

\begin{tabular}{|cccccc||}
\hline \multicolumn{7}{|c|}{ Table 4.2.3. Missed Badge Cumulative External Radiation Exposure } \\
\hline $\begin{array}{c}\text { Number of Cases and } \\
\text { Controls }\end{array}$ & $\begin{array}{c}\text { Mean } \\
(\mathbf{m S v})\end{array}$ & $\begin{array}{c}\text { Median } \\
(\mathbf{m S v})\end{array}$ & $\begin{array}{c}\text { Min } \\
(\mathbf{m S v})\end{array}$ & $\begin{array}{c}\text { Max } \\
(\mathbf{m S v})\end{array}$ & $\begin{array}{c}\text { Missed } \\
\text { Exposure } \\
\text { (person-mSv) }\end{array}$ \\
\hline 175 (Cases \& Controls) & 0.50 & 0.23 & 0.03 & 3.64 & 87.6 \\
30 (Cases Only) & 0.54 & 0.21 & 0.03 & 3.51 & 16.2 \\
145 (Controls Only) & 0.49 & 0.23 & 0.03 & 3.64 & 71.4 \\
\hline
\end{tabular}

\subsection{Cumulative Bone Marrow Dose Descriptive Statistics}

\subsubsection{Bone marrow dose estimates from occupational sources}

External ionizing radiation exposures from onsite occupational sources were converted from badge exposure values to a cumulative bone marrow dose estimate for each of the 201 radiationmonitored cases and controls. For the radiation-monitored cases and controls, the cumulative bone marrow dose value, which is an estimate of radiation dose to the bone marrow only, is 
lower $(3,430$ person $\mathrm{mSv}$ ) (Table 4.3.1.) than the cumulative badge exposure value, which is a measure of whole body exposure (4,658 person $\mathrm{mSv}$ ) (Table 4.2.1.B.). Summary tables of bone marrow dose values for estimated missed and offsite exposures are presented in Appendix K, Tables $1 \& 2$ ).

\begin{tabular}{||cccccc||}
\hline \multicolumn{7}{|c|}{$\begin{array}{c}\text { Table 4.3.1. Cumulative Bone Marrow Dose from Onsite Sources Radiation } \\
\text { Monitored Cases and Controls }\end{array}$} \\
\hline $\begin{array}{c}\text { Number of Radiation } \\
\text { Monitored Cases and } \\
\text { Controls }\end{array}$ & $\begin{array}{c}\text { Mean } \\
\text { (mSv) }\end{array}$ & $\begin{array}{c}\text { Median } \\
\text { (mSv) }\end{array}$ & $\begin{array}{c}\text { Min } \\
(\mathbf{m S v})\end{array}$ & $\begin{array}{c}\text { Max } \\
(\mathbf{m S v})\end{array}$ & $\begin{array}{c}\text { Collective } \\
\text { BMD } \\
\text { (person-mSv) }\end{array}$ \\
\hline 201 (Cases \& Controls) & 17.06 & 3.45 & 0 & 222.7 & 3,429 \\
34 (Cases Only) & 29.11 & 7.88 & 0 & 144.8 & 990 \\
167 (Controls Only) & 14.60 & 2.82 & 0 & 222.7 & 2,440 \\
\hline
\end{tabular}

\subsubsection{Bone marrow dose estimates from work-related medical $x$-ray exams}

Medical records from the shipyard indicate that external ionizing radiation exposure resulted from work-related medical x-rays that were performed for the following reasons: 1) as part of annual radiation-worker medical qualification examinations; 2) as part of radiation background physical examinations; and 3) as part of mass tuberculosis screenings given (all shipyard employees) in 1948, 1951, 1952, and 1956 (Daniels et al., 2004b).

The cases received a total of 589 work-related medical examinations that included one $\mathrm{x}$-ray compared to 2,110 for the controls. The average number of work-related medical $\mathrm{x}$-ray examinations is similar for the cases and the controls: 5.1 per case and 4.5 per control, respectively (Table 4.3.2.A). However, radiation-monitored cases and controls received an average of 7 work-related medical x-rays compared to 3 for non-radiation-monitored cases and controls (Table 4.3.2.A). This difference is due to primarily to the shipyard practice, discontinued in 1969, of giving a chest x-ray as part of each yearly radiation-worker qualifying physical examination (Daniels et al., 2004b). 


\begin{tabular}{|c|c|c|c|c|}
\hline \multicolumn{5}{|c|}{$\begin{array}{l}\text { Table 4.3.2.A. Frequency by Type of Medical Examination that Included a } \\
\text { Work-Related Medical X-Ray for All Cases, All Controls and } \\
\text { Radiation-Monitored and Non-Monitored Cases and Controls }\end{array}$} \\
\hline $\begin{array}{c}\text { Type of Shipyard } \\
\text { Medical Exam that } \\
\text { Included an X-ray Exam }\end{array}$ & $\begin{array}{c}\text { All Cases } \\
n=115\end{array}$ & $\begin{array}{l}\text { All } \\
\text { Controls } \\
\mathbf{n}=\mathbf{4 6 0}\end{array}$ & $\begin{array}{c}\text { Radiation- } \\
\text { Monitored } \\
\text { Cases and } \\
\text { Controls } \\
\text { n=201 } \\
\end{array}$ & $\begin{array}{c}\text { Non- } \\
\text { Radiation- } \\
\text { Monitored } \\
\text { Cases and } \\
\text { Controls } \\
\text { n=374 } \\
\end{array}$ \\
\hline $\begin{array}{l}\text { Radiation Qualification } \\
\text { Physical }\end{array}$ & 194 & 572 & 715 & 51 \\
\hline $\begin{array}{l}\text { Radiation Background } \\
\text { Physical }\end{array}$ & 28 & 88 & 77 & 39 \\
\hline Mass TB Screening & 186 & 636 & 285 & 537 \\
\hline $\begin{array}{l}\text { Pre-Employment } \\
\text { Screening Examination }\end{array}$ & 68 & 294 & 123 & 239 \\
\hline Termination Physical & 20 & 101 & 41 & 80 \\
\hline Disability Physical & 8 & 48 & 26 & 30 \\
\hline Offsite Physical & 11 & 71 & 16 & 66 \\
\hline Other & 74 & 300 & 203 & 171 \\
\hline Total* & 589 & 2,110 & 1,486 & 1,213 \\
\hline $\begin{array}{l}\text { Avg. number of work- } \\
\text { related x-rays }\end{array}$ & 5.12 & 4.5 & 7.39 & 3.2 \\
\hline
\end{tabular}


However, mean bone marrow dose values are only moderately higher for the radiation-monitored cases and controls $(5.97 \mathrm{mSv})$ than the non-radiation-monitored cases and controls $(4.10 \mathrm{mSv})$, less than a $2 \mathrm{mSv}$ difference (Table 4.3.2.B.), since monitored workers received greater numbers of x-rays using the lower dose direct radiographic technique. The mean bone marrow dose from work-related medical x-rays for the radiation-monitored cases is $6.63 \mathrm{mSv}$ and is $2.16 \mathrm{mSv}$ greater than the mean for the non-radiation-monitored cases which is $4.47 \mathrm{mSv}$. There is less difference $(1.84 \mathrm{mSv})$ in the mean bone marrow dose values between the radiation-monitored controls $(5.84 \mathrm{mSv})$ and the non-radiation-monitored controls (4.0 mSv) (Table 4.3.2.B.).

\begin{tabular}{|c|c|c|c|c|c|}
\hline \multicolumn{6}{|c|}{$\begin{array}{l}\text { Table 4.3.2.B. Cumulative Bone Marrow Dose from Work-Related } \\
\text { Medical X-Rays Given at PNS-Radiation Monitored and } \\
\text { Non-Monitored Cases and Controls Separately }\end{array}$} \\
\hline & $\begin{array}{l}\text { Mean } \\
(\mathrm{mSv})\end{array}$ & $\begin{array}{c}\text { Median } \\
(\mathbf{m S v})\end{array}$ & $\begin{array}{c}\text { Min } \\
(\mathbf{m S v})\end{array}$ & $\begin{array}{c}\text { Max } \\
(\mathbf{m S v})\end{array}$ & $\begin{array}{l}\text { Collective } \\
\text { BMD } \\
\text { (person-mSv) } \\
\end{array}$ \\
\hline $\begin{array}{l}\text { (Rad-Monitored Cases \& } \\
\text { Controls) } n=197\end{array}$ & 5.97 & 6.12 & 0.04 & 15.08 & 1,178 \\
\hline $\begin{array}{l}\text { (Rad-Monitored Cases } \\
\text { Only) } n=34\end{array}$ & 6.63 & 6.42 & 0.04 & 14.08 & 225.6 \\
\hline $\begin{array}{l}\text { (Rad-Monitored Controls } \\
\text { Only) } n=163\end{array}$ & 5.84 & 6.04 & 0.04 & 15.08 & 952.2 \\
\hline $\begin{array}{l}\text { Non-Monitored Cases \& } \\
\text { Controls } n=354\end{array}$ & 4.10 & 4.50 & 0.04 & 16.54 & 1,454 \\
\hline $\begin{array}{l}\text { (Non-Monitored Cases } \\
\text { Only) } n=77\end{array}$ & 4.47 & 4.50 & 0.04 & 16.54 & 344.6 \\
\hline $\begin{array}{l}\text { (Non-Monitored Controls } \\
\text { Only) } n=277\end{array}$ & 4.00 & 4.50 & 0.04 & 13.50 & 1,109 \\
\hline
\end{tabular}

However, when the radiation-monitored $(n=197)$ and non-monitored $(n=354)$ cases and controls are combined (Table 4.3.2.C.) the median bone marrow dose values from work-related medical $\mathrm{x}$-rays are the same $(4.50 \mathrm{mSv})$ for the 551 cases and controls combined, the 111 cases and the 440 controls (Table 4.3.2.C.) which illustrates the heavy influence of the workers who had only medical x-ray exposure. 


\begin{tabular}{|c|c|c|c|c|c|}
\hline \multicolumn{6}{|c|}{$\begin{array}{l}\text { Table 4.3.2.C. Cumulative Bone Marrow Dose from Work-Related Medical } \\
\text { X-Rays Given at PNS-Radiation Monitored Cases and } \\
\text { Controls Combined With Non-Radiation Monitored Cases and } \\
\text { Controls }\end{array}$} \\
\hline $\begin{array}{l}\text { Number of Cases and } \\
\text { Controls }\end{array}$ & $\begin{array}{l}\text { Mean } \\
(\mathrm{mSv})\end{array}$ & $\begin{array}{c}\text { Median } \\
(\mathrm{mSv})\end{array}$ & $\underset{(\mathrm{mSv})}{\operatorname{Min}}$ & $\begin{array}{c}\operatorname{Max} \\
(\mathbf{m S v})\end{array}$ & $\begin{array}{c}\text { Collective } \\
\text { BMD } \\
\text { (person-mSv) }\end{array}$ \\
\hline 551 (Cases \& Controls) & 4.78 & 4.50 & 0.04 & 16.54 & 2,632 \\
\hline 111 (Cases Only) & 5.13 & 4.50 & 0.04 & 16.54 & 570.2 \\
\hline 440 (Controls Only) & 4.68 & 4.50 & 0.04 & 15.08 & 2,061 \\
\hline
\end{tabular}

\subsubsection{Cumulative bone marrow dose from onsite occupational sources and work-related medical $x$-rays combined}

The collective cumulative bone marrow dose from onsite sources combined with work-related medical x-rays given at PNS was 4,607 person $\mathrm{mSv}$ for the 201 radiation-monitored cases and controls. The bone marrow dose from work-related medical x-rays accounted for $26 \%(1,178$ person $\mathrm{mSv}$ ) of the collective cumulative dose for the radiation-monitored cases and controls. The collective bone marrow dose was 1,216 person $\mathrm{mSv}$ for the 34 radiation-monitored cases, $19 \%$ (225.6 person $\mathrm{mSv}$ ) of which was due to work-related medical x-rays. The 167 radiationmonitored controls had a collective dose of 3,392 person $\mathrm{mSv}, 28 \%$ (952.2 person $\mathrm{mSv}$ ) of which was due to medical x-ray dose (Table 4.3.3.A.).

\begin{tabular}{|cccccc||}
\hline Table 4.3.3.A. Cumulative Bone Marrow Dose from Work-Related Medical \\
C-Rays and Occupational Dose Combined-Radiation \\
Monitored Cases and Controls \\
Mond
\end{tabular}


A bone marrow dose from occupational and work-related medical x-ray doses combined was assigned to 555 radiation-monitored and non-radiation-monitored cases and controls (Table 4.3.3.B.). Only 4 cases and 16 controls had no bone marrow dose from any source being considered in this study. The collective cumulative bone marrow dose from occupational sources and work-related medical x-rays combined for the 555 cases and controls was 6,061 person $\mathrm{mSv}$ of which $43 \%$ (2,632 person $\mathrm{mSv}$ ) was from work-related medical x-rays. The 111 cases had a collective dose of 1,560 person $\mathrm{mSv}$, of which $37 \%(570.2$ person $\mathrm{mSv}$ ) was from work-related medical x-rays.

The 444 controls had a collective dose of 4,501 person $\mathrm{mSv}$, of which $46 \%(2,061$ person $\mathrm{mSv})$ was from work-related medical x-rays (Table 4.3.3.B.). The percentage of the collective cumulative bone marrow dose from work-related medical x-ray exposure is greater among the 555 cases and controls than the 201 radiation-monitored workers (43\% vs. $26 \%)$ because 354 of the 555 cases and controls had bone marrow dose from medical x-rays only and no bone marrow dose from occupational exposures.

\begin{tabular}{|c|c|c|c|c|c|}
\hline \multicolumn{6}{|c|}{$\begin{array}{l}\text { Table 4.3.3.B. Cumulative Bone Marrow Dose from Onsite } \\
\text { Occupational Sources and Work-Related Medical } \\
\text { X-rays Combined }\end{array}$} \\
\hline $\begin{array}{c}\text { Number of Cases and } \\
\text { Controls }\end{array}$ & $\begin{array}{l}\text { Mean } \\
(\mathrm{mSv})\end{array}$ & $\begin{array}{c}\text { Median } \\
(\mathrm{mSv})\end{array}$ & $\begin{array}{l}\text { Min } \\
(\mathrm{mSv})\end{array}$ & $\begin{array}{c}\text { Max } \\
(\mathbf{m S v})\end{array}$ & $\begin{array}{l}\text { Collective } \\
\text { BMD } \\
\text { (person-mSv) }\end{array}$ \\
\hline 555 (Cases \& Controls) & 10.92 & 4.62 & 0.04 & 236.4 & 6,061 \\
\hline 111 (Cases Only) & 14.05 & 6.0 & 0.04 & 147.0 & 1,560 \\
\hline 444 (Controls Only) & 10.13 & 4.54 & 0.04 & 236.4 & 4,501 \\
\hline
\end{tabular}

\subsection{Solvent Exposure Duration Descriptive Statistics}

There were 63 cases and 244 controls identified as employed in job and shop categories likely to involve benzene and carbon tetrachloride exposure (Table 4.4). The mean and median values for cumulative employment duration in any of the exposed groups were 14.5 and 14.3 years for the cases and 10.0 and 7.7 years for the controls. The machining group included more cases (30) and controls (112) than any of the other exposed groups. The mean and median cumulative employment duration in the machining group was 15.6 and 16.1 years for the cases and 10.7 and 10.1 years for the controls (Table 4.4). Distributions of solvent duration (years) for radiationmonitored and non-monitored cases and controls appears in Appendix K, Tables 33-36. 
Table 4.4. Frequency of Cases and Controls by Job/Shop with Likely Solvent Exposure Including Benzene and Carbon Tetrachloride

\begin{tabular}{|c|c|c|c|c|c|c|}
\hline $\begin{array}{c}\text { PNS } \\
\text { Job/Shop }\end{array}$ & Cases & Controls & $\begin{array}{c}\text { Mean } \\
\text { Duration } \\
\text { (yrs.) } \\
\text { (Cases) } \\
\end{array}$ & $\begin{array}{c}\text { Median } \\
\text { Duration } \\
\text { (yrs.) } \\
\text { (Cases) } \\
\end{array}$ & $\begin{array}{c}\text { Mean } \\
\text { Duration } \\
\text { (yrs.) } \\
\text { (Controls) } \\
\end{array}$ & $\begin{array}{c}\text { Median } \\
\text { Duration } \\
\text { (yrs.) } \\
\text { (Controls) } \\
\end{array}$ \\
\hline $\begin{array}{l}\text { Painting } \\
\text { Group }\end{array}$ & 2 & 12 & 13.0 & 13.0 & 9.2 & 8.8 \\
\hline $\begin{array}{l}\text { Welding } \\
\text { Group }\end{array}$ & 11 & 34 & 14.0 & 13.1 & 11.4 & 7.8 \\
\hline $\begin{array}{l}\text { Transportation } \\
\text { Group }\end{array}$ & 9 & 27 & 9.3 & 5.8 & 5.2 & 3.0 \\
\hline $\begin{array}{l}\text { Electrical } \\
\text { Group }\end{array}$ & 19 & 44 & 8.0 & 6.1 & 9.9 & 5.5 \\
\hline $\begin{array}{l}\text { Machining } \\
\text { Group }\end{array}$ & 31 & 113 & 15.6 & 16.1 & 10.7 & 10.1 \\
\hline $\begin{array}{l}\text { Woodworking } \\
\text { Group }\end{array}$ & 3 & 28 & 4.1 & 2.5 & 5.9 & 2.1 \\
\hline $\begin{array}{l}\text { Total Solvent } \\
\text { Exposed } \\
\text { Group* }\end{array}$ & 63 & 244 & 14.5 & 14.3 & 10.0 & 7.7 \\
\hline
\end{tabular}

\subsection{Results of Conditional Logistic Regression Analysis}

The conditional logistic regression analysis, which assumes a log-linear model, includes the evaluation of the exposure-response relationship between external ionizing radiation and leukemia mortality among PNS civilian workers. The whole-body radiation exposure variable includes estimated missed exposures and exposures received from onsite and offsite sources. The analysis involved in the selection of the lag period, assessment of interactions, and evaluation of confounding is described and the results of the final model reported. Separate analysis excluding estimated missed radiation exposure and exposure from offsite sources from the radiation exposure variable is included. Also, the impact of exposure from work-related medical x-rays on leukemia risk is reported. A description of the source of radiation exposure included in the radiation dose variable in each table in section 4.5-5.0 is located in Appendix K, Table 30 . 


\subsubsection{Determination of lag period - primary exposure variable-cumulative radiation badge exposure}

Lag periods of zero, two, five, and seven years were evaluated using the likelihood ratio statistic test with whole body radiation exposure (onsite, offsite, and estimated missed exposures combined) as the only variable included in the model. The estimated missed exposure portion of the variable was not lagged because it was not assigned to specific time periods. While there was little difference in the odds ratios and confidence limits among the lag periods, the two-year lag was chosen for use in remaining modeling because of the slightly higher likelihood ratio test, biological plausibility, and previous research literature (BEIR V, 1990). The odds ratio, 95\% CI, likelihood ratio test chi-square, and $p$-value for each lag period are listed in Table 4.5.1.

\begin{tabular}{|c|c|c|c|c|c|c|c|c|}
\hline \multicolumn{9}{|c|}{$\begin{array}{l}\text { Table 4.5.1. Occupational Badge Exposure Variable with Zero, Two, Five and Seven } \\
\text { Year Lags }\end{array}$} \\
\hline $\begin{array}{l}\text { Exposure } \\
\text { Variable } \\
(1 \mathrm{mSv}) \\
\end{array}$ & DF & $\begin{array}{c}\text { Parameter } \\
\text { Estimate }\end{array}$ & SE & $\begin{array}{l}\text { Odds } \\
\text { Ratio }\end{array}$ & $\begin{array}{r}95 \\
\text { Confi } \\
\text { Lir }\end{array}$ & $\begin{array}{l}\% \\
\text { lence } \\
\text { lits }\end{array}$ & $\begin{array}{l}\text { LR Test } \\
\text { Chi-Sq }\end{array}$ & $\begin{array}{r}\text { Pr }> \\
\text { Chi-So }\end{array}$ \\
\hline $\begin{array}{l}\text { Badge Exposure } \\
\text { Zero Lag }\end{array}$ & 1 & 0.00410 & 0.00304 & 1.00 & 0.99 & 1.01 & 1.68 & 0.20 \\
\hline $\begin{array}{l}\text { Occupational } \\
\text { Badge Exposure } \\
\text { Lagged } 2 \text { Years }\end{array}$ & 1 & 0.00422 & 0.00306 & 1.00 & 0.99 & 1.01 & 1.76 & 0.18 \\
\hline $\begin{array}{l}\text { Occupational } \\
\text { Badge Exposure } \\
\text { Lagged } 5 \text { Years }\end{array}$ & 1 & 0.00424 & 0.00317 & 1.00 & 0.99 & 1.01 & 1.65 & 0.20 \\
\hline $\begin{array}{l}\text { Occupational } \\
\text { Badge Exposure } \\
\text { Lagged } 7 \text { Years }\end{array}$ & 1 & 0.00421 & 0.00324 & 1.00 & 0.99 & 1.01 & 1.55 & 0.21 \\
\hline
\end{tabular}

\subsubsection{Assessment of interactions with the primary exposure metric-cumulative radiation badge exposure}

An assessment of possible interactions between radiation badge exposure, as the primary exposure variable, and the study variables (gender, solvent exposure duration, time since last (radiation) exposed and radiation worker status) was conducted. Interaction between radiation badge exposure and solvent duration and radiation worker status and solvent duration was evaluated. It was not possible to evaluate any 2-way or 3-way interactions involving gender and most interactions involving radiation worker status because only males were radiation workers and had a badge exposure data. Time since last exposure was included as a main effect in each 
model, and was included as an interaction term with cumulative radiation exposure in a separate test - described is section 4.5.5 - as it was expected a priori that this is an important interaction to analyze based on the literature (BEIR V, 1990).

When the full model (A) is compared to the reduced model (B), there is no significant difference; therefore, the interactions in the full model were dropped. When the reduced model (B) is compared to the main-effects-only model (C), there is no significant difference and the 2-way exposure interactions were dropped, leaving the main-effects-only model (Table 4.5.2.A). All of the variables included in both models A and B are included in Appendix K, Tables $3 \& 4$.

\begin{tabular}{|c|c|c|c|c|}
\hline \multicolumn{5}{|c|}{ Table 4.5.2.A. Model Fit Statistics-Two-Year Lag } \\
\hline Model & DF & $\begin{array}{l}\text {-2 LOG L } \\
\text { With } \\
\text { Covariates }\end{array}$ & $\begin{array}{l}\text {-2 LOG L } \\
\text { With } \\
\text { Covariates } \\
\text { Differences }\end{array}$ & $\begin{array}{c}\text { Critical } \\
\text { Value- } \\
\text { Chi-Sq } \\
(\mathbf{0 . 0 5}) \\
\end{array}$ \\
\hline $\begin{array}{l}\text { A) Full model with 2-way } \\
\text { interactions and main effects } \\
\text { Interactions Included } \\
\text { (Occupational badge exposure-2 yr } \\
\text { lag * solvent duration) and } \\
\text { (radiation worker status * solvent } \\
\text { duration) (Appendix K Table 3) } \\
\text { B) Reduced model 2-way exposure } \\
\text { interactions and main effects } \\
\text { Interaction Included } \\
\text { (Occupational badge exposure * } \\
\text { solvent duration interaction) } \\
\text { (Appendix K Table 4) } \\
\text { C) Reduced model-main effects } \\
\text { (Table 4.5.2.B) }\end{array}$ & 9 & 341.79 & $\begin{array}{c}\mathrm{B}-\mathrm{A}=0.22 \\
1 \mathrm{df} \\
\mathrm{C}-\mathrm{B}=1.24 \\
1 \mathrm{df}\end{array}$ & 3.84 \\
\hline
\end{tabular}

Variables in the main effects model (C), gender, radiation worker status, solvent exposure duration, and time since last exposure were evaluated as possible confounders. A variable was considered a possible confounder if there is a greater than $10 \%$ change in the parameter estimate of the radiation badge exposure variable when the variable is removed from the model.

Variables that are determined not to be confounders are considered for removal from the model. Gender is considered a confounder - and left in the model - because its removal causes a $12 \%$ change in the radiation exposure parameter estimate (Appendix K, Table 5).

The solvent exposure duration variable is not a confounder; when removed from the model, the change in the radiation badge exposure parameter estimate is only $7 \%$ and it is not correlated 
with badge exposure $(p=0.14)$ (Appendix K, Tables $5 \& 6)$. While consideration was given to removing the variable from the model it was kept because it is an occupational exposure of interest. Radiation worker status is considered a confounder — and left in the model — because its removal causes an $80 \%$ change in the radiation badge exposure parameter estimate (Appendix $\mathrm{K}$, Table 5).

\begin{tabular}{|c|c|c|c|c|c|c|c|c|}
\hline Variable & DF & $\begin{array}{l}\text { Parameter } \\
\text { Estimate }\end{array}$ & $\begin{array}{c}\text { Standard } \\
\text { Error }\end{array}$ & $\begin{array}{l}\text { Chi- } \\
\text { Square }\end{array}$ & $\begin{array}{l}\operatorname{Pr}> \\
\text { ChiSq }\end{array}$ & $\begin{array}{l}\text { Odds } \\
\text { Ratio }\end{array}$ & $\begin{array}{r}9 \\
\text { Conf } \\
\text { Li }\end{array}$ & $\begin{array}{l}\% \\
\text { dence } \\
\text { dits }\end{array}$ \\
\hline Occupational & & & & & & $\begin{array}{c}(10 \mathrm{mSv}) \\
1.09\end{array}$ & 1.01 & 1.16 \\
\hline $\begin{array}{l}\text { Badge Exposure } \\
\text { Lagged } 2 \text { Years }\end{array}$ & 1 & 0.0082 & 0.0036 & 5.291 & 0.021 & $\begin{array}{c}(1 \mathrm{mSv}) \\
1.01\end{array}$ & 1.00 & 1.02 \\
\hline $\begin{array}{l}\text { Gender } \\
(1=\text { Female, } \\
0=\text { Male })\end{array}$ & 1 & -1.235 & 0.6141 & 4.045 & 0.044 & 0.29 & 0.09 & 0.97 \\
\hline $\begin{array}{l}\text { Radiation Worker } \\
\text { flag }(1=\text { Yes, } \\
0=\mathrm{No})\end{array}$ & 1 & -0.8255 & 0.2726 & 9.173 & 0.0035 & 0.44 & 0.26 & 0.75 \\
\hline $\begin{array}{l}\text { Solvent Duration } \\
\text { Exp - Lagged } 2 \\
\text { Years }\end{array}$ & 1 & 0.0348 & 0.0117 & 8.889 & 0.0039 & 1.04 & 1.01 & 1.06 \\
\hline $\begin{array}{l}\text { TSLE is } \geq 5 \text { year } \\
\text { and }<10 \text { years }\end{array}$ & 1 & -0.1718 & 0.3604 & 0.2274 & 0.6345 & 0.84 & 0.42 & 1.71 \\
\hline $\begin{array}{l}\text { TSLE is } \geq 2.5 \\
\text { years and }<5 \text { years }\end{array}$ & 1 & 0.6625 & 0.4072 & 2.647 & 0.1048 & 1.94 & 0.87 & 4.31 \\
\hline $\begin{array}{l}\text { TSLE is } \geq 0 \text { years } \\
\text { and }<2.5 \text { years }\end{array}$ & 1 & -0.4926 & 0.4112 & 1.435 & 0.2319 & 0.61 & 0.27 & 1.37 \\
\hline
\end{tabular}

TSLE was first evaluated as a continuous variable and was not significant in the main effects model $(\mathrm{OR}=0.99 ; 95 \% \mathrm{CI}=0.98,1.02)$ (Appendix K, Table 28). No interactions involving TSLE as a continuous variable were found to be significant (Appendix K, Tables 25-27).

The time since last exposure (TSLE) variable was also modeled as a categorical variable and included the following three categories: category 1 ( $\geq 5$ years TSLE and $<10$ years TSLE), category 2 ( $\geq 2.5$ years and $<5$ years TSLE), and category 3 ( 0 years TSLE and $<2.5$ years TSLE). Each of the three categories was compared to the fourth category of $\geq 10$ years of time since last exposure. 
The categorical variable time since last exposure is not a confounder because when removed from the model there is only a $7 \%$ change in the radiation badge exposure variable and there is no significant correlation between any of the categories and the radiation exposure and case status variables (Appendix $\mathrm{K}$, Tables 5 \& 6). There was not a significant elevation of leukemia mortality in any of the TSLE categories but there was a non-significant elevation of the odds ratio in the $\geq 2.5$ years and $<5$ years TSLE category ( $\mathrm{OR}=1.94 ; 95 \% \mathrm{CI}=0.87,4.31$ ) (Table 4.5.2.B). The variable was dropped from the model, but its role as an effect modifier is explored in section 4.5.5.

\subsubsection{Final regression model-occupational badge exposure}

The final log-linear model includes a significant positive exposure response relation between disease (leukemia mortality) and exposure (external ionizing radiation), adjusting for gender, radiation worker status, and solvent exposure duration $(\mathrm{OR}=1.08$ at $10 \mathrm{mSv}$ of exposure; $95 \%$ $\mathrm{CI}=1.01,1.16)$. The final model was also analyzed using a linear excess relative risk model which yielded higher risk estimates $(\mathrm{RR}=1.02$ at $1 \mathrm{mSv} ; 95 \%$ likelihood-based $\mathrm{CI}=1.00,1.09$; and $\mathrm{RR}=1.23$ at $10 \mathrm{mSv}$; 95\% likelihood-based $\mathrm{CI}=1.03,1.88$ ) than the log linear model. A table of the risk coefficients by dose category using the log-linear model appears in Appendix K Table 37.

To evaluate the potential impact of estimated missed radiation exposure and radiation exposure from offsite sources, the radiation exposure variable in the final log-linear model was modified by excluding exposure from both of these sources. When the radiation exposure variable includes only badge exposure from onsite occupational sources, there is still a significant positive exposure response between leukemia mortality and radiation exposure and the odds ratio and confidence limits remain essentially unchanged $(\mathrm{OR}=1.08$ at $10 \mathrm{mSv}$ of exposure; $95 \%$ $\mathrm{CI}=1.01,1.16$ ) (Appendix K, Table 7).

The log-linear model results also include a significant positive exposure response between leukemia mortality and the duration of time worked in any of the a priori solvent-exposed job and shop categories - painting, welding, transportation, electrical, machining, and woodworking- $(\mathrm{OR}=1.03$ at one year of exposure; $95 \% \mathrm{CI}=1.01,1.06)$.

The parameter estimate for radiation worker status in the log-linear model is negative (Table 4.5.3.) and reflects the fact that radiation-monitored workers had a lower overall leukemia risk than non-monitored workers, which is a finding that is supported by a previous NIOSH mortality study (Silver et al., 2004). 


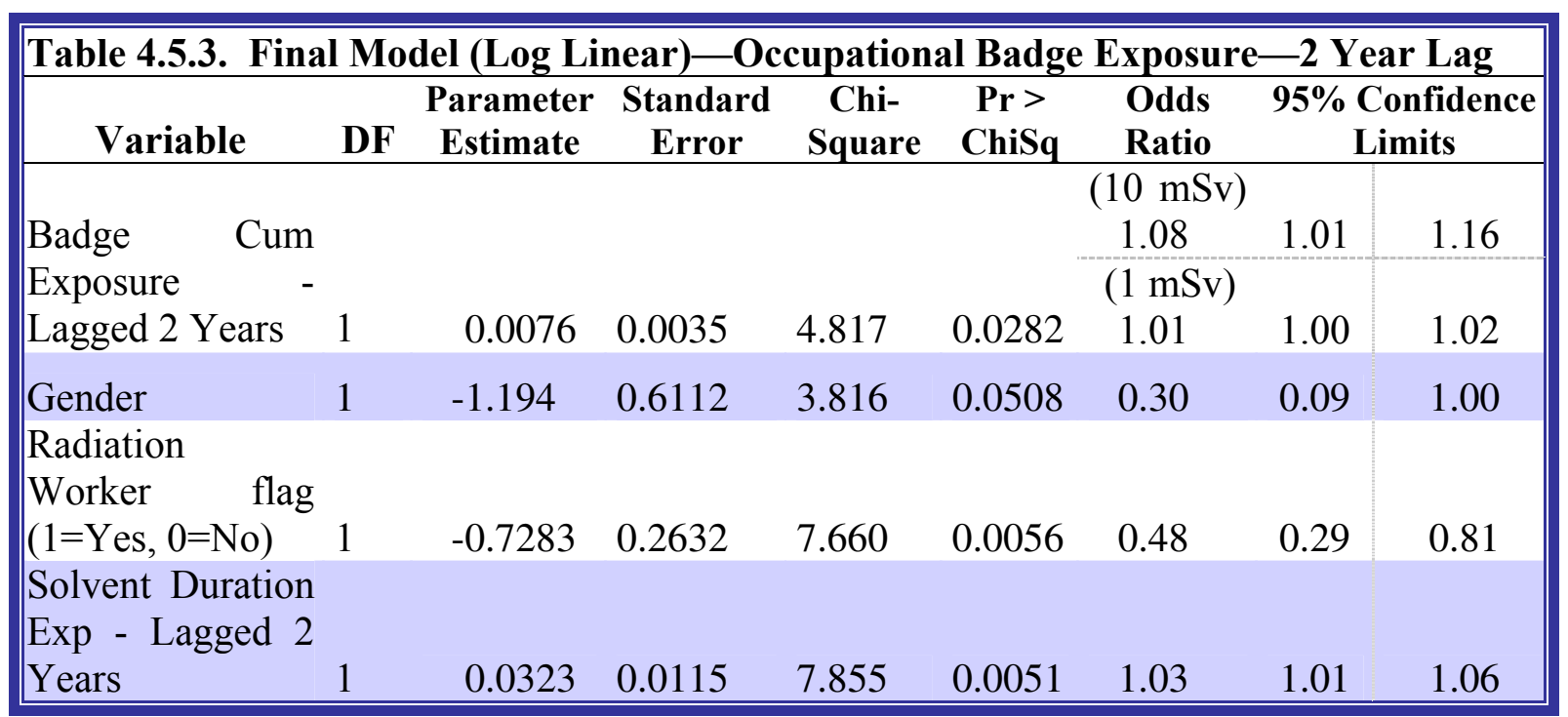

\subsubsection{Final regression model using bone marrow dose}

External ionizing radiation exposures (estimated missed exposures and exposures from onsite and offsite sources combined) were converted to a cumulative bone marrow dose estimate for each case and control so that impact of exposures from work-related medical x-rays could be analyzed. A lag period of two years was selected using the likelihood ratio test for the analysis of the occupational bone marrow dose separately and combined with work-related medical x-ray dose (Appendix K, Tables 8 \& 9). The model fit statistics show that there were no significant interaction terms found in the model that includes only occupational bone marrow dose (full vs. reduced: $-2 \log \mathrm{L}=0.211 \mathrm{df} ; p=0.64$; reduced vs. main effects: $-2 \log \mathrm{L}=1.231 \mathrm{df} ; p=$ 0.26) (Appendix K Table 10) or the model that combines bone marrow dose from both occupational sources and work-related medical x-rays (full vs. reduced: $-2 \log \mathrm{L}=2.562 \mathrm{df}$; $p=0.28$; reduced vs. main effects: $-2 \log \mathrm{L}=1.253 \mathrm{df} ; p=0.74$ ) (Appendix K, Table 14). All of the interaction terms for both the full and reduced models for both the occupational bone marrow dose only model and the model combining occupational and medical x-ray bone marrow dose are listed in (Appendix K, Tables 11,12, 13 \& 15, 16, 17).

\subsubsection{Final log-linear regression model-primary exposure variable-bone marrow dose from occupational sources}

In the final regression model with only bone marrow dose from occupational radiation exposure included, there is a significant positive dose response between leukemia mortality and bone marrow dose adjusting for gender, radiation worker status, solvent exposure duration, and time since last exposed. The odds ratio is 1.11 at $10 \mathrm{mSv}$ of exposure and the $95 \% \mathrm{CI}=1.01,1.22$ (Table 4.5.4.1). The increase in the leukemia risk estimate with occupational bone marrow dose 
only compared to the model with occupational badge exposure only ( $\mathrm{OR}=1.08$ at $10 \mathrm{mSv}$ of exposure; $95 \% \mathrm{CI}=1.01,1.16)$ because there is less $(1,258 \mathrm{mSv})$ cumulative bone marrow dose than whole body exposure (Appendix K, Table 19).

\begin{tabular}{|c|c|c|c|c|c|c|c|c|}
\hline \multicolumn{9}{|c|}{$\begin{array}{l}\text { Table 4.5.4.1. Final Regression Model-Occupational Bone Marrow Dose Only- } \\
\text { Two Year Lag }\end{array}$} \\
\hline \multirow[t]{2}{*}{ Variable } & \multirow[t]{2}{*}{ DF } & \multirow[t]{2}{*}{$\begin{array}{l}\text { Parameter } \\
\text { Estimate }\end{array}$} & \multirow[t]{2}{*}{$\begin{array}{l}\text { Standard } \\
\text { Error }\end{array}$} & \multirow[t]{2}{*}{$\begin{array}{l}\text { Chi- } \\
\text { Square }\end{array}$} & \multirow[t]{2}{*}{$\begin{array}{l}\text { Pr }> \\
\text { ChiSq }\end{array}$} & \multirow{2}{*}{$\begin{array}{c}\begin{array}{c}\text { Odds } \\
\text { Ratio }\end{array} \\
(10 \mathrm{mSv}) \\
1.11\end{array}$} & \multicolumn{2}{|c|}{$\begin{array}{c}\mathbf{9 5 \%} \\
\text { Confidence } \\
\text { Limits } \\
\end{array}$} \\
\hline & & & & & & & 1.01 & 1.22 \\
\hline $\begin{array}{l}\text { Occ BMD Lag } 2 \\
\text { Years }\end{array}$ & 1 & 0.0105 & 0.0047 & 5.031 & 0.0249 & $\begin{array}{l}(1 \mathrm{mSv}) \\
1.01\end{array}$ & 1.00 & 1.02 \\
\hline Gender & 1 & -1.193 & 0.6111 & 3.813 & 0.0509 & 0.30 & 0.092 & 1.00 \\
\hline $\begin{array}{l}\text { Radiation Worker } \\
(1=\text { Yes, } 0=\text { No })\end{array}$ & 1 & -0.7312 & 0.2629 & 7.737 & 0.0054 & 0.48 & 0.29 & 0.81 \\
\hline $\begin{array}{l}\text { Solv Duration Exp } \\
\text { - Lag } 2 \text { Years }\end{array}$ & 1 & 0.0323 & 0.0115 & 7.865 & 0.0050 & 1.03 & 1.01 & 1.06 \\
\hline
\end{tabular}

\subsubsection{Final regression model-primary exposure variable-occupational bone marrow dose combined with medical $x$-ray bone marrow dose}

When bone marrow dose from exposure due to work-related medical x-rays is combined with dose from occupational sources (including estimates from missed doses and offsite sources) the dose response is significant $(\mathrm{OR}=1.11$ at $10 \mathrm{mSv}$ of exposure; $95 \% \mathrm{CI}=1.02,1.22)$ (Table 4.5.4.2) and almost identical to that of the model that includes only occupational bone marrow dose $(\mathrm{OR}=1.11$ at $10 \mathrm{mSv}$ of exposure; $95 \% \mathrm{CI}=1.01,1.22)$ (Table 4.5.4.1).

An analysis combining bone marrow dose from only onsite occupational sources (excluding estimates from missed doses and offsite sources) with work-related medical x-rays was conducted. The exposure response relationship between leukemia mortality and bone marrow dose remains almost unchanged with the exclusion of missed and offsite dose $(\mathrm{OR}=1.16$ at 10 $\mathrm{mSv}$ of exposure; $95 \% \mathrm{CI}=1.09,1.22$ ) (Appendix $\mathrm{K}$, Table 18).

Both models with and without work-related medical x-ray dose included show a significant positive exposure response between disease (leukemia mortality) and the duration of time workers were exposed to solvents, adjusting for gender and radiation worker status (Tables 4.5.4.1\& 2). 


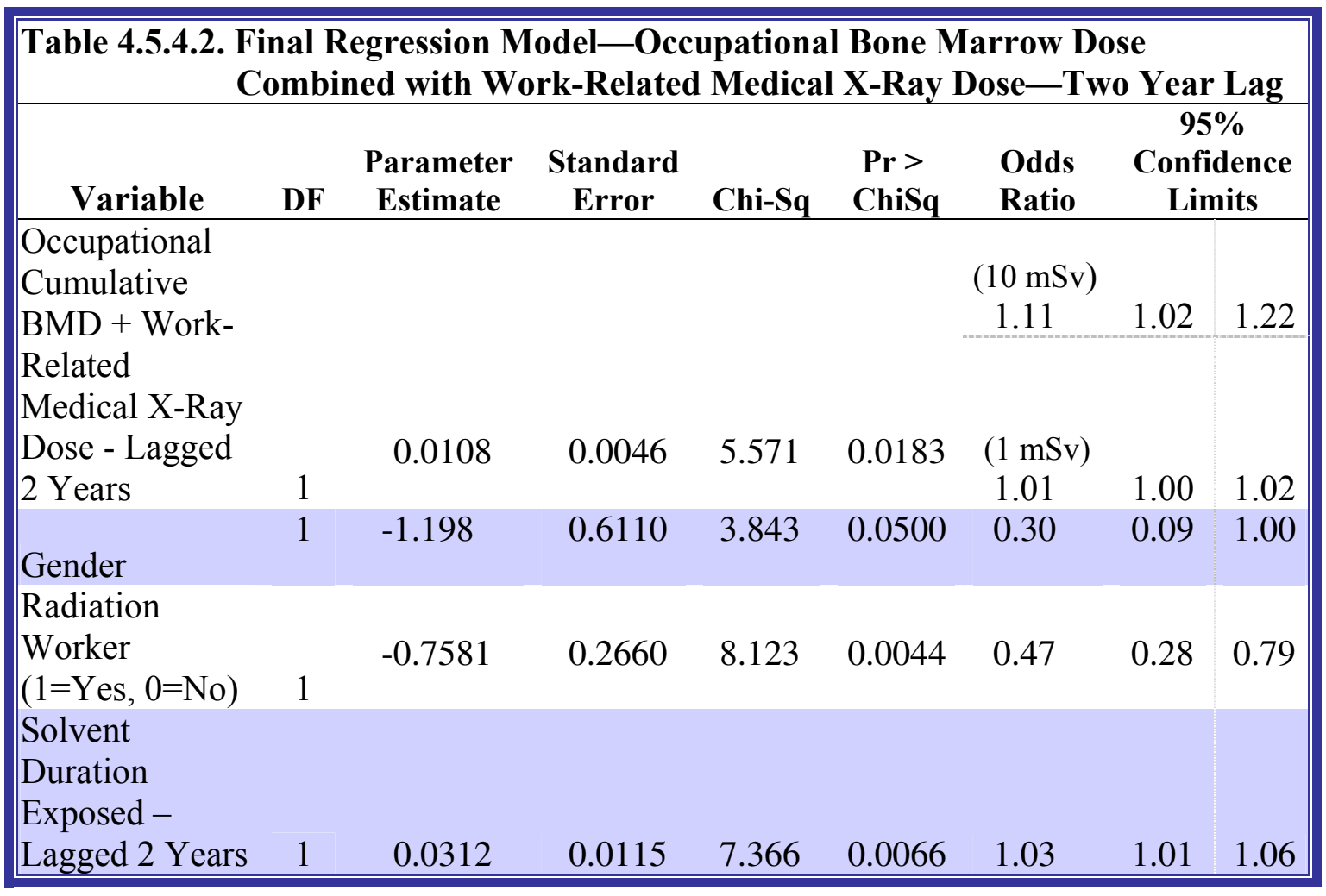

\subsubsection{Sensitivity analysis_badge exposure and time since last exposure variable interaction}

An evaluation of the interaction between each of the time since last exposure (TSLE) categories and the radiation exposure variable were evaluated. There were two analyses, each using different TSLE categories. The variance covariance tables generated from SAS and the formula that was used to derive the parameter estimates, standard error, odds ratio, and $95 \%$ confidence interval for each interaction are located in Appendix K, Tables 20-22.

The first analysis modeled the time since last exposure (TSLE) variable using the following four categories: category 1 ( $>10$ years TSLE), category 2 ( $\geq 5$ years TSLE and $<10$ years TSLE); category 3 ( $\geq 2.5$ years and $<5$ years TSLE); and category 4 ( $\geq 0$ years TSLE and $<2.5$ years TSLE). The coefficients for these interactions were used to calculate the exposure-response trends for each of the four different TSLE categories. The exposure variable included in each interaction was modeled at both 1 and $10 \mathrm{mSv}$ (Tables 4.5.5.A. \& 4.5.5.B.). 
The odds ratios for the interactions between radiation exposure and the $\geq 10$ years TSLE category, the $\geq 5$ years and $<10$ years TSLE category, the $\geq 2.5$ years and $<5$ years TSLE category, show evidence of substantial interaction (Likelihood Ratio Test $(L R T)=8.28 . p=0.04)$. The wave-like odds ratio pattern indicate that the exposure-response relationships are possibly different among the TSLE categories with the exposure response relationship elevated but not significant in the $\geq 0$ and $<2.5$ years TSLE, and significantly elevated in the $\geq 2.5$ year and $<5$ year TSLE category and decreasing in the $\geq 5$ year and $<10$ year TSLE category (Table 4.5.5.A). However, the $\geq 2.5$ year and $<5$ year TSLE group which is the only one exhibiting a significant exposure response relationship has fewer cases and controls $(n=42)$ than the other groups.

\begin{tabular}{|c|c|c|c|c|c|c|}
\hline \multicolumn{7}{|c|}{\begin{tabular}{|l} 
Table 4.5.5.A. Cumulative Badge Exposure Variable-No Lag-and four \\
TSLE Category Variable Interactions $(1 \mathrm{mSv})^{*}$
\end{tabular}} \\
\hline Variable & DF & $\begin{array}{l}\text { Parameter } \\
\text { Estimate }\end{array}$ & $\begin{array}{l}\text { Standard } \\
\text { Error }\end{array}$ & $\begin{array}{c}\text { Odds } \\
\text { Ratio } \\
(1 \mathrm{mSv})\end{array}$ & $\begin{array}{r}\text { Con } \\
\text { L }\end{array}$ & $\begin{array}{l}\text { o } \\
\text { ence } \\
\text { its }\end{array}$ \\
\hline $\begin{array}{l}\text { Exposure at } \\
\geq 10 \text { year TSLE }\end{array}$ & 1 & 0.0071 & 0.0040 & 1.01 & 0.99 & 1.02 \\
\hline $\begin{array}{l}\text { Cum Rad } \\
\text { Exposure at } \geq 5 \\
\text { and }<10 \text { years } \\
\text { TSLE }\end{array}$ & 1 & -0.0408 & 0.0417 & 0.96 & 0.89 & 1.04 \\
\hline $\begin{array}{l}\text { Cum Rad } \\
\text { Exposure at } \geq 2.5 \\
\text { and }<5 \text { years } \\
\text { TSLE }\end{array}$ & 1 & 0.0507 & 0.0214 & 1.05 & 1.01 & 1.10 \\
\hline $\begin{array}{l}\text { Cum Rad } \\
\text { Exposure at } \geq 0 \\
\text { and }<2.5 \text { years } \\
\text { TSLE }\end{array}$ & 1 & 0.0090 & 0.0081 & 1.01 & 0.99 & 1.03 \\
\hline
\end{tabular}


As a test of the sensitivity of the TSLE/radiation exposure interaction to the categorization scheme employed, the second analysis modeled the TSLE variable using the following three categories: category $1(>7$ years TSLE), category $2(>3$ years and

\begin{tabular}{|c|c|c|c|c|c|c|}
\hline \multicolumn{7}{|c|}{\begin{tabular}{|c|} 
Table 4.5.5.B. Cumulative Badge Exposure Variable-No Lag-and \\
Four TSLE Category Variable Interactions (10 mSv)*
\end{tabular}} \\
\hline Variable & DF & $\begin{array}{c}\text { Parameter } \\
\text { Estimate }\end{array}$ & $\begin{array}{c}\text { Standard } \\
\text { Error }\end{array}$ & $\begin{array}{c}\text { Odds } \\
\text { Ratio } \\
(10 \mathrm{mSv}) \\
\end{array}$ & $\begin{array}{r}9 \\
\text { Conf } \\
\text { Lit } \\
\end{array}$ & $\begin{array}{l}\% \\
\text { dence } \\
\text { dits }\end{array}$ \\
\hline $\begin{array}{l}\text { Cum Rad Exposure } \\
\text { at } \geq 10 \text { year TSLE }\end{array}$ & 1 & 0.0709 & 0.0396 & 1.073 & 0.99 & 1.16 \\
\hline $\begin{array}{l}\text { Cum Rad Exposure } \\
\text { at } \geq 5 \text { and }<10 \\
\text { years TSLE }\end{array}$ & 1 & -0.3857 & 0.417 & 0.68 & 0.30 & 1.54 \\
\hline $\begin{array}{l}\text { Cum Rad Exposure } \\
\text { at } \geq 2.5 \text { and }<5 \\
\text { years TSLE }\end{array}$ & 1 & 0.5068 & 0.2147 & 1.66 & 1.09 & 2.52 \\
\hline $\begin{array}{l}\text { Cum Rad Exposure } \\
\text { at } \geq 0 \text { and }<2.5 \\
\text { years TSLE }\end{array}$ & 1 & 0.0953 & 0.0768 & 1.10 & 0.94 & 1.28 \\
\hline
\end{tabular}
$\leq 7$ years TSLE), and category 3 ( $\geq 0$ years TSLE and $\leq 3$ years TSLE). The coefficients for these interactions represent the exposure-response relationships among the three different TSLE categories. The exposure variable included in each interaction was modeled at both 1 and 10 $\mathrm{mSv}$ (Tables 4.5.5.C. \& 4.5.5.D.).

The odds ratios for the interactions between radiation exposure and the $>7$ years TSLE category, the $>3$ years and $\leq 7$ years TSLE category, and the $\geq 0$ years and $\leq 3$ years TSLE category also show evidence for significant interaction (LRT $=7.27, p=0.03$ ). As in the first analysis the odds ratios indicate that the exposure-response relationships are possibly different among the TSLE categories (Table 4.5.5.C). The exposure response relationship is elevated but not significantly in the $\geq 0$ and $\leq 3$ year TSLE category, significantly elevated in the $>3$ years and $\leq 7$ year TSLE category and again decreases in the $>7$ year TSLE category. While lengthening the $\geq 2.5$ and $<5$ year TSLE category in the first analysis to $>3$ and $\leq 7$ years TSLE in the second analysis did increase the number of cases and controls-from 42 to 56-however, the number of cases (12) remained unchanged. 


\begin{tabular}{|c|c|c|c|c|c|c|}
\hline $\begin{array}{l}\text { Table 4.5.5.C. Cumula } \\
\text { TSLE C }\end{array}$ & e Ba & $\begin{array}{l}\text { ge Exposur } \\
\text { Variable Ir }\end{array}$ & $\begin{array}{l}\text { Variable- } \\
\text { eractions* }\end{array}$ & o Lag- & $\mathbf{T h}$ & \\
\hline Variable & DF & $\begin{array}{c}\text { Parameter } \\
\text { Estimate }\end{array}$ & $\begin{array}{c}\text { Standard } \\
\text { Error }\end{array}$ & $\begin{array}{c}\text { Odds } \\
\text { Ratio } \\
(1 \mathrm{mSv})\end{array}$ & $\begin{array}{r}\text { Con } \\
\text { L } \\
\end{array}$ & $\begin{array}{l}\text { \%o } \\
\text { dence } \\
\text { nits }\end{array}$ \\
\hline $\begin{array}{c}\text { Cum Rad Exposure at } \\
>7 \text { year TSLE }\end{array}$ & 1 & 0.0062 & 0.0039 & 1.006 & 0.99 & 1.01 \\
\hline $\begin{array}{l}\text { Cum Rad Exposure at } \\
>3 \text { and } \leq 7 \text { years TSLE }\end{array}$ & 1 & 0.0488 & 0.0174 & 1.050 & 1.02 & 1.09 \\
\hline $\begin{array}{l}\text { Cum Rad Exposure at } \\
\geq 0 \text { and } \leq 3 \text { years TSLE }\end{array}$ & 1 & 0.0070 & 0.0078 & 1.007 & 0.99 & 1.02 \\
\hline
\end{tabular}

\begin{tabular}{|c|c|c|c|c|c|c|}
\hline \multicolumn{7}{|c|}{$\begin{array}{l}\text { Table 4.5.5.D. Cumulative Badge Exposure Variable-No Lag-and Three } \\
\text { TSLE Category Variable Interactions* }\end{array}$} \\
\hline Variable & DF & $\begin{array}{l}\text { Parameter } \\
\text { Estimate }\end{array}$ & $\begin{array}{l}\text { Standard } \\
\text { Error }\end{array}$ & $\begin{array}{c}\text { Odds } \\
\text { Ratio } \\
(\mathbf{1 0} \mathbf{~ m S v})\end{array}$ & $\begin{array}{r}9 \\
\text { Conf } \\
\text { Li }\end{array}$ & ence \\
\hline$>7$ year TSLE & 1 & 0.0699 & 0.0393 & 1.064 & 0.99 & 1.15 \\
\hline $\begin{array}{l}\text { Cum Rad Exposure at } \\
>3 \text { and } \leq 7 \text { years TSLE }\end{array}$ & 1 & 0.4916 & 0.1737 & 1.635 & 1.16 & 2.30 \\
\hline $\begin{array}{l}\text { Cum Rad Exposure at } \\
\geq 0 \text { and } \leq 3 \text { years TSLE }\end{array}$ & 1 & 0.0685 & 0.0782 & 1.071 & 0.92 & 1.25 \\
\hline
\end{tabular}

\subsubsection{Sensitivity analysis-occupational and work-related medical $x$-ray bone marrow dose combined and time since last exposure variable interaction}

Possible interactions between each of the TSLE categories and the bone marrow dose from occupational sources and work-related medical x-rays combined were also evaluated. For this analysis the time since last exposure variable is defined as the time between either the date of the last medical x-ray examination or last monitoring date (which ever is later) and the cutoff date. The variance covariance tables generated from SAS and the formula that was used to derive the parameter estimates, standard error, 
odds ratio, and 95\% confidence interval for each interaction are located in Appendix K, Tables 20,23 and 24.

This analysis modeled the TSLE variable using the following categories: category 1 ( $>10$ years TSLE), category 2 ( $\geq 5$ years TSLE and $<10$ years TSLE), category $3(>=2.5$ years and $<5$ years TSLE), and category 4 ( $\geq 0$ years TSLE and $<2.5$ years TSLE). The coefficients for these interactions represent the exposure-response relationships for each of the four TSLE categories. The exposure variable included in each interaction was modeled at $1 \mathrm{mSv}$ (Table 4.5.6.A.). The odds ratios for the interactions between bone marrow dose and the different TSLE categories are also listed in Table 4.5.6.A.

\begin{tabular}{|c|c|c|c|c|c|c|}
\hline \multicolumn{7}{|c|}{$\begin{array}{l}\text { Table 4.5.6.A. Cumulative Bone Marrow Dose from Occupational Sources and } \\
\text { Work-Related Medical X-Rays -No Lag-and Four TSLE } \\
\text { Category Variable Interactions* }\end{array}$} \\
\hline Variable & \multirow{2}{*}{ DF } & \multirow{2}{*}{$\begin{array}{c}\begin{array}{c}\text { Parameter } \\
\text { Estimate }\end{array} \\
0.0091\end{array}$} & \multirow{2}{*}{$\begin{array}{c}\text { Standard } \\
\text { Error } \\
0.0059\end{array}$} & \multirow{2}{*}{$\begin{array}{c}\begin{array}{c}\text { Odds } \\
\text { Ratio } \\
(\mathbf{1 ~} \mathbf{~ m S v})\end{array} \\
1.01\end{array}$} & \multicolumn{2}{|c|}{$\begin{array}{l}95 \% \\
\text { Confidence } \\
\text { Limits }\end{array}$} \\
\hline$\geq 10$ year TSLE & & & & & 0.99 & 1.02 \\
\hline $\begin{array}{l}\text { Occ }+ \text { X-Ray Dose at } \\
\geq 5 \text { and }<10 \text { years TSLE }\end{array}$ & 1 & 0.0188 & 0.0134 & 1.02 & 0.99 & 1.05 \\
\hline $\begin{array}{l}\text { Occ }+ \text { X-Ray Dose at } \\
\geq 2.5 \text { and }<5 \text { years TSLE }\end{array}$ & 1 & 0.0100 & 0.0115 & 1.01 & 0.99 & 1.03 \\
\hline $\begin{array}{l}\text { Occ }+ \text { X-Ray Dose at } \\
\geq 0 \text { and }<2.5 \text { years TSLE }\end{array}$ & 1 & 0.0109 & 0.0094 & 1.01 & 0.99 & 1.03 \\
\hline
\end{tabular}

The odds ratios are very similar and range from 1.01 to 1.02 respectively (Table 4.5.6.A.). Unlike the analysis of interactions between TSLE categories and occupational badge exposure model, there is no evidence for substantial interaction between the TSLE categories and occupational plus work-related medical x-ray exposures (LRT $=0.49, \mathrm{p}=0.92$ and Tables 4.5.6.A.).

The second analysis modeled the time since last exposure (TSLE) variable using the following three categories: category 1 ( $>7$ years), category 2 ( $>3$ years and $\leq 7$ years TSLE); and category 3 ( $\geq 0$ years TSLE and $\leq 3$ years TSLE). The coefficients for these interactions represent the exposure-response relationships among the three different TSLE categories. The exposure variable included in each interaction was modeled at $1 \mathrm{mSv}$ (Tables 4.5.6.B). 
The odds ratios for the interactions between radiation exposure and the different TSLE categories are listed in Table 4.5.6.B. The interaction is not significant (LRT $=0.0843, p=0.96$ ). As indicated, the odds ratios are very similar $(\mathrm{ORs}=1.01)$. The possibility of an exposure response relationship is borderline in the $>7$ years TSLE category, however the result is not significant $(\mathrm{OR}=1.01(95 \% \mathrm{CI}=1.00,1.02)$.

\begin{tabular}{|c|c|c|c|c|c|c|}
\hline \multicolumn{7}{|c|}{\begin{tabular}{|l} 
Table 4.5.6.B Cumulative Bone Marrow Dose from Occupational Sources and \\
Work-Related Medical X-Rays-No lag-and Three TSLE \\
Category Variable Interactions*
\end{tabular}} \\
\hline \multirow{2}{*}{\begin{tabular}{|l|} 
Variable \\
Occ + X-Ray Dose at \\
$>7$ year TSLE
\end{tabular}} & \multirow{2}{*}{ DF } & \multirow{2}{*}{$\begin{array}{c}\text { Parameter } \\
\text { Estimate } \\
0.0111\end{array}$} & \multirow{2}{*}{$\begin{array}{l}\text { Standard } \\
\text { Error } \\
0.0055\end{array}$} & \multirow{2}{*}{$\begin{array}{c}\begin{array}{c}\text { Odds } \\
\text { Ratio }\end{array} \\
(\mathbf{1} \mathbf{~ m S v}) \\
1.01\end{array}$} & \multicolumn{2}{|c|}{$\begin{array}{l}95 \% \\
\text { Confidence } \\
\text { Limits } \\
\end{array}$} \\
\hline & & & & & 1.00 & 1.02 \\
\hline $\begin{array}{l}\text { Occ }+ \text { X-Ray Dose at } \\
>3 \text { and } \leq 7 \text { years TSLE }\end{array}$ & 1 & 0.0139 & 0.0116 & 1.01 & 0.99 & 1.04 \\
\hline $\begin{array}{l}\text { Occ }+X \text {-Ray Dose at } \\
\geq 0 \text { and } \leq 3 \text { years TSLE }\end{array}$ & 1 & 0.0100 & 0.0092 & 1.01 & 0.99 & 1.03 \\
\hline
\end{tabular}

\section{Discussion}

This case-control study of 115 leukemia deaths at the Portsmouth Naval Shipyard evaluated the relation between external ionizing radiation dose and leukemia mortality after potential confounders and effect modifiers such as solvent exposure, radiation worker status, and age were considered. Lag assumptions of $0,2,5$, and 7 years were tested first with each radiation dose term individually and then in each final regression models. The two-year lag was determined by both methods to be the best fit and was used in all regression models in the study analysis. Radiation doses lagged 2 years for both the radiation-monitored cases and controls appears in Appendix K, Tables 31-32.

A positive association was found with a log-linear model between leukemia mortality and increasing external ionizing whole-body radiation exposure, after adjusting for radiation worker status and solvent exposure duration $(\mathrm{OR}=1.01$ at $1 \mathrm{mSv} ; 95 \% \mathrm{CI}=1.00,1.02$ and $\mathrm{OR}=1.08$ at 10 $\mathrm{mSv} ; 95 \% \mathrm{CI}=1.01,1.16$ ). When the radiation exposure variable was modified (by removing pre-PNS occupational radiation exposure contained in an individual's record and estimated missed radiation exposure) to include only exposure that occurred onsite, the odds ratio and confidence limits remained unchanged (Appendix K, Table 7). Both offsite and missed radiation 
exposures combined accounted for only $2 \%$ of the total badge exposure for the cases and controls. The interaction between age and radiation badge exposure was assessed and found to be not significant $(p=0.07)$. Also, a birth cohort analysis was conducted and revealed no differences in leukemia mortality among birth cohort groups. A linear excess relative risk model was also used and yielded higher risk estimates (RR 1.02 at $1 \mathrm{mSv} ; 95 \%$ likelihood-based $\mathrm{CI}=1.00,1.09$, and 1.23 at $10 \mathrm{mSv}$; 95\% likelihood-based $\mathrm{CI}=1.03,1.88$ ) than the log linear model.

Analyses were conducted using both the log linear and linear ERR models, excluding all cases and controls with more than $100 \mathrm{mSv}$ of cumulative external ionizing radiation dose to illustrate the effect on the risk estimates and confidence intervals without highly exposed subjects. The log linear model exhibited no change in the point estimate; however, the confidence interval does include one $(\mathrm{OR}=1.01$ at $1 \mathrm{mSv} ; 95 \% \mathrm{CI}=0.99,1.03)$. The linear ERR model also exhibited no change in the point estimate, and the confidence interval also includes one $(\mathrm{RR}=1.02$ at $1 \mathrm{mSv}$; $95 \% \mathrm{CI}=0.99,1.11$ )

Because some analyses of leukemia risk in nuclear workers have shown an increase in the risk estimate when chronic lymphocytic leukemia (CLL) cases are excluded, an analysis in this study was also conducted excluding CLL cases. The significant exposure response remained unchanged when all 14 of the cases identified with CLL were excluded from the analysis. Of the 14 cases of CLL, three had a history of radiation exposure. Added together, their collective exposure was only 50.33 person $\mathrm{mSv}$.

The finding of a significant exposure-response relationship between leukemia mortality and radiation exposure is consistent with the most recent NIOSH studies of PNS workers. Analysis of the source cohort (Silver et al. 2004), exhibited no overall increase in leukemia mortality $(\mathrm{SMR}=1.01,95 \% \mathrm{CI}=0.84,1.22)$, but the Standardized Risk Ratio (SRR) was significantly increased in some groups of workers. Silver et al. (2004) reported significant elevations in leukemia mortality with increased exposure among radiation-monitored workers who received between $10 \mathrm{mSv}$ and $49.9 \mathrm{mSv}$ and those with more than $50 \mathrm{mSv}$ of total cumulative radiation exposure compared to workers who received less than $1 \mathrm{mSv}$ of cumulative radiation exposure. The trend test over the four exposed groups was statistically significant. However, their study did not incorporate medical x-ray dose, nor did it consider confounding or effect modification.

The positive dose-response pattern for leukemia reported by Silver et al. was also observed in a recent analysis of 13,468 PNS radiation-monitored workers by Yiin et al. (2004). A nonstatistically significant elevation in excess relative risk (ERR) of $10.9 \%(95 \% \mathrm{CI}=-0.09 \%$, $38.0 \%$ ) per $10 \mathrm{mSv}$ of external radiation exposure, was observed after potential confounders were considered in the analysis (Yiin et al., 2004).

In this study, the linear ERR model estimated an excess relative risk of $23 \%(95 \% \mathrm{CI}=3 \%$, $88 \%$ ) per $10 \mathrm{mSv}$ of external radiation exposure from occupational sources after potential 
confounders were included. The ERR has been estimated in previous studies between $-4.1 \%$ and $19.0 \%$ at $10 \mathrm{mSv}$ for workers exposed to penetrating ionizing radiation (Fraser et al., 1993) and approximately 4\% for individuals in the Japanese Life Span Study who were simultaneously exposed at various ages and developed diseases at different times after exposure (BEIR V,1990; Schubauer-Berigan and Wenzl, 2001). In contrast, workers receive fractionated exposures over periods of time, often several decades in length. A linear quadratic model is often used in analyses of individuals in the Japanese Life Span Study because it fits data better than a simple linear model (BEIR V, 1990; Ron, 1998). The addition of a quadratic term, however, did not improve the model fit in the linear ERR analyses used in this case-control study.

A statistically significant positive relationship was found between leukemia mortality and the duration of time workers were employed in six a priori determined job categories (machining, transportation, welding, electrical, painting, and woodworking) determined to have had potential exposure to benzene or carbon tetrachloride. The association between radiation exposure and leukemia was not confounded by employment in these job categories where solvent exposure may have occurred. When work in the categories is removed from the regression model there is a less than $10 \%$ change in the radiation exposure parameter estimate. Because the variable is not significantly correlated with radiation exposure $(p=0.14)$ and not a confounder, it appears that it may present an excess leukemia mortality risk that is independent of the excess risk from radiation exposure. Yiin et al. (2004) reported an elevated but not significant leukemia risk among 13,468 radiation-monitored-workers ever exposed to solvents $(\mathrm{RR}=1.14 ; 95 \% \mathrm{CI}=0.56$, 2.34). It is important to note that the solvent exposure metric in the cohort-level analysis of the radiation-monitored workers was dichotomous (ever/never worked in a potentially exposed job), unlike in our case-control study, where it was feasible to utilize detailed work history information to determine the amount of time each worker was actually employed in jobs with potential solvent exposure. When the dichotomous solvent exposure metric was used in this casecontrol study, it also was not significant.

Time Since Last (radiation) Exposure (TSLE) was first evaluated as a continuous variable and found not to be statistically significant $(\mathrm{OR}=0.99$ at one year; $95 \% \mathrm{CI}=0.98,1.02)$ (Appendix $\mathrm{K}$, Table 28). There was also no statistically significant interaction between TSLE (as a continuous variable) and radiation exposure, $(\mathrm{OR}=1.00 ; 95 \% \mathrm{CI}=0.99,1.00)$ (Appendix $\mathrm{K}$, Table 27). The TSLE variable was then modeled as a categorical variable using the following categories: category 1 ( $\geq 5$ years TSLE and $<10$ years TSLE), category $2(\geq 2.5$ years and $<5$ years TSLE), and category 3 ( 0 years TSLE and $<2.5$ years TSLE). Each of the three categories was compared to the fourth category of $\geq 10$ years of time since last exposure. As with the continuous variable analysis, there was no significant elevation of leukemia mortality in any of the TSLE categories, but there was a non-significant elevation of the odds ratio in the $\geq 2.5$ years and $<5$ years TSLE category $(\mathrm{OR}=1.94 ; 95 \% \mathrm{CI}=0.87,4.31)$ (Table 4.5.2.B).

Finally, in a separate analysis we examined the interaction between radiation exposure and the different TSLE categories. A significant exposure-response relationship was found in the $2.5-5$ 
years since last exposure category compared to the $>10$ years since last exposure category indicating that there is evidence of heterogeneity in the radiation exposure-response relationships among different time since last exposed categories. The choice of categories for TSLE categorical classification did not greatly alter these findings as there was also a significant exposure-response relationship found in the 3-7 years since last exposure category compared to the $>7$ years since last exposure category.

This finding helps describe the temporal dynamics of leukemia risk following radiation exposure and is supported by other study findings. Studies of individuals in the Japanese Life Span Study and medically exposed cohorts have reported a wave-like pattern of leukemia risk after exposure, with peaks observed from approximately 5 to 15 years after exposure which then decrease (Little et al., 1999; BEIR V, 1990; Schubauer-Berigan and Wenzl, 2001). Studies of 21,500 Russian nuclear workers at the Mayak complex who received very high radiation exposures also report the pattern (Shilnikova et al., 2003).

An evaluation of leukemia mortality and radiation exposure was also done using a time windows of exposure approach described by Rothman (Rothman \& Greenland, 1998). The total radiation exposure accrued by each case and control in the period $0<2.5$ years prior to case failure (or, for controls, prior to the attained age of the case), $2.5<5$ years prior, $5<10$ years prior and $\geq 10$ years prior was determined. Then the association between leukemia mortality and total exposure accrued in each window of exposure was examined.

As with the approach using total lifetime cumulative radiation exposures in the interaction with TSLE categories, the leukemia risk using the windows of exposure approach appears to be heterogeneous. While the effect estimate is elevated in the $2.5<5$ year exposure window $(\mathrm{OR}=1.02$ at $1 \mathrm{mSv} ; 95 \% \mathrm{CI}=0.94,1.11)$, the total radiation dose between $5<10$ years appears to have the greatest effect on leukemia mortality $(\mathrm{OR}=1.04$ at $1 \mathrm{mSv} ; 95 \% \mathrm{CI}=1.00,1.07)$ and the effect estimate declines in the window $\geq 10$ years $(\mathrm{OR}=1.01$ at $1 \mathrm{mSv} ; 95 \% \mathrm{CI}=0.99,1.01)$ (Appendix K Table 29). The window of exposure method better accounts for the fact that radiation exposures at PNS were not single, acute exposures (in which time since exposure is easily defined) but are protracted exposures with different times since exposure for each recorded exposure.

It was observed in this study that the incorporation of dose from work-related medical x-ray exposures does not change the leukemia risk estimate. When the regression model includes bone marrow dose from both occupational sources and work-related medical x-rays, there is a significant dose response. However, when the bone marrow dose from work-related medical xrays is removed, the dose-response relationship remains unchanged. The leukemia risk estimate in the regression model with only occupational bone marrow dose (converted from the badge exposure $)$ is slightly higher $(\mathrm{OR}=1.11$ at $10 \mathrm{mSv} ; 95 \% \mathrm{CI}=1.01,1.22)$ compared to the model with only occupational badge exposure $(\mathrm{OR}=1.08$ at $10 \mathrm{mSv} ; 95 \% \mathrm{CI}=1.01,1.16)$ because there is less $(1,259 \mathrm{mSv})$ cumulative bone marrow dose than whole body exposure. 
There are several possible reasons that the inclusion of work-related medical x-ray exposures made no difference in the leukemia risk estimate despite the fact that medical x-ray exposures were not randomly distributed among the cases and controls (radiation- monitored cases and controls received 2.3 times the work-related medical x-rays of non-monitored cases and controls [Table 4.3.2.A.]). First, these results may provide evidence that the effects produced from workrelated medical X-rays are of similar magnitude per unit dose as other occupational radiation exposure. Second, the collective dose contributed from work-related medical x-rays in this study was small compared to badge dose. There was no documentation that PNS ever employed stereoscopic x-ray techniques that were common at Department of Energy (DOE) facilities during the 1940s and 1950s. Therefore, estimates of medical x-ray exposures from photofluorography for PNS workers are lower (1.50 mSv per chest examination) than those estimated in a previous NIOSH study of workers employed at DOE facilities where stereoscopic techniques were used (3.85 mSv per chest examination) (Cardarelli et al., 2002). Also, there was only a narrow window of time (from 1963 through 1968) when radiation-monitored workers received a chest $\mathrm{x}$-ray as part of a yearly radiation qualifying physical examination, and available shipyard records indicate that the use of the photofluorographic x-ray technique for work-related medical x-ray examinations was discontinued at the shipyard after May of 1966 (Daniels et al., 2004b). After May 1966, all work-related medical x-rays used direct radiographic, not photofluorographic, techniques, which dropped average estimated exposures to the active bone marrow from $1.5 \mathrm{mSv}$ per examination to $0.04 \mathrm{mSv}$ per examination.

Overall leukemia mortality was greater among the 374 non-radiation-monitored cases and controls than for the 201 radiation-monitored workers in the study, which is consistent with the findings of the two mortality studies of PNS workers (Rinsky et al., 1988; Silver et al., 2004). As a result there is a substantial change between the radiation exposure coefficient in the unadjusted model that only includes the cumulative radiation exposure variable with a 2 year lag $(0.0042)$ (Table 4.5.1) and the radiation exposure coefficient (0.0082) in the adjusted main effects model (including radiation worker indicator, gender, solvent exposure duration, and three time since last [radiation] exposure categories variables) (Table 4.5.2.B). The radiation worker indicator variable is mainly responsible for the dramatic change in the cumulative dose coefficient because when the radiation worker indicator variable is removed from the main effect model, the parameter estimate for the radiation exposure drops from 0.0082 to 0.0035 . Because overall leukemia mortality is greater among non-radiation-monitored workers and the inclusion of the variable makes such a dramatic difference in the radiation exposure coefficient, an analysis including only the 201 radiation-monitored workers in the study was conducted with both log linear and linear ERR models. Gender was dropped from these models because there are no female radiation-monitored workers; the radiation-monitored worker indication variable was also dropped because all workers included in the analysis were radiation-monitored workers.

The final log linear model includes a significant positive exposure-response relationship between disease (leukemia mortality) and exposure (external ionizing radiation), adjusting for solvent 
exposure duration; $(\mathrm{OR}=1.02$ at $1 \mathrm{mSv}$ of exposure; $95 \% \mathrm{CI}=1.01,1.03$ and $\mathrm{OR}=1.20$ at $10 \mathrm{mSv}$ of exposure; $95 \% \mathrm{CI}=1.05,1.37)$. Solvent exposure duration is elevated but no longer statistically significant $(\mathrm{OR}=1.05$ at one year of exposure; $95 \% \mathrm{CI}=0.99,1.10)$. The final linear excess relative risk model yielded higher risk estimates $(\mathrm{RR}=1.04$ at $1 \mathrm{mSv} ; 95 \%$ likelihoodbased $\mathrm{CI}=1.01,1.19$; and $\mathrm{RR}=1.40$ at $10 \mathrm{mSv}$; $95 \%$ likelihood-based $\mathrm{CI}=1.05,2.89$ ) than the log linear model.

\subsection{Study Limitations}

In evaluating these findings, it is important to consider that the relatively small number of study subjects who were radiation-monitored limited the number of informative cases. However, while the bone marrow doses were increased with the addition of medical x-rays this changed risk estimates very little, suggesting possibly robust findings.

It is also possible that the number of work-related medical x-ray examinations was underestimated for the cases and controls. This is because information about the type and frequency of x-rays was gathered from existing medical records and, although records were available for $90 \%$ of the cases and controls, the amount of pertinent information in the medical records varied considerably. This variation was due in part to differences in recording practices by attending physicians and changes in record management policies throughout the years.

To evaluate the impact of work-related medical x-ray exposures on leukemia risk, bone marrow doses from both medical x-rays and occupational exposures were estimated. Many generalizations were required in the development of the dose conversion factors that were applied to cases and controls who received medical x-ray examinations. Therefore, large uncertainties are possible when estimating a particular worker's bone marrow dose, given the variability of several critical parameters over the period of the study. These parameters include, but are not limited to, x-ray procedures and equipment; exposure geometry; incident photon energies; and worker age, sex, and anatomy (Daniels et al., 2004b).

Because the PNS civilian worker cohort and the cases and controls included in this study were overwhelmingly white and male, meaningful analysis of the leukemia risk for either females or non-whites was not possible. However, these results can be generalized to other occupational cohorts that are predominately white and male who received small protracted exposures to low LET (linear energy transfer) radiation.

When comparing the leukemia risk after last exposure in this study with those of individuals included in the Japanese Life Span Study and Russian nuclear workers, it is important to note that the time since last exposed variable in our study is an approximation of the time since exposure variable used in the Life Span and Russian studies. This is because we used the last radiation monitoring date for each of the radiation-monitored cases and controls to define the TSLE variable, while in the other studies, the time since exposure references a single fixed date in time. 
Misclassification of workers exposed to the solvents, benzene and carbon tetrachloride is likely. Subjective determinations, based on examination of sparse industrial hygiene data supplemented by field surveys and discussions with Portsmouth Naval Shipyard personnel, had to be used to designate the various shops and jobs with possible benzene and carbon tetrachloride exposure. Efforts were made to reduce misclassification in coding of all work history information by ensuring that all coders were blind to designation of cases and controls.

Also, actual solvent exposure estimates were not known for the cases and controls, necessitating the use of duration of employment in potential solvent-exposed jobs as a surrogate for cumulative solvent exposure estimates. Despite this limitation, there is no evidence of confounding by these solvents of the radiation dose-response relationship observed in this study.

Smoking was not included as a study variable in the analysis because of the lack of readily available individual smoking information in the PNS medical records. There is increasing evidence suggesting that certain forms of adult leukemia; myeloid and acute nonlymphocytic, may be associated with cigarette smoking (Austin and Cole, 1986; Williams and Horm, 1977). However, for diseases such as leukemia that are less related to smoking it is not likely that the increased risk estimate is a result of confounding by smoking (Axelson and Steenland, 1988).

\subsection{Conclusions}

This study of a workforce exposed to both radiation and known or potential chemical leukemogens provides an estimate of leukemia risk in an occupational context rather than relying on extrapolation from high dose-rate exposures. The findings support other nuclear worker studies that collectively observe slight elevations in leukemia mortality - other than chronic lymphocytic leukemia (CLL) - that appear to be related to increases in low LET radiation exposure (Cragle et al., 1999; Douglas et al., 1994; Schubauer-Berigan and Wenzl, 2001). In the current study, we explored the role of solvent exposures on leukemia risk in greater detail than previous studies involving PNS workers, and observed a significant exposure response between leukemia mortality and the duration of time workers were employed in job categories where solvent exposures were probable.

This case-control study unlike previous PNS studies provides an in-depth analysis of the impact of work-related medical x-ray exposures on leukemia risk using detailed information from worker medical records. The study observed that incorporating dose from work-related medical $\mathrm{x}$-ray exposures had little impact on the radiation-related risk estimate for leukemia in the PNS workers.

The study results reveal information about temporal aspects of the significant radiation exposure response relationship that was observed. The study observed a significant relationship between radiation and leukemia mortality in the $\geq 2.5$ year and $<5$ years time since last exposure category compared to longer periods. These findings support those of other occupational studies; significant elevations in leukemia risk appear sooner after the last exposure in worker cohorts. 
Observation of health risks among individuals in the Japanese Life Span Study did not begin until more than five years after these acute exposures.

\subsection{Future Research Directions}

Previous studies of nuclear workers and PNS workers have been limited by lower power to detect radiation-related risk due to relatively small numbers of leukemia cases, low radiation exposures, and limited cohort sizes (Schubauer-Berigan and Wenzl, 2001; Rinsky et al., 1988; Stern et al., 1986). To address this issue, studies that combine cohorts of workers for analysis have been and are being conducted; however, differences in radiation exposures and varied dosimetry practices make combined analysis difficult. Because of the similarity of radiological exposures and standardized procedures for monitoring and recording radiological and chemical exposures at all naval shipyards, a combined case-control study of naval shipyards may present a more efficient opportunity for future leukemia studies with more statistical power.

Further research is needed to determine how the rates at which workers receive radiation exposure affect leukemia risk. There have been multiple studies that suggest leukemia incidence is higher among animals subjected to a high dose-rate exposure of low-LET radiation than those subjected to a low dose-rate exposure to low-LET radiation (BEIR V, 1990). Therefore, research leading to the development of methods that can be used in analytic studies to account for the effects of dose-rate on leukemia risk would be desirable.

Currently, there are few occupational radiation studies that attempt to control for possible chemical leukemogens such as benzene or other solvents. Despite the fact that chemical exposure assessments are complex for large cohorts of workers and exposure records are sparse, continued research toward the development of methods to estimate the joint effects of workplace exposures such as solvent and radiation exposure are needed. 


\section{References}

Agency for Toxic Substances Disease Registry (ATSDR). Toxicological Profile for Benzene. Atlanta, GA.: United States Department of Health and Human Services; 1997.

Agency for Toxic Substances Disease Registry (ATSDR). Toxicological Profile for Carbon Tetrachloride. Atlanta, GA.: United States Department of Health and Human Services; 1994.

Agency for Toxic Substances Disease Registry (ATSDR). Toxicological Profile for Ethylene Glycol and Propylene Glycol. Atlanta, GA.: United States Department of Health and Human Services; 1997.

American Cancer Society. Cancer Facts \& Figures 2002. American Cancer Society. 2002;4.

Andersson M, Storm HH, Mouridsen HT. Incidence of new primary cancers after adjuvant tamoxifen therapy and radiotherapy for early breast cancer. J Natl Cancer Inst. 1991;83:1013-7.

Austin H, Cole P. Cigarette smoking and leukemia. J Chronic Dis. 1986;39:417-21.

Axelson O, Steenland K. Indirect methods of assessing the effects of tobacco use in occupational studies. Am J Ind Med. 1988;13:105-18.

Beaumont JJ, Steenland K, Minton A, Meyer S. A computer program for incidence density sampling of controls in case- control studies nested within occupational cohort studies. Am J Epidemiol. 1989;129:212-9.

BEIR V Report. Biological Effects of Ionizing Radiation (BEIR V). Health Effects of Exposure to Low Levels of Ionizing Radiation. Washington D.C.: National Academy Press; 1990.

Bender AP, Parker DL, Johnson RA, et al. Minnesota Highway Maintenance Worker Study: cancer mortality. Am J Ind Med. 1989;15:545-56.

Bethwaite P, Cook A, Kennedy J, Pearce N. Acute leukemia in electrical workers: a New Zealand case-control study. Cancer Causes Control. 2001;12:683-9.

Bethwaite PB, Pearce N, Fraser J. Cancer risks in painters: study based on the New Zealand Cancer Registry. Br J Ind Med. 1990;47:742-6. 
Blattner WA, Gibbs WN, Saxinger C, et al. Human T-cell leukaemia/lymphoma virus-associated lymphoreticular neoplasia in Jamaica. Lancet. 1983;2:61-4.

Boffetta P, Stellman SD, Garfinkel L. Diesel exhaust exposure and mortality among males in the American Cancer Society prospective study. Am J Ind Med. 1988;14:403-15.

Boice JD, Inskip P. Radiation-Induced Leukemia. Henderson ES, Lister TA, Greaves MF. Leukemia. 6th ed ed. Philadelphia: W.B. Saunders; 1996:195-209.

Boice JD Jr, Blettner M, Kleinerman RA, et al. Radiation dose and leukemia risk in patients treated for cancer of the cervix. J Natl Cancer Inst. 1987;79:1295-311.

Boice JD Jr, Day NE, Andersen A, et al. Second cancers following radiation treatment for cervical cancer. An international collaboration among cancer registries. J Natl Cancer Inst. 1985;74:955-75.

Bond GG, McLaren EA, Baldwin CL, Cook RR. An update of mortality among chemical workers exposed to benzene. Br J Ind Med. 1986;43:685-91.

Borders RJ; The Dictionary of Health Physics and Nuclear Sciences Terms. Hebron, CT: RSA Publications; 1991.

Borson R, Loeb V Jr. Acute and chronic leukemias in adults. CA Cancer J Clin. 1994;44:323-5.

Brann J. International Agency for Research on Cancer: (PNS) Dosimetry Questionaire. Lyon, France: IARC; 1998.

Brown LM, Gibson R, Blair A, et al. Smoking and risk of leukemia. Am J Epidemiol. 1992;135:763-8.

Brown WM, Doll R. Mortality from cancer and other causes after radiotherapy for ankylosing spondylitis. Br Med J. 1965;5474:1327-32.

Brownson RC, Novotny TE, Perry MC. Cigarette smoking and adult leukemia. A meta-analysis. Arch Intern Med. 1993;153:469-75.

Busk TH. Some Observations on Heredity in Breast Cancer and Leukemia. Ann Eugen (London). 1948;213-229.

Caldwell GG, Kelley D, Zack M, Falk H, Heath CW Jr. Mortality and cancer frequency among military nuclear test (Smoky) participants, 1957 through 1979. JAMA. 1983;250:620-4. 
Cardarelli J, Spitz H, Rice C, Buncher R, Elson H, Succop P. Significance of radiation exposure from work-related chest X-rays for epidemiological studies of radiation workers. Am J Ind Med. 2002;42:490-501.

Cardis E, Gilbert ES, Carpenter L, et al. Effects of low doses and low dose rates of external ionizing radiation: cancer mortality among nuclear industry workers in three countries. Radiat Res. 1995;142:117-32.

Cartwright RA, Bernard SM, Bird CC, et al. Chronic lymphocytic leukaemia: case- control epidemiological study in Yorkshire. Br J Cancer. 1987;56:79-82.

Centers for Disease Control and Prevention (U.S.). Leukemia among persons present at an atmospheric nuclear test (SMOKY). Morbidity and Mortality Weekly Report. 1979; 28:361-362.

Centers for Disease Control and Prevention (U.S.). Recommendations for Counseling Persons Infected with Human T-Lymphotrophic Virus, Types I and II. Morbidity and Mortality Weekly Report. 1993;42:1-13.

Checkoway H, Wilcosky T, Wolf P, Tyroler H. An evaluation of the associations of leukemia and rubber industry solvent exposures. Am J Ind Med. 1984;5:239-49.

Checkoway H, Pearce NE, Crawford-Brown DJ; Research Methods in Occupational Epidemiology. New York: Oxford University Press; 1989. Monographs in Epidemiology and Biostatistics.

Chen R, Seaton A. A meta-analysis of painting exposure and cancer mortality. Cancer Detect Prev. 1998;22:533-9.

Cole P, Delzell E, Acquavella J. Exposure to butadiene and lymphatic and hematopoietic cancer. Epidemiology. 1993;4:96-103.

Coleman M, Beral V. A review of epidemiological studies of the health effects of living near or working with electricity generation and transmission equipment. Int J Epidemiol. 1988;17:1-13.

Cragle DL, McLain RW, Qualters JR, et al. Mortality among workers at a nuclear fuels production facility. Am J Ind Med. 1988;14:379-401.

Cragle DL, Watkins JP, Robertson-Demers K. Mortality among workers at the Savannah River Nuclear Fuels Production Facility. ASA 1998 Proceedings of the Section on Statistics in Epidemiology: Alexandria, VA. American Statistical Association; 1999. 
Curtis RE, Boice JD Jr, Stovall M, et al. Risk of leukemia after chemotherapy and radiation treatment for breast cancer. $N$ Engl J Med. 1992;326:1745-51.

Curtis RE, Boice JD Jr, Stovall M, et al. Relationship of leukemia risk to radiation dose following cancer of the uterine corpus. J Natl Cancer Inst. 1994;86:1315-24.

Curtis RE, Boice JD Jr, Stovall M, Flannery JT, Moloney WC. Leukemia risk following radiotherapy for breast cancer. J Clin Oncol. 1989;7:21-9.

Curtis RE, Hankey BF, Myers MH, Young JL Jr. Risk of leukemia associated with the first course of cancer treatment: an analysis of the Surveillance, Epidemiology, and End Results Program experience. J Natl Cancer Inst. 1984;72:531-44.

Cuttner J. Increased incidence of hematologic malignancies in first-degree relatives of patients with chronic lymphocytic leukemia. Cancer Invest. 1992;10:103-9.

Cytel Statistical Software. Egret Siz: Sample Size and Power for Nonlinear Regression Reference Manual. Version 1 ed. Cambridge, MA: Cytel Software Corporation; 1997.

Daniels RD, Taulbee TD, Chen P-H. Radiological Exposure Assessment for the epidemiologic study of civilian employees at the Portsmouth Naval Shipyard, Kittery, Maine (2004). Final Technical Report Cincinnati, Ohio: National Institute for Occupational Safety and Health; Division of Surveillance, Hazard Evaluations, and Field Studies. 2004a.

Daniels RD, Spitz H. Evaluation of Occupational Radiation Exposure from Work-Related Medical X-rays at the Portsmouth Naval Shipyard (2004) Final Technical Report Cincinnati, Ohio: National Institute for Occupational Safety and Health; Division of Surveillance, Hazard Evaluations, and Field Studies. 2004b.

Darby SC, Doll R, Gill SK, Smith PG. Long term mortality after a single treatment course with X-rays in patients treated for ankylosing spondylitis. Br J Cancer. 1987;55:179-90.

Darby SC, Kendall GM, Fell TP, et al. Further follow up of mortality and incidence of cancer in men from the United Kingdom who participated in the United Kingdom's atmospheric nuclear weapon tests and experimental programmes. BMJ. 1993;307:1530-5.

Darby SC, Nakashima E, Kato H. A parallel analysis of cancer mortality among atomic bomb survivors and patients with ankylosing spondylitis given X-ray therapy. J Natl Cancer Inst. 1985;75:1-21.

Doll R, Peto R. Mortality in relation to smoking: 20 years' observations on male British doctors. Br Med J. 1976;2:1525-36. 
Doody MM, Mandel JS, Lubin JH, Boice JD Jr. Mortality among United States radiologic technologists, 1926-90. Cancer Causes Control. 1998;9:67-75.

Douglas AJ, Omar RZ, Smith PG. Cancer mortality and morbidity among workers at the Sellafield plant of British Nuclear Fuels. Br J Cancer. 1994;70:1232-43.

Dupree-Ellis E, Watkins J, Ingle JN, Phillips J. External radiation exposure and mortality in a cohort of uranium processing workers. Am J Epidemiol. 2000;152:91-5.

Epstein, Charles J, McCoy EE, National Down Syndrome Society (U.S.), Symposium; Oncology and Immunology of Down Syndrome Proceedings of the National Down Syndrome Society Symposium Held in New York, December 4 and 5, 1986. New York: Liss; 1987. Progress in Clinical and Biological Research.

Evans JS, Wennberg JE, McNeil BJ. The influence of diagnostic radiography on the incidence of breast cancer and leukemia. $N$ Engl J Med. 1986;315:810-5.

Federation of American Scientists: Military Analysis Network. Nuclear Propulsion. Federation of American Scientists; 2000:9.

Finch SC and Linet MS; Chronic leukaemias. In Epidemiology of Haematological Disease. Part I (AF Fleming, ed.). London: Bailliere Tindal; 1992.

Finkelstein MM. Leukemia after exposure to benzene: temporal trends and implications for standards. Am J Ind Med. 2000;38:1-7.

Finlay J, Luft B, Yousem S, et al. Chronic infectious mononucleosis syndrome, pancytopenia, and polyclonal B-lymphoproliferation terminating in acute lymphoblastic leukemia. Am J Pediatr Hematol Oncol. 1986;8:18-27.

Fisher B, Rockette H, Fisher ER, Wickerham DL, Redmond C, Brown A. Leukemia in breast cancer patients following adjuvant chemotherapy or postoperative radiation: the NSABP experience. J Clin Oncol. 1985;3:1640-58.

Fong CT, Brodeur GM. Down's syndrome and leukemia: epidemiology, genetics, cytogenetics and mechanisms of leukemogenesis. Cancer Genet Cytogenet. 1987;28:55-76.

Fraser, P, Carpenter, L, Maconochie, N, Higgins, C, Booth, M, Beral, V. Cancer mortality and morbidity in employees of the United Kingdom Atomic Energy Authority, 1946-86. Br J Cancer. 1993; 67 (3) 615-24.

Fraumeni JF Jr, Vogel CL, DeVita VT. Familial chronic lymphocytic leukemia. Ann Intern Med. 1969;71:279-84. 
Frome EL, Cragle DL, Watkins JP, et al. A mortality study of employees of the nuclear industry in Oak Ridge, Tennessee. Radiat Res. 1997;148:64-80.

Garfinkel L, Boffetta P. Association between smoking and leukemia in two American Cancer Society prospective studies. Cancer. 1990;65:2356-60.

Garland FC, Shaw E, Gorham ED, Garland CF, White MR, Sinsheimer PJ. Incidence of leukemia in occupations with potential electromagnetic field exposure in United States Navy personnel. Am J Epidemiol. 1990;132:293-303.

Gilbert ES, Cragle DL, Wiggs LD. Updated analyses of combined mortality data for workers at the Hanford Site, Oak Ridge National Laboratory, and Rocky Flats Weapons Plant. Radiat Res. 1993;136:408-21.

Gilbert ES, Marks S. An analysis of the mortality of workers in a nuclear facility. Radiat Res. 1979;79:122-48.

Gilbert ES, Omohundro E, Buchanan JA, Holter NA. Mortality of workers at the Hanford site: 1945-1986. Health Phys. 1993;64:577-90.

Ginzburg HM, Reis E. Consequences of the nuclear power plant accident at Chernobyl. Public Health Rep. 1991;106:32-40.

Goldman John M. Chronic Myeloid Leukaemia--The XXI Century. Leukemia and Lymphoma. 1993;11:7-9.

Goldman LS, Wintrobe M, Dameshek W. Nitrogen mustard therapy. JAMA. 1946;126.

Goldman M. The Russian radiation legacy: its integrated impact and lessons. Environ Health Perspect. 1997;105 Suppl 6:1385-91.

Greenberg ER, Rosner B, Hennekens C, Rinsky R, Colton T. An investigation of bias in a study of nuclear shipyard workers. Am J Epidemiol. 1985;121:301-8.

Gunz FW. The epidemiology and genetics of the chronic leukaemias. Clin Haematol. 1977;6:3-20.

Gunz FW. Leukemia in the Past. Linet MS. The Leukemias Epidemiologic Aspects. New York: Oxford University Press; 1985.

Gunz FW, Fitzgerald PH, Crossen PE, Mackenzie IS, Powles CP, Jensen GR. Multiple cases of leukemia in a sibship. Blood. 1966;27:482-9. 
Gunz FW, Gunz JP, Veale AM, Chapman CJ, Houston IB. Familial leukaemia: a study of 909 families. Scand J Haematol. 1975;15:117-31.

Gunz FW, Veale AM. Leukemia in close relatives--accident or predisposition? J Natl Cancer Inst. 1969;42:517-24.

Gunz FW. Leukemia in New Zealand and Australia. Pathol Microbiol. 1964;697-704.

Hornung RW, Meinhardt TJ. Quantitative risk assessment of lung cancer in U.S. uranium miners. Health Phys. 1987;52:417-30.

Hunter D; The Diseases of Occupations. 5th ed ed. London: English Universities Press; 1975.

Hutchison GB, MacMahon B, Jablon S, Land CE. Review of report by Mancuso, Stewart and Kneale of radiation exposure of Hanford workers. Health Phys. 1979;37:207-20.

International Agency for Research on Cancer. IARC Monographs on Dry Cleaning, Some Chlorinated Solvents and Other Industrial Chemicals. Lyon, France: IARC; 1995.

International Agency for Research on Cancer. IARC Monographs on Occupational Exposures in Paint Manufacture and Painting; Eval Carcinog Risk Humans. Vol. 47 ed. Lyon, France: IARC; 1989.

International Agency for Research on Cancer. IARC Monographs on the Evaluation of Carcinogenic Risks to Humans: Chromium, Nickel and Welding. Lyon, France: IARC; 1990.

International Agency for Research on Cancer. IARC Monographs on the Evaluation of the Carcinogenic Risk of Chemicals to Man. Wood, Leather, and Some Associated Industries. Volume 25 ed. Lyon, France: IARC; 1981.

International Commission on Radiological Protection (ICRP). Conversion Coefficients for Use in Radiological Protection Against External Radiation, ICRP Publication 74. Tarrytown, New York: Pergamon Press; 1996.

International Commission on Radiological Protection (ICRP) Recommendations of the International Commission on Radiological Protection. Publication 26. (adopted on 17 January 1977). Radiol Med (Torino). 1978 Jan; 64(1 Suppl):1-53.

Jacobson LO, Spurr CL, Barron ESG. Nitrogen mustard therapy. JAMA. 1946;263.

Jorde LB; Medical Genetics . 2nd ed ed. St. Louis: Mosby; 1999. 
Kabat GC, Augustine A, Hebert JR. Smoking and adult leukemia: a case-control study. J Clin Epidemiol. 1988;41:907-14.

Kalyanaraman VS, Sarngadharan MG, Robert-Guroff M, Miyoshi I, Golde D, Gallo RC. A new subtype of human T-cell leukemia virus (HTLV-II) associated with a T-cell variant of hairy cell leukemia. Science. 1982;218:571-3.

Kendall GM, Muirhead CR, MacGibbon BH, et al. Mortality and occupational exposure to radiation: first analysis of the National Registry for Radiation Workers. BMJ. 1992;304:220-5.

Kirk RE, Othmer DF, Kroschwitz JI, Howe-Grant M; Encyclopedia of Chemical Technology. 4th ed. New York: Wiley; 1991: 371.

Klaassen C; Casarett \& Doull's Toxicology: The basic science of poisons. 5th ed. McGraw-Hill Health Professions Division; 1996:214-217.

Kleinbaum DG, Klein M; Logistic Regression A Self-Learning Text . Second Edition ed. New York: Springer-Verlag; 2002.

Kolstad HA, Lynge E, Olsen J, Breum N. Incidence of lymphohematopoietic malignancies among styrene-exposed workers of the reinforced plastics industry. Scand J Work Environ Health. 1994;20:272-8.

Koshurnikova NA, Bysogolov GD, Bolotnikova MG, et al. Mortality among personnel who worked at the Mayak complex in the first years of its operation. Health Phys. 1996;71:90-3.

Koshurnikova NA, Shilnikova NS, Okatenko PV, et al. Characteristics of the cohort of workers at the Mayak nuclear complex. Radiat Res. 1999;152:352-63.

Kossenko MM, Hoffman DA, Thomas TL. Stochastic effects of environmental radiation exposure in populations living near the Mayak Industrial Association: preliminary report on study of cancer morbidity. Health Phys. 2000;79:55-62.

Lemen RA, Meinhardt TJ, Crandall MS, Fajen JM, Brown DP. Environmental epidemiologic investigations in the styrene-butadiene rubber production industry. Environ Health Perspect. 1990;86:103-6.

Lindquist R, Nilsson B, Eklund G, Gahrton G. Increased risk of developing acute leukemia after employment as a painter. Cancer. 1987;60:1378-84.

Linet MS, Cartwright RA. The Leukemias. Schottenfeld D, Fraumeni JF. Cancer Epidemiology and Prevention. 2nd ed ed. New York: Oxford University Press; 1996:841-892. 
Linet MS, Van Natta ML, Brookmeyer R, et al. Familial cancer history and chronic lymphocytic leukemia. A case- control study. Am J Epidemiol. 1989;130:655-64.

Little MP, Weiss HA, Boice JD Jr, Darby SC, Day NE, Muirhead CR. Risks of leukemia in Japanese atomic bomb survivors, in women treated for cervical cancer, and in patients treated for ankylosing spondylitis. Radiat Res. 1999;152:280-92.

Logue JN, Barrick MK, Jessup GL Jr. Mortality of radiologists and pathologists in the Radiation Registry of Physicians. J Occup Med. 1986;28:91-9.

Lynge E, Anttila A, Hemminki K. Organic solvents and cancer. Cancer Causes Control. 1997;8:406-19.

Mancuso TF, Stewart A, Kneale G. Radiation exposures of Hanford workers dying from cancer and other causes. Health Phys. 1977;33:369-85.

Matanoski GM, Santos-Burgoa C, Schwartz L. Mortality of a cohort of workers in the styrenebutadiene polymer manufacturing industry (1943-1982). Environ Health Perspect. 1990;86:107-17.

Matanoski GM, Seltser R, Sartwell PE, Diamond EL, Elliott EA. The current mortality rates of radiologists and other physician specialists: specific causes of death. Am J Epidemiol. 1975;101:199-210.

Matanoski GM, Stockwell HG, Diamond EL, et al. A cohort mortality study of painters and allied tradesmen. Scand J Work Environ Health. 1986;12:16-21.

McCraw DS, Joyner RE, Cole P. Excess leukemia in a refinery population. J Occup Med. $1985 ; 27: 220-2$.

McDonough WD, Captain USN. Portsmouth, New Hampshire: United States Navy; 1978.

McLaughlin JK, Hrubec Z, Linet MS, Heineman EF, Blot WJ, Fraumeni JF Jr. Cigarette smoking and leukemia. J Natl Cancer Inst. 1989;81:1262-3.

McMichael AJ, Spirtas R, Gamble JF, Tousey PM. Mortality among rupper workers: Relationship to specific jobs. J Occup Med. 1976;18:178-85.

Mecucci C, Ghione F, Louwagie A, Criel A, Van den Berghe H. Variant translocation (7;922) during lymphoid blastic crisis in a case of Ph1-positive chronic myelogenous leukemia with previous EBV infection. Acta Haematol. 1986;75:46-8. 
Meinhardt TJ, Lemen RA, Crandall MS, Young RJ. Environmental epidemiologic investigation of the styrene-butadiene rubber industry. Mortality patterns with discussion of the hematopoietic and lymphatic malignancies. Scand J Work Environ Health. 1982;8:250-9.

Mitus J, Rosenthal D. The adult leukemias. Murphy G, Lawrence W, Lenhard R. American Cancer Society Textbook of Clinical Oncology. 2nd Ed. 2nd ed. The American Cancer Society; 1995.

Muirhead CR, Goodill AA, Haylock RG, et al. Occupational radiation exposure and mortality: second analysis of the National Registry for Radiation Workers. J Radiol Prot. 1999;19:3-26.

Murray WE, Terpilak MS. Cincinnati, Ohio: National Institute for Occupational Safety and Health; Division of Surveillance, Hazard Evaluations, and Field Studies.; 1983.

Najarian T, Colton T. Mortality from leukaemia and cancer in shipyard nuclear workers. Lancet. 1978;1:1018-20.

Narod SA, Stiller C, Lenoir GM. An estimate of the heritable fraction of childhood cancer. $\mathrm{Br} J$ Cancer. 1991;63:993-9.

National Council on Radiation Protection and Measurements; Exposure of the U.S. Population From Occupational Radiation Recommendations of the National Council on Radiation Protection and Measurements. Bethesda, MD: NCRP; 1989. NCRP Report.

National Institute for Occupational Safety and Health. Study Protocol: Update of Epidemiological Study of Civilian Workers at the Portsmouth Naval Shipyard in Kittery Maine. National Institute for Occupational Safety and Health; Health-Related Energy Research Branch; 1997.

Omar RZ, Barber JA, Smith PG. Cancer mortality and morbidity among plutonium workers at the Sellafield plant of British Nuclear Fuels. Br J Cancer. 1999;79:1288-301.

Paci E, Buiatti E, Seniori Costantini AS, et al. Aplastic anemia, leukemia and other cancer mortality in a cohort of shoe workers exposed to benzene. Scand J Work Environ Health. 1989;15:313-8.

Paffenbarger RS Jr, Wing AL, Hyde RT. Characteristics in youth predictive of adult-onset malignant lymphomas, melanomas, and leukemias: brief communication. J Natl Cancer Inst. 1978;60:89-92.

Pearce N, Reif J, Fraser J. Case-control studies of cancer in New Zealand electrical workers. Int J Epidemiol. 1989;18:55-9. 
Pierce DA, Shimizu Y, Preston DL, Vaeth M, Mabuchi K. Studies of the mortality of atomic bomb survivors. Report 12, Part I. Cancer: 1950-1990. Radiat Res. 1996;146:1-27.

Piller G. Leukaemia - a brief historical review from ancient times to 1950. Br J Haematol. 2001;112:282-92.

Pontisso P, Locasciulli A, Schiavon E, et al. Detection of hepatitis B virus DNA sequences in bone marrow of children with leukemia. Cancer. 1987;59:292-6.

Portsmouth Naval Shipyard (PNS). Portsmouth, New Hampshire: United States Navy; 1980.

Pottern LM, Linet M, Blair A, et al. Familial cancers associated with subtypes of leukemia and non-Hodgkin's lymphoma. Leuk Res. 1991;15:305-14.

Preston-Martin S, Peters JM. Prior employment as a welder associated with the development of chronic myeloid leukaemia. Br J Cancer. 1988;58:105-8.

Proctor NH, Hughes JP, Hathaway GJ; Proctor and Hughes' Chemical Hazards of the Workplace. 4rd ed ed. New York: Van Nostrand Reinhold; 1996.

Radford EP, Doll R, Smith PG. Mortality among patients with ankylosing spondylitis not given X-ray therapy. N Engl J Med. 1977;297:572-6.

Rahu M, Tekkel M, Veidebaum T, et al. The Estonian study of Chernobyl cleanup workers: II. Incidence of cancer and mortality. Radiat Res. 1997;147:653-7.

Ries LAG, Eisner MP, Kosary CL, et al., Editors. SEER Cancer Statistics Review, 1973-1999. Bethesda, MD: National Cancer Institute; 2002.

Rinsky RA, Smith AB, Hornung R, et al. Benzene and leukemia. An epidemiologic risk assessment. $N$ Engl J Med. 1987;316:1044-50.

Rinsky RA, Young RJ, Smith AB. Leukemia in benzene workers. Am J Ind Med. 1981;2:217-45.

Rinsky RA, Zumwalde RD, Waxweiler RJ, et al. Cancer mortality at a Naval Nuclear Shipyard. Lancet. 1981;1:231-5.

Rinsky RA, Zumwalde RD, Waxweiler RJ, et al. Epidemiologic study of civilian employees at the Portsmouth Naval Shipyard, Kittery, Maine. Final Technical Report Cincinnati, Ohio: National Institute for Occupational Safety and Health; Division of Surveillance, Hazard Evaluations, and Field Studies.; 1980. 
Ron, E. Ionizing radiation and cancer risk: evidence from epidemiology. Radiat Res. 1998; 150 (5 Suppl) S30-41.

Rothman, Kenneth J and Greenland, Sander Modern Epidemiology. Philadelphia, PA : Lippincott-Raven; 1998:675-709.

Ruddon RW; Cancer Biology. New York: Oxford University Press; 1995.

Rushton L, Alderson MR. An epidemiological survey of eight oil refineries in Britain. Br J Ind Med. 1981;38:225-34.

Savitz DA, Cai J, van Wijngaarden E, et al. Case-cohort analysis of brain cancer and leukemia in electric utility workers using a refined magnetic field job-exposure matrix. Am J Ind Med. 2000;38:417-25.

Savitz DA, Calle EE. Leukemia and occupational exposure to electromagnetic fields: review of epidemiologic surveys. J Occup Med. 1987;29:47-51.

Savitz DA, Loomis DP. Magnetic field exposure in relation to leukemia and brain cancer mortality among electric utility workers. Am J Epidemiol. 1995;141:123-34.

Schubauer-Berigan MK, Wenzl TB. Leukemia mortality among radiation-exposed workers. Occup Med. 2001;16:271-87.

Schweitzer M, Melief CJ, Ploem JE. Chronic lymphocytic leukaemia in 5 siblings. Scand J Haematol. 1973;11:97-105.

Seeley RR, Stephens TD, Tate P; Anatomy and Physiology. 5th ed ed. Boston, Mass: McGrawHill; 2000.

Shigematsu I. The 2000 Sievert Lecture--lessons from atomic bomb survivors in Hiroshima and Nagasaki. Health Phys. 2000;79:234-41.

Shimizu Y, Kato H, Schull WJ, Preston DL, Fujita S, Pierce DA. Studies of the mortality of Abomb survivors. 9. Mortality, 1950-1985: Part 1. Comparison of risk coefficients for sitespecific cancer mortality based on the DS86 and T65DR shielded kerma and organ doses. Radiat Res. 1989;118:502-24.

Shimizu Y, Schull WJ, Kato H. Cancer risk among atomic bomb survivors. The RERF Life Span Study. Radiation Effects Research Foundation. JAMA. 1990;264:601-4.

Shore RE. Electromagnetic radiations and cancer. Cause and prevention. Cancer. 1988;62:1747-54. 
Siegel M. Smoking and leukemia: evaluation of a causal hypothesis. Am J Epidemiol. 1993;138:1-9.

Silver SR, Rinsky RA, Cooper SP, Hornung RW, Lai D. Effect of follow-up time on risk estimates: a longitudinal examination of the relative risks of leukemia and multiple myeloma in a rubber hydrochloride cohort. Am J Ind Med. 2002;42:481-9.

Silver S, Daniels RD, Yiin J, et al. Epidemiologic study of civilian employees at the Portsmouth Naval Shipyard, Kittery, Maine (2004). Final Technical Report Cincinnati, Ohio: National Institute for Occupational Safety and Health; Division of Surveillance, Hazard Evaluations, and Field Studies.

Smith PG, Doll R. Mortality among patients with ankylosing spondylitis after a single treatment course with x rays. Br Med J (Clin Res Ed). 1982;284:449-60.

Smith PG, Doll R. Mortality from cancer and all causes among British radiologists. Br J Radiol. 1981;54:187-94.

Smith PG, Douglas AJ. Mortality of workers at the Sellafield plant of British Nuclear Fuels. $\mathrm{Br}$ Med J (Clin Res Ed). 1986;293:845-54.

Steinberg AG. The Genetics of Acute Leukemia in Children. Cancer. 1960;985.

Stern FB, Waxweiler RA, Beaumont JJ, et al. A case-control study of leukemia at a naval nuclear shipyard. Am J Epidemiol. 1986;123:980-92.

Strom DJ. Estimating individual and collective doses to groups with 'less than detectable' doses: a method for use in epidemiologic studies. Health Phys. 1986;51:437-45.

Szklo M, Nieto FJ. Epidemiology Beyond the Basics. Gaithersburg, Maryland: Aspen; 2000.

Taylor EJ.; Dorland's Illustrated Medical Dictionary. 27th ed. Philadelphia: W.B. Saunders Company; 1988.

The United Nations Scientific Committee on the Effects of Atomic Radiation. Sources and Effects of Ionizing Radiation: Annex I: Epidemiological Evaluation of RadiationInduced Cancer. Volume II ed. New York: United Nations; 2000.

The United States Department of Energy Office of Environmental Management. Linking Legacies Connecting the Cold War Nuclear Weapons Production Processes to Their Environmental Consequences. Washington, D.C. : United States Department of Energy; 1997. 
The United States Department of Health Services. The health consequences of smoking. Cancer. A Report of the Sergeon General of the United States. United States Government Printing Office. 1982;[DHHS (PHS) 82-50179].

Theriault G. Electromagnetic fields and cancer risks. Rev Epidemiol Sante Publique. 1992;40:S55-62.

Tynes T, Jynge H, Vistnes AI. Leukemia and brain tumors in Norwegian railway workers, a nested case- control study. Am J Epidemiol. 1994;139:645-53.

Videbaek A. Heredity in Human Leukaemia and Its Relation to Cancer. Copenhagen: Munksgaard; 1947.

Vigliani EC, Forni A. Benzene and leukemia. Environ Res. 1976;11:122-7.

Villeneuve PJ, Agnew DA, Miller AB, Corey PN, Purdham JT. Leukemia in electric utility workers: the evaluation of alternative indices of exposure to $60 \mathrm{~Hz}$ electric and magnetic fields. Am J Ind Med. 2000;37:607-17.

Watanabe KK, Kang HK, Dalager NA. Cancer mortality risk among military participants of a 1958 atmospheric nuclear weapons test. Am J Public Health. 1995;85:523-7.

Weiss HA, Darby SC, Doll R. Cancer mortality following X-ray treatment for ankylosing spondylitis. Int J Cancer. 1994;59:327-38.

Welch LS, Cullen MR. Effect of exposure to ethylene glycol ethers on shipyard painters: III. Hematologic effects. Am J Ind Med. 1988;14:527-36.

Wiggs LD, Johnson ER, Cox-DeVore CA, Voelz GL. Mortality through 1990 among white male workers at the Los Alamos National Laboratory: considering exposures to plutonium and external ionizing radiation. Health Phys. 1994;67:577-88.

Wilcosky TC, Checkoway H, Marshall EG, Tyroler HA. Cancer mortality and solvent exposures in the rubber industry. Am Ind Hyg Assoc J. 1984;45:809-11.

Williams RR, Horm JW. Association of cancer sites with tobacco and alcohol consumption and socioeconomic status of patients: interview study from the Third National Cancer Survey. J Natl Cancer Inst. 1977;58:525-47.

Wing S, Shy CM, Wood JL, Wolf S, Cragle DL, Frome EL. Mortality among workers at Oak Ridge National Laboratory. Evidence of radiation effects in follow-up through 1984. JAMA. 1991;265:1397-402. 
Wong O. An industry wide mortality study of chemical workers occupationally exposed to benzene. II. Dose response analyses. Br J Ind Med. 1987;44:382-95.

Wujcik D. Leukemia. The Care of Individuals With Cancer: Part VI From Cancer Nursing Principles and Practice. Second ed. Boston: Jones and Bartlett; 1992.

Yiin J, Silver S, Daniels RD, et al. Risk of Lung Cancer and Leukemia from Exposure to Ionizing Radiation and Potential Confounders among Workers at the Portsmouth Naval Shipyard. Cincinnati, Ohio: National Institute for Occupational Safety and Health; Division of Surveillance, Hazard Evaluations, and Field Studies. 2004.

Yin SN, Li GL, Tain FD, et al. Leukaemia in benzene workers: a retrospective cohort study. Br J Ind Med. 1987;44:124-8.

Zack M, Adami HO, Ericson A. Maternal and perinatal risk factors for childhood leukemia. Cancer Res. 1991;51:3696-701. 


\section{Appendix A}

\section{Definition and Description of Leukemia}

Leukemia is the name used to describe a variety of hematologic (related to blood and bloodforming organs) malignancies that begin in the blood-forming cells of the bone marrow. When leukemia occurs, the body produces too many abnormally immature blood cells. In most leukemias, the abnormally immature blood cells produced are white blood cells (leukocytes); however, abnormal numbers of immature red blood cells (erythrocytes) and platelets (thrombocytes) may also occur. Major symptoms of leukemia include infections due to a decrease in normal white blood cells, anemia due to a decrease in normal red blood cells, and excessive bleeding due to a decrease in normal platelets. Leukemias are classified by form as either acute or chronic (characterizes how quickly the disease develops), and by type, either myeloid or lymphoid (characterizes the type of blood cell that is primarily affected) (Wujcik, 1992; Ruddon, 1995).

\subsection{Acute and Chronic Leukemias}

The acute form of leukemia is characterized by a rapid increase in the number of immature blood cells that remain immature and are unable to perform their normal function, resulting in a short survival time without immediate medical intervention. Acute leukemia is often difficult to diagnose because the symptoms (fever; flu-like symptoms; changes in energy level, appetite and temperament; joint or bone pain; and tendency to bruise or bleed easily) are often vague and present for a short period of time (less than three months). The chronic form of leukemia usually progresses more slowly than acute leukemia. Unlike the immature cells that characterize acute leukemia, the predominant cell characterizing chronic leukemia appears mature, but does not function normally. Chronic leukemia usually has a gradual onset, prolonged clinical course, and a relatively longer survival time (Wujcik, 1992; Ruddon, 1995).

\subsection{Myeloid and Lymphoid Leukemias}

The bone marrow, which is the soft material that fills the cavities of the bones, is where adult blood cells are produced. There are two blood cell lines produced by the bone marrow, the myeloid and lymphoid cell lines, which are involved in blood cell production. The myeloid cell line includes cells that mature into erythrocytes (red blood cells), thrombocytes (platelets), and some leukocytes (white blood cells). The white blood cells from the myeloid cell line include macrophages (which ingest foreign particles), eosinophils (which trigger allergies), and neutrophils (which protect against bacterial infections). The lymphoid cell line includes both Tcell (released from the thymus gland) and B-cell (released from the bone marrow) lymphocytes, which produce antibodies that attack foreign substances in the body. Leukemia is a disease that is characterized by an interruption in the maturation of either the myeloid or lymphoid cell line causing production of ineffective blood cells that are unable to function correctly (Seeley et al., 2002; Wujcik, 1992). 


\section{Identification of Leukemia as a Clinical Entity-A Brief History}

There is no evidence in the medical literature that would suggest that leukemia had been identified or described before the 19th century (Piller, 2002). It is thought that A. Velpeau provided the first accurate description of a leukemia case in 1827. He was treating a 63-year-old patient who became ill in 1825 with fever, weakness, and swelling of the abdomen. The patient died soon after admission to the hospital and the autopsy revealed that he had a severely enlarged liver and spleen. His blood contained colorless corpuscles and appeared thick "like gruel...resembling in consistency and color the yeast of red wine" (Gunz, 1985; Piller, 2002). It was this peculiar characteristic of the blood which first attracted early observers such as Rudolph Virchow, a German pathologist, who first introduced the term leukemia in 1847 to describe this unusual appearance of the blood (Gunz, 1985).

In 1856, Virchow published a summary of a series of studies he conducted examining the pathology of leukemia. These remarkable studies provided several important insights into the pathology of leukemia that are still relevant today, and were made when little knowledge existed on the sites and mechanisms of hematopoiesis and on the function of the blood cell. First, he explained that the colorless corpuscles he had observed are always present in normal blood and that their increase does not necessarily indicate the presence of leukemia. Second, he described leukemia as a clearly defined pathologic state characterized by not only an increase in "colorless cells, but also a decrease in the number of red corpuscles." Third, he explained that some patients exhibited enlargement of the lymph nodes or spleen months or even years before changes developed and were observed in the blood. He concluded that changes in the organs of leukemia patients precede those in the blood (Gunz, 1985).

Following the work of Vichow, there were several other important 19th century discoveries related to leukemia. In 1870, Newman demonstrated that the bone marrow is an important site for the formation of blood corpuscles. This discovery was followed in 1879 by Gower's report that anemia in leukemia patients may be caused by either diminished formation of red blood cells or by their excessive destruction. In 1889, Ebstein was the first to describe acute leukemia as a distinct clinical entity. Franekel's report soon followed in which revealed in 1895 acute leukemia is more common than chronic leukemia. By the end of the nineteenth century, much progress had been made in establishing a clear definition and classification of subtypes of leukemia, however, these advancements provided little help in advancing the treatment of the disease (Piller, 2001). 


\section{Leukemia Treatment-A Brief History}

Attempts were made to treat leukemia soon after the disease was identified, but all proved to be unsuccessful. It was not until 1865-some 38 years after Velpeau provided the first description of leukemia - that the first leukemia remission was reported in a patient with chronic granulocytic leukemia. The patient had been treated with a tonic that contained arsenious oxide. After this remission was reported, arsenic became the standard treatment for chronic leukemia for the next 30 years (Gunz, 1985). The next advance in the treatment of chronic leukemia occurred in 1902, when x-rays (discovered by Rontgen in 1895) were found to be effective in treating chronic leukemias. Like arsenic, however, $\mathrm{x}$-rays proved to be ineffective for treating acute leukemia, and offered only temporary relief and no cure for chronic leukemia (Gunz, 1985).

In 1910 it was discovered that the organic solvent benzol is destructive to blood cells. For this reason, it was used to treat leukemia. Its toxic effects were so severe and unpredictable however, that it was widely used for only about 10 years. Until the 1940s, treatment was limited to x-ray therapy for chronic leukemia, which provided only symptomatic relief, not a cure (Gunz, 1985). Acute leukemias continued to be non-responsive to any type of intervention. During World War II, while research was being conducted on the military uses of mustard gas, it was discovered that nitrogen mustards are a strong bone marrow depressant. Furthermore, clinical trials conducted in secrecy during World War II on patients with advanced Hodgkin's disease, lymphosarcomas, and leukemia revealed that these agents could induce excellent remissions of lymphomas, although their antileukemic activity was limited (Gunz, 1985).

The results of these clinical trials were published after the end of World War II in 1946, in the Journal of the American Medical Association (Goldman, et al., 1946; Jacobson, et al., 1946). Also in 1946, Gillman and Philips published a study indicating that the effects from the nitrogen mustards in the treatment of leukemia closely resembled those from x-rays (Gilman and Philips, 1946). These published findings stimulated further research into the development of other theraputic chemical agents that were used to treat primarily chronic leukemia. Between 1946 and 1956, several compounds were synthesized in the United States and Great Britain including triethlenemelamine, busulfan, and chlorambucil, which became known collectively as the alkylating agents. Unlike nitrogen mustards, they could be taken by mouth, but their acute toxicity to the bone marrow and other tissues was pronounced (Gunz, 1985).

None of the new chemical agents however, were effective in treating acute leukemia. Significant progress in treating acute leukemia did not occur until the mid-1950s, when Dr. Sidney Farber of Boston first used the folic acid antagonist aminopterin to treat 16 children with acute leukemia. Farber reported that although aminopterin was extremely toxic, 10 of 16 children with acute lymphocytic leukemia (ALL) who were treated with it achieved a temporary remission. This finding provided new hope that effective treatment of acute leukemia was possible. Current standard leukemia treatment regimens produce remission in approximately $70 \%$ of adults with 
ALL, and long-term survival rates averaging approximately $40 \%$. Current treatment has also improved long-term survival for adults with chronic lymphocytic leukemia (CLL); however, current long term survival remains very low for both acute myeloid leukemia (AML) (20\%) and chronic myeloid leukemia (CML) (25\%) (Borson and Loeb, 1994).

\section{Leukemia Mortality in the United States}

\subsection{Mortality from All Leukemia Types Combined-Trends for Males and Females, All Races}

The American Cancer Society (ACS) estimates that there will be 21,700 leukemia deaths [12,100 $(56 \%)$ males and 9,600 (44\%) females] in the United States in 2002. Since the 1960s, there has been a significant decrease in childhood leukemia mortality in the United States among both white and nonwhite children due primarily to therapeutic treatment advances (The American Cancer Society, 2002). Adults have not experienced a similar decline in mortality. According to information from the National Cancer Institute, the age-adjusted leukemia mortality for both adult men and adult women gradually increased from 1950 to 1972, (Appendix B, Tables 1 \& 2). This increase was due primarily to increases among elderly non-white adults (Linet and Cartwright, 1996; The American Cancer Society, 2002; Ries et al., 2002). Between 1973 and 1999, however, leukemia mortality for both adult men and women declined slightly (Ries et al., 2002).

\subsection{Mortality from All Leukemia Types Combined-Trends for Males of All Races}

According to data provided by the National Center for Health Statistics (NCHS) between 1973 and 1999, the age-adjusted mortality for all leukemias among males of all races gradually declined. The decline was most pronounced from 1995 to 1998, during which time the rates decreased from 10.8 per 100,000 to 10.1 per 100,000 (Appendix B, Table 3) (Ries et al., 2002).

\subsection{Mortality from All Leukemia Types Combined-Trends for Females of All Races}

The age-adjusted mortality for all leukemia types combined is lower for females than for males. According to the NCHS, the age-adjusted mortality among females of all races gradually decreased from 1973 to 1998 . The combined female rates reached a high of 6.5 per 100,000 in 1980, and a low of 5.9 per 100,000 in 1998 (Appendix B, Table 4) (Ries et al., 2002).

\subsection{Mortality from All Leukemia Types Combined-Trends for White Males and Females}

The age-adjusted mortality for white males from all leukemia types combined has slowly increased from 1973 to 1980, reaching a high of 11.5 per 100,000 in 1980 (Appendix B, Table 5). The rates declined slowly from 1981 to 1987 , followed by a more pronounced decline from 
1995 to 1998 , when rates fell from 11.0 per 100,000 in 1995 to 10.3 per 100,000 in 1998 . The age-adjusted mortality for white females is lower than that for white males and has also declined slowly from 1980 to 1999 , reaching a high of 6.6 per 100,000 in 1980 and a low of 6.0 per 100,000 in 1998 (Ries et al., 2002).

\subsection{Leukemia Mortality for All Leukemia Types Combined-Black Males and Females}

The age-adjusted mortality for all leukemia types combined for black males is lower than for white males and gradually increased from a low of 8.2 per 100,000 in 1973 to a high of 10.3 per 100,000 in 1989. It then decreased gradually from 1989 to 1999 (Appendix B, Table 5). The ageadjusted mortality for black females for all types of leukemia combined, which is lower than for white or black males and white females, increased from 1973 to 1981 and then declined gradually from 1982 to 1997 (Appendix B, Table 5) (Ries et al., 2002).

\section{Leukemia Incidence in the United States}

\subsection{Incidence of All Leukemia Types Combined}

The American Cancer Society estimates that there will be 30,800 new cases of leukemia diagnosed in the United States in 2002 [17,600 (57\%) males and 13,200 (43\%) females]. Acute and chronic types of leukemia are projected to occur in approximately equal proportions in these new cases. Incidence rates are highest among white males and lowest among black females (The American Cancer Society, 2002).

\subsection{Incidence of All Leukemia Types Combined-Trends for White Males and Females}

According to the National Cancer Institute's Surveillance, Epidemiology and End Results (SEER) data base, age-adjusted leukemia incidence rates among white males have remained stable from 1973 through 1995, when they began to decrease (Appendix B, Table 5). Age-adjusted incidence rates among white females have also remained stable from 1973 through 1995, after which they to began to decline (The National Cancer Institute, 2002; Ries, 2002).

\subsection{Incidence of All Leukemia Types Combined-Trends for Black Males and Females}

The age-adjusted incidence rates for black men and women have shown more variation than the rates for white males and females; however, incidence rates for both groups have been decreasing since 1973 (Appendix B, Table 5) (Ries et al., 2002). 


\subsection{Survival Rates for All Leukemia Types Combined-Both Males and Females}

Currently, the one-year survival rate for males and females of all races with leukemia is $63.5 \%$, while the five-year survival rate decreases to $46.4 \%$. This decrease is due in part to the poor survival rate of individuals with acute myeloid leukemia. The fiveyear survival rates for all types have improved since the early 1960s (Table 5.4); however, there is still no known cure for leukemia (Ries et al., 2002).

\section{The Four Major Leukemia Subtypes-Incidence, Mortality, and Five-Year Survival Rates}

\subsection{Acute Myeloid Leukemia (AML)}

The American Cancer Society estimates that there will be 10,600 new AML cases diagnosed in 2002 [5,900 (56\%) males and 4,700 (44\%) females] (The

\begin{tabular}{|c|c|c|}
\hline \multicolumn{3}{|c|}{$\begin{array}{l}\text { Table 5.4. Changes in the Five Year } \\
\text { Survival Rates for All } \\
\text { Leukemia Types } \\
\text { Combined: from the } \\
\text { National Cancer Institute } \\
\text { (Ries et al., 2002) }\end{array}$} \\
\hline $\begin{array}{c}\text { Year of } \\
\text { Diagnosis }\end{array}$ & $\begin{array}{c}\text { Whites } \\
\text { (Male and } \\
\text { Female) } \\
\end{array}$ & $\begin{array}{c}\text { Blacks } \\
\text { (Male and } \\
\text { Female) } \\
\end{array}$ \\
\hline 1960-1963 & $14 \%$ & Not available \\
\hline 1970-1973 & $22 \%$ & Not available \\
\hline 1974-1976 & $35.2 \%$ & $31.2 \%$ \\
\hline 1977-1979 & $38.0 \%$ & $30.4 \%$ \\
\hline 1980-1982 & $39.5 \%$ & $32.9 \%$ \\
\hline 1983-1985 & $42.0 \%$ & $33.6 \%$ \\
\hline 1986-1988 & $44.2 \%$ & $38.0 \%$ \\
\hline 1989-1991 & $45.8 \%$ & $34.1 \%$ \\
\hline 1992-1998 & $47.3 \%$ & $38.4 \%$ \\
\hline
\end{tabular}

American Cancer Society, 2002). The incidence rates for AML increase dramatically among adults over the age of 40; it is the most common form of leukemia among older adults and is most prevalent in the sixth, seventh, and eighth decades of life (The American Cancer Society, 2002). The incidence of AML is less than 1/100,000 among individuals younger than 35 years of age and rises dramatically for individuals older than 60 years of age (especially white males) (Appendix B, Table 6). The American Cancer Society estimates that 7,400 deaths [4,000 (54\%) male and 3,400 (46\%) female] will result from AML in 2002. Mortality rates rise sharply after age 50, particularly for white males (Appendix B-Table 7). Currently, the five-year survival rate for adults with AML who achieve a complete remission following chemotherapy is approximately 25\% (The American Cancer Society, 2002; Ries et al., 2002).

\subsection{Chronic Lymphocytic Leukemia (CLL)}

CLL is the second most common form of adult leukemia and $90 \%$ of the new cases are diagnosed in individuals who are older than age 50 (Appendix B, Table 8) (Reis et al., 2002). It is estimated that 7,000 new cases [4,100 (59\%) male and 2,900 (41\%) female] will be diagnosed in 2002 and that 4,500 deaths [2,600 (58\%) male and 1,900 (42\%) female] will result from CLL in 2002. Mortality rates rise sharply after age 60, particularly for white and black males (Appendix B-Table 9). Currently, the overall five-year survival rate for adults with CLL is approximately 60\% (The American Cancer Society, 2002; Ries et al., 2002). 


\subsection{Chronic Myeloid Leukemia (CML)}

It is estimated that there will be 4,400 new cases [2,500 (57\%) males and 1,900 (43\%) females] of CML diagnosed in 2002. CML incidence also rises with age (Appendix B, Table 10), and the overall five-year survival rate for CML is approximately $32 \%$. It is estimated that 2,000 deaths [1,100 (55\%) males and 900 (45\%) females] will result from CML in 2002. Mortality rises dramatically for white and black males and females after age 60; however, the rise after age 60 is most pronounced for white males (Appendix B, Table 11) (The American Cancer Society, 2002; Ries et al., 2002).

\subsection{Acute Lymphocytic Leukemia (ALL)}

ALL accounts for $78 \%$ of childhood leukemias but only $5 \%$ of leukemias in adults older than 40 years of age. Age-specific patterns in the United States show a peak among children ages 2-4, with a decline in rates to a low at ages $25-59$, followed by an increase to a second, slightly lower peak at ages 85 and older (The American Cancer Society, 2002). It is estimated that 3,800 new adult ALL cases [2,200 (58\%) males and 1,600 (42\%) females] will be diagnosed in 2002 . Incidence rises most dramatically among white males after age 70 (Appendix B, Table 12). The overall five-year survival rate is approximately $40 \%$, and it is estimated that there will be 1,400 adult deaths [800 (57\%) male and 600 (43\%) female] from ALL in 2002. Mortality rises dramatically for blacks and whites of both sexes after age 60 (Appendix B, Table 13) (The American Cancer Society, 2002; Ries et al., 2002).

\section{Risk Factors}

\subsection{General}

The exact cause of leukemia is not yet known. However, leukemias are associated with certain environmental, occupational, and genetic risk factors. Primary occupational risks include exposure to ionizing radiation (BEIR V, 1990; Cardis et al., 1995; Cardarelli et al., 2002) and benzene (Proctor and Hughes, 1996; Vigliani, et al., 1976; Rinsky et al., 1981; Bond et al., 1986; Rinsky et al., 1987). Non-occupational risks include diagnostic x-rays (Evans et al., 1986), radiation therapy (Curtis et al., 1984; Boice et al., 1987), alkylating chemotherapy drugs (Ruddon 1995), and smoking (Austin et al., 1986; McLaughlin et al., 1989; Brown et al., 1992; Kabat et al., 1988; Brownson et al., 1993). Additional associations have been noted with familial and genetic disorders, and chromosomal syndromes (including Down, Klinefelters's, and Bloom's syndromes) (Mitus et al., 1995; Ruddon, 1995; Klassen, 1996).

\subsection{Familial and Genetic Factors}

Beginning in the 1940's, evidence of a relationship between genetic factors and the incidence of leukemia - especially chronic lymphocytic leukemia (CLL) - began to emerge from case-control and case-series studies examining the incidence of leukemia among family members (Schweitzer, 1973; Gunz, 1966; Fraumeni et al., 1969; Linet, 1989; Finch and Linet, 1992; 
Cuttner, 1992). A case-control study conducted by Videbaek in 1947 was the first to suggest an increased incidence of all forms of leukemia among relatives of leukemia patients (Videbaek, 1947; Gunz and Veale, 1969). Videbaek's findings were not confirmed in subsequent studies in the 1950s and early 1960s and were criticized on both methodological and statistical grounds (Gunz, 1966; Steinberg, 1960; Busk, 1948). However, three case-survey studies conducted from the mid-1960s and 1970s with a combined total of 1500 families (Gunz, 1964; Gunz and Veale, 1969; Gunz et al., 1975) did support the findings reported by Vidabaek. These studies reported that the familial incidence of leukemia is nearly three times higher than expected among relatives of leukemia patients, and that the incidence of a second case is higher among first-degree relatives (parent, sibling, and child) than more distant relatives. They also reported that the risk of familial leukemia appears to be greatest among relatives of patients with CLL, while less so among relatives of patients with acute leukemias. (Gunz, 1964; Gunz and Veale 1969; Gunz et al., 1975; Gunz, 1977; Cuttner, 1992).

Some case-control studies have reported excess leukemia among family members of cases, supporting the findings reported by Vidabaek in 1947 and subsequent case-series studies (Cartwright, 1987; Linet, 1989; Pottern, 1991). Pottern, in a case-control study that included 578 leukemia cases, reported that a history of stomach cancer in either parent and prostate cancer in fathers was associated with a two-fold elevation in the incidence of CLL (Pottern, 1991).

\subsection{Chromosomal Syndromes}

An elevated risk of leukemia has been reported among children with certain hereditary and congenital conditions that are accompanied by chromosomal instabilities (Linet and Cartwright, 1996). Multiple studies have reported that children with Down syndrome have a 20 - to 30-fold increased incidence of acute leukemia of various cell types, compared to the general population (Epstein and McCoy, 1987; Fong and Brodeur, 1987; Zack et al., 1991). Narod, in a survey of 16,564 cases of childhood cancer diagnosed in Great Britain from 1971 to 1983, reported that Down syndrome was diagnosed in more than $90 \%$ of the children who had both a genetic disorder and leukemia (Narod et al., 1991). The age of onset for leukemia in children with Down syndrome is bimodal, peaking first in the newborn period and again at 3-6 years. This increased risk extends into adulthood. (Fong and Brodeur, 1987)

Other disorders with chromosomal abnormalities or fragilities associated with leukemia include the following: Klinefelter's syndrome, which is seen in approximately 1/1000 male births and is a condition characterized by small testes and atrophy of the seminiferous tubules. It is associated most often with AML. (Jorde, 1999). Bloom syndrome is characterized by permanent dilation of facial blood vessels, creating small focal red lesions, photosensitivity, and dwarfism (of prenatal onset) (Jorde, 1999). It is associated with a significant increase in ALL in younger individuals and AML in older individuals (Linet and Cartwright, 1996). Fanconi's anemia is characterized by pancytopenia (deficiency of all cell elements of the blood) and underdevelopment of the bone 
marrow. It is estimated that $10-20 \%$ of individuals with this disorder develop AML (Linet and Cartwright, 1996).

In general, the factors responsible for the chromosome changes in individuals with leukemia are unknown, although chromosomal abnormalities in a few cases have been linked to exposure to ionizing radiation, benzene, other solvents, pesticides, or to treatment with certain types of chemotherapy drugs. It is not known if chromosomal defects cause or just coexist with leukemia; however, presence of chromosomal abnormality and/or fragility appears to favor progression to a malignant state (Linet and Cartwright, 1996).

\subsection{Viruses}

\subsubsection{HTLV - Types I and II}

Since 1980, the Human T-Lymphotrophic Type 1 Virus (HTLV-1) has been established as the primary etiologic factor in adult T-cell leukemia-lymphoma (Blattner, 1993; Linet and Cartwright, 1996). Adult T-cell leukemia (ATL) is an aggressive form of leukemia difficult to distinguish from CLL, that is uniformly fatal (CDC, 1993). Transmission of HTLV-1 occurs prenatally from mother to child, or through sexual contact, blood transfusion, or sharing contaminated needles. In the United States, most of those infected report either birth in endemic countries (southwest Japan, the Caribbean basin, Melanesia, and Africa) or sexual contact with a person from an endemic country (CDC, 1993).

The Human T-Lymphotrophic Type II Virus (HTLV-II) infection was first isolated from two patients with hairy-cell leukemia (CLL variant) in 1982. However, currently the infection is not clearly associated with hairy-cell or any other types of leukemias (Kalyanaraman et al., 1982; CDC, 1993).

\subsubsection{Epstein-Barr Virus}

The Epstein-Barr virus is a member of the herpes virus family and one of the most common human viruses (Linet and Cartwright, 1996). Case report studies have associated the virus with a lymphoproliferation terminating in acute lymphocytic leukemia (ALL) (Finlay et al., 1986) or chronic myeloid leukemia (CML) (Mecucci et al., 1986; Linet and Cartwright, 1996).

\subsubsection{Hepatitis B Virus}

Hepatitis B is a viral disease caused by the hepatitis B virus that is endemic worldwide. It is characterized by hepatic cell destruction leading to anorexia, jaundice, and hepatomegaly (enlargement of the liver). In most cases, the hepatic cells regenerate and individuals recover (Taylor, 1988). The hepatitis B virus has been found in the hemopoietic cells of adults with AML prior to treatment with blood transfusions (Linet and Cartwright, 1996). In a study of 51 children diagnosed with leukemia, Pontisso et al., reported that 55\% with myeloid leukemia tested positive for hepatitis B prior to receiving any transfusion therapy (Pontisso, et al., 1987; Linet and Cartwright, 1996). 


\subsection{Cigarette Smoking}

An association between cigarette smoking and leukemia was not reported until the mid-1980s, decades after the association between smoking and lung cancer was first established in 1950 (Linet and Cartwright, 1996). In 1976, a 20 -year follow-up of 34,440 British doctors who replied to a questionnaire about their smoking habits failed to find an increase in leukemia among smokers (Doll and Peto, 1976). The 1982 United States Surgeon General's Report on the Health Consequences of Smoking reported that while cigarette smoking is a major cause of cancers of the lung, larynx, oral cavity, and esophagus, leukemia is not considered a tobacco-related cancer (U.S. Department of Health Services, 1982).

In 1986, in a review of several leukemia cohort and case-control studies, Austin and Cole suggested that sufficient epidemiological evidence existed to provide some support for the inference that cigarette smoking is a risk factor for leukemia (Austin and Cole, 1986). They noted that a 1977 case-control study that included 172 leukemia incident cases identified from the third National Cancer Survey Tumor Registry reported an increased risk of all leukemia (RR $=1.89 ; 95 \%$ CI $1.38,2.5)$ and an increased risk of myeloid leukemia $(\mathrm{RR}=2.09 ; 95 \% \mathrm{CI} 1.18$, 3.71) (Austin and Cole, 1986; Williams and Horm, 1977). They also cited a 1978 case-control study by Paffenbarger et al., of male Harvard and University of Pennsylvania alumni that included 96 lymphatic and myeloid leukemia deaths. They reported a statistically significant increased risk of all leukemias $(\mathrm{RR}=1.7 ; 95 \% \mathrm{CI} 1.1,2.7)$, and myeloid leukemia $(\mathrm{RR}=2.3$; 95\% CI 1.1, 4.6) but not of lymphatic leukemia ( $\mathrm{RR}=1.3$; 95\% CI 0.5, 3.2) (Austin and Cole, 1986; Paffenbarger, 1978; Siegle, 1993).

Garfinkel and Bofetta conducted two American Cancer Society prospective cohort mortality studies that included 1,387 leukemia deaths. They reported a positive association between myeloid leukemia and smoking in men in both studies $(\mathrm{SMR}=2.44$ and $1.32 ; \mathrm{p}<0.05)$ but not with smoking among women. They also reported no elevation in lymphatic leukemia mortality risk among men and women in both studies (Garfinkel and Boffetta, 1990). A meta-analysis of seven cohort and eight case-control studies published from 1970 to 1992 was conducted by Brownson et al., in 1993. They reported that the cohort study data suggested an elevated risk of myeloid leukemia associated with cigarette smoking $(\mathrm{RR}=1.4 ; 95 \% \mathrm{CI} 1.2,1.6)$ and that the case-control study data suggested an elevated risk of acute nonlymphocytic leukemia with cigarette smoking $(\mathrm{RR}=1.3 ; 95 \% \mathrm{CI} 1.1,1.5)$ (Brownson et al., 1993). In a 1993 review article, Siegel reported that most of the fifteen studies he reviewed supported an association between myeloid leukemia and smoking. He also reported that there is insufficient information to rule out a possible association between smoking and lymphatic leukemia or between acute and chronic leukemia types (Siegel, 1993). It is thought that constituents such as benzene found in tobacco smoke may be responsible for the increased risk of leukemia among smokers (Linet and Cartwright, 1996). 


\subsection{Solvent Exposure}

\subsubsection{Benzene}

Benzene was first isolated from coal tar Naphtha by Faraday in 1825. It is used for the manufacturing of some types of rubber, lubricants, dyes, and pesticides. Natural sources of benzene include volcanoes and forest fires. It is also a part of crude oil and cigarette smoke (Hunter, 1975; ATSDR, 1997). Delore and Borgomano described the first case of acute leukemia among benzene-exposed workers in 1928 (Rinsky et al., 1987). Since 1928, numerous studies have reported excess incidence of leukemia among workers employed in shoe, chemical, and rubber manufacturing, where exposure to benzene occurred. In 1989, Paci reported significantly elevated levels of mortality from acute leukemia among both men and women employed at a shoe manufacturing plant in Italy, which used adhesives that were prepared with benzene (Paci et al., 1989). In 1981, the National Institute for Occupational Safety and Health (NIOSH) conducted a retrospective cohort mortality study of 748 rubber workers exposed to benzene during the production of rubber hydrochloride at two Ohio facilities. The workers included in the study were exposed to benzene for at least one day between 1940 and 1950. The NIOSH researchers reported a five-fold excess risk of death from all types of leukemia combined and a ten-fold excess risk of death from myeloid and monocytic leukemias combined. They also reported that the duration of exposure to benzene was brief and 58\% of the cohort was exposed for less than one year (Rinsky et al., 1981). The findings of these studies were instrumental in the decision by the International Agency for Research on Cancer (IARC) to recognize benzene as a cause of AML in humans (IARC, 1981).

Subsequent cohort mortality studies of workers employed in chemical manufacturing and oil refineries and exposed to benzene in the United States (Wong, 1987; McCraw, 1985), the United Kingdom (Rushton and Alderson, 1981), and China (Yin et al., 1987) have also reported excess leukemia deaths among benzene-exposed workers.

\subsubsection{Carbon Tetrachloride}

Carbon tetrachloride has been used in the manufacture of fluorocarbon propellants, as a solvent for oils, fats, lacquers, varnishes, rubber waxes, and resins; as a degreasing and cleaning agent; and as a fumigant to kill insects in grain (Proctor and Hughes, 1996; ATSDR, 1994). Lynge et al. conducted a review of the epidemiological evidence on the relationship between organic solvents and cancer. They reported that there is some evidence of excess risk of lymphohematopoietic malignancies among workers exposed to carbon tetrachloride (Lynge, 1997). Wilcosky et al. analyzed the effect of multiple solvent exposures among a 6,678-member cohort of workers employed at a rubber and tire manufacturing plant. They conducted a case-control study comparing the exposure histories of a $20 \%$ age-stratified random sample of the cohort with the exposure histories of cohort members who died between 1964 and 1973 from stomach cancer, respiratory system cancer, prostate cancer, lymphosarcoma, and lymphatic leukemia. They reported that lymphatic leukemia was strongly related to carbon tetrachloride $(\mathrm{OR}=15.3$; $\mathrm{p}<0.0001)$ and carbon disulfide $(\mathrm{OR}=8.9 ; \mathrm{p}=0.0003)$ exposure (Wilcosky et al., 1984; 
Checkoway et al., 1984). Neither carbon tetrachloride nor carbon disulfide has been shown in other studies to be leukemogenic (Checkoway et al., 1984). The International Agency for Research on Cancer (IARC) has reported that there is sufficient evidence to conclude that carbon tetrachloride is an animal carcinogen, and inadequate evidence to support a conclusion that it is a human carcinogen (IARC, 1995).

\subsubsection{Ethylene Glycol}

Ethylene glycol is a solvent used in the paint and plastics industry. It is also used to make antifreeze and de-icing solutions for cars, airplanes, and boats (ATSDR, 1997). There are no studies to date that report an association between ethylene glycol and leukemia. However, Welch and Cullen conducted a study examining the effect of exposures to ethylene glycol ethers among a group of 73 shipyard painters and 40 controls. They reported that significant portions of the painters were anemic (10\%) and granulocytopenic (5\%), while none of the controls were affected (Welch and Cullen, 1988).

\subsubsection{Styrene and Butadiene}

Studies conducted primarily during the 1970s and 1980s first suggested a possible increased risk of lymphohematopoietic cancers among rubber industry workers exposed to styrene and butadiene (Lynge et al., 1997). However, excess leukemia among workers occupationally exposed to styrene and butadiene has not been reported consistently. McMichael et al. conducted a mortality study of 6,678 males employed at a single rubber manufacturing plant where styrene monomers and butadiene were processed. The study examined associations between specific causes of death and a history of having worked in certain job categories within the plant. They reported that lymphatic leukemias were significantly associated with solvent-exposure job categories such as finishing and repair (McMichael et al., 1976). In 1982, Meinhardt et al. conducted a mortality study of 2,756 workers employed at two styrene-butadiene rubber producing plants and reported a non-statistically significant elevation in leukemia mortality (Meinhardt et al., 1982). An update of this cohort completed in 1990 reported a small increase in leukemia mortality. The increase in leukemia mortality however, appeared among workers with smaller but not longer duration of solvent exposure. This finding appears inconsistent with a causal association (Lemen, 1990).

A cohort mortality study of 12,110 male workers employed for at least one year in eight styrenebutadiene polymer manufacturing plants in the United States and Canada and followed for vital status from 1943 through 1982 reported no excess in leukemia mortality (Matanoski et al., 1990). Also, a meta-analysis that included 17,448 workers with an average follow-up of 22 years conducted by Cole et al. in 1993 found little evidence of excess leukemia risk among workers exposed to styrene and butadiene $(\mathrm{SMR}=1.05 ; 95 \% \mathrm{CI} .74,1.46)$ (Cole et al., 1993).

A Danish cancer-incidence study that included 36,610 workers of 386 reinforced plastics companies and 14,293 workers not exposed to styrene from similar industries reported an 
increased excess risk of leukemia ( $\mathrm{SIR}=1.54 ; 95 \% \mathrm{CI}, 1.04,2.19)$ among individuals employed in the 1960s. During this period (which was the period of highest recorded styrene levels), the average recorded exposure level was $767 \mathrm{mg} / \mathrm{m} 3$ (Kolstad et al., 1994, Lynge et al., 1997).

\subsection{Ionizing Radiation-Atomic Bomb Exposures}

\subsubsection{Japanese Atomic Bomb Survivors}

The United States government, under the auspices of the National Academy of Sciences, established the Atomic Bomb Casualty Commission (ABCC) in Hiroshima and Nagasaki in 1947 and 1948, respectively. The ABCC, which was reorganized in 1975 into the Radiation Effects Research Foundation (RERF), established the Life Span Study (LSS) in 1950 to study the health effects on individuals who were exposed to atomic bomb radiation (Shigematsu, 2000). Subjects included in the LSS included atomic bomb survivors who were residing in Hiroshima or Nagasaki at the time the first nationwide survey of survivors was conducted in 1950. The LSS study population of 120,128 individuals includes 91,228 individuals exposed to radiation, 26,517 who were not in either city at the time of the bombing, and 2,383 individuals for whom a radiation dose could not be estimated (Shimizu et al., 1990). Through 1990, the LSS has documented 249 leukemia deaths from approximately 2,735,335 person-years of follow-up (Pierce et al., 1996). Approximately 55\% of the leukemia occurrence among the survivors from 1950 through 1985 was attributable to radiation exposure from the bombs. This is a proportion far greater than estimated for other cancers (Shimizu et al., 1989; Linet and Cartwright, 1996). The LSS reported that mortality is significantly elevated for acute myelogenous leukemia (AML), chronic myelogenous leukemia (CML), and acute lymphoblastic leukemia (ALL). For individuals who were under the age of 30 at the time of the bomb detonation, ALL is the most prevalent type of leukemia. AML is the most prevalent for those who were age 45 and older at the time of the bomb blast (Shimizu et al., 1989). Mortality from CML peaked within five years of exposure and the relative risk of developing CML was greater in younger individuals (younger than 15 years of age at the time of the bomb blast) than in older individuals (Linet and Cartwright, 1996). The study also demonstrated that the younger a person was at the time of the blast, the greater the risk of leukemia in the first few years after the blast and the more rapid the decline in risk in later years (BEIR V, 1990). The LSS has not shown an association with chronic lymphocytic leukemia (CLL), however; this could be due to the very low background rates of CLL among the Japanese (UNSCEAR, 2000).

\subsubsection{Military Personnel Present During Nuclear Weapons Testing}

Epidemiologic studies of military personnel who were present at several above- ground nuclear tests have shown conflicting results with respect to leukemia risk (Schubauer-Berigan and Wenzl, 2001). A 1979 Centers for Disease Control and Prevention (CDC) report indicated that military personnel who participated in the 1957 above-ground nuclear test in Nevada (SMOKY) had an excess of leukemia cases when compared to individuals of the same age and sex in the general population (CDC, 1979). A follow-up study of this cohort in 1983 reported no excess in total cancer among 3,017 of the 3,217 military participants. Leukemia was the only cancer that 
was significantly elevated. The study reported a 2.5-fold increase in leukemia, primarily AML and CML, among individuals with cumulative gamma radiation exposures (measured by individual film badges) that ranged from 0-10,397 mrem (Caldwell, 1983; Watanabe, 1995, Linet and Cartwright, 1996). Leukemia mortality however, has not been elevated in other cohorts of military personnel involved in other above-ground tests. A 1985 survey by Robinette et al., of 46,186 military personnel who participated in two above-ground tests at the Nevada Test Site (NTS) and three in the Pacific Ocean reported no excess of non-leukemia deaths. Excluding the 1957 (SMOKY) test, the survey reported 46 leukemia deaths vs. 52.4 expected (Boice and Inskip, 1996). It is possible that the leukemia excess among SMOKY participants was due to chance or circumstances peculiar to that test (Boice and Inskip, 1996; Linet and Cartwright, 1996).

A mortality study of British military and civilian personnel who participated in the United Kingdom's atmospheric nuclear weapon tests and experimental programs was conducted by Darby et al. in 1994. The study which included 21,358 military and civilian personnel reported no excess mortality due to leukemia or multiple myeloma (Darby et al., 1993).

\subsection{Ionizing Radiation-Occupational Studies of United States, British, and Russian Nuclear Workers}

During the past 25 years there have been multiple studies examining the association between leukemia and ionizing radiation among workers employed in a variety of areas of the nuclear industry in the United States, Great Britain, and the former Soviet Union. British cohorts are often smaller and the exposures in some British cohorts are greater than many of those in U.S. studies. While several important studies of leukemia and other cancers have been conducted in the former Soviet Union, these cohorts of nuclear workers have much higher radiation exposures than either the U.S. or British cohorts (Schubauer-Berigan and Wenzl, 2001).

\subsubsection{The United States Department of Energy Hanford Facility}

The Hanford Facility was established in 1942 on 360,000 acres in southeast Washington State. During its operation, the primary functions of the plant included the fabrication of nuclear reactor fuel, the operation of nine nuclear reactors and five isotope separation facilities, and the fabrication of plutonium components for nuclear weapons (U.S. Department of Energy, 1997). There have been several large cohort mortality studies of Hanford workers since the late 1970's that have examined an association between ionizing radiation exposure and leukemia mortality (Schubauer-Berigan and Wenzl, 2001). A 1977 mortality study conducted by Mancusco et al. of 24,939 male workers employed from 1944 through 1972 reported that workers who died of leukemia and other lymphatic neoplasm's had received higher cumulative radiation doses compared to workers who died of other cancers and non-cancers (Mancusco, 1977). A reanalysis of the data used in the Mancusco study was done by Hutchinson et al. in 1979. They conducted the analysis while adjusting for age and calendar year of death which reduced the number of cancer sites exhibiting a dose response relationship with radiation. They reported no 
relationship between lymphatic and hematopoietic cancers other than myeloma (Hutchinson et al., 1979). Several other studies have reported no association between radiation exposure and leukemia among Hanford workers. Gilbert and Marks conducted a mortality study of 12,522 radiation-monitored white male workers employed at Hanford for at least two years from 1944 through 1965, with vital status follow-up through 1974. They reported no excess leukemia mortality among the workers, and no association between leukemia mortality and levels of radiation exposure (Gilbert and Marks, 1979). In 1993, Gilbert, et al. reported no excess leukemia mortality among 32,643 male and female radiation-monitored Hanford workers employed for at least six months from 1944 through 1978. They also reported no positive association between cumulative radiation exposure and leukemia mortality among these workers (Gilbert et al., 1993).

\subsubsection{The United States Department of Energy Savannah River Plant}

The Savannah River Plant is located on 192,000 acres, approximately 13 miles south of Aiken, South Carolina. The facility was built in the early 1950's and its primary purpose was to produce, purify, and process radioisotopes such as plutonium and tritium. To accomplish this, the site operated five nuclear reactors and two chemical separation plants (U.S. Department of Energy, 1997). Cragle et al. conducted a mortality study of 6,687 hourly and 2,745 salaried white male production workers employed at Savannah River for at least 90 days from 1952 to 1974, with vital status follow-up through 1980. They reported non-statistically significant elevation in mortality from all leukemias combined among salaried workers $(\mathrm{SMR}=1.05)$ and hourly workers $(\mathrm{SMR}=1.63)$. They did report a statistically significant increase in leukemia mortality among hourly employees first hired before 1955 and employed between 5 and 15 years (SMR = 2.75; 95\% CI 1.01, 5.99) (Cragle et al., 1988).

In 1998, Cragle et al. updated this mortality study by including six additional years of follow-up. Using a two-year lag period, they reported a significant trend of increased leukemia mortality with increased radiation exposure among the 20 non-CLL leukemia deaths (Chi-square $1 \mathrm{df}$ $=3.86, \mathrm{p}<0.05)$. They also reported an elevated excess relative risk of $13.6 \%(90 \% \mathrm{CI} 0.61$, 50.62) per $10 \mathrm{mSv}$ of cumulative dose for non-CLL cases (Cragle et al., 1999; SchubauerBerigan and Wenzl, 2001). [Sievert (Sv) is the measure of dose equivalent in SI. It is the product of absorbed dose in grays and a weighting factor for radiation type. (Borders, 1991)]

\subsubsection{The United States Department of Energy Oak Ridge National Laboratory (ORNL)}

The Oak Ridge facility is located on 58,000 acres, approximately 20 miles west of Knoxville, Tennessee. Established in the early 1940s, its primary functions have included lithium enrichment and storage, and the production of enriched and commercial grade uranium, ceramic weapons components, and radioisotopes (U.S. Department of Energy, 1997). Wing et al. conducted a mortality study of 8,318 white men employed for at least 30 days at the Oak Ridge National Laboratory from 1943 to 1972, who were followed up for vital status through 1984. They reported a significant increase in leukemia mortality in all workers (SMR $=1.63$; 95\% CI 
$1.06,2.35)$ and workers who were monitored for exposure to internal radiation $(\mathrm{SMR}=2.23$; 95\% CI 1.27, 3.62) (Wing et al., 1991). Frome et al. conducted a mortality study of 28,347 white males employed for at least 30 days at either the Oak Ridge National Laboratory or the Oak Ridge Y-12 facility from 1943 to 1985, who were followed up for vital status through 1985. They reported no positive association between leukemia mortality and external ionizing radiation exposure among the workers (Frome et al., 1997). Gilbert et al. conducted a multi-site mortality study of radiation-monitored workers that included 32,643 male and female Hanford workers, 6,348 male Oak Ridge National Laboratory workers, and 5,952 male workers from the Rocky Flats Weapons Plant in Colorado. They reported no exposure related increase in leukemia mortality risk for the three sites combined (Gilbert et al., 1993).

\subsubsection{The Department of Energy Los Alamos National Laboratory}

The Los Alamos National Laboratory (LANL) covers 75 square miles in northern New Mexico. Established in 1943, its primary functions included the design and development of nuclear weapons and nuclear weapons components, and the production of small quantities of plutonium metal. The current focus at LANL is academic and industrial research (U.S. Department of Energy, 1997). Wiggs et al. conducted a mortality study of 15,727 white males employed at LANL from 1943 through 1977, with no restriction on employment duration, and with follow-up for vital status through 1994 . They reported that leukemia mortality was not significantly elevated among the workers $(\mathrm{SMR}=1.01 ; 95 \%$ CI $0.73,1.35)$. Among the 8,318 workers who were monitored for external ionizing radiation exposure, they reported a nonsignificant positive trend between increasing exposure and lymphocytic leukemia mortality but not myeloid leukemia mortality (Wiggs et al., 1994).

\subsubsection{The Mallinckrodt Chemical Works}

The Mallinckrodt Chemical Works was located in St. Louis, Missouri, and processed uranium that was used a fuel for the first nuclear reactors and in the first atomic bomb that was dropped on Hiroshima. In 1957, the St. Louis plant was closed and moved to Weldon Springs, Missouri, where production continued until the plant was closed in 1966 (U.S. Department of Energy, 1997). Dupree-Ellis et al. conducted a mortality study of 2,514 radiation-monitored white males employed at the Mallinckrodt facility for at least 30 days from 1942 to 1966, who were followed for vital status through 1993. They reported a nonstatistically significant elevation in leukemia mortality (SMR = 1.11; 95\% CI 0.57, 1.89) (Dupree-Ellis, et al., 2000; Schubauer-Berigan and Wenzl, 2001).

\subsubsection{British Nuclear Worker Studies_-The Sellafield Plant}

The Sellafield plant, owned by British Nuclear Fuels, began operation in 1947 for the production of plutonium for nuclear weapons (Omar, 1999). Smith and Douglas conducted an initial mortality study of 14,327 workers employed at the facility from 1947 to 1975 , and followed them for vital status through the end of 1983. They reported no leukemia excess among the workers (Smith and Douglas, 1986). However, in a follow-up study by Douglas et al. that 
extended vital status follow-up through 1988, a significant positive association between cumulative external radiation exposure and leukemia mortality (two-year lag; $p=0.009$ ) was reported among the 10,276 radiation workers. The average cumulative exposure of the radiation workers was $128.1 \mathrm{mSv}$ (Douglas et al., 1994). Omar et al. updated the study by adding a year of follow-up to the cohort; they also reported a significant positive association between cumulative external radiation exposure and leukemia mortality (no lag; $p=0.03$ : two-year lag; $p=0.05$ ) (Omar, 1999).

\subsubsection{The United Kingdom's National Registry for Radiation Workers (NRRW)}

Established in 1976, this national registry currently includes approximately 125,000 British men and women who have been exposed to ionizing radiation and for whom exposure records were kept. Nuclear workers included in the registry were employed at nuclear weapons production facilities, defense facilities, nuclear medicine production companies, and nuclear utility companies (Muirhead et al., 1999; Schubauer-Berigan and Wenzl, 2001). Kendall et al. conducted a mortality study that included 95,217 radiation workers employed by five major British nuclear industry facilities who participated in the NRRW. They reported a significant positive association between cumulative external radiation exposure and non-CLL leukemia mortality $(p=0.03)$ (Kendall et al., 1992). The excess leukemia risk however, was evident at only one of the five facilities (Sellafield) included in the study (Boice and Inskip, 1996).

Muirhead et al. conducted a second NRRW study which included an expanded cohort of 124,743 workers, with vital status follow-up extended through the end of 1992 for all workers. They reported borderline evidence of a positive association between cumulative external radiation exposure and non-CLL leukemia mortality $(p=0.067)$ (Muirhead et al., 1999).

\subsubsection{Russian Nuclear Workers- The Mayac Production Complex}

The Mayac production complex was the first nuclear complex built in the former Soviet Union. The complex, located in the Southern Ural Mountains, began operation in 1948 and included a nuclear reactor, a radiochemical plant for the chemical separation of plutonium from irradiated nuclear fuel, and a plutonium production plant (Koshurnikova, 1999). It has been reported that there were several technological failures during the early years of operation that resulted in large releases of radionuclides, exposing workers and local populations (Kossenko et al., 2000). It has also been reported that $6.5 \%$ of the nuclear reactor workers and $22.8 \%$ of workers employed in the radiochemical plant working from 1948 to 1953 received annual doses equal to or greater than 1Gy (Schubauer-Berigan and Wenzl, 2001). Koshurnikova et al. conducted a mortality study of 8,855 Mayak workers employed from 1948 through 1972. They reported no excess leukemia mortality risk among reactor workers or plutonium production workers. They did report a statistically significant excess in leukemia mortality among the 1,839 males who worked in the radiochemical processing facility $(\mathrm{SMR}=3.17$; 95\% CI 1.45, 6.93) (Koshurnikova, et al., 1996). A major limitation of the Mayac worker mortality studies is lack of a well developed national disease rate tracking system in the former Soviet Union (Schubauer-Berigan and Wenzl, 2001). 


\subsubsection{The Chernobyl Clean-Up Workers}

The Chernobyl Nuclear Power Plant accident occurred on April 26, 1986, and resulted in largescale fires, explosions, and both immediate and delayed deaths of plant operators and emergency service workers called to the site. Large amounts of radioactive nuclides that included krypton, xenon, cesium, iodine, strontium, and plutonium were released, contaminating a large land area surrounding the plant (Ginzburg and Reis, 1991). Following the accident, 600,000 workers were sent to the site to clean up the environment and entomb the reactor. Typical occupational exposures for the workers were stated to be $0.35 \mathrm{~Gy}$. [Gray (Gy) is the name of the SI unit of absorbed dose. $1 \mathrm{~Gy}=1 \mathrm{~J} \mathrm{Kg}-1=100 \mathrm{rad}$ (Boice and Inskip, 1996)]. To date there have been no significant additional cancers reported among the clean-up workers (Goldman, 1997). Rahu et al. conducted a mortality study of 4,742 men from Estonia who had participated in the Chernobyl cleanup from 1986 to 1991 . They reported a total of 144 deaths were observed (SMR $=0.98$; $95 \%$ CI $0.82,1.14)$ and no increased incidence of either all cancers (25 incident cases observed vs. 26.5 expected) or leukemia (no cases observed vs. 1.0 expected) (Rahu et al., 1997).

\subsection{Exposures from Medical X-Ray Treatment}

\subsubsection{Ankylosing Spondylitis}

There have been several mortality studies of British patients diagnosed with ankylosing spondylitis who received x-ray therapy as a treatment (Brown and Doll, 1965; Radford et al., 1977; Smith et al., 1982). Ankylosing spondylitis is a progressive rheumatic disease that mainly affects the spine and is characterized by the fusion of joints and bones (Taylor, 1988). Darby et al. conducted a mortality study that included 14,106 British patients with ankylosing spondylitis who had been given a single course of x-ray treatment during 1935 and 1954 . They reported a three-fold increase in leukemia mortality, and that mortality risk was highest from 2.5 to 4.9 years after the treatment (Darby et al., 1987). Weiss et al. conducted a mortality study of 15,577 adult ankylosing spondylitis patients, of whom 14,556 had received radiation treatment typically given once a day for a two-week period. The vital status of the patients was followed through 1991. They reported that among the patients receiving radiation therapy there was a significant increase in leukemia mortality $(\mathrm{RR}=2.74,95 \% \mathrm{CI} 2.10,3.53)$ (Weiss et al., 1994).

\subsubsection{Cervical and Uterine Cancer Treatment}

Radiation therapy for the treatment of cervical and uterine cancers involves extensive exposure of the active bone marrow to ionizing radiation and has been linked in some studies to the development of secondary leukemia. Boice et al. examined the frequency of occurrence and type of second cancers among 182,040 women treated for cervical cancer. They reported that among the 82,616 women who were treated with fractionated doses of radiation from 1935 to 1970 , there was a 1.3-fold excess of acute and non-lymphocytic leukemia (Boice et al., 1985). Curtis et al. examined 110,000 women who were diagnosed with invasive uterine cancer from 1935 through 1985 and received partial-body radiation therapy. They reported that radiotherapy did not increase the risk of CLL $(\mathrm{RR}=0.90 ; 95 \%$ CI $0.4,1.9)$. However, for all leukemias combined 
excluding CLL, they reported a significant risk of leukemia $(R R=1.92 ; 95 \%$ CI 1.3, 2.9) (Curtis et al., 1994).

\subsubsection{Breast Cancer}

Excess incidence of AML has been reported in studies of breast cancer patients treated with radiation therapy during oncology clinical trials (Fisher et al., 1985; Linet and Cartwright, 1996). Andersson et al. conducted a study of the incidence of new primary cancers among 3,538 postmenopausal Danish patients who had received surgical treatment for primary breast cancer. They reported an increased incidence of AML among the patients who received postoperative radiotherapy (Andersson et al., 1991; Linet and Cartwright, 1996). Curtis et al. conducted a nested case-control study that included 48 women diagnosed with breast cancer from 1935 to 1972 who received radiation therapy and later developed leukemia. They reported that radiation therapy did not increase the overall risk of leukemia $(\mathrm{RR}=1.16 ; 90 \% \mathrm{CI}, 0.6,2.1)$ (Curtis et al., 1989). Curtis et al. conducted another case-control study in 1992 that included 90 women diagnosed with breast cancer from 1973 to 1985 who received radiation therapy and were later diagnosed with leukemia. They reported that the risk of leukemia was significantly increased for women who received radiation therapy only without alkylating agents (Curtis et al., 1992).

\section{Occupations Associated with Increased Risk of Leukemia}

\subsection{Radiologists and $X$-Ray Technicians}

Smith and Doll conducted a mortality study of males who joined the British Radiological Society from 1897 to 1954 . They reported that radiologists who entered the profession prior to 1921 suffered a six-fold increase in leukemia mortality risk, while individuals who entered the profession after 1921 had no increase in leukemia mortality risk (Smith and Doll, 1981; Linet and Cartwright, 1996). Matanoski et al. conducted a mortality study of U.S. radiologists who joined the Radiological Society of North America over a 50-year period beginning in 1920. They reported that radiologists who joined the society from 1920 to 1929 had an 8.8-fold increase in leukemia mortality and radiologists who joined between 1930 and 1939 had a 3.4-fold increase in leukemia mortality. They reported no excess leukemia mortality among radiologists who joined the society after 1940 (Matanoski et al., 1975; Linet and Cartwright, 1996). Other mortality studies of U.S. radiologists (Logue et al., 1986) and radiologic technologists (Doody et al., 1998) have reported no increase in leukemia mortality among workers employed after 1940 (Schubauer-Berigan and Wenzl, 2001).

\subsection{Garage and Transportation Maintenance Workers}

Some studies have reported a possible increase in leukemia mortality risk among highway transportation maintenance workers (Linet and Cartwright, 1996). The Minnesota Department of Health conducted a cohort mortality study of 4,849 workers employed by the Minnesota Highway Maintenance Department from 1945 to 1984. Leukemia mortality was significantly elevated $(\mathrm{SMR}=4.25 ; 95 \% \mathrm{CI} 1.71,8.76)$ among workers employed 30 to 39 years (Bender, 
1989). The American Cancer Society conducted a prospective mortality study of 461,981 males ages 40 to 79 who were exposed to diesel exhaust and reported an association based on small numbers with increased leukemia mortality (Boffetta et al., 1988). It is thought that a possible increased risk of leukemia among maintenance workers reported in these studies could be due to a variety of exposures such as diesel fuels, asphalts and tars, herbicides, gasoline, aromatic hydrocarbons, and benzene (Linet and Cartwright, 1996).

\subsection{Painters}

Painters are exposed to various complex mixtures, including dyes, pigments, and organic solvents with known carcinogenic potential (Bethwaite et al., 1990). In 1989, the International Agency for Research on Cancer (IARC) determined that there was sufficient evidence that certain cancers could result from occupational exposures as a painter (IARC, 1989). Matanoski et al. conducted a cohort mortality study of 57,175 members of the International Brotherhood of Painters and Allied Trades (IBPAT) who were employed in the United States from 1975 through 1979. Members of the cohort were categorized into mixed local unions that were composed primarily or exclusively of painters and specialty local unions that included members of specific allied trades such as glaziers, tile and carpet layers, and wood finishers. The mortality experience of members of the mixed local unions was compared to that of the specialty local unions and a statistically significant difference in leukemia mortality was reported (SMR $=1.23$ for the mixed group; $\mathrm{SMR}=.51$ for the specialty group; $p=0.022$ ) (Matanoski et al., 1986). A case-control study that included 125 Swedish adults diagnosed with acute leukemia and 125 matched controls reported that regular exposure to solvents is associated with an increase risk of developing acute leukemia. The study also reported that painters whose median time of solvent exposure was 16 years had the greatest increased risk $(\mathrm{OR}=13 ; 95 \% \mathrm{CI} 2.0,5.54)$ of acute leukemia (Lindquist, 1987). Bethwaite et al. conducted a series of case-control studies whose cases and controls were selected from a group of 19,904 individuals over the age of 20 and listed on the New Zealand cancer registry from 1980 to 1984 . The goal of the study was to examine a possible association between cancer mortality from different types of cancer (including leukemia) and work as a painter. The study reported no increased risk of leukemia mortality $(\mathrm{OR}=0.54 ; 95 \% \mathrm{CI} 0.23$, 1.30) among painters (Bethwaite et al., 1990). It is thought that a variation in the composition of the paint used in Sweden and New Zealand may possibly account for the different findings reported by Lindquist and Bethwaite (Linet and Cartwright, 1996). A meta-analysis conducted by Chen and Seaton in 1998 reported excess leukemia risk among painters (SMR $=187 ; 95 \% \mathrm{CI}$ 114.5, 306.7). The excess deaths from leukemia however, could have been due to exposure to benzene mixed with other organic solvents (Chen and Seaton, 1998).

\subsection{Welders}

Welders are exposed to a variety of airborne contaminants, depending upon the specific technology and materials used in the welding process. Some epidemiological studies have reported elevated leukemia risk among welders (Linet and Cartwright, 1996). In a review of eleven epidemiologic surveys that examined leukemia and occupational exposure to 
electromagnetic fields, Savitz and Calle reported no elevated risk among welders from all leukemias $(\mathrm{RR}=0.9 ; 95 \% \mathrm{CI} 0.7,1.2)$, or acute leukemia $(\mathrm{RR}=1.0 ; 95 \% \mathrm{CI} 0.7,1.5)$ and a nonstatistically significant elevation in acute myelogenous leukemia $(\mathrm{RR}=1.7: 95 \% \mathrm{CI} 0.5,4.5)$ (Savitz and Calle, 1987). A case-control study of 130 CML patients in Los Angeles County, California, reported a significant association between occupation as a welder and CML (Crude $\mathrm{OR}=19 ; 95 \%$ CI 2.78, 232.54) (Preston-Martin and Peters, 1988). A nested case-control study within a population of 24,545 male nuclear shipyard workers in Portsmouth, New Hampshire reported an elevated risk of all leukemia $(\mathrm{OR}=2.3 ; 95 \% \mathrm{CI} 0.92,5.5)$ and a statistically significant increased risk of myeloid leukemia $(\mathrm{OR}=3.8 ; 95 \% \mathrm{CI} 1.3,11.5)$ among welders (Stern et al., 1986). Because there is limited evidence in humans and inadequate evidence in experimental animals for the carcinogenicity of welding fumes and gases, the International Agency for Research on Cancer (IARC) has concluded that welding fumes are only possibly carcinogenic to humans (IARC, 1990).

\subsection{Electrical Workers}

Epidemiological studies have inconsistently reported a positive association between electromagnetic field exposure and leukemia among electrical workers (Villeneuve et al., 2000). Coleman and Beral conducted a review of eleven studies conducted from1978 to 1988 that examined the health effects of exposure to extremely low frequency (ELF) non-ionizing electromagnetic fields. They performed a pooled analysis of these studies and reported an excess risk of leukemia $(\mathrm{RR}=1.18 ; 95 \% \mathrm{CI} 1.09,1.29)$ and acute myeloid leukemia $(\mathrm{RR}=1.46 ; 95 \%$ CI 1.27, 1.65) among electrical workers (Coleman and Beral, 1988). It was not possible to determine from these studies if the elevated leukemia was due to electromagnetic fields or other exposures such as benzene, or if the increase is specific to certain jobs within the electrical industry (Shore, 1988 and Theriault, 1992). A New Zealand case-control study of 110 incident leukemia cases diagnosed between 1989 and 1991 reported an elevated risk of acute leukemia among electrical workers $(\mathrm{OR}=1.9 ; 95 \% \mathrm{CI} 1.0,3.8)$. An exposure-response effect was also reported with acute leukemia rising with increasing occupational magnetic field exposure (Bethwaite et al., 2001). In 1989, a series of case-control studies were conducted involving 19,904 male cancer patients over the age of twenty and diagnosed from 1980 to 1984 from the New Zealand Cancer Registry. An elevation in leukemia risk among electrical workers $(\mathrm{OR}=$ $1.62 ; 95 \%$ CI 1.04, 2.52) was reported, which was primarily due to chronic leukemia (OR = 2.12), not acute leukemia (Pearce et al., 1989). A study of active-duty naval personnel from 1974 to 1984 reported a small elevated incidence of leukemia among individuals employed as electrician's mate (SIR $=2.4 ; 95 \%$ CI 1.0, 5.0) (Garland, 1990). Other studies of electrical workers have reported no excess risk of leukemia. A nested case-control study of Norwegian railway workers, however, reported no elevation in leukemia mortality among men employed on electric railways compared with those employed on non-electric railways (Tynes et al., 1994). A cohort study of 138,905 men employed at five electric power companies in the United States from 1950 to 1986 did not support an association between leukemia and occupational magnetic field exposure (Savitz and Loomis, 1995). Also, a case-cohort analysis of male electric utility 
workers who died of leukemia selected from this cohort of 138,905 reported no association between leukemia and electromagnetic field exposure (Savitz et al., 2000). 


\section{Appendix B - Tables}

Table 1: Cancer Mortality in the United States (Males) 1950-1991

Cancer Mortality in the United States

Changing Patterns for 11 Major Cancers in U.S. Males, 1950-1991

Death Rates for Males, per 100,000, for 11 Sites

1950-1991, Age-adjusted to 1970 U.S. Standard Population
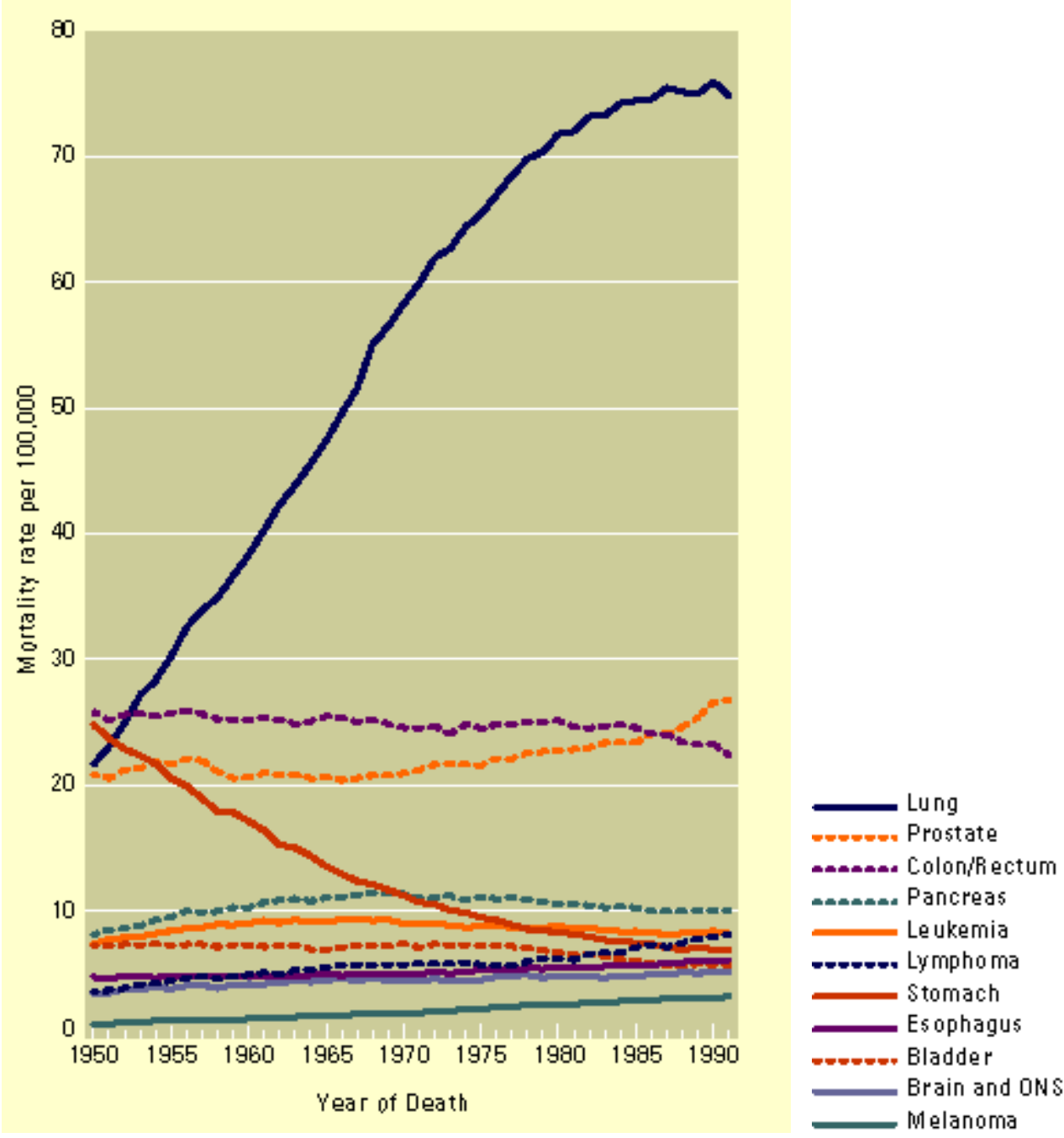
Table 2: Cancer Mortality in the United States (Females) 1950-1991

\section{Cancer Morality in the United States \\ Changing Patterns for 12 Major Cancers in U.S. Females, 1950-1991}

Death Rates for Females, per 100,000, for 12 Sites, 1950-1991, Age-adjusted to 1970 U.S. Standard Population

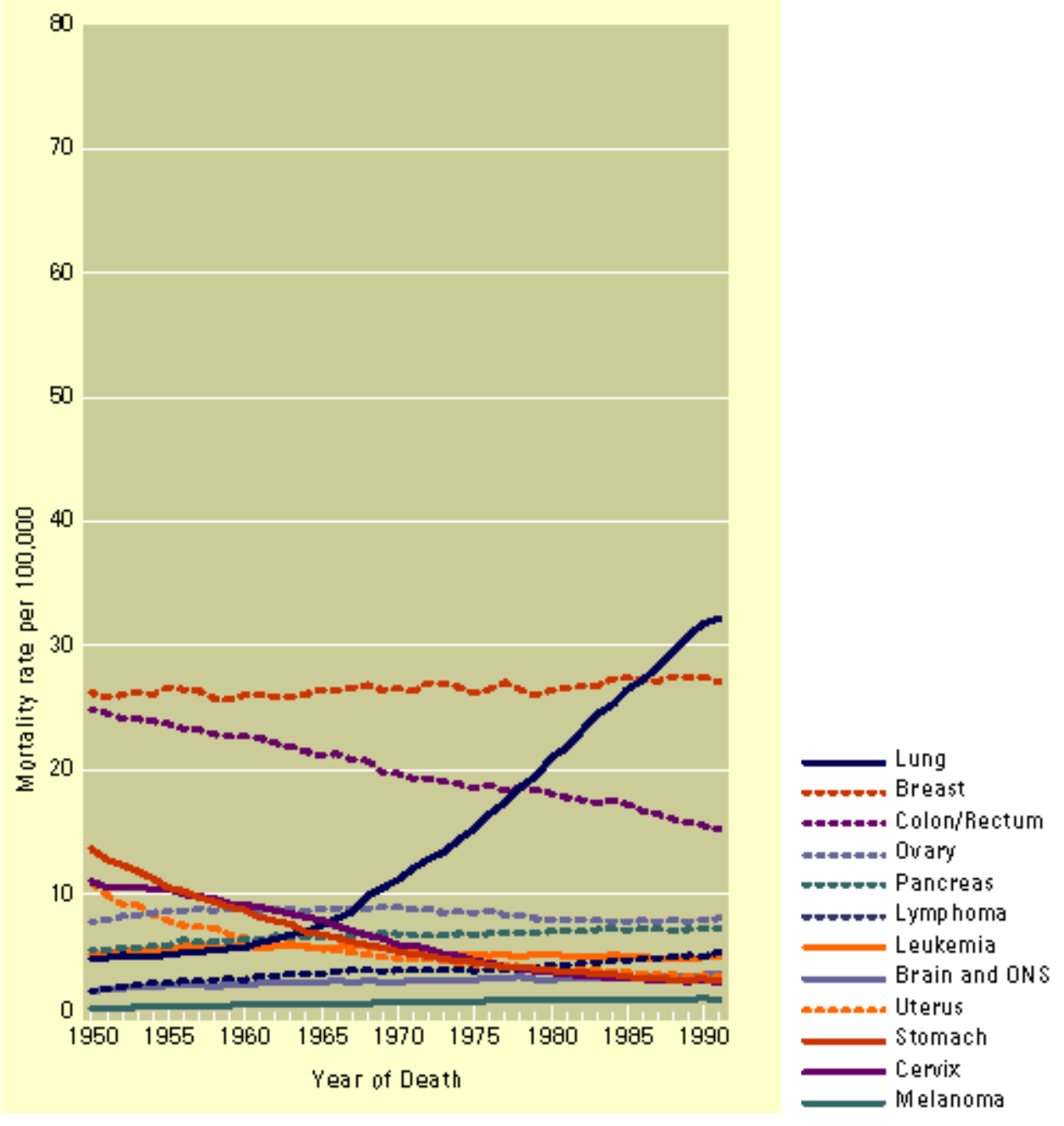


Table 3: Mortality—All Leukemia Types Combined—Males

All Leukemia Types Combined-Males

U.S. Mortality Age-Adjusted Rates-1973-1999

Standard Population $=2000$ U.S.

Age at death $=$ All Ages

(Rates are from the NCHS public use data file)

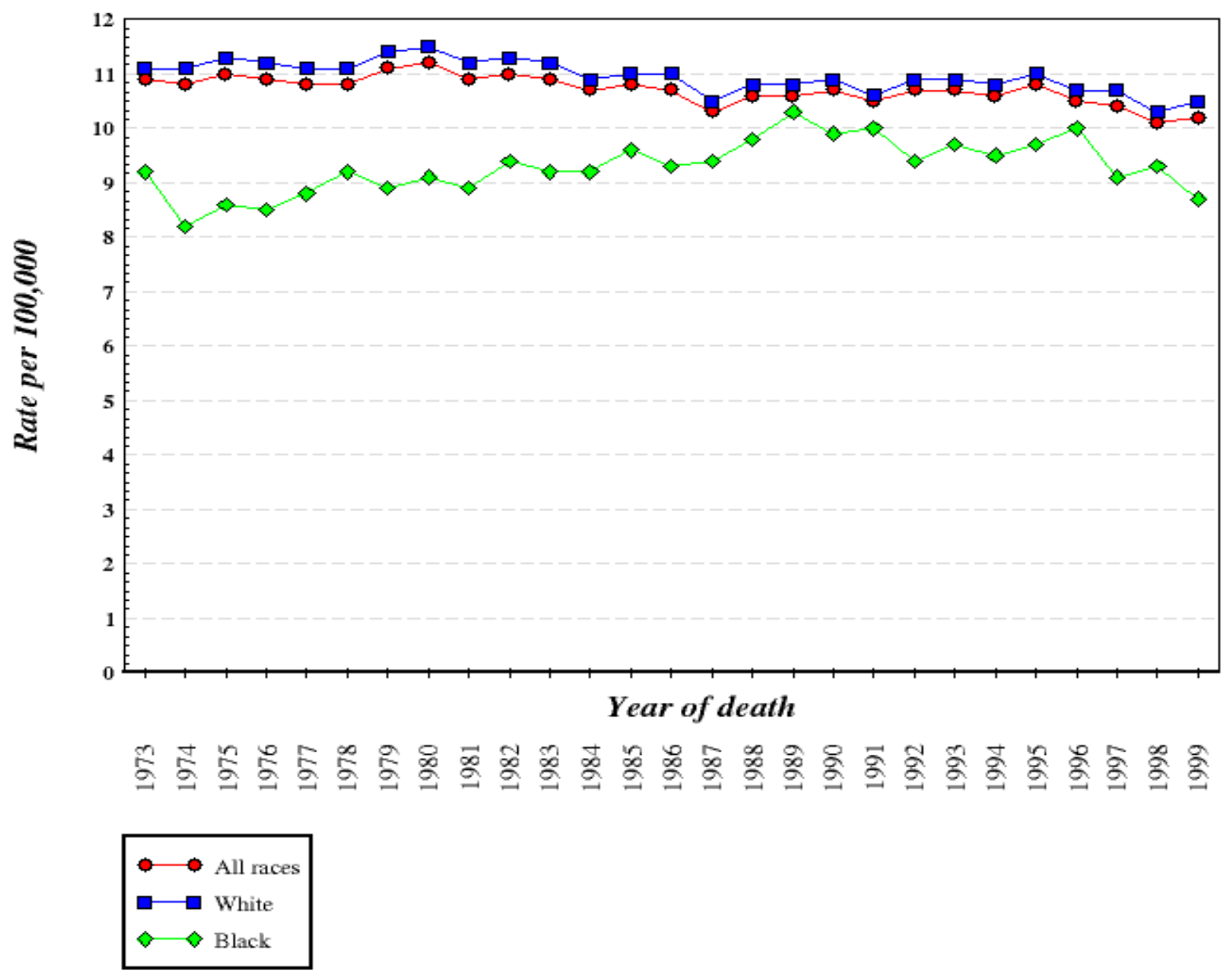


Table 4: Mortality_All Leukemia Types Combined_Females

All Leukemia Types Combined-Females

U.S. Mortality Age-Adjusted Rates-1973-1999

Standard Population $=2000$ U.S.

Age at Death $=$ All Ages

(Rates are from the NCHS public use data file)

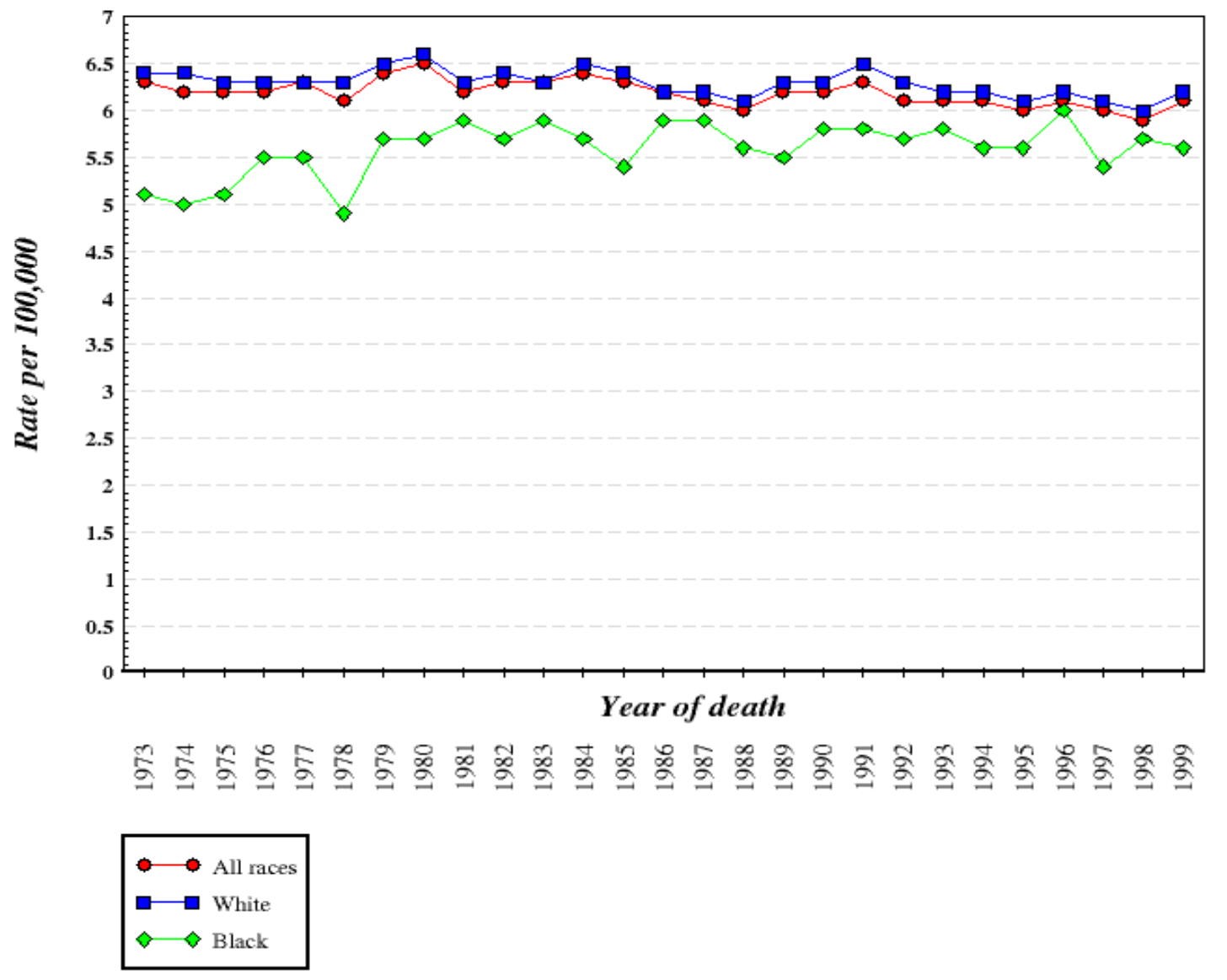


Table 5: SEER Incidence and Mortality Rates-1973-1999

SEER Incidence and Mortality Rates for All Leukemia Types Combined:

White and Black Males and Females

1973-1999 (Reis et al., 2002)

SEER Incidence and U.S. Death Rates ${ }^{+}$

\section{Leukemias}
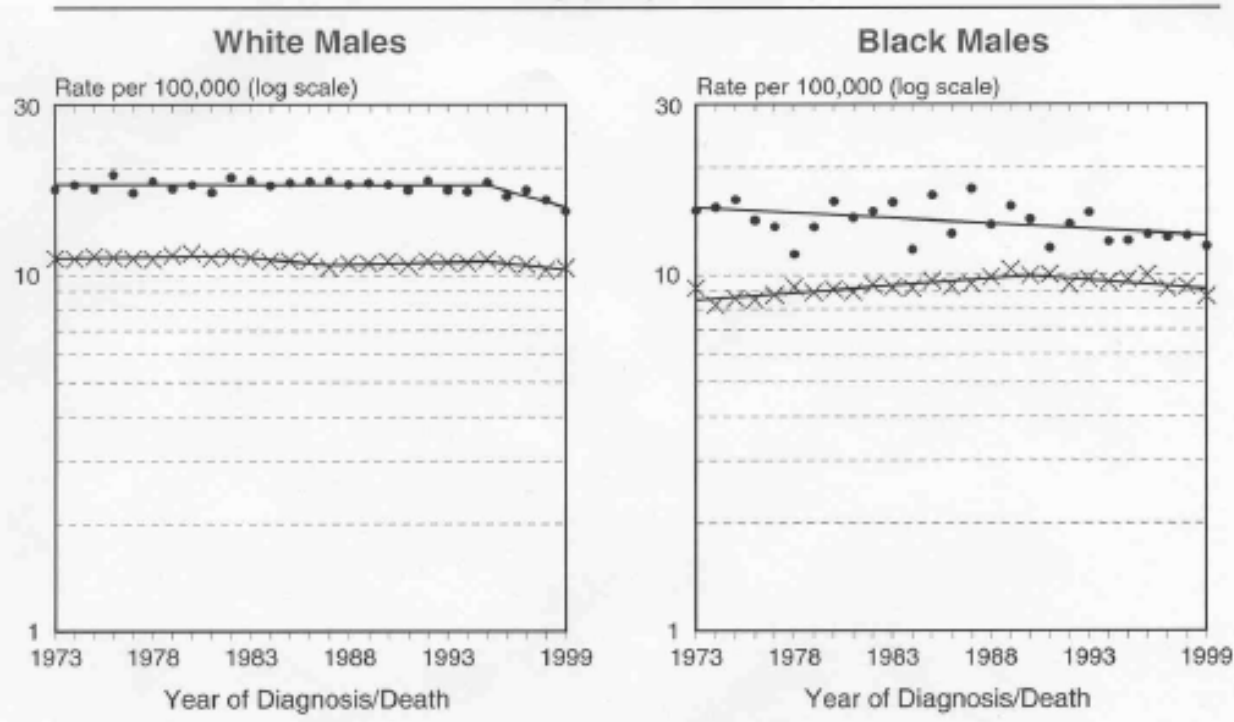

White Females

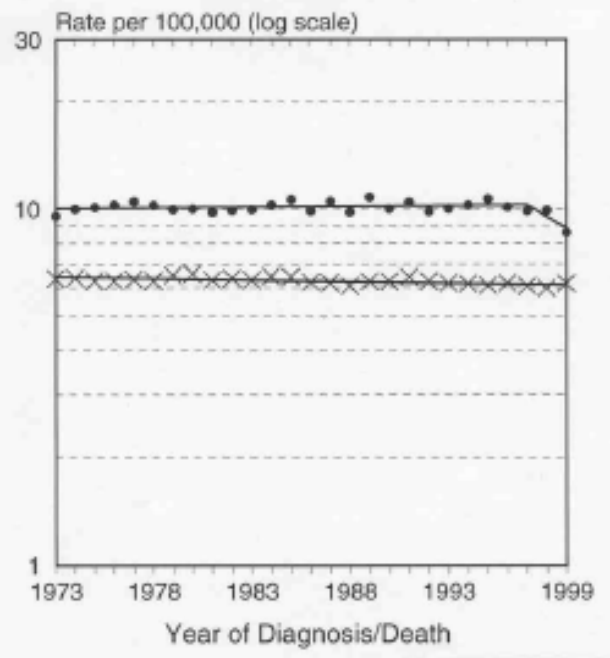

Black Females

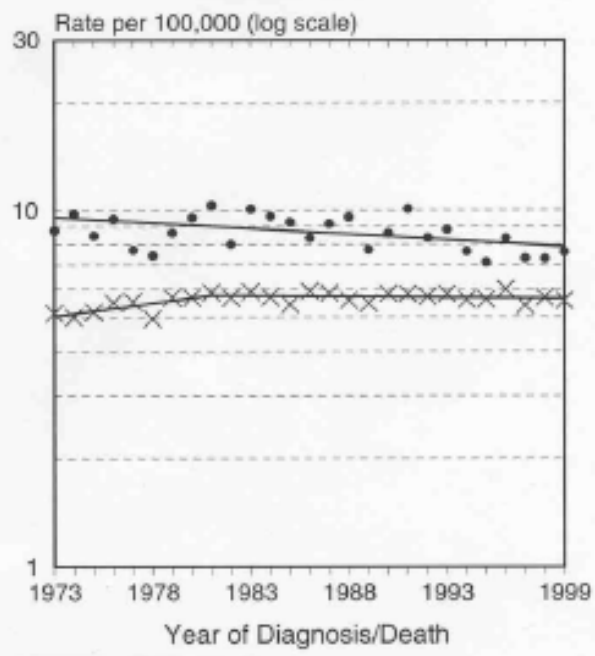

\section{- Incidence $\times$ Mortality}

+ Source: SEER 9 areas and NCHS public use data file. Rates are age-adjusted to the 2000 U.S. standard million population by 5-year age groups. Regression lines are calculated using the Joinpoint Regression Program. 
Table 6: Acute Myeloid Leukemia—Incidence—1973-1999

Acute Myeloid Leukemia-Incidence

SEER Incidence Age-Adjusted Rates

Standard population $=2000$ U.S.

Year of diagnosis $=1973-1999$

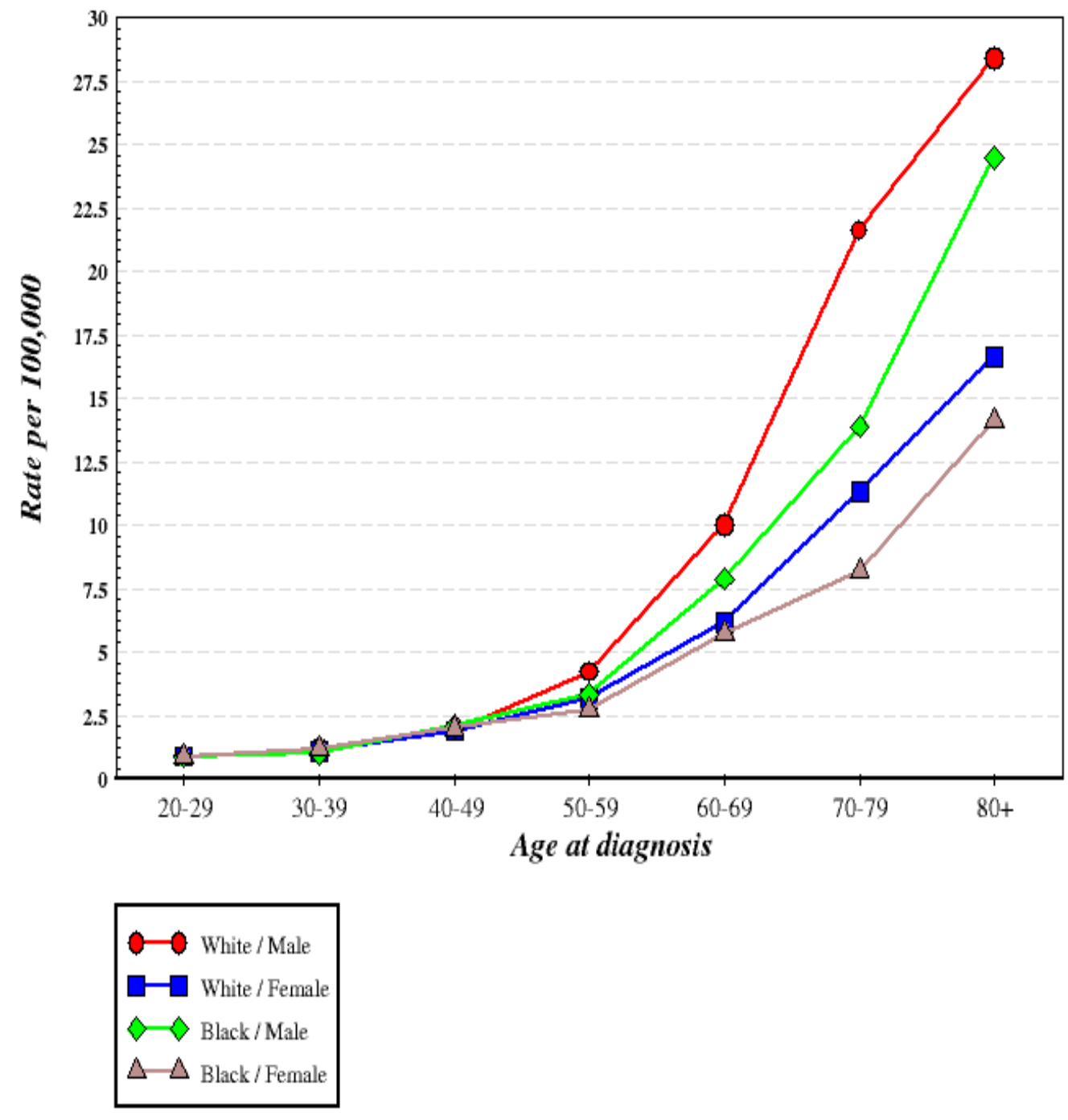


Table 7: Acute Myeloid Leukemia—Mortality—1969-1999

Acute Myeloid Leukemia-Mortality

SEER Mortality Age-Adjusted Rates

Standard population $=$ U.S. 2000

Year of death $=1969-1999$

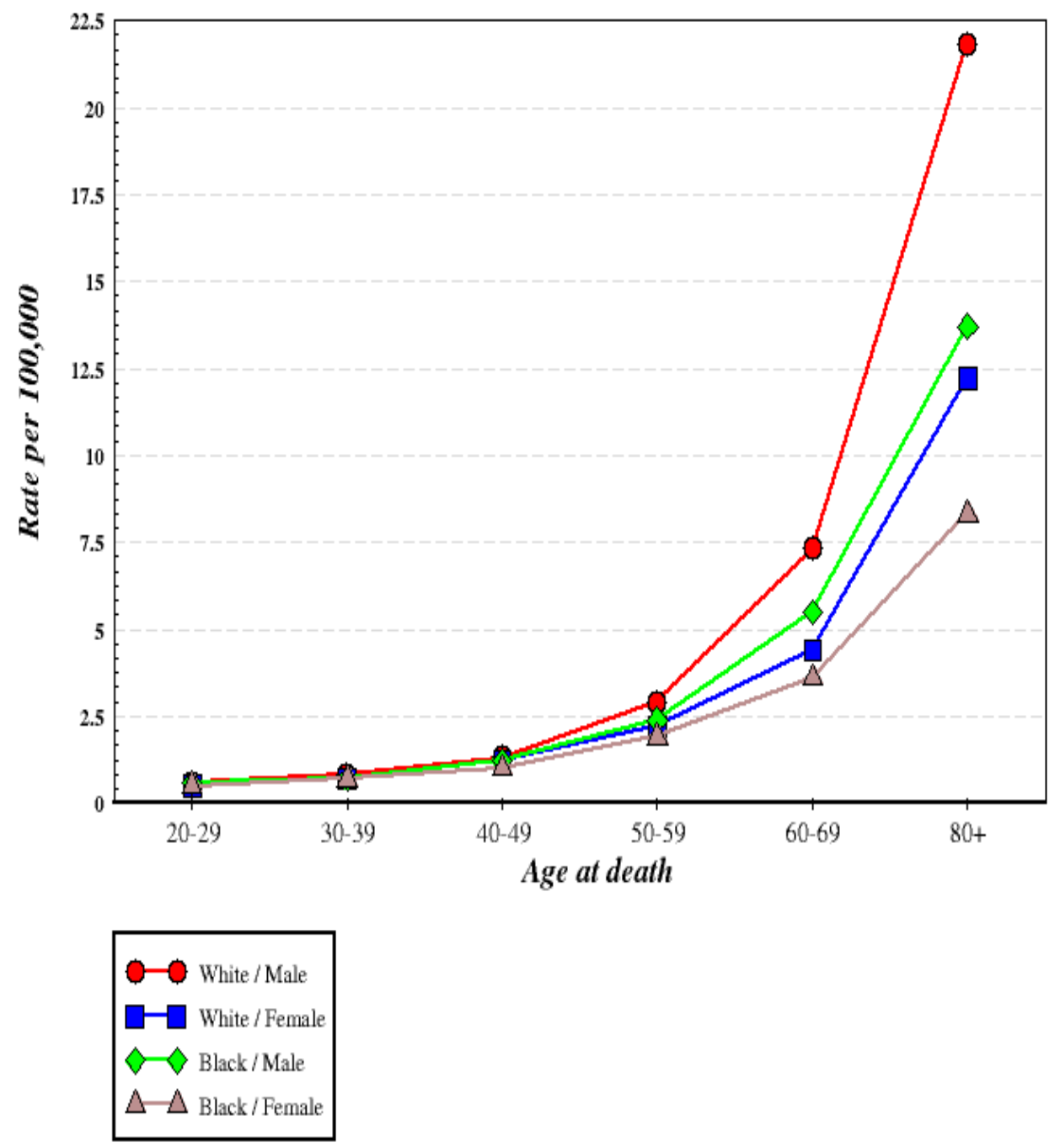


Table 8: Chronic Lymphocytic Leukemia—Incidence—1973-1999

Chronic Lymphocytic Leukemia-Incidence

SEER Incidence Age-Adjusted Rates

Standard population $=2000$ U.S.

Year of Diagnosis $=1973-1999$

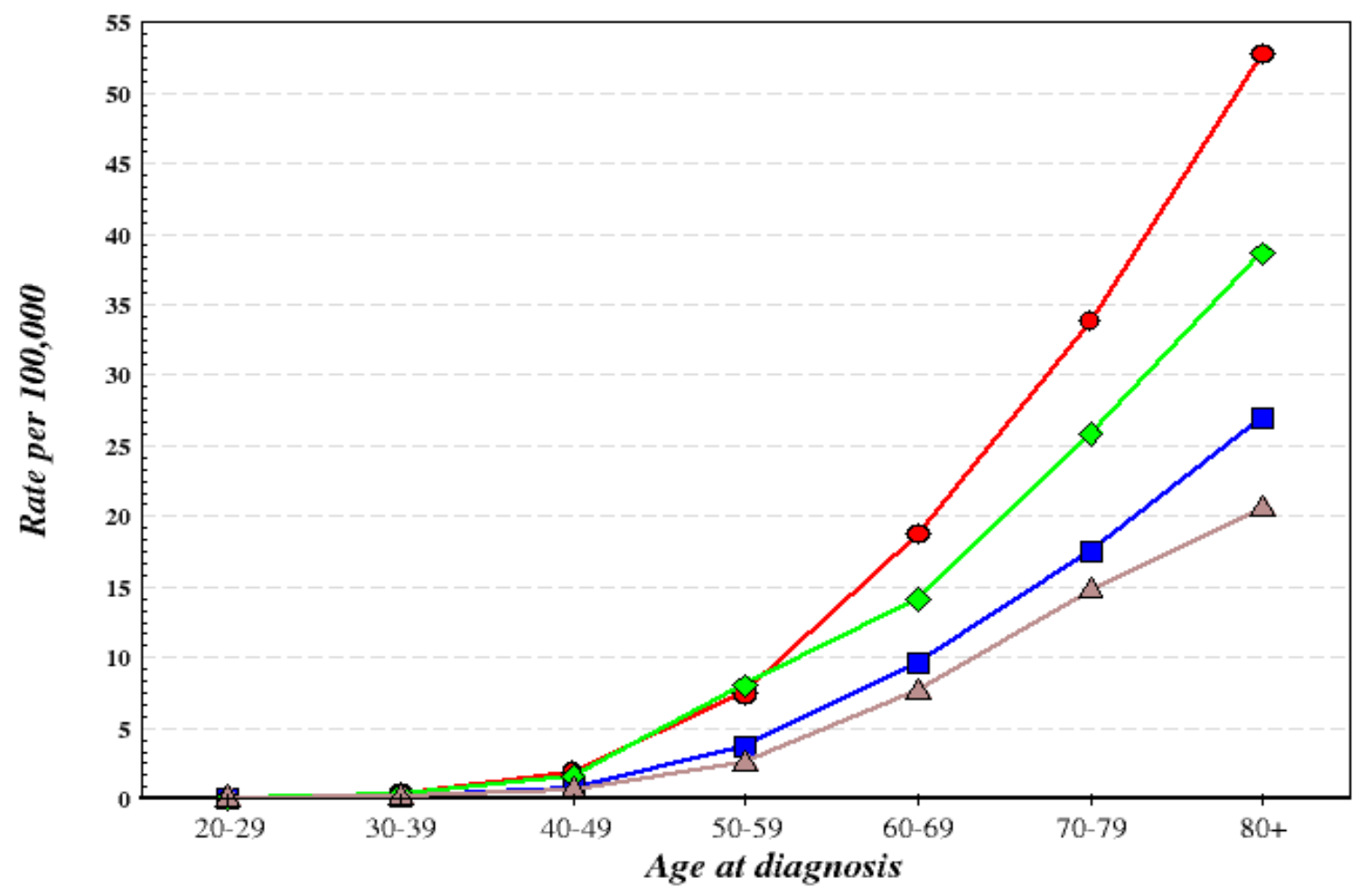

$$
\begin{aligned}
& \square \text { White / Male } \\
& \triangle \triangle \text { White / Female } \\
& \triangle \triangle \text { Black / Male } \\
& \Delta \triangle \text { B / Female }
\end{aligned}
$$


Table 9: Chronic Lymphocytic Leukemia—Mortality—1969-1999

Chronic Lymphocytic Leukemia-Mortality

SEER Mortality Age-Adjusted Rates

Standard population $=2000$ U.S.

Year of death $=1969-1999$

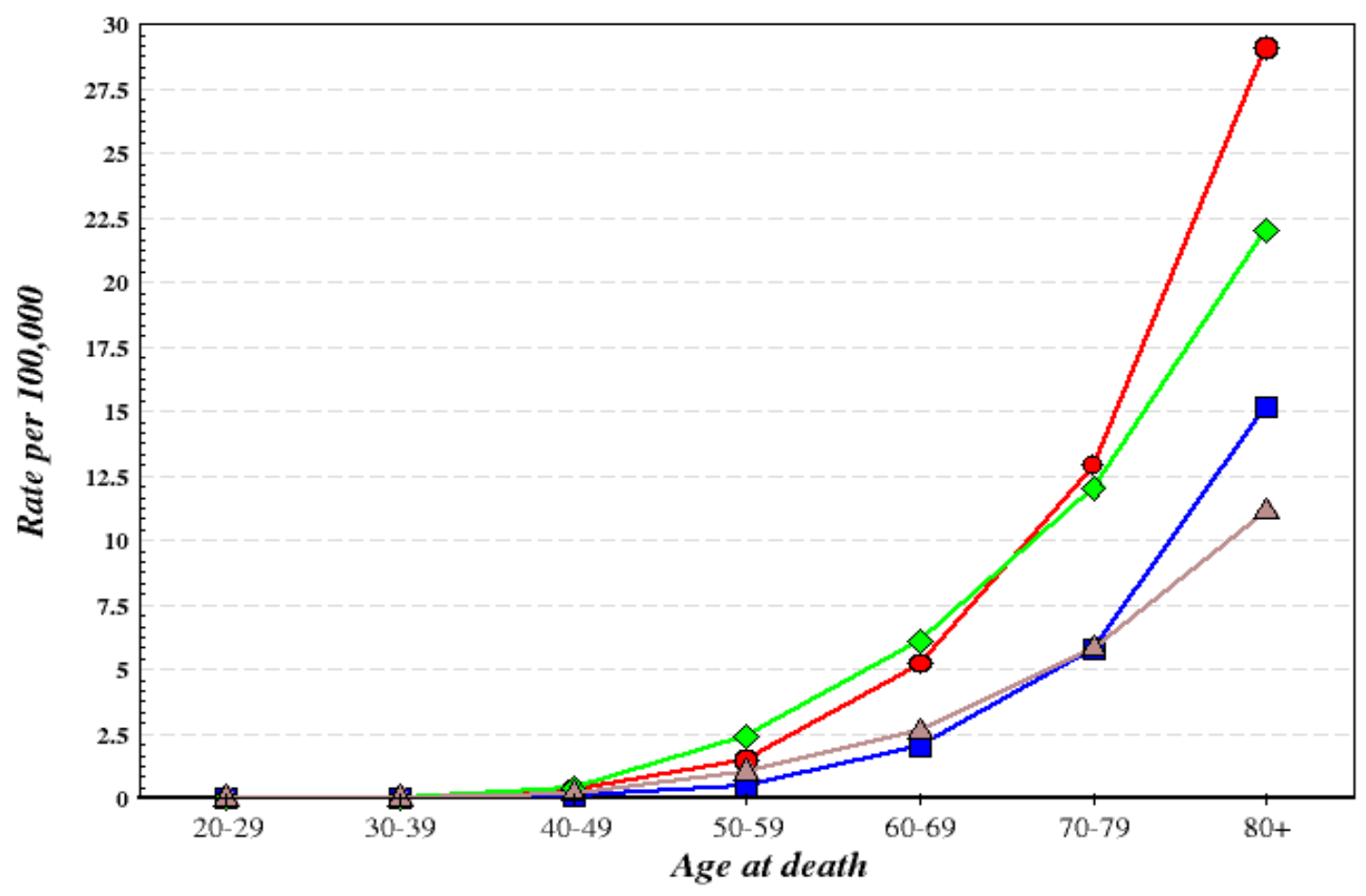

$$
\begin{aligned}
& \therefore \text { White / Male } \\
& \Delta \triangle \text { White / Female } \\
& \triangle \Delta \text { Black / Male } / \text { Female }
\end{aligned}
$$


Table 10: Chronic Myeloid Leukemia_Incidence—1973-1999

\section{Chronic Myeloid Leukemia-Incidence \\ SEER Incidence Age-Adjusted Rates \\ Standard population $=2000$ U.S. \\ Year of diagnosis $=1973-1999$}

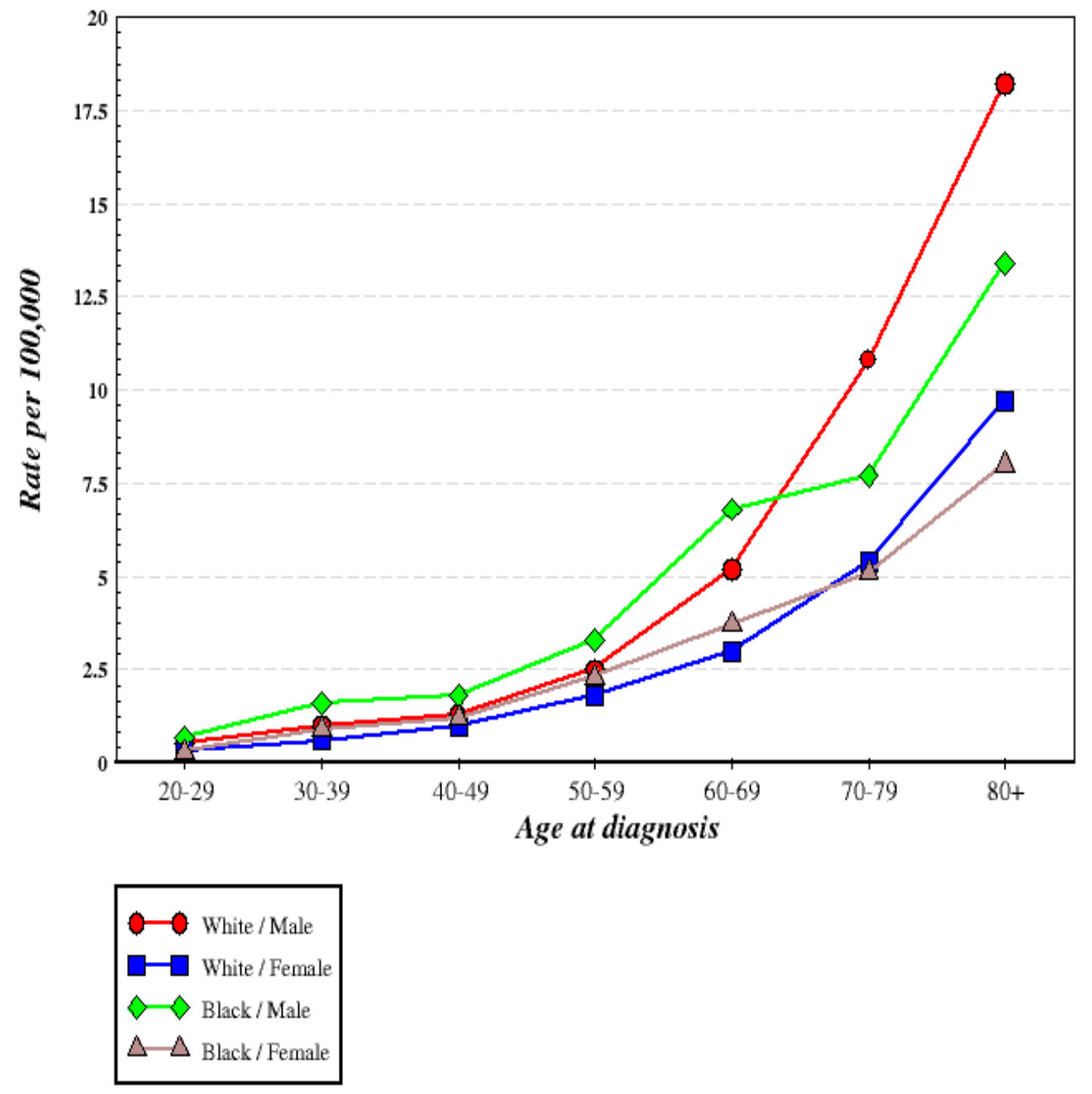


Table 11: Chronic Myeloid Leukemia-Mortality—1969-1999

\section{Chronic Myeloid Leukemia-Mortality \\ SEER Mortality Age-Adjusted Rates \\ Standard population $=2000$ U.S. \\ Year of Death $=1969-1999$}

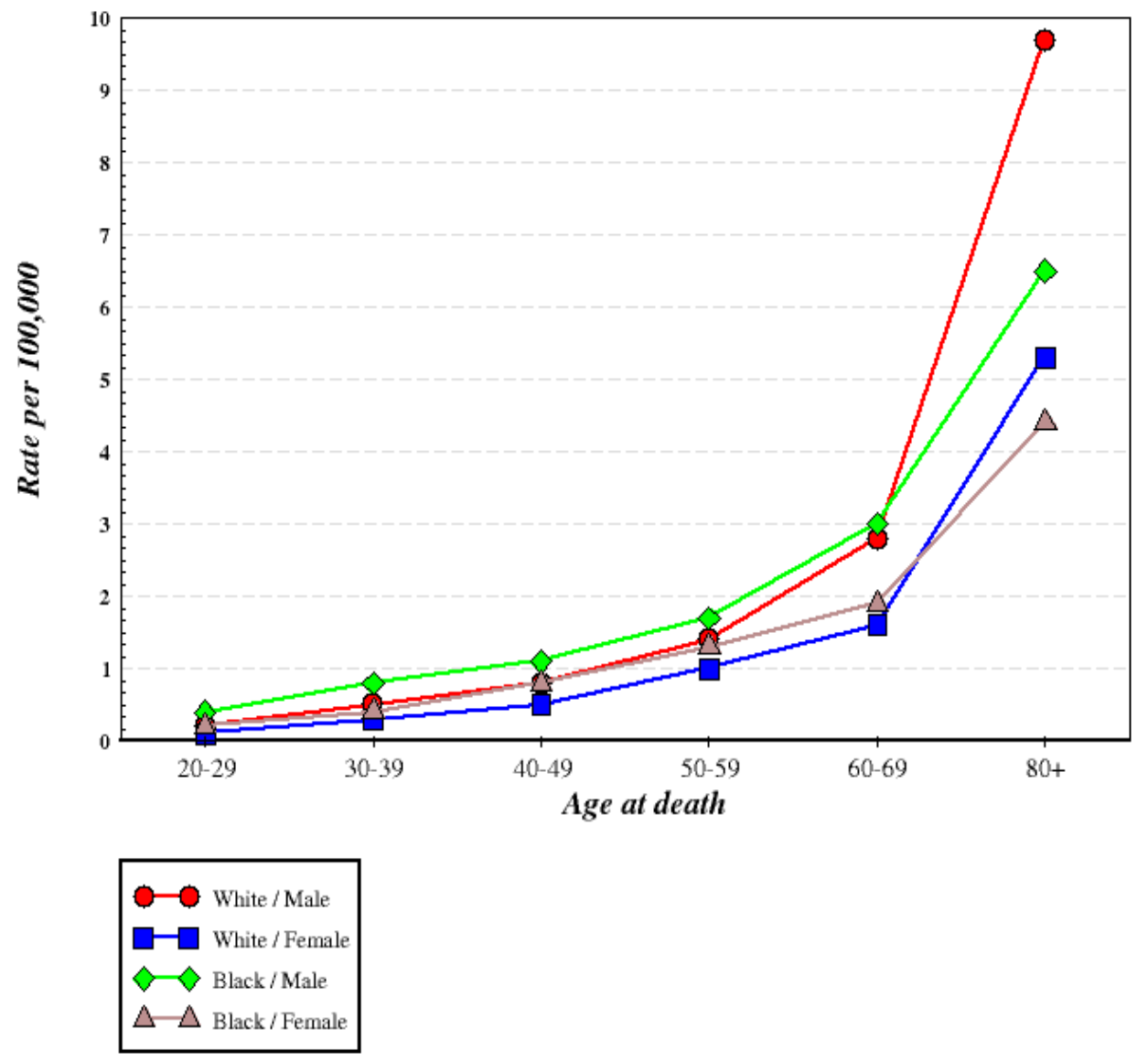


Table 12: Acute Lymphocytic Leukemia—Incidence—1973-1999

Acute Lymphocytic Leukemia-Incidence

SEER Incidence Age-Adjusted Rates

Standard population $=2000$ U.S.

Year of diagnosis $=1973-1999$

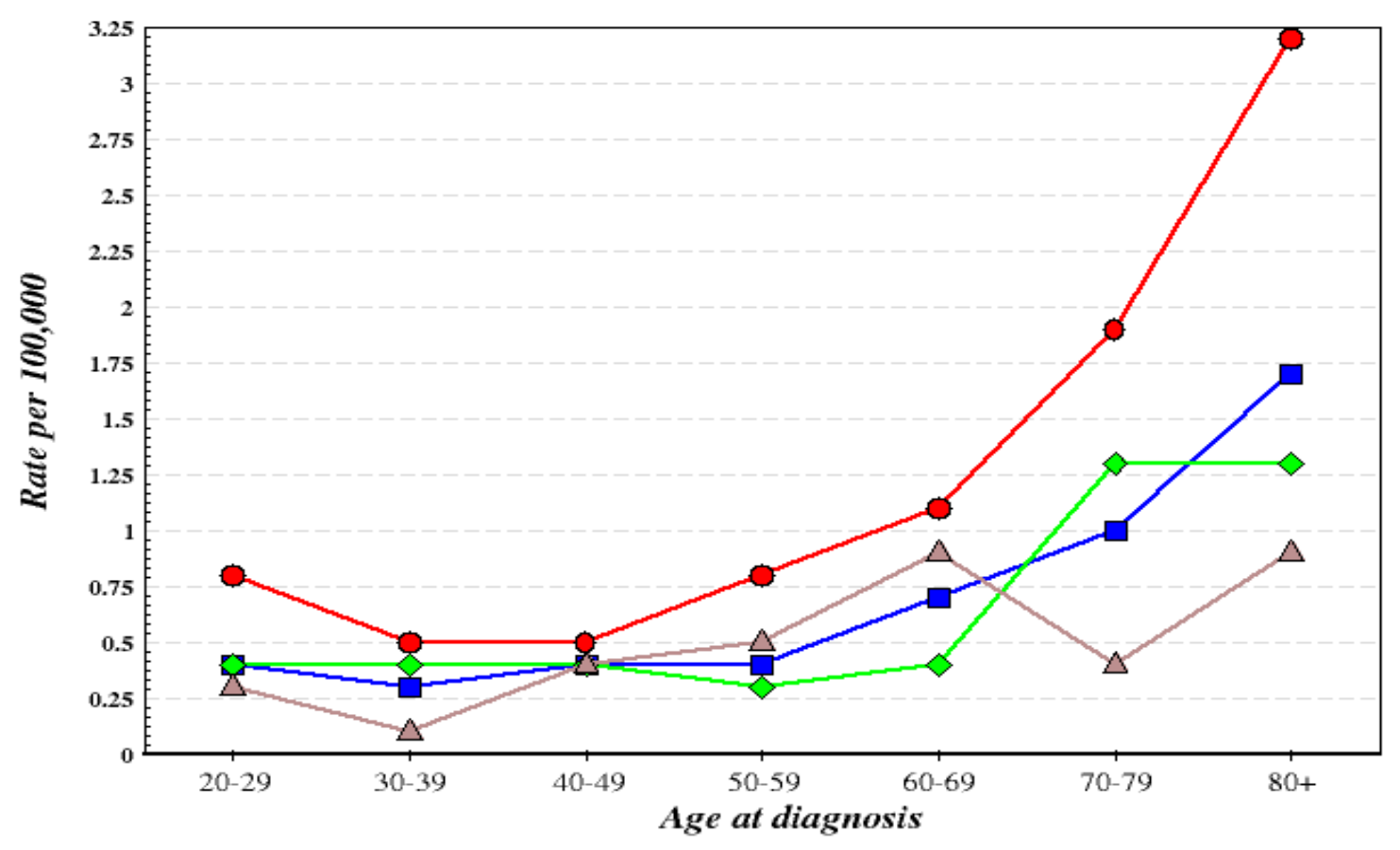

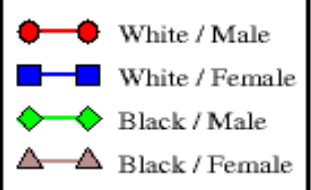


Table 13: Acute Lymphocytic Leukemia—Mortality—1969-1999

Table 13: Acute Lymphocytic Leukemia-Mortality

SEER Mortality Age-Adjusted Rates

Standard population $=2000$ U.S.

Year of death $=1969-1999$

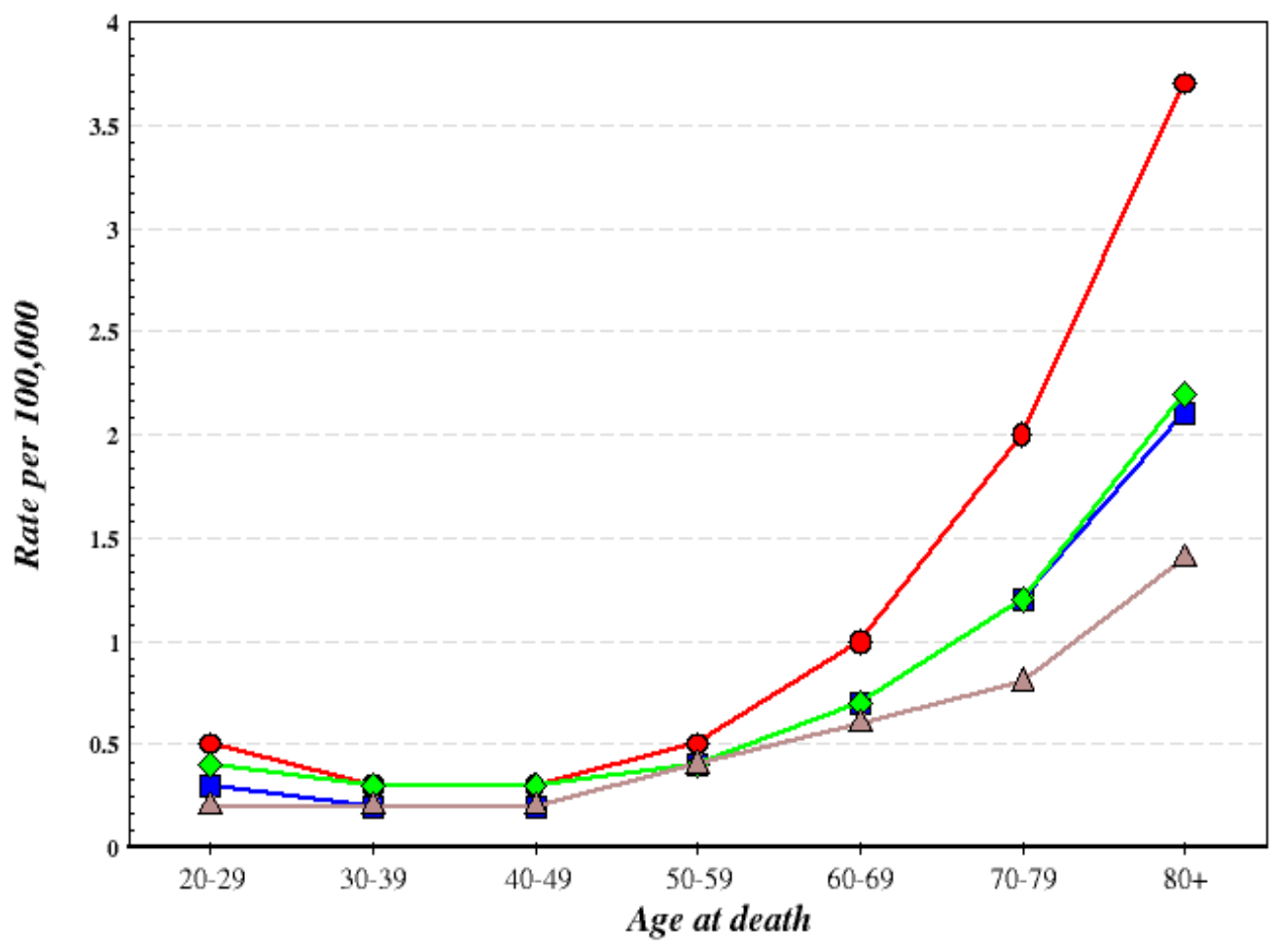

- White / Male

므. White/Female

$\diamond$ Black / Male

$\triangle \Delta$ Black / Female 


\section{Appendix C}

Number of Civilian Employees Working at the PNS by Fiscal Year

Portsmouth Naval Shipyard Employment

By Fiscal Year

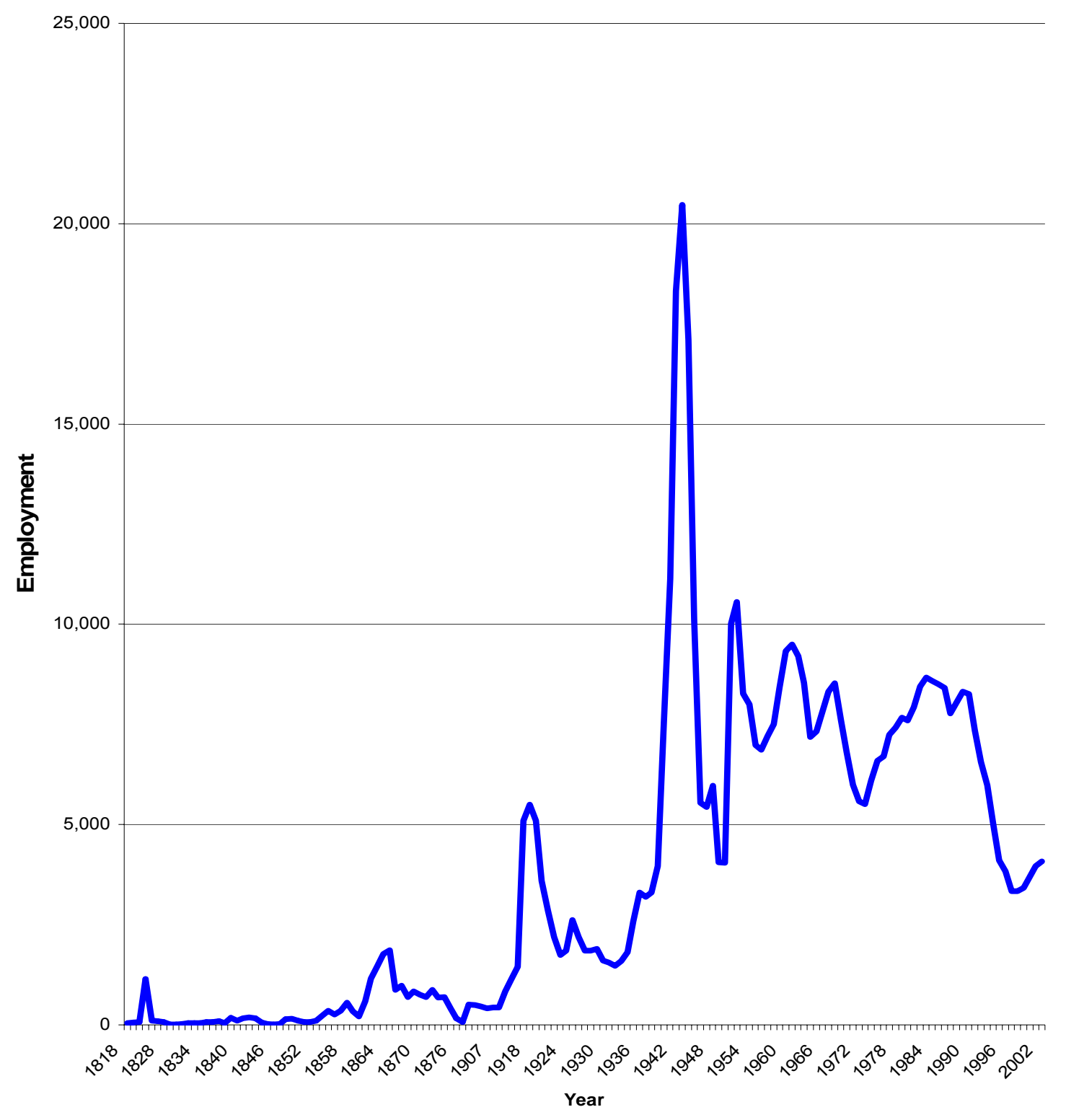




\section{Appendix D}

List of Construction, Overhauls, and Scheduled Maintenance October 1, 1955, to

December 11, 2002

Listing of all New Nuclear Submarine Construction, Overhauls, and Scheduled Maintenance Performed by Civilian Employees at the Portsmouth Naval Shipyard

October 1, 1955-December 11, 2002

Portsmouth Naval Shipyard History Of Nuclear Submarines

\begin{tabular}{|c|c|c|c|c|}
\hline $\begin{array}{l}\text { Nuclear Submarine } \\
\text { Name }\end{array}$ & $\begin{array}{l}\text { Submarine } \\
\text { Number }\end{array}$ & $\begin{array}{l}\text { Type } \\
\text { Availability }\end{array}$ & $\begin{array}{l}\text { Availability } \\
\text { Start Date }\end{array}$ & $\begin{array}{l}\text { Availability } \\
\text { Comp Date }\end{array}$ \\
\hline USS SWORDFISH & SSN 579 & $\begin{array}{l}\text { New } \\
\text { Construction }\end{array}$ & $10 / 01 / 55$ & $09 / 15 / 58$ \\
\hline USS THRESHER & SSN 593 & $\begin{array}{l}\text { New } \\
\text { Construction }\end{array}$ & $04 / 04 / 58$ & 08/01/61 \\
\hline $\begin{array}{l}\text { USS ABRAHAM } \\
\text { LINCOLN }\end{array}$ & SSBN 602 & $\begin{array}{l}\text { New } \\
\text { Construction }\end{array}$ & $08 / 01 / 58$ & $03 / 08 / 61$ \\
\hline $\begin{array}{l}\text { USS SEA } \\
\text { DRAGON }\end{array}$ & SSN 584 & $\begin{array}{l}\text { New } \\
\text { Construction }\end{array}$ & $04 / 01 / 59$ & $12 / 01 / 59$ \\
\hline USS NAUTILUS & SSN 571 & $\begin{array}{l}\text { Refueling } \\
\text { Overhaul }\end{array}$ & $06 / 03 / 59$ & $08 / 10 / 60$ \\
\hline USS TINOSA & SSN 606 & $\begin{array}{l}\text { New } \\
\text { Construction }\end{array}$ & $08 / 03 / 59$ & $11 / 28 / 64$ \\
\hline USS JACK & SSN 605 & $\begin{array}{l}\text { New } \\
\text { Construction }\end{array}$ & $04 / 01 / 60$ & $04 / 21 / 67$ \\
\hline $\begin{array}{l}\text { USS JOHN } \\
\text { ADAMS }\end{array}$ & SSBN 620 & $\begin{array}{l}\text { New } \\
\text { Construction }\end{array}$ & $02 / 06 / 61$ & $05 / 16 / 64$ \\
\hline $\begin{array}{l}\text { USS NATHANIEL } \\
\text { GREENE }\end{array}$ & SSBN 636 & $\begin{array}{l}\text { New } \\
\text { Construction }\end{array}$ & $02 / 01 / 62$ & $12 / 23 / 64$ \\
\hline USS SKIPJACK & SSN 585 & $\begin{array}{l}\text { Regular } \\
\text { Overhaul }\end{array}$ & $02 / 09 / 62$ & $09 / 19 / 62$ \\
\hline USS THRESHER & SSN 593 & $\begin{array}{l}\text { Post } \\
\text { Shakedown } \\
\text { Availability }\end{array}$ & $07 / 12 / 62$ & $04 / 10 / 63$ \\
\hline USS GRAYLING & SSN 646 & $\begin{array}{l}\text { New } \\
\text { Construction }\end{array}$ & $03 / 04 / 63$ & $12 / 01 / 69$ \\
\hline
\end{tabular}




\begin{tabular}{|c|c|c|c|c|}
\hline \multicolumn{5}{|c|}{ New Construction, Overhauls And Scheduled Maintenance Availabilities } \\
\hline $\begin{array}{l}\text { Nuclear Submarine } \\
\text { Name }\end{array}$ & $\begin{array}{l}\text { Submarine } \\
\text { Number }\end{array}$ & $\begin{array}{l}\text { Type } \\
\text { Availability }\end{array}$ & $\begin{array}{l}\text { Availability } \\
\text { Start Date }\end{array}$ & $\begin{array}{l}\text { Availability } \\
\text { Comp Date }\end{array}$ \\
\hline USS NAUTILUS & SSN 571 & $\begin{array}{l}\text { Regular } \\
\text { Overhaul }\end{array}$ & $01 / 20 / 64$ & $05 / 01 / 66$ \\
\hline USS SANDLANCE & SSN 660 & $\begin{array}{l}\text { New } \\
\text { Construction }\end{array}$ & $06 / 29 / 64$ & $10 / 02 / 71$ \\
\hline $\begin{array}{l}\text { USS JOHN } \\
\text { ADAMS }\end{array}$ & SSBN 620 & $\begin{array}{l}\text { Post Shakedown } \\
\text { Availability }\end{array}$ & $08 / 23 / 64$ & $09 / 26 / 64$ \\
\hline USS SEAWOLF & SSN 575 & $\begin{array}{l}\text { Refueling } \\
\text { Overhaul }\end{array}$ & $05 / 05 / 65$ & $08 / 21 / 67$ \\
\hline USS DACE & SSN 607 & $\begin{array}{l}\text { Post } \\
\text { Shakedown } \\
\text { Availability }\end{array}$ & $09 / 08 / 65$ & $11 / 22 / 65$ \\
\hline USS TULLIBEE & SSN 597 & $\begin{array}{l}\text { Refueling } \\
\text { Overhaul }\end{array}$ & $12 / 20 / 65$ & $11 / 28 / 68$ \\
\hline USS TINOSA & SSN 606 & $\begin{array}{l}\text { Post } \\
\text { Shakedown } \\
\text { Availability }\end{array}$ & $04 / 01 / 66$ & $06 / 18 / 66$ \\
\hline $\begin{array}{l}\text { USS SAM } \\
\text { HOUSTON }\end{array}$ & SSBN 609 & $\begin{array}{l}\text { Refueling } \\
\text { Overhaul }\end{array}$ & $08 / 24 / 66$ & $11 / 22 / 67$ \\
\hline USS NAUTILUS & SSN 571 & $\begin{array}{l}\text { Refueling } \\
\text { Overhaul }\end{array}$ & $08 / 15 / 67$ & $12 / 09 / 68$ \\
\hline USS JACK & SSN 605 & $\begin{array}{l}\text { Restricted } \\
\text { Availability }\end{array}$ & $10 / 11 / 67$ & $12 / 10 / 67$ \\
\hline $\begin{array}{l}\text { USS ANDREW } \\
\text { JACKSON }\end{array}$ & SSBN 619 & $\begin{array}{l}\text { Refueling } \\
\text { Overhaul }\end{array}$ & $03 / 14 / 68$ & $06 / 14 / 69$ \\
\hline USS JACK & SSN 605 & $\begin{array}{l}\text { Post } \\
\text { Shakedown } \\
\text { Availability }\end{array}$ & $11 / 01 / 68$ & $03 / 17 / 69$ \\
\hline USS TINOSA & SSN 606 & $\begin{array}{l}\text { Regular } \\
\text { Overhaul }\end{array}$ & $05 / 06 / 69$ & $12 / 16 / 71$ \\
\hline $\begin{array}{l}\text { USS SAM } \\
\text { RAYBURN }\end{array}$ & SSBN 635 & $\begin{array}{l}\text { Refueling } \\
\text { Overhaul }\end{array}$ & $01 / 19 / 70$ & $09 / 02 / 71$ \\
\hline USS JACK & SSN 605 & $\begin{array}{l}\text { Restricted } \\
\text { Availability }\end{array}$ & $02 / 28 / 70$ & $03 / 13 / 70$ \\
\hline USS JACK & SSN 605 & $\begin{array}{l}\text { Regular } \\
\text { Overhaul }\end{array}$ & $02 / 06 / 71$ & $04 / 27 / 72$ \\
\hline
\end{tabular}




\begin{tabular}{|c|c|c|c|c|}
\hline \multicolumn{5}{|c|}{$\begin{array}{l}\text { Portsmouth Naval Shipyard } \\
\text { History Of Nuclear Submarines }\end{array}$} \\
\hline $\begin{array}{l}\text { Nuclear Submarine } \\
\text { Name }\end{array}$ & $\begin{array}{l}\text { Submarine } \\
\text { Number }\end{array}$ & $\begin{array}{l}\text { Type } \\
\text { Availability }\end{array}$ & $\begin{array}{l}\text { Availability } \\
\text { Start Date }\end{array}$ & $\begin{array}{l}\text { Availability } \\
\text { Comp Date }\end{array}$ \\
\hline USS GEORGE & SSBN 643 & Refueling & $04 / 28 / 71$ & $07 / 31 / 72$ \\
\hline BANCROFT & & Overhaul & & \\
\hline USS LAPON & SSN 661 & $\begin{array}{l}\text { Regular } \\
\text { Overhaul }\end{array}$ & $10 / 26 / 71$ & $10 / 13 / 72$ \\
\hline USS SAM & SSBN 635 & Post & $01 / 11 / 72$ & $02 / 17 / 72$ \\
\hline RAYBURN & & $\begin{array}{l}\text { Conversion } \\
\text { Availability }\end{array}$ & & \\
\hline $\begin{array}{l}\text { USS } \\
\text { HAMMERHEAD }\end{array}$ & SSN 663 & $\begin{array}{l}\text { Regular } \\
\text { Overhaul }\end{array}$ & $03 / 14 / 72$ & $02 / 09 / 73$ \\
\hline USS GREENLING & SSN 614 & $\begin{array}{l}\text { Restricted } \\
\text { Availability }\end{array}$ & $04 / 04 / 72$ & $06 / 25 / 73$ \\
\hline USS SANDLANCE & SSN 660 & $\begin{array}{l}\text { Post } \\
\text { Shakedown } \\
\text { Availability/ } \\
\text { Restricted } \\
\text { Availability }\end{array}$ & $06 / 19 / 72$ & $08 / 28 / 72$ \\
\hline USS DACE & SSN 607 & $\begin{array}{l}\text { Restricted } \\
\text { Availability }\end{array}$ & $07 / 07 / 72$ & $07 / 30 / 72$ \\
\hline USS WILL & SSBN 659 & Refueling & $10 / 10 / 72$ & $02 / 08 / 74$ \\
\hline ROGERS & & Overhaul & & \\
\hline USS GEORGE & SSBN 643 & Post & $12 / 21 / 72$ & $01 / 31 / 73$ \\
\hline BANCROFT & & $\begin{array}{l}\text { Conversion } \\
\text { Availability }\end{array}$ & & \\
\hline USS TREPANG & SSN 674 & $\begin{array}{l}\text { Restricted } \\
\text { Availability/ } \\
\text { Intermediate } \\
\text { Dry Docking }\end{array}$ & $01 / 10 / 73$ & $02 / 07 / 73$ \\
\hline USS TULLIBEE & SSN 597 & $\begin{array}{l}\text { Refueling } \\
\text { Overhaul }\end{array}$ & $03 / 01 / 73$ & $08 / 30 / 74$ \\
\hline USS SEA DEVIL & SSN 664 & $\begin{array}{l}\text { Restricted } \\
\text { Availability/ } \\
\text { Intermediate } \\
\text { Dry Docking }\end{array}$ & $05 / 07 / 73$ & $06 / 29 / 73$ \\
\hline USS STURGEON & SSN 637 & $\begin{array}{l}\text { Restricted } \\
\text { Availability }\end{array}$ & $06 / 05 / 73$ & $04 / 16 / 74$ \\
\hline
\end{tabular}




\begin{tabular}{|c|c|c|c|c|}
\hline \multicolumn{5}{|c|}{ New Construction, Overhauls And Scheduled Maintenance Availabilities } \\
\hline $\begin{array}{l}\text { Nuclear Submarine } \\
\text { Name }\end{array}$ & $\begin{array}{l}\text { Submarine } \\
\text { Number }\end{array}$ & $\begin{array}{l}\text { Type } \\
\text { Availability }\end{array}$ & $\begin{array}{l}\text { Availability } \\
\text { Start Date }\end{array}$ & $\begin{array}{l}\text { Availability } \\
\text { Comp Date }\end{array}$ \\
\hline USS GRAYLING & SSN 646 & $\begin{array}{l}\text { Regular } \\
\text { Overhaul }\end{array}$ & $07 / 02 / 73$ & $05 / 28 / 74$ \\
\hline $\begin{array}{l}\text { USS GEORGE C } \\
\text { MARSHALL }\end{array}$ & SSBN 654 & $\begin{array}{l}\text { Post } \\
\text { Conversion } \\
\text { Availability }\end{array}$ & $07 / 09 / 73$ & $08 / 13 / 73$ \\
\hline $\begin{array}{l}\text { USS GEORGE W. } \\
\text { CARVER }\end{array}$ & SSBN 656 & $\begin{array}{l}\text { Post } \\
\text { Conversion } \\
\text { Availability }\end{array}$ & $08 / 20 / 73$ & $09 / 27 / 73$ \\
\hline $\begin{array}{l}\text { USS FRANCIS S. } \\
\text { KEY }\end{array}$ & SSBN 657 & $\begin{array}{l}\text { Post } \\
\text { Conversion } \\
\text { Availability }\end{array}$ & $10 / 15 / 73$ & $11 / 13 / 73$ \\
\hline USS FLYING FISH & SSN 673 & $\begin{array}{l}\text { Regular } \\
\text { Overhaul }\end{array}$ & $11 / 15 / 73$ & $11 / 06 / 74$ \\
\hline $\begin{array}{l}\text { USS JOHN } \\
\text { ADAMS }\end{array}$ & SSBN 620 & $\begin{array}{l}\text { Refueling } \\
\text { Overhaul }\end{array}$ & $02 / 01 / 74$ & $04 / 15 / 76$ \\
\hline $\begin{array}{l}\text { USS MARIANO G. } \\
\text { VALLEJO }\end{array}$ & SSBN 658 & $\begin{array}{l}\text { Post } \\
\text { Conversion } \\
\text { Availability }\end{array}$ & $05 / 09 / 74$ & $06 / 12 / 74$ \\
\hline $\begin{array}{l}\text { USS WILL } \\
\text { ROGERS }\end{array}$ & SSBN 659 & $\begin{array}{l}\text { Post Conversion } \\
\text { Availability }\end{array}$ & $06 / 28 / 74$ & $08 / 09 / 74$ \\
\hline USS SEA DEVIL & SSN 664 & $\begin{array}{l}\text { Regular } \\
\text { Overhaul }\end{array}$ & $07 / 01 / 74$ & $06 / 22 / 75$ \\
\hline USS TUNNY & SSN 682 & $\begin{array}{l}\text { Post } \\
\text { Shakedown } \\
\text { Availability }\end{array}$ & $08 / 20 / 74$ & $10 / 09 / 74$ \\
\hline USS TREPANG & SSN 674 & $\begin{array}{l}\text { Regular } \\
\text { Overhaul }\end{array}$ & $10 / 15 / 74$ & $10 / 24 / 75$ \\
\hline USS BILLFISH & SSN 676 & $\begin{array}{l}\text { Regular } \\
\text { Overhaul }\end{array}$ & $01 / 13 / 75$ & $12 / 11 / 75$ \\
\hline $\begin{array}{l}\text { USS GEORGE W. } \\
\text { CARVER }\end{array}$ & SSBN 656 & $\begin{array}{l}\text { Restricted } \\
\text { Availability }\end{array}$ & $03 / 28 / 75$ & $05 / 20 / 75$ \\
\hline $\begin{array}{l}\text { USS HENRY } \\
\text { CLAY }\end{array}$ & SSBN 625 & $\begin{array}{l}\text { Refueling } \\
\text { Overhaul }\end{array}$ & $04 / 29 / 75$ & $07 / 29 / 77$ \\
\hline USS JACK & SSN 605 & $\begin{array}{l}\text { Refueling } \\
\text { Overhaul }\end{array}$ & $10 / 01 / 75$ & $01 / 23 / 78$ \\
\hline
\end{tabular}




\section{Portsmouth Naval Shipyard History Of Nuclear Submarines}

\begin{tabular}{|c|c|c|c|c|}
\hline $\begin{array}{l}\text { Nuclear Submarine } \\
\text { Name }\end{array}$ & $\begin{array}{l}\text { Submarine } \\
\text { Number }\end{array}$ & $\begin{array}{l}\text { Type } \\
\text { Availability }\end{array}$ & $\begin{array}{l}\text { Availability } \\
\text { Start Date }\end{array}$ & $\begin{array}{l}\text { Availability } \\
\text { Comp Date }\end{array}$ \\
\hline USS TECUMSEH & SSBN 628 & $\begin{array}{l}\text { Technical } \\
\text { Availability }\end{array}$ & $10 / 22 / 75$ & $11 / 30 / 75$ \\
\hline USS TREPANG & SSN 674 & $\begin{array}{l}\text { Restricted } \\
\text { Availability }\end{array}$ & $10 / 25 / 75$ & $11 / 04 / 75$ \\
\hline $\begin{array}{l}\text { USS DANIEL } \\
\text { BOONE }\end{array}$ & SSBN 629 & $\begin{array}{l}\text { Regular } \\
\text { Overhaul }\end{array}$ & $03 / 23 / 76$ & $03 / 24 / 78$ \\
\hline USS WHALE & SSN 638 & $\begin{array}{l}\text { Refueling } \\
\text { Overhaul }\end{array}$ & $09 / 15 / 76$ & 07/07/78 \\
\hline $\begin{array}{l}\text { USS JOHN } \\
\text { ADAMS }\end{array}$ & SSBN 620 & $\begin{array}{l}\text { Post } \\
\text { Shakedown } \\
\text { Availability }\end{array}$ & $09 / 29 / 76$ & $11 / 03 / 76$ \\
\hline $\begin{array}{l}\text { USS JOHN C. } \\
\text { CALHOUN }\end{array}$ & SSBN 630 & $\begin{array}{l}\text { Regular } \\
\text { Overhaul }\end{array}$ & $01 / 17 / 77$ & $12 / 22 / 78$ \\
\hline $\begin{array}{l}\text { USS WILLIAM H. } \\
\text { BATES }\end{array}$ & SSN 680 & $\begin{array}{l}\text { Selected } \\
\text { Restricted } \\
\text { Availability }\end{array}$ & 03/07/77 & $05 / 02 / 77$ \\
\hline $\begin{array}{l}\text { USS RICHARD B. } \\
\text { RUSSELL }\end{array}$ & SSN 687 & $\begin{array}{l}\text { Selected } \\
\text { Restricted } \\
\text { Availability }\end{array}$ & 05/09/77 & $06 / 29 / 77$ \\
\hline USS CAVALLA & SSN 684 & $\begin{array}{l}\text { Selected } \\
\text { Restricted } \\
\text { Availability }\end{array}$ & $06 / 13 / 77$ & 08/07/77 \\
\hline $\begin{array}{l}\text { USS JAMES } \\
\text { MADISON }\end{array}$ & SSBN 627 & $\begin{array}{l}\text { Extended Refit } \\
\text { Period }\end{array}$ & $09 / 11 / 77$ & $11 / 07 / 77$ \\
\hline USS TECUMSEH & SSBN 628 & $\begin{array}{l}\text { Regular } \\
\text { Overhaul }\end{array}$ & $09 / 27 / 77$ & $06 / 27 / 79$ \\
\hline $\begin{array}{l}\text { USS HENRY } \\
\text { CLAY }\end{array}$ & SSBN 625 & $\begin{array}{l}\text { Post } \\
\text { Shakedown } \\
\text { Availability }\end{array}$ & $01 / 06 / 78$ & $02 / 23 / 78$ \\
\hline $\begin{array}{l}\text { USS SAM } \\
\text { RAYBURN }\end{array}$ & SSBN 635 & $\begin{array}{l}\text { Regular } \\
\text { Overhaul }\end{array}$ & $02 / 01 / 78$ & $10 / 23 / 79$ \\
\hline $\begin{array}{l}\text { USS VON } \\
\text { STEUBEN }\end{array}$ & SSBN 632 & $\begin{array}{l}\text { Extended Refit } \\
\text { Period }\end{array}$ & $03 / 10 / 78$ & $05 / 06 / 78$ \\
\hline $\begin{array}{l}\text { USS CASIMIR } \\
\text { PULASKI }\end{array}$ & SSBN 633 & $\begin{array}{l}\text { Extended Refit } \\
\text { Period }\end{array}$ & $05 / 18 / 78$ & 07/17/78 \\
\hline
\end{tabular}




\begin{tabular}{|c|c|c|c|c|}
\hline \multicolumn{5}{|c|}{ New Construction, Overhauls And Scheduled Maintenance Availabilities } \\
\hline $\begin{array}{l}\text { Nuclear Submarine } \\
\text { Name }\end{array}$ & $\begin{array}{l}\text { Submarine } \\
\text { Number }\end{array}$ & $\begin{array}{l}\text { Type } \\
\text { Availability }\end{array}$ & $\begin{array}{l}\text { Availability } \\
\text { Start Date }\end{array}$ & $\begin{array}{l}\text { Availability } \\
\text { Comp Date }\end{array}$ \\
\hline $\begin{array}{l}\text { USS STONEWALL } \\
\text { JACKSON }\end{array}$ & SSBN 634 & $\begin{array}{l}\text { Regular } \\
\text { Overhaul }\end{array}$ & $08 / 07 / 78$ & $03 / 28 / 80$ \\
\hline $\begin{array}{l}\text { USS SIMON } \\
\text { BOLIVAR }\end{array}$ & SSBN 641 & $\begin{array}{l}\text { Regular } \\
\text { Overhaul }\end{array}$ & $03 / 02 / 79$ & $12 / 28 / 80$ \\
\hline $\begin{array}{l}\text { USS NATHAN } \\
\text { HALE }\end{array}$ & SSBN 623 & $\begin{array}{l}\text { Extended Refit } \\
\text { Period }\end{array}$ & $04 / 24 / 79$ & $06 / 20 / 79$ \\
\hline USS ARCHERFISH & SSN 678 & $\begin{array}{l}\text { Selected } \\
\text { Restricted } \\
\text { Availability }\end{array}$ & 07/30/79 & $10 / 01 / 79$ \\
\hline USS TULLIBEE & SSN 597 & $\begin{array}{l}\text { Refueling } \\
\text { Overhaul }\end{array}$ & $08 / 18 / 79$ & $10 / 04 / 82$ \\
\hline $\begin{array}{l}\text { USS ALEXANDER } \\
\text { HAMILTON }\end{array}$ & SSBN 617 & $\begin{array}{l}\text { Extended Refit } \\
\text { Period }\end{array}$ & 09/01/79 & $10 / 28 / 79$ \\
\hline $\begin{array}{l}\text { USS BENJAMIN } \\
\text { FRANKLIN }\end{array}$ & SSBN 640 & $\begin{array}{l}\text { Regular } \\
\text { Overhaul }\end{array}$ & $11 / 12 / 79$ & $09 / 18 / 81$ \\
\hline USS TINOSA & SSN 606 & $\begin{array}{l}\text { Selected } \\
\text { Restricted } \\
\text { Availability }\end{array}$ & $01 / 07 / 80$ & $03 / 22 / 80$ \\
\hline USS PARGO & SSN 650 & $\begin{array}{l}\text { Selected } \\
\text { Restricted } \\
\text { Availability }\end{array}$ & $02 / 20 / 80$ & $04 / 19 / 80$ \\
\hline $\begin{array}{l}\text { USS GEORGE C. } \\
\text { MARSHALL }\end{array}$ & SSBN 654 & $\begin{array}{l}\text { Extended Refit } \\
\text { Period }\end{array}$ & $03 / 31 / 80$ & $05 / 27 / 80$ \\
\hline USS BILLFISH & SSN 676 & $\begin{array}{l}\text { Selected } \\
\text { Restricted } \\
\text { Availability }\end{array}$ & $04 / 18 / 80$ & $06 / 15 / 80$ \\
\hline $\begin{array}{l}\text { USS GEORGE } \\
\text { BANCROFT }\end{array}$ & SSBN 643 & $\begin{array}{l}\text { Regular } \\
\text { Overhaul }\end{array}$ & 06/01/80 & $03 / 05 / 82$ \\
\hline $\begin{array}{l}\text { USS GEORGE W. } \\
\text { CARVER }\end{array}$ & SSBN 656 & $\begin{array}{l}\text { Extended Refit } \\
\text { Period }\end{array}$ & $06 / 17 / 80$ & $08 / 11 / 80$ \\
\hline USS WHALE & SSN 638 & $\begin{array}{l}\text { Selected } \\
\text { Restricted } \\
\text { Availability }\end{array}$ & $07 / 29 / 80$ & $09 / 26 / 80$ \\
\hline USS TREPANG & SSN 674 & $\begin{array}{l}\text { Regular } \\
\text { Overhaul }\end{array}$ & $11 / 17 / 80$ & $11 / 16 / 82$ \\
\hline
\end{tabular}




\begin{tabular}{|c|c|c|c|c|}
\hline \multicolumn{5}{|c|}{ New Construction, Overhauls And Scheduled Maintenance Availabilities } \\
\hline $\begin{array}{l}\text { Nuclear Submarine } \\
\text { Name }\end{array}$ & $\begin{array}{l}\text { Submarine } \\
\text { Number }\end{array}$ & $\begin{array}{l}\text { Type } \\
\text { Availability }\end{array}$ & $\begin{array}{l}\text { Availability } \\
\text { Start Date }\end{array}$ & $\begin{array}{l}\text { Availability } \\
\text { Comp Date }\end{array}$ \\
\hline USS GREENLING & SSN 614 & $\begin{array}{l}\text { Selected } \\
\text { Restricted } \\
\text { Availability }\end{array}$ & $01 / 21 / 81$ & $03 / 17 / 81$ \\
\hline $\begin{array}{l}\text { USS } \\
\text { KAMEHAMEHA }\end{array}$ & SSBN 642 & $\begin{array}{l}\text { Regular } \\
\text { Overhaul }\end{array}$ & $04 / 01 / 81$ & $12 / 09 / 82$ \\
\hline $\begin{array}{l}\text { USS } \\
\text { PHILADELPHIA }\end{array}$ & SSN 690 & $\begin{array}{l}\text { Selected } \\
\text { Restricted } \\
\text { Availability }\end{array}$ & $04 / 20 / 81$ & $06 / 17 / 81$ \\
\hline USS ARCHERFISH & SSN 678 & $\begin{array}{l}\text { Selected } \\
\text { Restricted } \\
\text { Availability }\end{array}$ & $08 / 05 / 81$ & $09 / 29 / 81$ \\
\hline $\begin{array}{l}\text { USS JAMES } \\
\text { MONROE }\end{array}$ & SSBN 622 & $\begin{array}{l}\text { Extended Refit } \\
\text { Period }\end{array}$ & $09 / 20 / 81$ & $11 / 16 / 81$ \\
\hline $\begin{array}{l}\text { USS JAMES K. } \\
\text { POLK }\end{array}$ & SSBN 645 & $\begin{array}{l}\text { Regular } \\
\text { Overhaul }\end{array}$ & 09/30/81 & $04 / 21 / 83$ \\
\hline USS TINOSA & SSN 606 & $\begin{array}{l}\text { Selected } \\
\text { Restricted } \\
\text { Availability }\end{array}$ & 01/08/82 & 03/08/82 \\
\hline USS GATO & SSN 615 & $\begin{array}{l}\text { Selected } \\
\text { Restricted } \\
\text { Availability }\end{array}$ & 03/09/82 & 05/06/82 \\
\hline USS BILLFISH & SSN 676 & $\begin{array}{l}\text { Regular } \\
\text { Overhaul }\end{array}$ & $05 / 19 / 82$ & $11 / 05 / 83$ \\
\hline $\begin{array}{l}\text { USS ANDREW } \\
\text { JACKSON }\end{array}$ & SSBN 619 & $\begin{array}{l}\text { Extended Refit } \\
\text { Period }\end{array}$ & $06 / 17 / 82$ & $08 / 21 / 82$ \\
\hline USS GROTON & SSN 694 & $\begin{array}{l}\text { Selected } \\
\text { Restricted } \\
\text { Availability }\end{array}$ & $06 / 17 / 82$ & $09 / 28 / 82$ \\
\hline USS PARGO & SSN 650 & $\begin{array}{l}\text { Selected } \\
\text { Restricted } \\
\text { Availability }\end{array}$ & $10 / 01 / 82$ & $11 / 19 / 82$ \\
\hline USS JACK & SSN 605 & $\begin{array}{l}\text { Regular } \\
\text { Overhaul }\end{array}$ & $10 / 04 / 82$ & $04 / 08 / 85$ \\
\hline $\begin{array}{l}\text { NAVAL } \\
\text { RESEARCH ONE }\end{array}$ & NR-1 & $\begin{array}{l}\text { Regular } \\
\text { Overhaul }\end{array}$ & $11 / 10 / 82$ & $08 / 29 / 83$ \\
\hline
\end{tabular}




\section{Portsmouth Naval Shipyard History Of Nuclear Submarines}

\begin{tabular}{|c|c|c|c|c|}
\hline $\begin{array}{l}\text { Nuclear Submarine } \\
\text { Name }\end{array}$ & $\begin{array}{l}\text { Submarine } \\
\text { Number }\end{array}$ & $\begin{array}{l}\text { Type } \\
\text { Availability }\end{array}$ & $\begin{array}{l}\text { Availability } \\
\text { Start Date }\end{array}$ & $\begin{array}{l}\text { Availability } \\
\text { Comp Date }\end{array}$ \\
\hline USS GREENLING & SSN 614 & $\begin{array}{l}\text { Selected } \\
\text { Restricted } \\
\text { Availability }\end{array}$ & $01 / 11 / 83$ & $03 / 13 / 83$ \\
\hline $\begin{array}{l}\text { USS DANIEL } \\
\text { WEBSTER }\end{array}$ & SSBN 626 & $\begin{array}{l}\text { Extended Refit } \\
\text { Period }\end{array}$ & $02 / 13 / 83$ & $04 / 09 / 83$ \\
\hline USS ARCHERFISH & SSN 678 & $\begin{array}{l}\text { Regular } \\
\text { Overhaul }\end{array}$ & $03 / 01 / 83$ & $10 / 14 / 84$ \\
\hline USS WHALE & SSN 638 & $\begin{array}{l}\text { Selected } \\
\text { Restricted } \\
\text { Availability }\end{array}$ & $04 / 15 / 83$ & $06 / 10 / 83$ \\
\hline USS TINOSA & SSN 606 & $\begin{array}{l}\text { Regular } \\
\text { Overhaul }\end{array}$ & 07/13/83 & 09/30/85 \\
\hline USS DACE & SSN 607 & $\begin{array}{l}\text { Selected } \\
\text { Restricted } \\
\text { Availability }\end{array}$ & $10 / 01 / 83$ & $11 / 30 / 83$ \\
\hline USS DALLAS & SSN 700 & $\begin{array}{l}\text { Selected } \\
\text { Restricted } \\
\text { Availability }\end{array}$ & $01 / 07 / 84$ & $03 / 07 / 84$ \\
\hline $\begin{array}{l}\text { USS ULYSSES S. } \\
\text { GRANT }\end{array}$ & SSBN 631 & $\begin{array}{l}\text { Refueling } \\
\text { Overhaul }\end{array}$ & $02 / 01 / 84$ & $06 / 11 / 87$ \\
\hline $\begin{array}{l}\text { USS JAMES } \\
\text { MONROE }\end{array}$ & SSBN 622 & $\begin{array}{l}\text { Extended Refit } \\
\text { Period }\end{array}$ & $03 / 07 / 84$ & $05 / 05 / 84$ \\
\hline USS GATO & SSN 615 & $\begin{array}{l}\text { Selected } \\
\text { Restricted } \\
\text { Availability }\end{array}$ & $04 / 09 / 84$ & $06 / 09 / 84$ \\
\hline USS BOSTON & SSN 703 & $\begin{array}{l}\text { Selected } \\
\text { Restricted } \\
\text { Availability }\end{array}$ & $06 / 15 / 84$ & $08 / 15 / 84$ \\
\hline $\begin{array}{l}\text { USS } \\
\text { PHILADELPHIA }\end{array}$ & SSN 690 & $\begin{array}{l}\text { Regular } \\
\text { Overhaul }\end{array}$ & $06 / 25 / 84$ & $01 / 21 / 86$ \\
\hline USS GREENLING & SSN 614 & $\begin{array}{l}\text { Regular } \\
\text { Overhaul }\end{array}$ & $10 / 01 / 84$ & $10 / 09 / 87$ \\
\hline $\begin{array}{l}\text { USS ALEXANDER } \\
\text { HAMILTON }\end{array}$ & SSBN 617 & $\begin{array}{l}\text { Extended Refit } \\
\text { Period }\end{array}$ & $11 / 07 / 84$ & $01 / 09 / 85$ \\
\hline USS SNOOK & SSN 592 & $\begin{array}{l}\text { Special } \\
\text { Availability }\end{array}$ & $01 / 15 / 85$ & $03 / 27 / 85$ \\
\hline
\end{tabular}




\begin{tabular}{|c|c|c|c|c|}
\hline \multicolumn{5}{|c|}{ New Construction, Overhauls And Scheduled Maintenance Availabilities } \\
\hline $\begin{array}{l}\text { Nuclear Submarine } \\
\text { Name }\end{array}$ & $\begin{array}{l}\text { Submarine } \\
\text { Number }\end{array}$ & $\begin{array}{l}\text { Type } \\
\text { Availability }\end{array}$ & $\begin{array}{l}\text { Availability } \\
\text { Start Date }\end{array}$ & $\begin{array}{l}\text { Availability } \\
\text { Comp Date }\end{array}$ \\
\hline $\begin{array}{l}\text { USS SIMON } \\
\text { BOLIVAR }\end{array}$ & SSBN 641 & $\begin{array}{l}\text { Refueling } \\
\text { Overhaul }\end{array}$ & $02 / 01 / 85$ & $11 / 20 / 87$ \\
\hline $\begin{array}{l}\text { USS HENRY } \\
\text { CLAY }\end{array}$ & SSBN 625 & $\begin{array}{l}\text { Extended Refit } \\
\text { Period }\end{array}$ & $03 / 03 / 85$ & $04 / 28 / 85$ \\
\hline $\begin{array}{l}\text { USS ANDREW } \\
\text { JACKSON }\end{array}$ & SSBN 619 & $\begin{array}{l}\text { Extended Refit } \\
\text { Period }\end{array}$ & $06 / 21 / 85$ & $08 / 18 / 85$ \\
\hline USS TREPANG & SSN 674 & $\begin{array}{l}\text { Selected } \\
\text { Restricted } \\
\text { Availability }\end{array}$ & $08 / 01 / 85$ & $09 / 28 / 85$ \\
\hline USS DACE & SSN 607 & $\begin{array}{l}\text { Selected } \\
\text { Restricted } \\
\text { Availability }\end{array}$ & $09 / 30 / 85$ & $85 / 12 / 02$ \\
\hline USS GROTON & SSN 694 & $\begin{array}{l}\text { Regular } \\
\text { Overhaul }\end{array}$ & $10 / 01 / 85$ & $05 / 20 / 88$ \\
\hline $\begin{array}{l}\text { USS JAMES K. } \\
\text { POLK }\end{array}$ & SSBN 645 & $\begin{array}{l}\text { Refueling } \\
\text { Overhaul }\end{array}$ & $01 / 15 / 86$ & $11 / 29 / 88$ \\
\hline $\begin{array}{l}\text { USS DANIEL } \\
\text { WEBSTER }\end{array}$ & SSBN 626 & $\begin{array}{l}\text { Extended Refit } \\
\text { Period }\end{array}$ & $02 / 28 / 86$ & $04 / 25 / 86$ \\
\hline USS BILLFISH & SSN 676 & $\begin{array}{l}\text { Selected } \\
\text { Restricted } \\
\text { Availability }\end{array}$ & $05 / 01 / 86$ & $06 / 28 / 86$ \\
\hline USS GATO & SSN 615 & $\begin{array}{l}\text { Regular } \\
\text { Overhaul }\end{array}$ & $05 / 28 / 86$ & $02 / 26 / 90$ \\
\hline USS ARCHERFISH & SSN 678 & $\begin{array}{l}\text { Selected } \\
\text { Restricted } \\
\text { Availability }\end{array}$ & 09/30/86 & $12 / 05 / 86$ \\
\hline $\begin{array}{l}\text { USS } \\
\text { KAMEHAMEHA }\end{array}$ & SSBN 642 & $\begin{array}{l}\text { Refueling } \\
\text { Overhaul }\end{array}$ & $11 / 30 / 86$ & $12 / 23 / 89$ \\
\hline USS BOSTON & SSN 703 & $\begin{array}{l}\text { Selected } \\
\text { Restricted } \\
\text { Availability }\end{array}$ & $01 / 22 / 87$ & $03 / 22 / 87$ \\
\hline $\begin{array}{l}\text { USS JAMES } \\
\text { MONROE }\end{array}$ & SSBN 622 & $\begin{array}{l}\text { Extended Refit } \\
\text { Period }\end{array}$ & $03 / 12 / 87$ & $05 / 10 / 87$ \\
\hline USS AUGUSTA & SSN 710 & $\begin{array}{l}\text { Selected } \\
\text { Restricted } \\
\text { Availability }\end{array}$ & $05 / 22 / 87$ & $07 / 22 / 87$ \\
\hline
\end{tabular}




\begin{tabular}{|c|c|c|c|c|}
\hline \multicolumn{5}{|c|}{ New Construction, Overhauls And Scheduled Maintenance Availabilities } \\
\hline $\begin{array}{l}\text { Nuclear Submarine } \\
\text { Name }\end{array}$ & $\begin{array}{l}\text { Submarine } \\
\text { Number }\end{array}$ & $\begin{array}{l}\text { Type } \\
\text { Availability }\end{array}$ & $\begin{array}{l}\text { Availability } \\
\text { Start Date }\end{array}$ & $\begin{array}{l}\text { Availability } \\
\text { Comp Date }\end{array}$ \\
\hline USS LAFAYETTE & SSBN 616 & $\begin{array}{l}\text { Extended Refit } \\
\text { Period }\end{array}$ & $05 / 31 / 87$ & $07 / 28 / 87$ \\
\hline USS TINOSA & SSN 606 & $\begin{array}{l}\text { Selected } \\
\text { Restricted } \\
\text { Availability }\end{array}$ & $08 / 03 / 87$ & $10 / 15 / 87$ \\
\hline USS SKIPJACK & SSN 585 & $\begin{array}{l}\text { Selected } \\
\text { Restricted } \\
\text { Availability }\end{array}$ & 09/30/87 & $12 / 21 / 87$ \\
\hline USS TULLIBEE & SSN 597 & Inactivation & $09 / 30 / 87$ & $07 / 01 / 88$ \\
\hline USS BLUEFISH & SSN 675 & $\begin{array}{l}\text { Refueling } \\
\text { Overhaul }\end{array}$ & $12 / 01 / 87$ & $06 / 17 / 90$ \\
\hline USS SCULPIN & SSN 590 & $\begin{array}{l}\text { Selected } \\
\text { Restricted } \\
\text { Availability }\end{array}$ & $01 / 05 / 88$ & $03 / 12 / 88$ \\
\hline $\begin{array}{l}\text { USS CITY OF } \\
\text { CORPUS CHRISTI }\end{array}$ & SSN 705 & $\begin{array}{l}\text { Selected } \\
\text { Restricted } \\
\text { Availability }\end{array}$ & $01 / 18 / 88$ & $03 / 10 / 88$ \\
\hline USS SHARK & SSN 591 & $\begin{array}{l}\text { Selected } \\
\text { Restricted } \\
\text { Availability }\end{array}$ & $05 / 02 / 88$ & $07 / 28 / 88$ \\
\hline USS SANDLANCE & SSN 660 & $\begin{array}{l}\text { Regular } \\
\text { Overhaul }\end{array}$ & $06 / 01 / 88$ & $08 / 08 / 90$ \\
\hline $\begin{array}{l}\text { USS } \\
\text { ALBUQUERQUE }\end{array}$ & SSN 706 & $\begin{array}{l}\text { Selected } \\
\text { Restricted } \\
\text { Availability }\end{array}$ & $06 / 13 / 88$ & 08/19/88 \\
\hline $\begin{array}{l}\text { USS } \\
\text { PHILADELPHIA }\end{array}$ & SSN 690 & $\begin{array}{l}\text { Selected } \\
\text { Restricted } \\
\text { Availability }\end{array}$ & $09 / 07 / 88$ & $11 / 06 / 88$ \\
\hline USS DALLAS & SSN 700 & $\begin{array}{l}\text { Depot } \\
\text { Modernization } \\
\text { Period }\end{array}$ & $10 / 03 / 88$ & 09/27/89 \\
\hline $\begin{array}{l}\text { USS DANIEL } \\
\text { WEBSTER }\end{array}$ & SSBN 626 & $\begin{array}{l}\text { Intermediate } \\
\text { Dry Docking }\end{array}$ & $02 / 24 / 89$ & 03/20/89 \\
\hline USS TREPANG & SSN 674 & $\begin{array}{l}\text { Refueling } \\
\text { Overhaul }\end{array}$ & $03 / 01 / 89$ & $11 / 01 / 91$ \\
\hline
\end{tabular}




\section{Portsmouth Naval Shipyard History Of Nuclear Submarines}

\begin{tabular}{|c|c|c|c|c|}
\hline $\begin{array}{l}\text { Nuclear Submarine } \\
\text { Name }\end{array}$ & $\begin{array}{l}\text { Submarine } \\
\text { Number }\end{array}$ & $\begin{array}{l}\text { Type } \\
\text { Availability }\end{array}$ & $\begin{array}{l}\text { Availability } \\
\text { Start Date }\end{array}$ & $\begin{array}{l}\text { Availability } \\
\text { Comp Date }\end{array}$ \\
\hline USS BOSTON & SSN 703 & $\begin{array}{l}\text { Depot } \\
\text { Modernization } \\
\text { Period }\end{array}$ & $06 / 15 / 89$ & $05 / 18 / 90$ \\
\hline USS JACK & SSN 605 & Inactivation & $10 / 01 / 89$ & $07 / 27 / 90$ \\
\hline $\begin{array}{l}\text { USS GEORGE W. } \\
\text { CARVER }\end{array}$ & SSBN 656 & $\begin{array}{l}\text { Extended Refit } \\
\text { Period }\end{array}$ & $10 / 18 / 89$ & $12 / 16 / 89$ \\
\hline USS GREENLING & SSN 614 & $\begin{array}{l}\text { Selected } \\
\text { Restricted } \\
\text { Availability }\end{array}$ & $01 / 10 / 90$ & 03/18/90 \\
\hline $\begin{array}{l}\text { USS CITY OF } \\
\text { CORPUS CHRISTI }\end{array}$ & SSN 705 & $\begin{array}{l}\text { Depot } \\
\text { Modernization } \\
\text { Period }\end{array}$ & 03/01/90 & 03/10/91 \\
\hline USS TINOSA & SSN 606 & $\begin{array}{l}\text { Selected } \\
\text { Restricted } \\
\text { Availability }\end{array}$ & $03 / 12 / 90$ & $05 / 06 / 90$ \\
\hline $\begin{array}{l}\text { USS L. MENDEL } \\
\text { RIVERS }\end{array}$ & SSN 686 & $\begin{array}{l}\text { Refueling } \\
\text { Overhaul }\end{array}$ & 05/07/90 & $06 / 05 / 93$ \\
\hline USS LAFAYETTE & SSBN 616 & $\begin{array}{l}\text { Extended Refit } \\
\text { Period }\end{array}$ & $06 / 05 / 90$ & $08 / 03 / 90$ \\
\hline USS PITTSBURGH & SSN 720 & $\begin{array}{l}\text { Selected } \\
\text { Restricted } \\
\text { Availability }\end{array}$ & $09 / 04 / 90$ & $10 / 18 / 90$ \\
\hline $\begin{array}{l}\text { USS } \\
\text { ALBUQUERQUE }\end{array}$ & SSN 706 & $\begin{array}{l}\text { Depot } \\
\text { Modernization } \\
\text { Period }\end{array}$ & $10 / 01 / 90$ & 07/19/91 \\
\hline $\begin{array}{l}\text { NAVAL } \\
\text { RESEARCH ONE }\end{array}$ & NR-1 & $\begin{array}{l}\text { Refueling } \\
\text { Overhaul }\end{array}$ & $11 / 06 / 90$ & $11 / 29 / 92$ \\
\hline USS NORFOLK & SSN 714 & $\begin{array}{l}\text { Depot } \\
\text { Modernization } \\
\text { Period }\end{array}$ & $02 / 27 / 91$ & $05 / 01 / 92$ \\
\hline $\begin{array}{l}\text { USS WILL } \\
\text { ROGERS }\end{array}$ & SSBN 659 & $\begin{array}{l}\text { Extended Refit } \\
\text { Period }\end{array}$ & $06 / 24 / 91$ & 08/21/91 \\
\hline $\begin{array}{l}\text { USS DANIEL } \\
\text { BOONE }\end{array}$ & SSBN 629 & $\begin{array}{l}\text { Extended Refit } \\
\text { Period }\end{array}$ & $07 / 12 / 91$ & $09 / 05 / 91$ \\
\hline USS TECUMSEH & SSBN 628 & $\begin{array}{l}\text { Extended Refit } \\
\text { Period }\end{array}$ & 09/09/91 & $11 / 01 / 91$ \\
\hline
\end{tabular}




\begin{tabular}{|c|c|c|c|c|}
\hline \multicolumn{5}{|c|}{$\begin{array}{l}\text { Portsmouth Naval Shipyard } \\
\text { History Of Nuclear Submarines }\end{array}$} \\
\hline $\begin{array}{l}\text { Nuclear Submarine } \\
\text { Name }\end{array}$ & $\begin{array}{l}\text { Submarine } \\
\text { Number }\end{array}$ & $\begin{array}{l}\text { Type } \\
\text { Availability }\end{array}$ & $\begin{array}{l}\text { Availability } \\
\text { Start Date }\end{array}$ & $\begin{array}{l}\text { Availability } \\
\text { Comp Date }\end{array}$ \\
\hline USS FINBACK & SSN 670 & $\begin{array}{l}\text { Selected } \\
\text { Restricted } \\
\text { Availability }\end{array}$ & $09 / 30 / 91$ & $11 / 27 / 91$ \\
\hline $\begin{array}{l}\text { USS } \\
\text { MINNEAPOLIS/ST. } \\
\text { PAUL }\end{array}$ & SSN 708 & $\begin{array}{l}\text { Depot } \\
\text { Modernization } \\
\text { Period }\end{array}$ & 09/30/91 & 09/01/92 \\
\hline USS SILVERSIDES & SSN 679 & $\begin{array}{l}\text { Selected } \\
\text { Restricted } \\
\text { Availability }\end{array}$ & $11 / 20 / 91$ & 02/07/92 \\
\hline USS PARGO & SSN 650 & $\begin{array}{l}\text { Selected } \\
\text { Restricted } \\
\text { Availability }\end{array}$ & $01 / 06 / 92$ & 02/29/92 \\
\hline USS GATO & SSN 615 & $\begin{array}{l}\text { Selected } \\
\text { Restricted } \\
\text { Availability }\end{array}$ & $03 / 02 / 92$ & 04/29/92 \\
\hline $\begin{array}{l}\text { USS } \\
\text { HAMMERHEAD }\end{array}$ & SSN 663 & $\begin{array}{l}\text { Selected } \\
\text { Restricted } \\
\text { Availability }\end{array}$ & $03 / 23 / 92$ & $05 / 19 / 92$ \\
\hline USS CINCINNATI & SSN 693 & $\begin{array}{l}\text { Selected } \\
\text { Restricted } \\
\text { Availability }\end{array}$ & 05/19/92 & $07 / 21 / 92$ \\
\hline USS AUGUSTA & SSN 710 & $\begin{array}{l}\text { Depot } \\
\text { Modernization } \\
\text { Period }\end{array}$ & $06 / 01 / 92$ & $10 / 23 / 93$ \\
\hline USS GREENLING & SSN 614 & $\begin{array}{l}\text { Selected } \\
\text { Restricted } \\
\text { Availability }\end{array}$ & $06 / 30 / 92$ & 08/27/92 \\
\hline USS PHOENIX & SSN 702 & $\begin{array}{l}\text { Selected } \\
\text { Restricted } \\
\text { Availability }\end{array}$ & 08/10/92 & $11 / 01 / 92$ \\
\hline $\begin{array}{l}\text { USS } \\
\text { PHILADELPHIA }\end{array}$ & SSN 690 & $\begin{array}{l}\text { Engineered } \\
\text { Refueling } \\
\text { Overhaul }\end{array}$ & $10 / 01 / 92$ & $12 / 23 / 94$ \\
\hline USS WHALE & SSN 638 & $\begin{array}{l}\text { Selected } \\
\text { Restricted } \\
\text { Availability } \\
\qquad 114\end{array}$ & $03 / 01 / 93$ & $04 / 25 / 93$ \\
\hline
\end{tabular}




\begin{tabular}{|c|c|c|c|c|}
\hline \multicolumn{5}{|c|}{ New Construction, Overhauls And Scheduled Maintenance Availabilities } \\
\hline $\begin{array}{l}\text { Nuclear Submarine } \\
\text { Name }\end{array}$ & $\begin{array}{l}\text { Submarine } \\
\text { Number }\end{array}$ & $\begin{array}{l}\text { Type } \\
\text { Availability }\end{array}$ & $\begin{array}{l}\text { Availability } \\
\text { Start Date }\end{array}$ & $\begin{array}{l}\text { Availability } \\
\text { Comp Date }\end{array}$ \\
\hline USS PITTSBURGH & SSN 720 & $\begin{array}{l}\text { Depot } \\
\text { Modernization } \\
\text { Period }\end{array}$ & $05 / 03 / 93$ & $08 / 29 / 94$ \\
\hline USS ARCHERFISH & SSN 678 & $\begin{array}{l}\text { Selected } \\
\text { Restricted } \\
\text { Availability }\end{array}$ & $06 / 01 / 93$ & $07 / 24 / 93$ \\
\hline $\begin{array}{l}\text { NAVAL } \\
\text { RESEARCH ONE }\end{array}$ & NR-1 & $\begin{array}{l}\text { Restricted } \\
\text { Availability }\end{array}$ & 08/09/93 & $10 / 12 / 93$ \\
\hline USS MEMPHIS & SSN 691 & $\begin{array}{l}\text { Engineered } \\
\text { Refueling } \\
\text { Overhaul }\end{array}$ & 02/07/94 & 08/06/96 \\
\hline USS TREPANG & SSN 674 & $\begin{array}{l}\text { Selected } \\
\text { Restricted } \\
\text { Availability }\end{array}$ & $10 / 03 / 94$ & $12 / 01 / 94$ \\
\hline USS GRAYLING & SSN 646 & $\begin{array}{l}\text { Selected } \\
\text { Restricted } \\
\text { Availability }\end{array}$ & $01 / 09 / 95$ & $03 / 08 / 95$ \\
\hline $\begin{array}{l}\text { USS } \\
\text { ALEXANDRIA }\end{array}$ & SSN 757 & $\begin{array}{l}\text { Selected } \\
\text { Restricted } \\
\text { Availability }\end{array}$ & $01 / 09 / 95$ & $03 / 15 / 95$ \\
\hline USS OMAHA & SSN 692 & Inactivation & $02 / 07 / 95$ & $01 / 31 / 96$ \\
\hline USS ASHEVILLE & SSN 758 & $\begin{array}{l}\text { Selected } \\
\text { Restricted } \\
\text { Availability }\end{array}$ & $03 / 10 / 95$ & $05 / 23 / 95$ \\
\hline USS LA JOLLA & SSN 701 & $\begin{array}{l}\text { Selected } \\
\text { Restricted } \\
\text { Availability }\end{array}$ & $05 / 10 / 95$ & $07 / 20 / 95$ \\
\hline $\begin{array}{l}\text { USS SALT LAKE } \\
\text { CITY }\end{array}$ & SSN 716 & $\begin{array}{l}\text { Selected } \\
\text { Restricted } \\
\text { Availability }\end{array}$ & $06 / 28 / 95$ & $09 / 25 / 95$ \\
\hline $\begin{array}{l}\text { USS JEFFERSON } \\
\text { CITY }\end{array}$ & SSN 759 & $\begin{array}{l}\text { Selected } \\
\text { Restricted } \\
\text { Availability }\end{array}$ & $08 / 16 / 95$ & $11 / 14 / 95$ \\
\hline USS DALLAS & SSN 700 & $\begin{array}{l}\text { Engineered } \\
\text { Refueling } \\
\text { Overhaul }\end{array}$ & $10 / 23 / 95$ & $02 / 12 / 98$ \\
\hline
\end{tabular}




\section{Portsmouth Naval Shipyard History Of Nuclear Submarines}

\begin{tabular}{|c|c|c|c|c|}
\hline $\begin{array}{l}\text { Nuclear Submarine } \\
\text { Name }\end{array}$ & $\begin{array}{l}\text { Submarine } \\
\text { Number }\end{array}$ & $\begin{array}{l}\text { Type } \\
\text { Availability }\end{array}$ & $\begin{array}{l}\text { Availability } \\
\text { Start Date }\end{array}$ & $\begin{array}{l}\text { Availability } \\
\text { Comp Date }\end{array}$ \\
\hline USS ARCHERFISH & SSN 678 & $\begin{array}{l}\text { Selected } \\
\text { Restricted } \\
\text { Availability }\end{array}$ & $01 / 22 / 96$ & $03 / 25 / 96$ \\
\hline USS POGY & SSN 647 & $\begin{array}{l}\text { Selected } \\
\text { Restricted } \\
\text { Availability }\end{array}$ & $02 / 01 / 96$ & $04 / 01 / 96$ \\
\hline USS BOISE & SSN 764 & $\begin{array}{l}\text { Intermediate } \\
\text { Maintenance } \\
\text { Availability }\end{array}$ & $02 / 26 / 96$ & 03/28/96 \\
\hline $\begin{array}{l}\text { USS NEW YORK } \\
\text { CITY }\end{array}$ & SSN 696 & Inactivation & 03/19/96 & 07/10/97 \\
\hline USS AUGUSTA & SSN 710 & $\begin{array}{l}\text { Selected } \\
\text { Restricted } \\
\text { Availability }\end{array}$ & $04 / 08 / 96$ & $06 / 15 / 96$ \\
\hline USS MONTPELIER & SSN 765 & $\begin{array}{l}\text { Intermediate } \\
\text { Maintenance } \\
\text { Availability }\end{array}$ & $06 / 06 / 96$ & $07 / 15 / 96$ \\
\hline $\begin{array}{l}\text { USS PHOENIX } \\
\text { PHASE I }\end{array}$ & SSN 702 & $\begin{array}{l}\text { Intermediate } \\
\text { Maintenance } \\
\text { Availability }\end{array}$ & 06/11/96 & $06 / 25 / 96$ \\
\hline $\begin{array}{l}\text { USS } \\
\text { MINNEAPOLIS ST. } \\
\text { PAUL }\end{array}$ & SSN 708 & $\begin{array}{l}\text { Intermediate } \\
\text { Maintenance } \\
\text { Availability }\end{array}$ & 07/15/96 & $08 / 16 / 96$ \\
\hline $\begin{array}{l}\text { USS PHOENIX } \\
\text { PHASE II }\end{array}$ & SSN 702 & $\begin{array}{l}\text { Intermediate } \\
\text { Maintenance } \\
\text { Availability }\end{array}$ & $07 / 22 / 96$ & 08/23/96 \\
\hline $\begin{array}{l}\text { NAVAL } \\
\text { RESEARCH ONE }\end{array}$ & NR-1 & $\begin{array}{l}\text { Selected } \\
\text { Restricted } \\
\text { Availability }\end{array}$ & 08/06/96 & $10 / 18 / 96$ \\
\hline USS SCRANTON & SSN 756 & $\begin{array}{l}\text { Intermediate } \\
\text { Maintenance } \\
\text { Availability }\end{array}$ & $08 / 12 / 96$ & 09/13/96 \\
\hline USS ALBANY & SSN 753 & $\begin{array}{l}\text { Intermediate } \\
\text { Maintenance } \\
\text { Availability }\end{array}$ & $09 / 16 / 96$ & $10 / 25 / 96$ \\
\hline USS GROTON & SSN 694 & $\begin{array}{c}\text { Inactivation } \\
116\end{array}$ & $10 / 01 / 96$ & 03/30/98 \\
\hline
\end{tabular}




\begin{tabular}{|c|c|c|c|c|}
\hline \multicolumn{5}{|c|}{$\begin{array}{l}\text { Portsmouth Naval Shipyard } \\
\text { History Of Nuclear Submarines }\end{array}$} \\
\hline \multicolumn{5}{|c|}{ New Construction, Overhauls And Scheduled Maintenance Availabilities } \\
\hline $\begin{array}{l}\text { Nuclear Submarine } \\
\text { Name }\end{array}$ & $\begin{array}{l}\text { Submarine } \\
\text { Number }\end{array}$ & $\begin{array}{l}\text { Type } \\
\text { Availability } \\
\end{array}$ & $\begin{array}{l}\text { Availability } \\
\text { Start Date }\end{array}$ & $\begin{array}{l}\text { Availability } \\
\text { Comp Date }\end{array}$ \\
\hline USS TREPANG & SSN 674 & $\begin{array}{l}\text { Selected } \\
\text { Restricted } \\
\text { Availability }\end{array}$ & $10 / 15 / 96$ & $12 / 13 / 96$ \\
\hline USS PROVIDENCE & SSN 719 & $\begin{array}{l}\text { Selected } \\
\text { Restricted } \\
\text { Availability }\end{array}$ & $10 / 17 / 96$ & $12 / 21 / 96$ \\
\hline USS ATLANTA & SSN 712 & $\begin{array}{l}\text { Intermediate } \\
\text { Maintenance } \\
\text { Availability }\end{array}$ & $10 / 28 / 96$ & $11 / 22 / 96$ \\
\hline $\begin{array}{l}\text { USS OKLAHOMA } \\
\text { CITY }\end{array}$ & SSN 723 & $\begin{array}{l}\text { Intermediate } \\
\text { Maintenance } \\
\text { Availability }\end{array}$ & $10 / 28 / 96$ & $11 / 22 / 96$ \\
\hline $\begin{array}{l}\text { USS OKLAHOMA } \\
\text { CITY }\end{array}$ & SSN 723 & $\begin{array}{l}\text { Depot } \\
\text { Modernization } \\
\text { Period }\end{array}$ & $01 / 06 / 97$ & $03 / 18 / 98$ \\
\hline USS RICKOVER & SSN 709 & $\begin{array}{l}\text { Intermediate } \\
\text { Maintenance } \\
\text { Availability }\end{array}$ & $01 / 13 / 97$ & $03 / 13 / 97$ \\
\hline $\begin{array}{l}\text { USS } \\
\text { MINNEAPOLIS } \\
\text { SAINT PAUL }\end{array}$ & SSN 708 & $\begin{array}{l}\text { Intermediate } \\
\text { Maintenance } \\
\text { Availability }\end{array}$ & $01 / 27 / 97$ & $02 / 28 / 97$ \\
\hline USS SPRINGFIELD & SSN 761 & $\begin{array}{l}\text { Selected } \\
\text { Restricted } \\
\text { Availability }\end{array}$ & $02 / 03 / 97$ & $04 / 04 / 97$ \\
\hline $\begin{array}{l}\text { USS CITY OF } \\
\text { CORPUS CHRISTI }\end{array}$ & SSN 705 & $\begin{array}{l}\text { Selected } \\
\text { Restricted } \\
\text { Availability }\end{array}$ & $04 / 01 / 97$ & $05 / 31 / 97$ \\
\hline USS NARWHAL & SSN 671 & $\begin{array}{l}\text { Intermediate } \\
\text { Maintenance } \\
\text { Availability }\end{array}$ & $05 / 26 / 97$ & 06/30/97 \\
\hline USS NORFOLK & SSN 714 & $\begin{array}{l}\text { Intermediate } \\
\text { Maintenance } \\
\text { Availability }\end{array}$ & $05 / 27 / 97$ & 06/30/97 \\
\hline USS HOUSTON & SSN 713 & $\begin{array}{l}\text { Selected } \\
\text { Restricted } \\
\text { Availability }\end{array}$ & $06 / 30 / 97$ & 09/29/97 \\
\hline
\end{tabular}




\begin{tabular}{|c|c|c|c|c|}
\hline \multicolumn{5}{|c|}{ New Construction, Overhauls And Scheduled Maintenance Availabilities } \\
\hline $\begin{array}{l}\text { Nuclear Submarine } \\
\text { Name }\end{array}$ & $\begin{array}{l}\text { Submarine } \\
\text { Number }\end{array}$ & $\begin{array}{l}\text { Type } \\
\text { Availability }\end{array}$ & $\begin{array}{l}\text { Availability } \\
\text { Start Date }\end{array}$ & $\begin{array}{l}\text { Availability } \\
\text { Comp Date }\end{array}$ \\
\hline USS SAN JUAN & SSN 751 & $\begin{array}{l}\text { Intermediate } \\
\text { Dry Docking }\end{array}$ & $08 / 01 / 97$ & $09 / 24 / 97$ \\
\hline $\begin{array}{l}\text { USS } \\
\text { ALBUQUERQUE }\end{array}$ & SSN 706 & $\begin{array}{l}\text { Selected } \\
\text { Restricted } \\
\text { Availability }\end{array}$ & $10 / 01 / 97$ & $12 / 08 / 97$ \\
\hline USS PHOENIX & SSN 702 & Inactivation & $10 / 01 / 97$ & 03/17/99 \\
\hline USS MIAMI & SSN 755 & $\begin{array}{l}\text { Selected } \\
\text { Restricted } \\
\text { Availability }\end{array}$ & $10 / 15 / 97$ & $01 / 23 / 98$ \\
\hline USS PITTSBURGH & SSN 720 & $\begin{array}{l}\text { Selected } \\
\text { Restricted } \\
\text { Availability }\end{array}$ & $11 / 15 / 97$ & $02 / 04 / 98$ \\
\hline USS NORFOLK & SSN 714 & $\begin{array}{l}\text { Selected } \\
\text { Restricted } \\
\text { Availability }\end{array}$ & $03 / 02 / 98$ & $05 / 13 / 98$ \\
\hline USS HELENA & SSN 725 & $\begin{array}{l}\text { Depot } \\
\text { Modernization } \\
\text { Period }\end{array}$ & 03/09/98 & 04/01/99 \\
\hline $\begin{array}{l}\text { USS } \\
\text { PHILADELPHIA }\end{array}$ & SSN 690 & $\begin{array}{l}\text { Selected } \\
\text { Restricted } \\
\text { Availability }\end{array}$ & 06/09/98 & $10 / 08 / 98$ \\
\hline $\begin{array}{l}\text { NAVAL } \\
\text { RESEARCH ONE }\end{array}$ & NR-1 & $\begin{array}{l}\text { Selected } \\
\text { Restricted } \\
\text { Availability }\end{array}$ & $08 / 05 / 98$ & $11 / 03 / 98$ \\
\hline USS LA JOLLA & SSN 701 & $\begin{array}{l}\text { Engineered } \\
\text { Refueling } \\
\text { Overhaul }\end{array}$ & $10 / 01 / 98$ & $12 / 09 / 00$ \\
\hline $\begin{array}{l}\text { USS } \\
\text { ALEXANDRIA }\end{array}$ & SSN 757 & $\begin{array}{l}\text { Selected } \\
\text { Restricted } \\
\text { Availability }\end{array}$ & $10 / 05 / 98$ & $12 / 02 / 98$ \\
\hline $\begin{array}{l}\text { USS } \\
\text { MINNEAPOLIS } \\
\text { SAINT PAUL }\end{array}$ & SSN 708 & $\begin{array}{l}\text { Selected } \\
\text { Restricted } \\
\text { Availability }\end{array}$ & $01 / 28 / 99$ & $04 / 23 / 99$ \\
\hline $\begin{array}{l}\text { USS SALT LAKE } \\
\text { CITY }\end{array}$ & SSN 716 & $\begin{array}{l}\text { Selected } \\
\text { Restricted } \\
\text { Availability }\end{array}$ & $03 / 02 / 99$ & $05 / 02 / 99$ \\
\hline
\end{tabular}




\begin{tabular}{|c|c|c|c|c|}
\hline \multicolumn{5}{|c|}{ New Construction, Overhauls And Scheduled Maintenance Availabilities } \\
\hline $\begin{array}{l}\text { Nuclear Submarine } \\
\text { Name }\end{array}$ & $\begin{array}{l}\text { Submarine } \\
\text { Number }\end{array}$ & $\begin{array}{l}\text { Type } \\
\text { Availability }\end{array}$ & $\begin{array}{l}\text { Availability } \\
\text { Start Date }\end{array}$ & $\begin{array}{l}\text { Availability } \\
\text { Comp Date }\end{array}$ \\
\hline USS HARTFORD & SSN 768 & $\begin{array}{l}\text { Selected } \\
\text { Restricted } \\
\text { Availability }\end{array}$ & $05 / 01 / 99$ & $07 / 16 / 99$ \\
\hline USS SPRINGFIELD & SSN 761 & $\begin{array}{l}\text { Intermediate } \\
\text { Maintenance } \\
\text { Availability }\end{array}$ & $05 / 10 / 99$ & 06/18/99 \\
\hline USS TOLEDO & SSN 769 & $\begin{array}{l}\text { Selected } \\
\text { Restricted } \\
\text { Availability }\end{array}$ & $07 / 21 / 99$ & $10 / 14 / 99$ \\
\hline USS SAN JUAN & SSN 751 & $\begin{array}{l}\text { Intermediate } \\
\text { Maintenance } \\
\text { Availability }\end{array}$ & 09/01/99 & 09/30/99 \\
\hline USS HAMPTON & SSN 767 & $\begin{array}{l}\text { Intermediate } \\
\text { Maintenance } \\
\text { Availability }\end{array}$ & 09/07/99 & 09/30/99 \\
\hline USS ANNAPOLIS & SSN 760 & $\begin{array}{l}\text { Selected } \\
\text { Restricted } \\
\text { Availability }\end{array}$ & $09 / 29 / 99$ & $12 / 20 / 99$ \\
\hline USS SAN JUAN & SSN 751 & $\begin{array}{l}\text { Depot } \\
\text { Modernization } \\
\text { Period }\end{array}$ & $10 / 01 / 99$ & $12 / 14 / 00$ \\
\hline USS AUGUSTA & SSN 710 & $\begin{array}{l}\text { Selected } \\
\text { Restricted } \\
\text { Availability }\end{array}$ & $11 / 23 / 99$ & $02 / 10 / 00$ \\
\hline $\begin{array}{l}\text { USS CITY OF } \\
\text { CORPUS CHRISTI }\end{array}$ & SSN 705 & $\begin{array}{l}\text { Engineered } \\
\text { Refueling } \\
\text { Overhaul }\end{array}$ & $03 / 31 / 00$ & $03 / 25 / 02$ \\
\hline USS PROVIDENCE & SSN 719 & $\begin{array}{l}\text { Selected } \\
\text { Restricted } \\
\text { Availability }\end{array}$ & $05 / 09 / 00$ & $07 / 29 / 00$ \\
\hline USS SPRINGFIELD & SSN 761 & $\begin{array}{l}\text { Selected } \\
\text { Restricted } \\
\text { Availability }\end{array}$ & $10 / 02 / 00$ & $12 / 10 / 01$ \\
\hline $\begin{array}{l}\text { NAVAL } \\
\text { RESEARCH ONE }\end{array}$ & NR-1 & $\begin{array}{l}\text { Selected } \\
\text { Restricted } \\
\text { Availability }\end{array}$ & $11 / 28 / 00$ & $04 / 04 / 01$ \\
\hline
\end{tabular}




\begin{tabular}{|c|c|c|c|c|}
\hline \multicolumn{5}{|c|}{ New Construction, Overhauls And Scheduled Maintenance Availabilities } \\
\hline $\begin{array}{l}\text { Nuclear Submarine } \\
\text { Name }\end{array}$ & $\begin{array}{l}\text { Submarine } \\
\text { Number }\end{array}$ & $\begin{array}{l}\text { Type } \\
\text { Availability }\end{array}$ & $\begin{array}{l}\text { Availability } \\
\text { Start Date }\end{array}$ & $\begin{array}{l}\text { Availability } \\
\text { Comp Date }\end{array}$ \\
\hline USS MIAMI & SSN 755 & $\begin{array}{l}\text { Depot } \\
\text { Modernization } \\
\text { Period }\end{array}$ & $01 / 31 / 01$ & $02 / 11 / 02$ \\
\hline $\begin{array}{l}\text { USS } \\
\text { ALBUQUERQUE }\end{array}$ & SSN 706 & $\begin{array}{l}\text { Engineered } \\
\text { Refueling } \\
\text { Overhaul }\end{array}$ & 07/01/01 & \\
\hline $\begin{array}{l}\text { USS } \\
\text { ALEXANDRIA }\end{array}$ & SSN 757 & $\begin{array}{l}\text { Depot } \\
\text { Modernization } \\
\text { Period }\end{array}$ & $01 / 31 / 02$ & \\
\hline USS MEMPHIS & SSN 691 & $\begin{array}{l}\text { Red. Gear } \\
\text { Repl. Technical } \\
\text { Availability }\end{array}$ & $03 / 13 / 02$ & $12 / 11 / 02$ \\
\hline $\begin{array}{l}\text { USS CITY OF } \\
\text { CORPUS CHRISTI }\end{array}$ & SSN 705 & $\begin{array}{l}\text { C4I Upgrade } \\
\text { Technical } \\
\text { Availability }\end{array}$ & $05 / 23 / 02$ & \\
\hline USS MEMPHIS & SSN 691 & $\begin{array}{l}\text { Selected } \\
\text { Restricted } \\
\text { Availability }\end{array}$ & $07 / 15 / 02$ & $12 / 11 / 02$ \\
\hline USS NORFOLK & SSN 714 & $\begin{array}{l}\text { Engineered } \\
\text { Refueling } \\
\text { Overhaul }\end{array}$ & $10 / 15 / 02$ & \\
\hline $\begin{array}{l}\text { USS } \\
\text { PHILADELPHIA }\end{array}$ & SSN 690 & $\begin{array}{l}\text { Selected } \\
\text { Restricted } \\
\text { Availability }\end{array}$ & $10 / 01 / 02$ & \\
\hline USS HARTFORD & SSN 768 & $\begin{array}{l}\text { Selected } \\
\text { Restricted } \\
\text { Availability }\end{array}$ & $01 / 07 / 03$ & \\
\hline USS ANNAPOLIS & SSN 760 & $\begin{array}{l}\text { Depot } \\
\text { Modernization } \\
\text { Period } \\
\end{array}$ & $04 / 29 / 02$ & \\
\hline
\end{tabular}




\section{Appendix E}

Non-Work-Related Medical X-Ray

Examinations Given at PNS

\begin{tabular}{|c|c|c|c|}
\hline \multicolumn{4}{|c|}{$\begin{array}{l}\text { Frequency and Location of Non-Work-Related Medical } \\
\text { X-Ray Examinations Given at PNS } \\
\text { (Adapted from Daniels et al., 2004b) }\end{array}$} \\
\hline Body Location & Frequency & Percent & $\begin{array}{l}\text { Cumulative } \\
\text { Frequency }\end{array}$ \\
\hline Chest & 196 & 27.48 & 196 \\
\hline Lumbar-Sacral Spine & 65 & 9.11 & 261 \\
\hline Thoracic Spine & 3 & 0.42 & 264 \\
\hline Cervical Spine & 18 & 2.52 & 282 \\
\hline Hand, Wrist, or Finger & 146 & 20.47 & 428 \\
\hline Leg & 26 & 3.64 & 454 \\
\hline Arm & 6 & 0.84 & 460 \\
\hline Skull & 14 & 1.96 & 474 \\
\hline Barium Enema & 1 & 0.14 & 475 \\
\hline Upper GI & 3 & 0.42 & 478 \\
\hline Abdomen & 3 & 0.42 & 481 \\
\hline Knee & 47 & 6.59 & 528 \\
\hline Shoulder & 34 & 4.76 & 562 \\
\hline Foot, Toe, Ankle & 86 & 12.06 & 648 \\
\hline Hip, Pelvis & 6 & 0.84 & 654 \\
\hline Elbow & 54 & 7.57 & 708 \\
\hline Facial Bones & 2 & 0.28 & 710 \\
\hline Clavicle & 1 & 0.14 & 711 \\
\hline Sternum & 1 & 0.14 & 712 \\
\hline Coccyx & 1 & 0.14 & 713 \\
\hline
\end{tabular}




\section{Appendix F}

Actual and Estimated Routine and Diagnostic Medical X-Rays Combined Given at PNS

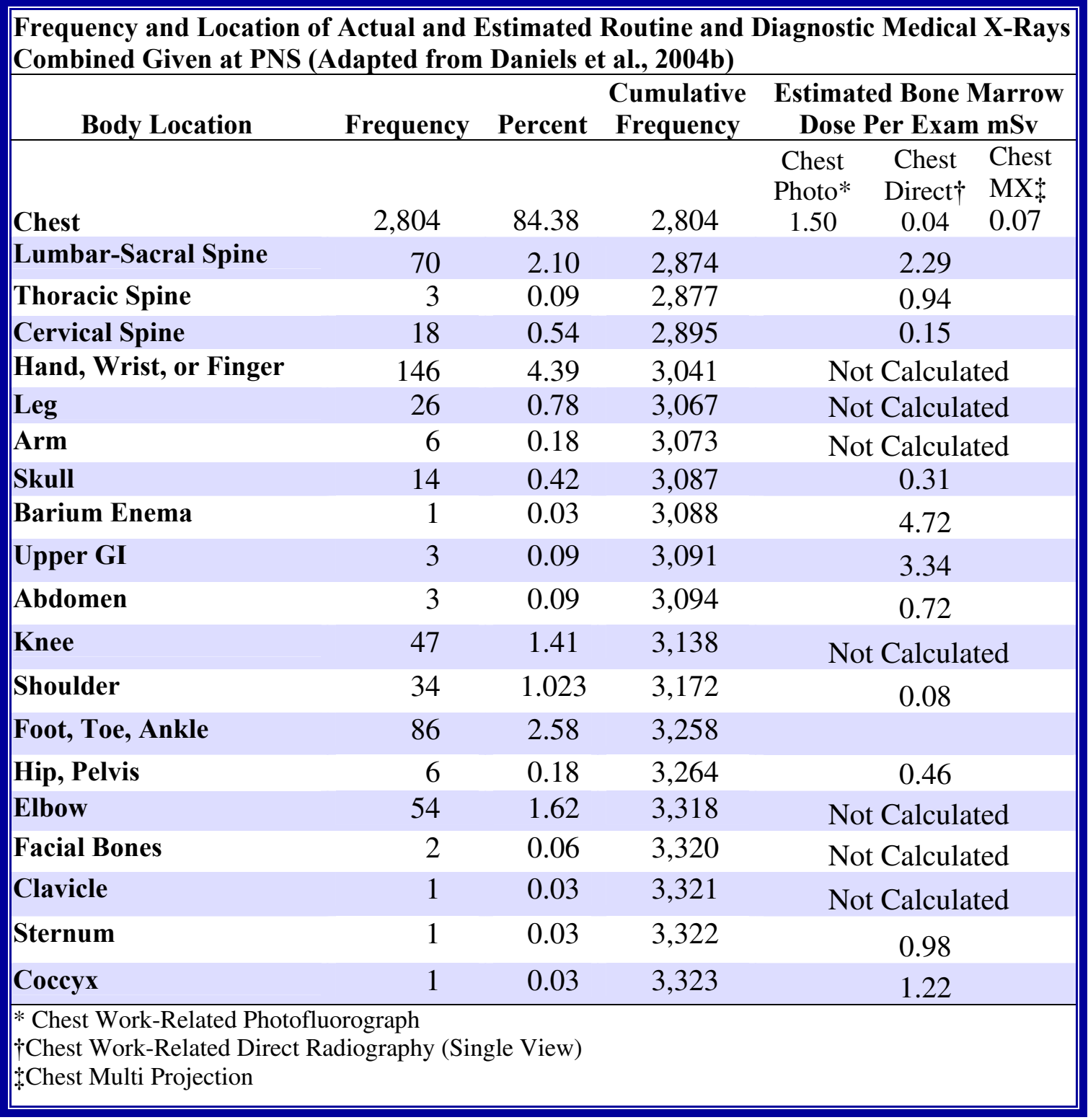




\section{Appendix G}

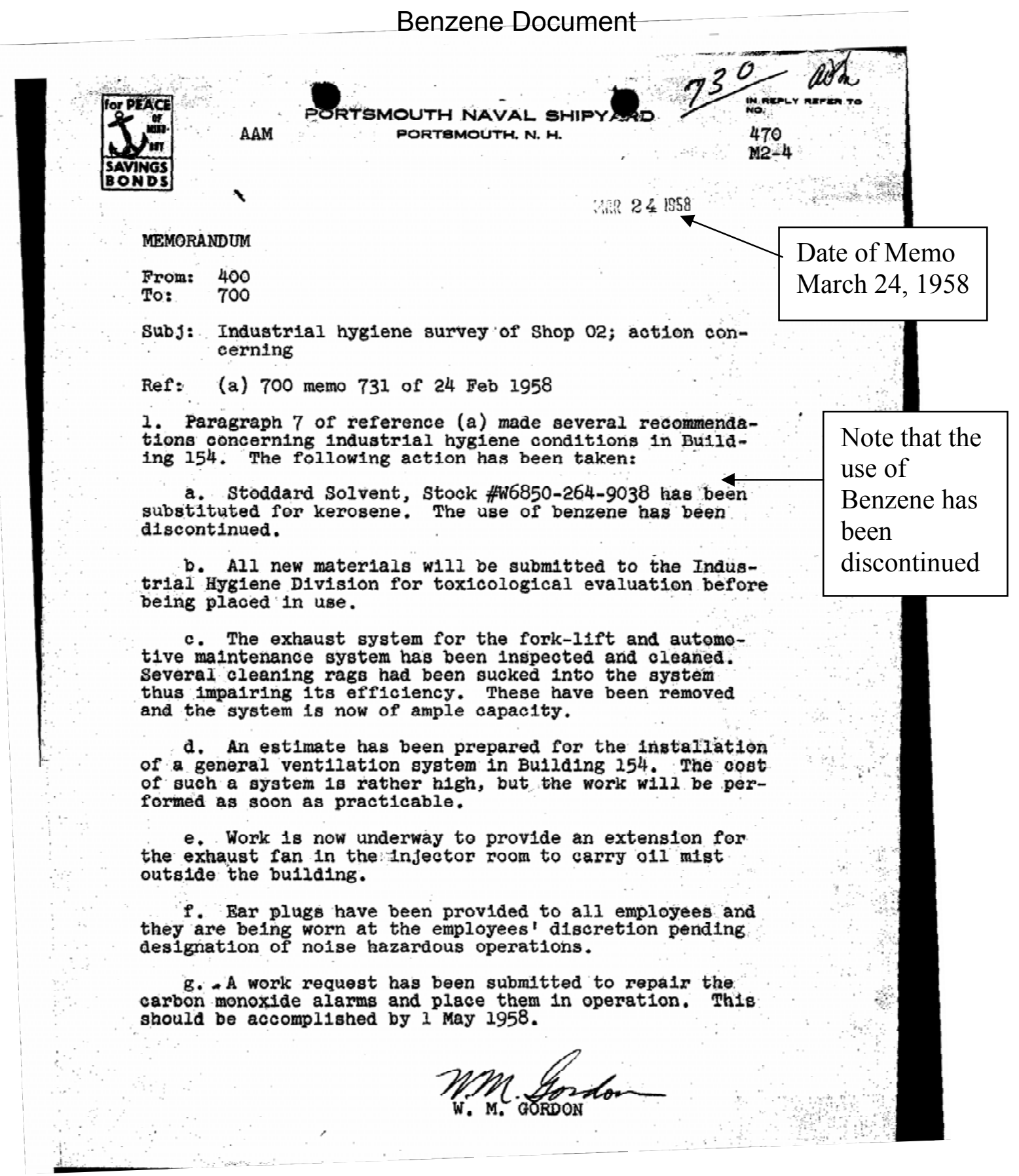




\section{Carbon Tetrachloride Document}

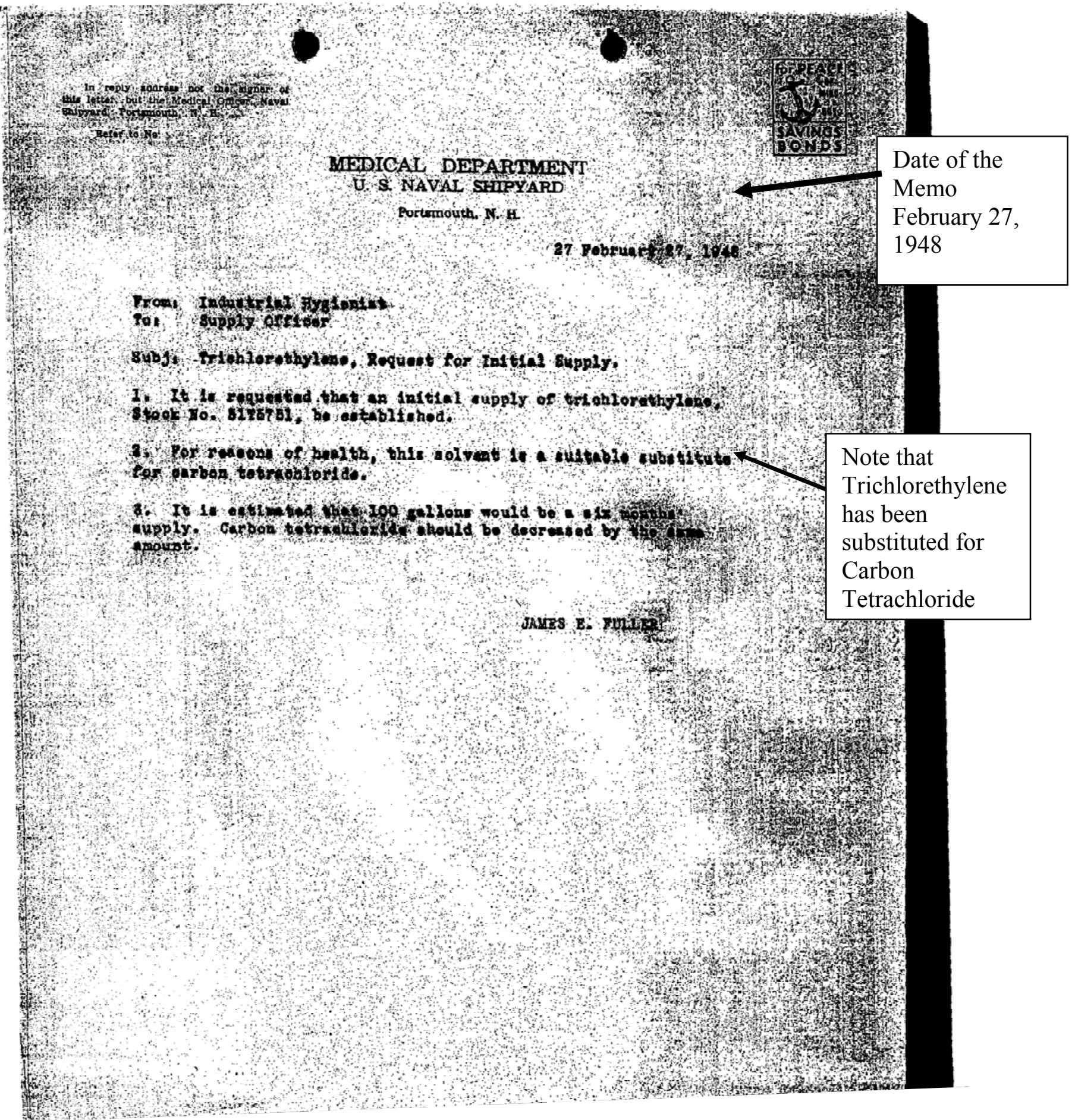




\section{Appendix $\mathbf{H}$}

Table 1: Illustration of Shop/Job Title Collapse Using Painters

Job Title Collapse

Jobs Titles Associated with Painting Group (03)

\begin{tabular}{|ll}
\hline Painter & Painter Helper \\
Painter Apprentice & Painter Supervisor \\
Painter Worker & Painting Foreman General
\end{tabular}

\section{Production Shop}

Paint Shops (71)

\begin{tabular}{|ll|}
\hline 71 & 271 \\
071 & 371 \\
171 &
\end{tabular}$+$

\section{Shop/Job/Code}

\section{Painting Group (03)}

Painter

Painter Helper

Painter Apprentice

Painter Worker

$=7103$

\begin{tabular}{l}
\multicolumn{1}{c}{ Exposed } \\
Job title with potential \\
solvent exposure \\
assigned to a production \\
shop where exposure \\
was likely to occur.
\end{tabular}




\section{Support Shop}

Maintenance Shops (07)

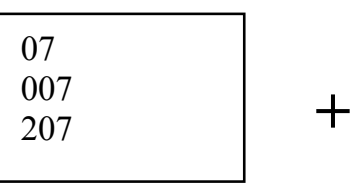

\section{Shop/Job/Code}

Painting Group (03)

\section{Painter}

Painter Helper

Painter Apprentice

$=0703$

Painter Worker

Painting Foreman General

\section{Exposed}

Job title with potential

solvent exposure

assigned to a support

shop where exposure

was likely to occur.

\section{Administrative Shop}

\section{Shop/Job/Code}

Planning \& Estimating Shops (04) Painting Group (03)

\begin{tabular}{|lll}
\hline 04 & 90 & 322 \\
20 & 93 & 368 \\
22 & 222 & 373 \\
24 & 278 & 393 \\
25 & 293 & 395 \\
44 & 320 & 396 \\
86 & 321 & 801
\end{tabular} \mid$+\quad \begin{aligned} & \quad \text { Painter } \\
& \text { Painter Helper } \\
& \text { Painter Apprentice } \\
& \text { Painter Supervisor } \\
& \text { Painter Worker } \\
& \text { Painting Foreman General }\end{aligned}$

Not Exposed

Job title with potential

solvent exposure but

assigned to an

administrative shop

where exposure were

not likely to occur. 
Table 2: Exposed Job And Shop Collapse

\begin{tabular}{|c|c|c|c|}
\hline $\begin{array}{l}\text { NIOSH } \\
\text { Exposure } \\
\text { Category }\end{array}$ & $\begin{array}{l}\text { NIOSH } \\
\text { Assigned } \\
\text { Job Code }\end{array}$ & $\begin{array}{l}\text { NIOSH } \\
\text { Assigned } \\
\text { Job Title }\end{array}$ & $\begin{array}{c}\text { Original } \\
\text { Site } \\
\text { Job Title }\end{array}$ \\
\hline Welding Group & $01 x$ & $\begin{array}{l}\text { Flame/Arc } \\
\text { Cutter }\end{array}$ & Flame Cutter \\
\hline Welding Group & $01 x$ & $\begin{array}{l}\text { Flame/Arc } \\
\text { Cutter }\end{array}$ & Gas Cutter/Burner \\
\hline Welding Group & $01 x$ & $\begin{array}{l}\text { Gas } \\
\text { Generating } \\
\text { Plant Operator }\end{array}$ & Gas Plant Operator \\
\hline Welding Group & $01 x$ & $\begin{array}{l}\text { Industrial } \\
\text { Equipment } \\
\text { Mechanic }\end{array}$ & Mechanic (Learner) \\
\hline Welding Group & $01 x$ & $\begin{array}{l}\text { Metal } \\
\text { Processing }\end{array}$ & Shielding Installer \\
\hline Welding Group & $01 x$ & $\begin{array}{l}\text { Metal } \\
\text { Processing }\end{array}$ & Struct Shop Gen Fmn \\
\hline Welding Group & $01 x$ & Welder & Electric Welder \\
\hline Welding Group & $01 x$ & Welder & Electric Welder Leadingman \\
\hline Welding Group & $01 x$ & Welder & $\begin{array}{l}\text { Electric Welder Leadingman } \\
\text { Spec }\end{array}$ \\
\hline Welding Group & $01 x$ & Welder & Electric Welder Quarterman \\
\hline Welding Group & $01 x$ & Welder & Electric Welder Snapper \\
\hline Welding Group & $01 x$ & Welder & Foreman Welder \\
\hline Welding Group & $01 x$ & Welder & Foreman Welder Electric \\
\hline Welding Group & 01x & Welder & Gas Welder \\
\hline Welding Group & $01 x$ & Welder & Operator(Acetylene) \\
\hline Welding Group & $01 x$ & Welder & Welder \\
\hline Welding Group & $01 x$ & Welder & Welder (Electric) \\
\hline
\end{tabular}


Table 2: Exposed Job And Shop Collapse

\begin{tabular}{|c|c|c|c|}
\hline $\begin{array}{l}\text { NIOSH } \\
\text { Exposure } \\
\text { Category }\end{array}$ & $\begin{array}{l}\text { NIOSH } \\
\text { Assigned } \\
\text { Job Code }\end{array}$ & $\begin{array}{l}\text { NIOSH } \\
\text { Assigned } \\
\text { Job Title }\end{array}$ & $\begin{array}{l}\text { Original } \\
\text { Site } \\
\text { Job Title }\end{array}$ \\
\hline Welding Group & $01 x$ & Welder & Welder (Limited) \\
\hline Welding Group & $01 x$ & Welder & Welder Apprentice \\
\hline Welding Group & $01 x$ & Welder & Welder Combination Apprentice \\
\hline Welding Group & $01 x$ & Welder & Welder Foreman \\
\hline Welding Group & $01 x$ & Welder & Welder General Foreman \\
\hline Welding Group & $01 x$ & Welder & Welder Helper \\
\hline Welding Group & $01 x$ & Welder & Welder Instructor \\
\hline Welding Group & $01 x$ & Welder & Welder Leadingman \\
\hline Welding Group & $01 x$ & Welder & Welder Limited \\
\hline Welding Group & $01 x$ & Welder & Welder Quarterman \\
\hline Welding Group & $01 x$ & Welder & Welder Special \\
\hline Welding Group & $01 x$ & Welder & Welder Trainee \\
\hline Welding Group & $01 x$ & Welder & Welding Worker \\
\hline $\begin{array}{l}\text { Transportation } \\
\text { Group }\end{array}$ & $02 x$ & $\begin{array}{l}\text { Equipment } \\
\text { Cleaner }\end{array}$ & Equipment Cleaner \\
\hline $\begin{array}{l}\text { Transportation } \\
\text { Group }\end{array}$ & $02 x$ & $\begin{array}{l}\text { Equipment } \\
\text { Cleaner }\end{array}$ & Equipment Cleaner Foreman \\
\hline $\begin{array}{l}\text { Transportation } \\
\text { Group }\end{array}$ & $02 x$ & $\begin{array}{l}\text { Equipment } \\
\text { Cleaner }\end{array}$ & $\begin{array}{l}\text { Equipment Cleaner General } \\
\text { Foreman }\end{array}$ \\
\hline $\begin{array}{l}\text { Transportation } \\
\text { Group }\end{array}$ & $02 x$ & $\begin{array}{l}\text { Equipment } \\
\text { Cleaner }\end{array}$ & Equipment Cleaner Leader \\
\hline $\begin{array}{l}\text { Transportation } \\
\text { Group }\end{array}$ & $02 x$ & $\begin{array}{l}\text { Equipment } \\
\text { Cleaner }\end{array}$ & $\begin{array}{l}\text { Equipment Cleaner Leader } \\
\text { Trainee }\end{array}$ \\
\hline $\begin{array}{l}\text { Transportation } \\
\text { Group }\end{array}$ & $02 x$ & Laborer & Laborer (Cleaner) \\
\hline $\begin{array}{l}\text { Transportation } \\
\text { Group }\end{array}$ & $02 x$ & Laborer & $\begin{array}{l}\text { Laborer (Cleaner) Leadingman } \\
\text { Foreman }\end{array}$ \\
\hline
\end{tabular}


Table 2: Exposed Job And Shop Collapse

\begin{tabular}{|c|c|c|c|}
\hline $\begin{array}{l}\text { NIOSH } \\
\text { Exposure } \\
\text { Category }\end{array}$ & $\begin{array}{c}\text { NIOSH } \\
\text { Assigned } \\
\text { Job Code }\end{array}$ & $\begin{array}{l}\text { NIOSH } \\
\text { Assigned } \\
\text { Job Title }\end{array}$ & $\begin{array}{l}\text { Original } \\
\text { Site } \\
\text { Job Title }\end{array}$ \\
\hline $\begin{array}{l}\text { Transportation } \\
\text { Group }\end{array}$ & $02 x$ & Laborer & Laborer Leadingman (Cleaner) \\
\hline $\begin{array}{l}\text { Transportation } \\
\text { Group }\end{array}$ & $02 x$ & Laborer & Laborer/Cleaner \\
\hline $\begin{array}{l}\text { Transportation } \\
\text { Group }\end{array}$ & $02 x$ & Laborer & $\begin{array}{l}\text { Laborer/Cleaner Leadingman } \\
\text { Foreman }\end{array}$ \\
\hline $\begin{array}{l}\text { Transportation } \\
\text { Group }\end{array}$ & $04 x$ & $\begin{array}{l}\text { Equipment } \\
\text { Cleaner }\end{array}$ & Component Cleaner \\
\hline $\begin{array}{l}\text { Transportation } \\
\text { Group }\end{array}$ & $04 x$ & $\begin{array}{l}\text { Equipment } \\
\text { Cleaner }\end{array}$ & Tank Cleaner \\
\hline $\begin{array}{l}\text { Transportation } \\
\text { Group }\end{array}$ & $16 x$ & $\begin{array}{l}\text { Fork Lift } \\
\text { Operator }\end{array}$ & High Lift Truck Operator \\
\hline $\begin{array}{l}\text { Transportation } \\
\text { Group }\end{array}$ & $16 x$ & $\begin{array}{l}\text { Fork Lift } \\
\text { Operator }\end{array}$ & Operator High Lift Truck \\
\hline $\begin{array}{l}\text { Transportation } \\
\text { Group }\end{array}$ & $38 x$ & $\begin{array}{l}\text { Automotive } \\
\text { Mechanic }\end{array}$ & Automotive Mechanic \\
\hline $\begin{array}{l}\text { Transportation } \\
\text { Group }\end{array}$ & $39 x$ & $\begin{array}{l}\text { Crane } \\
\text { Operator }\end{array}$ & Crane Operator \\
\hline $\begin{array}{l}\text { Transportation } \\
\text { Group }\end{array}$ & $39 x$ & $\begin{array}{l}\text { Crane } \\
\text { Operator }\end{array}$ & Crane Operator Trainee \\
\hline $\begin{array}{l}\text { Transportation } \\
\text { Group }\end{array}$ & $39 x$ & $\begin{array}{l}\text { Crane } \\
\text { Operator }\end{array}$ & $\begin{array}{l}\text { Operating Engineer (Hoisting } \\
\text { Equip) }\end{array}$ \\
\hline $\begin{array}{l}\text { Transportation } \\
\text { Group }\end{array}$ & $39 x$ & $\begin{array}{l}\text { Crane } \\
\text { Operator }\end{array}$ & $\begin{array}{l}\text { Operating Engineer } \\
\text { Foreman/Ldgman }\end{array}$ \\
\hline $\begin{array}{l}\text { Transportation } \\
\text { Group }\end{array}$ & $39 x$ & $\begin{array}{l}\text { Crane } \\
\text { Operator }\end{array}$ & $\begin{array}{l}\text { Operating Engineer (Hoisting } \\
\text { Equipment) }\end{array}$ \\
\hline $\begin{array}{l}\text { Transportation } \\
\text { Group }\end{array}$ & $40 x$ & $\begin{array}{l}\text { Motor Vehicle } \\
\text { Operator }\end{array}$ & Chauffeur \\
\hline
\end{tabular}


Table 2: Exposed Job And Shop Collapse

\begin{tabular}{|c|c|c|c|}
\hline $\begin{array}{l}\text { NIOSH } \\
\text { Exposure } \\
\text { Category }\end{array}$ & $\begin{array}{l}\text { NIOSH } \\
\text { Assigned } \\
\text { Job Code }\end{array}$ & $\begin{array}{l}\text { NIOSH } \\
\text { Assigned } \\
\text { Job Title }\end{array}$ & $\begin{array}{c}\text { Original } \\
\text { Site } \\
\text { Job Title }\end{array}$ \\
\hline $\begin{array}{l}\text { Transportation } \\
\text { Group }\end{array}$ & $40 x$ & $\begin{array}{l}\text { Motor Vehicle } \\
\text { Operator }\end{array}$ & Chauffeur (Heavy Duty) \\
\hline $\begin{array}{l}\text { Transportation } \\
\text { Group }\end{array}$ & $40 x$ & $\begin{array}{l}\text { Motor Vehicle } \\
\text { Operator }\end{array}$ & Motor Vehicle Operator \\
\hline $\begin{array}{l}\text { Transportation } \\
\text { Group }\end{array}$ & $40 x$ & $\begin{array}{l}\text { Motor Vehicle } \\
\text { Operator }\end{array}$ & Truck Driver \\
\hline $\begin{array}{l}\text { Transportation } \\
\text { Group }\end{array}$ & $40 x$ & $\begin{array}{l}\text { Motor Vehicle } \\
\text { Operator }\end{array}$ & Truck Driver (Heavy) \\
\hline $\begin{array}{l}\text { Transportation } \\
\text { Group }\end{array}$ & $42 x$ & $\begin{array}{l}\text { Locomotive } \\
\text { Engineer }\end{array}$ & Engineman \\
\hline $\begin{array}{l}\text { Transportation } \\
\text { Group }\end{array}$ & $42 x$ & $\begin{array}{l}\text { Locomotive } \\
\text { Engineer }\end{array}$ & Engineman (Hoist/Portable) \\
\hline $\begin{array}{l}\text { Transportation } \\
\text { Group }\end{array}$ & $43 x$ & $\begin{array}{l}\text { Oiler \& } \\
\text { Greaser }\end{array}$ & Oiler \\
\hline $\begin{array}{l}\text { Transportation } \\
\text { Group }\end{array}$ & $50 x$ & $\begin{array}{l}\text { Fuel } \\
\text { Distribution } \\
\text { System } \\
\text { Operator }\end{array}$ & $\begin{array}{l}\text { Liquid Fuel Distributing System } \\
\text { Operator }\end{array}$ \\
\hline $\begin{array}{l}\text { Transportation } \\
\text { Group }\end{array}$ & $50 x$ & $\begin{array}{l}\text { Fuel } \\
\text { Distribution } \\
\text { System } \\
\text { Operator }\end{array}$ & Liquid Fuel Pump Operator \\
\hline Painting Group & $03 x$ & Painter & Painter \\
\hline Painting Group & $03 x$ & Painter & Painter Apprentice \\
\hline Painting Group & $03 x$ & Painter & Painter Foreman General \\
\hline Painting Group & $03 x$ & Painter & Painter Helper \\
\hline Painting Group & $03 x$ & Painter & Painting Worker \\
\hline
\end{tabular}


Table 2: Exposed Job And Shop Collapse

\begin{tabular}{|c|c|c|c|}
\hline $\begin{array}{l}\text { NIOSH } \\
\text { Exposure } \\
\text { Category }\end{array}$ & $\begin{array}{c}\text { NIOSH } \\
\text { Assigned } \\
\text { Job Code }\end{array}$ & $\begin{array}{l}\text { NIOSH } \\
\text { Assigned } \\
\text { Job Title }\end{array}$ & $\begin{array}{c}\text { Original } \\
\text { Site } \\
\text { Job Title }\end{array}$ \\
\hline Electrician Group & $21 x$ & $\begin{array}{l}\text { Rubber } \\
\text { Products } \\
\text { Molder }\end{array}$ & Rubber Worker \\
\hline Electrician Group & $27 x$ & $\begin{array}{l}\text { Electronics } \\
\text { Mechanic }\end{array}$ & Electronics Mechanic \\
\hline Electrician Group & $27 x$ & $\begin{array}{l}\text { Electronics } \\
\text { Mechanic }\end{array}$ & $\begin{array}{l}\text { Electronics Mechanic } \\
\text { Apprentice }\end{array}$ \\
\hline Electrician Group & $27 x$ & $\begin{array}{l}\text { Electronics } \\
\text { Mechanic }\end{array}$ & Electronics Mechanic Helper \\
\hline Electrician Group & $27 x$ & $\begin{array}{l}\text { Electronics } \\
\text { Mechanic }\end{array}$ & Instrument Maker \\
\hline Electrician Group & $27 x$ & $\begin{array}{l}\text { Electronics } \\
\text { Mechanic }\end{array}$ & Instrument Mech (Electronic) \\
\hline Electrician Group & $27 x$ & $\begin{array}{l}\text { Electronics } \\
\text { Mechanic }\end{array}$ & Radio Mechanic \\
\hline Electrician Group & $27 x$ & $\begin{array}{l}\text { Electronics } \\
\text { Mechanic }\end{array}$ & Radio Mechanic (Layer Out) \\
\hline Electrician Group & $27 x$ & $\begin{array}{l}\text { Electronics } \\
\text { Mechanic }\end{array}$ & Radio Mechanic (Limited) \\
\hline Electrician Group & $41 x$ & $\begin{array}{l}\text { Electric Power } \\
\text { Controller }\end{array}$ & Electric Power Control \\
\hline Electrician Group & $41 x$ & $\begin{array}{l}\text { Electric Power } \\
\text { Controller }\end{array}$ & Power Plant Control man $(\mathrm{Hp})$ \\
\hline Electrician Group & $41 x$ & Electrician & Electrician \\
\hline Electrician Group & $41 x$ & Electrician & Electrician (Apsp) \\
\hline Electrician Group & $41 x$ & Electrician & Electrician (Power Plant) \\
\hline Electrician Group & $41 x$ & Electrician & Electrician Apprentice \\
\hline Electrician Group & $41 x$ & Electrician & Electrician Foreman \\
\hline
\end{tabular}


Table 2: Exposed Job And Shop Collapse

\begin{tabular}{|c|c|c|c|}
\hline $\begin{array}{c}\text { NIOSH } \\
\text { Exposure } \\
\text { Category }\end{array}$ & $\begin{array}{c}\text { NIOSH } \\
\text { Assigned } \\
\text { Job Code }\end{array}$ & $\begin{array}{c}\text { NIOSH } \\
\text { Assigned } \\
\text { Job Title }\end{array}$ & $\begin{array}{l}\text { Original } \\
\text { Site } \\
\text { Job Title }\end{array}$ \\
\hline Electrician Group & $41 x$ & Electrician & Electrician Foreman (General) \\
\hline Electrician Group & $41 x$ & Electrician & $\begin{array}{l}\text { Electrician Foreman } \\
\text { Leadingman }\end{array}$ \\
\hline Electrician Group & $41 x$ & Electrician & Electrician General Foreman \\
\hline Electrician Group & $41 x$ & Electrician & Electrician Helper \\
\hline Electrician Group & $41 x$ & Electrician & Electrician Instructor \\
\hline Electrician Group & $41 x$ & Electrician & Electrician Leadingman \\
\hline Electrician Group & $41 x$ & Electrician & Electrician Limited \\
\hline Electrician Group & $41 x$ & Electrician & Electrician Quarterman \\
\hline Electrician Group & $41 x$ & Electrician & Foreman General Electric \\
\hline Electrician Group & $41 x$ & Electrician & Helper Electrician \\
\hline Electrician Group & $41 x$ & Electrician & Wireman \\
\hline Electrician Group & $73 x$ & $\begin{array}{l}\text { Electronics } \\
\text { Technician }\end{array}$ & Electronics Technician \\
\hline Electrician Group & $73 x$ & $\begin{array}{l}\text { Electronics } \\
\text { Technician }\end{array}$ & $\begin{array}{l}\text { Electronics Technician } \\
\text { (Instrument) }\end{array}$ \\
\hline Electrician Group & $73 x$ & $\begin{array}{l}\text { Electronics } \\
\text { Technician }\end{array}$ & Elex Tech \\
\hline Electrician Group & $73 x$ & $\begin{array}{l}\text { Electronics } \\
\text { Technician }\end{array}$ & Elex Tech (Instrum) \\
\hline Machining Group & $13 x$ & Metal Worker & Flange Turner \\
\hline Machining Group & $22 x$ & Machinist & Inside Machinist \\
\hline Machining Group & $22 x$ & Machinist & Ldman Machinist Inside \\
\hline Machining Group & $22 x$ & Machinist & Machinist (Inside) \\
\hline Machining Group & $22 x$ & Machinist & Machinist (Inside) \\
\hline
\end{tabular}


Table 2: Exposed Job And Shop Collapse

\begin{tabular}{|c|c|c|c|}
\hline $\begin{array}{l}\text { NIOSH } \\
\text { Exposure } \\
\text { Category }\end{array}$ & $\begin{array}{c}\text { NIOSH } \\
\text { Assigned } \\
\text { Job Code }\end{array}$ & $\begin{array}{c}\text { NIOSH } \\
\text { Assigned } \\
\text { Job Title }\end{array}$ & $\begin{array}{l}\text { Original } \\
\text { Site } \\
\text { Job Title }\end{array}$ \\
\hline Machining Group & $22 x$ & $\begin{array}{l}\text { Metal Forming } \\
\text { Machine } \\
\text { Operator }\end{array}$ & Mach Operator \\
\hline Machining Group & $22 x$ & $\begin{array}{l}\text { Metal Forming } \\
\text { Machine } \\
\text { Operator }\end{array}$ & Machine Operator \\
\hline Machining Group & $22 x$ & $\begin{array}{l}\text { Metal Forming } \\
\text { Machine } \\
\text { Operator }\end{array}$ & Machine Tool Operator \\
\hline Machining Group & $22 x$ & Tool Grinder & Foreman Ldgmn Tool/Cutter $\mathrm{Gr}$ \\
\hline Machining Group & $22 x$ & Tool Grinder & Tool \& Cutter Grinder \\
\hline Machining Group & $22 x$ & Tool Grinder & Tool/Cutter Grinder \\
\hline Machining Group & $22 x$ & Tool Grinder & Tool/Cutter Grinder Foreman \\
\hline Machining Group & $22 x$ & Toolmaker & Toolmaker \\
\hline Machining Group & $22 x$ & Toolmaker & Toolmaker Leadingman \\
\hline Machining Group & $26 x$ & $\begin{array}{l}\text { Industrial } \\
\text { Equipment } \\
\text { Mechanic }\end{array}$ & Equipment Mechanic \\
\hline Machining Group & $26 x$ & $\begin{array}{l}\text { Industrial } \\
\text { Equipment } \\
\text { Mechanic }\end{array}$ & $\begin{array}{l}\text { Equipment Mechanic (Heavy } \\
\text { Duty) }\end{array}$ \\
\hline Machining Group & $26 x$ & $\begin{array}{l}\text { Industrial } \\
\text { Equipment } \\
\text { Mechanic }\end{array}$ & Equipment Mechanic Foreman \\
\hline Machining Group & $26 x$ & $\begin{array}{l}\text { Industrial } \\
\text { Equipment } \\
\text { Mechanic }\end{array}$ & Equipment Repairer \\
\hline Machining Group & $26 x$ & $\begin{array}{l}\text { Industrial } \\
\text { Equipment } \\
\text { Mechanic }\end{array}$ & $\begin{array}{l}\text { Mechanic Master (Outfitting } \\
\text { Group) }\end{array}$ \\
\hline
\end{tabular}


Table 2: Exposed Job And Shop Collapse

\begin{tabular}{|c|c|c|c|}
\hline $\begin{array}{c}\text { NIOSH } \\
\text { Exposure } \\
\text { Category }\end{array}$ & $\begin{array}{c}\text { NIOSH } \\
\text { Assigned } \\
\text { Job Code }\end{array}$ & $\begin{array}{c}\text { NIOSH } \\
\text { Assigned } \\
\text { Job Title }\end{array}$ & $\begin{array}{l}\text { Original } \\
\text { Site } \\
\text { Job Title }\end{array}$ \\
\hline Machining Group & $26 x$ & Machinist & Foreman (Ldm) Machinist \\
\hline Machining Group & $26 x$ & Machinist & Leadingman Machinist \\
\hline Machining Group & $26 x$ & Machinist & Machinery Worker \\
\hline Machining Group & $26 x$ & Machinist & Machinist \\
\hline Machining Group & $26 x$ & Machinist & Machinist Leadingman \\
\hline Machining Group & $26 x$ & Machinist & $\begin{array}{l}\text { Machinist Leadingman } \\
\text { (Marine) }\end{array}$ \\
\hline Machining Group & $26 x$ & Machinist & Machinist Leadingman Inside \\
\hline Machining Group & $26 x$ & Machinist & Machinist (Maintenance) \\
\hline Machining Group & $26 x$ & Machinist & Machinist (Maintenance) \\
\hline Machining Group & $26 x$ & Machinist & $\begin{array}{l}\text { Machinist (Maintenance) } \\
\text { Foreman }\end{array}$ \\
\hline Machining Group & $26 x$ & Machinist & $\begin{array}{l}\text { Machinist (Maintenance) Gen } \\
\text { Foreman }\end{array}$ \\
\hline Machining Group & $26 x$ & Machinist & $\begin{array}{l}\text { Machinist (Maintenance) } \\
\text { Ldgmn/Frman }\end{array}$ \\
\hline Machining Group & $26 x$ & Machinist & $\begin{array}{l}\text { Machinist (Maintenance) } \\
\text { Leadingman }\end{array}$ \\
\hline Machining Group & $26 x$ & Machinist & Machinist (Marine) \\
\hline Machining Group & $26 x$ & Machinist & $\begin{array}{l}\text { Machinist (Marine) } \\
\text { Leadingman }\end{array}$ \\
\hline Machining Group & $26 x$ & Machinist & Machinist (Marine) Apprentice \\
\hline Machining Group & $26 x$ & Machinist & $\begin{array}{l}\text { Machinist (Marine) Foreman } \\
\text { Leadingman }\end{array}$ \\
\hline Machining Group & $26 x$ & Machinist & $\begin{array}{l}\text { Machinist (Marine) General } \\
\text { Foreman }\end{array}$ \\
\hline Machining Group & $26 x$ & Machinist & Machinist (Marine) Helper \\
\hline
\end{tabular}


Table 2: Exposed Job And Shop Collapse

\begin{tabular}{|c|c|c|c|}
\hline $\begin{array}{l}\text { NIOSH } \\
\text { Exposure } \\
\text { Category }\end{array}$ & $\begin{array}{l}\text { NIOSH } \\
\text { Assigned } \\
\text { Job Code }\end{array}$ & $\begin{array}{l}\text { NIOSH } \\
\text { Assigned } \\
\text { Job Title }\end{array}$ & $\begin{array}{l}\text { Original } \\
\text { Site } \\
\text { Job Title }\end{array}$ \\
\hline Machining Group & $26 x$ & Machinist & Machinist (Marine) Leadingman \\
\hline Machining Group & $26 x$ & Machinist & Machinist (Marine) Master \\
\hline Machining Group & $26 x$ & Machinist & Machinist (Marine) Quarterman \\
\hline Machining Group & $26 x$ & Machinist & Machinist (Outside) \\
\hline Machining Group & $26 x$ & Machinist & Machinist (Outside) Master \\
\hline Machining Group & $26 x$ & Machinist & $\begin{array}{l}\text { Machinist (Repair Shops) Gen } \\
\text { Foreman }\end{array}$ \\
\hline Machining Group & $26 x$ & Machinist & Machinist Apprentice \\
\hline Machining Group & $26 x$ & Machinist & Machinist Foreman \\
\hline Machining Group & $26 x$ & Machinist & $\begin{array}{l}\text { Machinist Foreman } \\
\text { Maintenance }\end{array}$ \\
\hline Machining Group & $26 x$ & Machinist & $\begin{array}{l}\text { Machinist } \\
\text { Foreman/Leadingman }\end{array}$ \\
\hline Machining Group & $26 x$ & Machinist & $\begin{array}{l}\text { Machinist General Foreman } \\
\text { (Marine) }\end{array}$ \\
\hline Machining Group & $26 x$ & Machinist & $\begin{array}{l}\text { Machinist General Foreman } \\
\text { Maintenance }\end{array}$ \\
\hline Machining Group & $26 x$ & Machinist & Machinist Helper \\
\hline Machining Group & $26 x$ & Machinist & Machinist Helper (Marine) \\
\hline Machining Group & $26 x$ & Machinist & Machinist Instructor \\
\hline Machining Group & $26 x$ & Machinist & Machinist Leadingman \\
\hline Machining Group & $26 x$ & Machinist & $\begin{array}{l}\text { Machinist Leadingman } \\
\text { (Marine) }\end{array}$ \\
\hline Machining Group & $26 x$ & Machinist & Machinist Limited \\
\hline Machining Group & $26 x$ & Machinist & Machinist Marine \\
\hline Machining Group & $26 x$ & Machinist & Machinist Marine Leadingman \\
\hline
\end{tabular}


Table 2: Exposed Job And Shop Collapse

\begin{tabular}{|c|c|c|c|}
\hline $\begin{array}{c}\text { NIOSH } \\
\text { Exposure } \\
\text { Category }\end{array}$ & $\begin{array}{l}\text { NIOSH } \\
\text { Assigned } \\
\text { Job Code }\end{array}$ & $\begin{array}{c}\text { NIOSH } \\
\text { Assigned } \\
\text { Job Title }\end{array}$ & $\begin{array}{c}\text { Original } \\
\text { Site } \\
\text { Job Title }\end{array}$ \\
\hline Machining Group & $26 x$ & Machinist & Machinist Marine Quarterman \\
\hline Machining Group & $26 x$ & Machinist & Machinist Master (Marine) \\
\hline Machining Group & $26 x$ & Machinist & $\begin{array}{l}\text { Machinist Mechanic (Marine) } \\
\text { Apprentice }\end{array}$ \\
\hline Machining Group & $26 x$ & Machinist & Machinist Outside \\
\hline Machining Group & $26 x$ & Machinist & Machinist Progressman \\
\hline Machining Group & $26 x$ & Machinist & Machinist Quarterman \\
\hline Machining Group & $26 x$ & Machinist & Machinist Quarterman (Chief) \\
\hline Machining Group & $26 x$ & Machinist & Machinist Quarterman Inside \\
\hline Machining Group & $26 x$ & Machinist & Machinist Snapper \\
\hline Machining Group & $26 x$ & Machinist & Maintenance Machinist \\
\hline Machining Group & $26 x$ & Machinist & Marine Machinery Mach \\
\hline Machining Group & $26 x$ & Machinist & MMM Foreman \\
\hline Machining Group & $26 x$ & Machinist & Quarterman Machinist (Marine) \\
\hline Machining Group & $26 x$ & Machinist & Special Duties \\
\hline Machining Group & $26 x$ & $\begin{array}{l}\text { Marine } \\
\text { Machinery } \\
\text { Mechanic }\end{array}$ & Equip Mech Instr (Mach Marine) \\
\hline Machining Group & $26 x$ & $\begin{array}{l}\text { Marine } \\
\text { Machinery } \\
\text { Mechanic }\end{array}$ & $\begin{array}{l}\text { Equipment Mechanic (Mach } \\
\text { Marine) }\end{array}$ \\
\hline Machining Group & $26 x$ & $\begin{array}{l}\text { Marine } \\
\text { Machinery } \\
\text { Mechanic }\end{array}$ & $\begin{array}{l}\text { Equipment Mechanic (Machinist } \\
\text { Marine) }\end{array}$ \\
\hline Machining Group & $26 x$ & $\begin{array}{l}\text { Marine } \\
\text { Machinery } \\
\text { Mechanic }\end{array}$ & $\begin{array}{l}\text { Equipment Mechanic Foreman } \\
\text { (Mach Marine) }\end{array}$ \\
\hline
\end{tabular}


Table 2: Exposed Job And Shop Collapse

\begin{tabular}{|c|c|c|c|}
\hline $\begin{array}{l}\text { NIOSH } \\
\text { Exposure } \\
\text { Category }\end{array}$ & $\begin{array}{c}\text { NIOSH } \\
\text { Assigned } \\
\text { Job Code }\end{array}$ & $\begin{array}{l}\text { NIOSH } \\
\text { Assigned } \\
\text { Job Title }\end{array}$ & $\begin{array}{l}\text { Original } \\
\text { Site } \\
\text { Job Title }\end{array}$ \\
\hline Machining Group & $26 x$ & $\begin{array}{l}\text { Marine } \\
\text { Machinery } \\
\text { Mechanic }\end{array}$ & Maintenance \\
\hline Machining Group & $26 x$ & $\begin{array}{l}\text { Marine } \\
\text { Machinery } \\
\text { Mechanic }\end{array}$ & Maintenance Foreman \\
\hline Machining Group & $26 x$ & $\begin{array}{l}\text { Marine } \\
\text { Machinery } \\
\text { Mechanic }\end{array}$ & Marine Equip Mechanic \\
\hline Machining Group & $26 x$ & $\begin{array}{l}\text { Marine } \\
\text { Machinery } \\
\text { Mechanic }\end{array}$ & $\begin{array}{l}\text { Marine Equip Mechanic } \\
\text { Instructor }\end{array}$ \\
\hline Machining Group & $26 x$ & $\begin{array}{l}\text { Marine } \\
\text { Machinery } \\
\text { Mechanic }\end{array}$ & Marine Machinery Mechanic \\
\hline Machining Group & $26 x$ & $\begin{array}{l}\text { Marine } \\
\text { Machinery } \\
\text { Mechanic }\end{array}$ & $\begin{array}{l}\text { Marine Machinery Mechanic } \\
\text { Foreman }\end{array}$ \\
\hline Machining Group & $26 x$ & $\begin{array}{l}\text { Marine } \\
\text { Machinery } \\
\text { Mechanic }\end{array}$ & Marine Machinery Repairer \\
\hline Machining Group & $26 x$ & $\begin{array}{l}\text { Marine } \\
\text { Machinery } \\
\text { Mechanic }\end{array}$ & Mechanic Ship Maintenance \\
\hline Machining Group & $26 x$ & $\begin{array}{l}\text { Marine } \\
\text { Machinery } \\
\text { Mechanic }\end{array}$ & MM Repairer \\
\hline Machining Group & $26 x$ & $\begin{array}{l}\text { Ships Planner, } \\
\text { Analyst, \& } \\
\text { Progressman }\end{array}$ & Progressman (Machinist) \\
\hline
\end{tabular}


Table 2: Exposed Job And Shop Collapse

\begin{tabular}{|c|c|c|c|}
\hline $\begin{array}{c}\text { NIOSH } \\
\text { Exposure } \\
\text { Category }\end{array}$ & $\begin{array}{c}\text { NIOSH } \\
\text { Assigned } \\
\text { Job Code }\end{array}$ & $\begin{array}{c}\text { NIOSH } \\
\text { Assigned } \\
\text { Job Title }\end{array}$ & $\begin{array}{c}\text { Original } \\
\text { Site } \\
\text { Job Title }\end{array}$ \\
\hline Machining Group & $32 x$ & $\begin{array}{l}\text { Maintenance } \\
\text { Mechanic }\end{array}$ & Ship Maintenance Mechanic \\
\hline Machining Group & $32 x$ & $\begin{array}{l}\text { Maintenance } \\
\text { Mechanic }\end{array}$ & Ship Maintenance Mechanic \\
\hline Machining Group & $58 x$ & $\begin{array}{l}\text { Tool \& } \\
\text { Equipment } \\
\text { Repairing }\end{array}$ & Tool Room Mechanic \\
\hline Machining Group & $58 x$ & $\begin{array}{l}\text { Tool \& } \\
\text { Equipment } \\
\text { Repairing }\end{array}$ & Tool Room Mechanic Helper \\
\hline Machining Group & $58 x$ & $\begin{array}{l}\text { Tools \& Parts } \\
\text { Attending }\end{array}$ & Tool/Parts Attendant \\
\hline Machining Group & $58 x$ & $\begin{array}{l}\text { Tools \& Parts } \\
\text { Attending }\end{array}$ & Tool Room Attendant \\
\hline Machining Group & $58 x$ & $\begin{array}{l}\text { Tools \& Parts } \\
\text { Attending }\end{array}$ & Tool Room Keeper \\
\hline Machining Group & $58 x$ & $\begin{array}{l}\text { Tools \& Parts } \\
\text { Attending }\end{array}$ & Tools/Parts Attendant \\
\hline $\begin{array}{l}\text { Wood Working } \\
\text { Group }\end{array}$ & $19 x$ & Wood Crafter & Joiner \\
\hline $\begin{array}{l}\text { Wood Working } \\
\text { Group }\end{array}$ & $19 x$ & Wood Crafter & Joiner Apprentice \\
\hline $\begin{array}{l}\text { Wood Working } \\
\text { Group }\end{array}$ & $19 x$ & Wood Crafter & Joiner Helper \\
\hline $\begin{array}{l}\text { Wood Working } \\
\text { Group }\end{array}$ & $19 x$ & Wood Crafter & Joiner Leadingman \\
\hline $\begin{array}{l}\text { Wood Working } \\
\text { Group }\end{array}$ & $19 x$ & Wood Crafter & Joiner Leadingman/Foreman \\
\hline $\begin{array}{l}\text { Wood Working } \\
\text { Group }\end{array}$ & $19 x$ & Wood Crafter & Joiner Quarterman \\
\hline
\end{tabular}


Table 2: Exposed Job And Shop Collapse

\begin{tabular}{llll}
\hline \multicolumn{1}{c}{$\begin{array}{c}\text { NIOSH } \\
\text { Exposure } \\
\text { Category }\end{array}$} & $\begin{array}{c}\text { NIOSH } \\
\text { Assigned } \\
\text { Job Code }\end{array}$ & $\begin{array}{c}\text { NIOSH } \\
\text { Assigned } \\
\text { Job Title }\end{array}$ & \multicolumn{1}{c}{$\begin{array}{c}\text { Original } \\
\text { Site } \\
\text { Job Title }\end{array}$} \\
\hline $\begin{array}{l}\text { Wood Working } \\
\text { Group }\end{array}$ & $19 x$ & Wood Worker & Helper Woodworker \\
$\begin{array}{l}\text { Wood Working } \\
\text { Group }\end{array}$ & $19 x$ & Wood Worker & Woodworker \\
$\begin{array}{l}\text { Wood Working } \\
\text { Group }\end{array}$ & $19 x$ & Wood Worker & Woodworker Helper \\
$\begin{array}{l}\text { Wood Working } \\
\text { Group } \\
\text { Wood Working } \\
\text { Group }\end{array}$ & $19 x$ & Wood Worker & Woodworker Leader \\
$\begin{array}{l}\text { Wood Working } \\
\text { Group }\end{array}$ & $64 x$ & Molder & Leader Molder \\
$\begin{array}{l}\text { Wood Working } \\
\text { Group }\end{array}$ & $64 x$ & Molder & Leaderman Molder \\
$\begin{array}{l}\text { Wood Working } \\
\text { Group }\end{array}$ & $64 x$ & Molder & Molder \\
$\begin{array}{l}\text { Wood Working } \\
\text { Group }\end{array}$ & $66 x$ & Molder & Molder Helper \\
$\begin{array}{l}\text { Wood Working } \\
\text { Group }\end{array}$ & $66 x$ & Patternmaker & Patternmaker Apprentice \\
\hline \hline
\end{tabular}




\title{
Appendix I
}

\author{
Power Curve Graphic \\ Alpha Level $=0.05$
}

\section{Sample Size $=115$ Risk Sets}

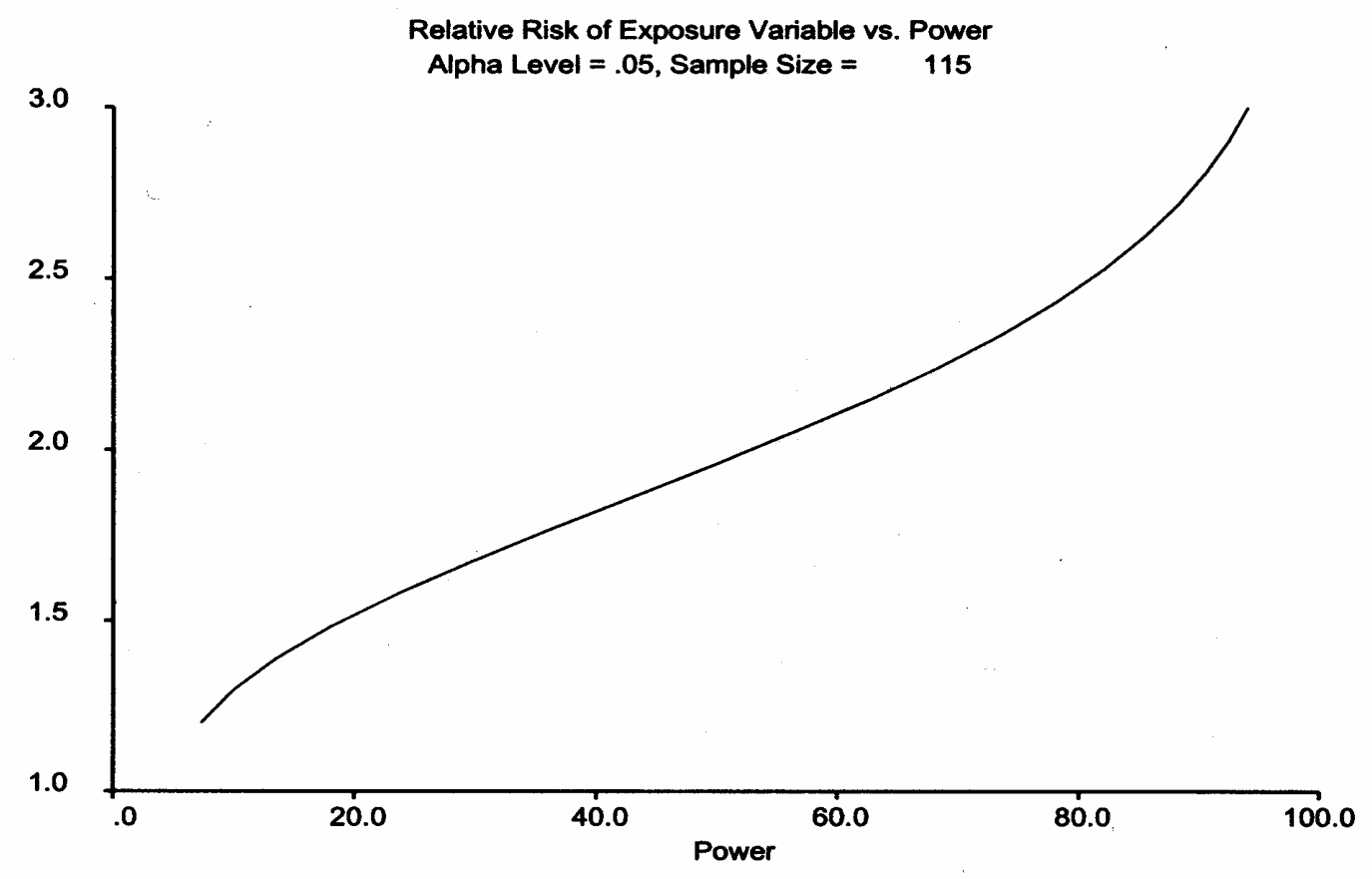




\section{Appendix $\mathbf{J}$}

\begin{tabular}{|c|c|c|c|}
\hline \multicolumn{4}{|c|}{$\begin{array}{l}\text { Table 1: Place of Birth for the Leukemia Cases } \\
\qquad(n=115)\end{array}$} \\
\hline Place of Birth & Frequency & Percent & $\begin{array}{l}\text { Cumulative } \\
\text { Frequency }\end{array}$ \\
\hline Canada & 3 & 2.61 & 3 \\
\hline Colorado & 1 & 0.87 & 4 \\
\hline France & 1 & 0.87 & 5 \\
\hline Holland & 1 & 0.87 & 6 \\
\hline Jamaica & 1 & 0.87 & 7 \\
\hline Maine & 40 & 34.78 & 47 \\
\hline Mass. & 20 & 17.39 & 67 \\
\hline New Hampshire & 34 & 29.57 & 101 \\
\hline New Jersey & 1 & 0.87 & 102 \\
\hline New York & 1 & 0.87 & 103 \\
\hline Panama & 1 & 0.87 & 104 \\
\hline Pennsylvania & 3 & 2.61 & 107 \\
\hline Poland & 1 & 0.87 & 108 \\
\hline Rhode Island & 2 & 1.74 & 110 \\
\hline Scotland & 1 & 0.87 & 111 \\
\hline Virginia & 1 & 0.87 & 112 \\
\hline Vermont & 2 & 1.74 & 114 \\
\hline Washington State & 1 & 0.87 & 115 \\
\hline
\end{tabular}


Table 2: States Where Cases Died $(n=115)$

\begin{tabular}{|lccc|}
\hline \multicolumn{1}{|c}{ State } & Frequency & Percent & $\begin{array}{c}\text { Cumulative } \\
\text { Frequency }\end{array}$ \\
\hline California & 3 & 2.61 & 3 \\
Connecticut & 2 & 1.74 & 5 \\
Washington, D.C. & 1 & 0.87 & 6 \\
Florida & 7 & 6.09 & 13 \\
Massachusetts & 19 & 16.52 & 32 \\
Maine & 36 & 31.30 & 68 \\
New Hampshire & 43 & 37.39 & 111 \\
Ohio & 1 & 0.87 & 112 \\
Pennsylvania & 1 & 0.87 & 113 \\
Vermont & 1 & 0.87 & 114 \\
Washington State & 1 & 0.87 & 115 \\
\hline
\end{tabular}




\section{Appendix K}

\begin{tabular}{||cccccc||}
\hline \multicolumn{2}{|c|}{ Table 1: Cumulative Bone Marrow Dose from Offsite Sources } \\
\hline $\begin{array}{c}\text { Number of Cases } \\
\text { and Controls }\end{array}$ & $\begin{array}{c}\text { Mean } \\
(\mathbf{m S v})\end{array}$ & $\begin{array}{c}\text { Median } \\
(\mathbf{m S v})\end{array}$ & $\begin{array}{c}\text { Min } \\
(\mathbf{m S v})\end{array}$ & $\begin{array}{c}\text { Max } \\
(\mathbf{m S v})\end{array}$ & $\begin{array}{c}\text { Collective } \\
\text { BMD } \\
\text { (person-mSv) }\end{array}$ \\
\hline 3 Controls Only & 2.54 & 3.37 & 0.63 & 3.63 & 7.63 \\
\hline
\end{tabular}




\begin{tabular}{||cccccc||}
\hline \multicolumn{6}{|c|}{ Table 2: Estimated Missed Cumulative Bone Marrow Dose } \\
\hline $\begin{array}{c}\text { Number of Cases and } \\
\text { Controls }\end{array}$ & $\begin{array}{c}\text { Mean } \\
\text { (mSv) }\end{array}$ & $\begin{array}{c}\text { Median } \\
(\mathbf{m S v})\end{array}$ & $\begin{array}{c}\text { Min } \\
(\mathbf{m S v})\end{array}$ & $\begin{array}{c}\text { Max } \\
(\mathbf{m S v})\end{array}$ & $\begin{array}{c}\text { Total } \\
(\mathbf{m S v})\end{array}$ \\
\hline 175 (Cases \& Controls) & 0.35 & 0.16 & 0.02 & 2.54 & 60.92 \\
30 (Cases Only) & 0.38 & 0.15 & 0.02 & 2.45 & 11.25 \\
145 (Controls Only) & 0.34 & 0.16 & 0.02 & 2.54 & 49.67 \\
\hline
\end{tabular}


Table 3: Full Model with 2-Way Interactions and Main Effects-Badge Exposure-Two Year Lag

\begin{tabular}{|c|c|c|c|c|c|c|c|c|}
\hline \multirow{2}{*}{\begin{tabular}{|l}
\multicolumn{1}{|c}{ Variable } \\
On \& Offsite Miss \\
Badge Cumulative \\
Exposure - Lagged \\
2 Years (1 mSv)
\end{tabular}} & \multirow{2}{*}{$\begin{array}{c}\text { DF } \\
\\
1\end{array}$} & \multirow{2}{*}{$\begin{array}{c}\begin{array}{c}\text { Parameter } \\
\text { Estimate }\end{array} \\
0.0108\end{array}$} & \multirow{2}{*}{$\begin{array}{c}\begin{array}{c}\text { Standard } \\
\text { Error }\end{array} \\
0.0049\end{array}$} & \multirow{2}{*}{$\begin{array}{c}\begin{array}{c}\text { Chi- } \\
\text { Square }\end{array} \\
\\
4.965\end{array}$} & \multirow{2}{*}{$\begin{array}{c}\mathbf{P r}>\mathbf{C h i} \\
\mathbf{S q}\end{array}$} & \multirow{2}{*}{$\begin{array}{r}\text { Odds } \\
\text { Ratio }\end{array}$} & \multicolumn{2}{|c|}{$\begin{array}{c}95 \% \\
\text { Confidence } \\
\text { Limits }\end{array}$} \\
\hline & & & & & & & 1.00 & 1.02 \\
\hline $\begin{array}{l}\text { Gender (1=Female, } \\
0=\text { Male) }\end{array}$ & 1 & -1.172 & 0.6186 & 3.589 & 0.0582 & 0.31 & 0.09 & 1.04 \\
\hline $\begin{array}{l}\text { Radiation Worker } \\
\text { (1=Yes, } 0=\text { No) } \\
\text { Lagged } 2 \text { yrs }\end{array}$ & 1 & -0.7380 & 0.3562 & 4.293 & 0.0383 & 0.48 & 0.24 & 0.96 \\
\hline $\begin{array}{l}\text { Solvent Duration } \\
\text { Exposed - Lagged } \\
2 \text { Years }\end{array}$ & 1 & 0.0436 & 0.0150 & 8.470 & 0.0036 & 1.05 & 1.01 & 1.08 \\
\hline $\begin{array}{l}\text { TSLE is } \geq 5 \text { year } \\
\text { and }<10 \text { years }\end{array}$ & 1 & -0.1684 & 0.3617 & 0.2170 & 0.6414 & 0.85 & 0.42 & 1.72 \\
\hline $\begin{array}{l}\text { TSLE is } \geq 2.5 \text { years } \\
\text { and }<5 \text { years }\end{array}$ & 1 & 0.6310 & 0.4077 & 2.396 & 0.1216 & 1.88 & 0.85 & 4.18 \\
\hline $\begin{array}{l}\text { TSLE is } \geq 0 \text { years } \\
\text { and }<2.5 \text { years }\end{array}$ & 1 & -0.5678 & 0.4148 & 1.8748 & 0.1710 & 0.57 & 0.25 & 1.28 \\
\hline $\begin{array}{l}\text { On \& Offsite } \\
\text { Badge Cumulative } \\
\text { Exposure * Solvent } \\
\text { Duration Exposure }\end{array}$ & 1 & -0.000318 & 0.0004 & 0.6389 & 0.4241 & 1.000 & 0.99 & 1.00 \\
\hline $\begin{array}{l}\text { Radiation Worker } \\
\text { * Solvent Duration } \\
\text { Exposed }\end{array}$ & 1 & -0.0123 & 0.0264 & 0.2160 & 0.6421 & 0.99 & 0.94 & 1.04 \\
\hline
\end{tabular}


Table 4: Reduced Model-2-way Exposure Interaction and Main Effects-Badge Exposure-Two Year Lag

\begin{tabular}{|c|c|c|c|c|c|c|c|c|}
\hline Variable & DF & $\begin{array}{c}\text { Parameter } \\
\text { Estimate }\end{array}$ & $\begin{array}{c}\text { Standard } \\
\text { Error }\end{array}$ & $\begin{array}{l}\text { Chi- } \\
\text { Square }\end{array}$ & $\begin{array}{c}\mathrm{Pr}>\mathrm{Chi} \\
\mathbf{S q}\end{array}$ & $\begin{array}{l}\text { Odds } \\
\text { Ratio }\end{array}$ & $\begin{array}{r}9 \\
\text { Con } \\
\text { L }\end{array}$ & $\begin{array}{l}\text { o } \\
\text { lence } \\
\text { its }\end{array}$ \\
\hline $\begin{array}{l}\text { On \& Offsite Miss } \\
\text { Badge Cum } \\
\text { Exposure - Lagged } \\
2 \text { Years } \\
(1 \text { mSv) }\end{array}$ & 1 & 0.0116 & 0.0046 & 6.362 & 0.0117 & 1.01 & 1.00 & 1.02 \\
\hline $\begin{array}{l}\text { Gender }(1=\text { Female } \\
0=\text { Male) }\end{array}$ & 1 & -1.196 & 0.6158 & 3.770 & 0.0522 & 0.30 & 0.09 & 1.01 \\
\hline $\begin{array}{l}\text { Radiation Worker } \\
\text { (1=Yes, } 0=\text { No) } \\
\text { Lagged } 2 \text { yrs. }\end{array}$ & 1 & -0.8470 & 0.2734 & 9.600 & 0.0019 & 0.43 & 0.25 & 0.73 \\
\hline $\begin{array}{l}\text { Solvent Duration } \\
\text { Exposure Lagged } \\
\text { 2 Years }\end{array}$ & 1 & 0.0398 & 0.0125 & 10.09 & 0.0015 & 1.04 & 1.02 & 1.07 \\
\hline $\begin{array}{l}\text { TSLE is } \geq 5 \text { year } \\
\text { and }<10 \text { years }\end{array}$ & 1 & -0.1713 & 0.3617 & 0.2241 & 0.6359 & 0.84 & 0.42 & 1.71 \\
\hline $\begin{array}{l}\text { TSLE is } \geq 2.5 \\
\text { years and }<5 \text { years }\end{array}$ & 1 & 0.6315 & 0.4074 & 2.403 & 0.1211 & 1.88 & 0.85 & 4.18 \\
\hline $\begin{array}{l}\text { TSLE is } \geq 0 \text { years } \\
\text { and }<2.5 \text { years }\end{array}$ & 1 & -0.56137 & 0.4148 & 1.831 & 0.1760 & 0.57 & 0.25 & 1.29 \\
\hline $\begin{array}{l}\text { On \& Offsite } \\
\text { Badge Cum } \\
\text { Exposure - Lagged } \\
2 \text { Years * Solvent } \\
\text { Duration } \\
\text { Exposure - Lagged } \\
2 \text { Years }\end{array}$ & 1 & -0.0004 & 0.0004 & 1.176 & 0.2781 & 1.00 & 0.99 & 1.00 \\
\hline
\end{tabular}




\begin{tabular}{|c|c|c|}
\hline Variable & $\begin{array}{c}\text { Parameter } \\
\text { Estimate }\end{array}$ & $\begin{array}{l}\text { Percent } \\
\text { Change }\end{array}$ \\
\hline $\begin{array}{l}\text { On \& Offsite Miss Badge } \\
\text { Cum Exposure - Lagged } 2 \\
\text { Years-Parameter Estimate } \\
\text { with all Variables in the } \\
\text { Model }\end{array}$ & 0.00816 & \\
\hline $\begin{array}{l}\text { Parameter Estimate } \\
\text { Excluding Gender }\end{array}$ & 0.00815 & .12 \\
\hline $\begin{array}{l}\text { Parameter Estimate } \\
\text { Excluding Radiation Worker } \\
\text { Status }\end{array}$ & 0.00349 & .80 \\
\hline $\begin{array}{l}\text { Parameter Estimate } \\
\text { Excluding Solvent Duration }\end{array}$ & 0.007624 & .07 \\
\hline $\begin{array}{l}\text { Parameter Estimate } \\
\text { Excluding TSLE }\end{array}$ & 0.00762 & .07 \\
\hline
\end{tabular}




\begin{tabular}{|c|c|c|c|c|c|c|c|c|}
\hline & $\begin{array}{c}\text { On \& Offsite } \\
\text { Badge Cum } \\
\text { Dose - } \\
\text { Lagged } 2 \\
\text { Years (1 mSv) }\end{array}$ & Gender & $\begin{array}{c}\text { Radiation } \\
\text { Worker }\end{array}$ & CASE & $\begin{array}{c}\text { Solvent } \\
\text { Duration }\end{array}$ & $\begin{array}{l}\text { TSLE } \geq 5 \\
\text { year and } \\
<10 \text { years }\end{array}$ & $\begin{array}{c}\text { TSLE } \geq 2.5 \\
\text { years and }<5 \\
\text { years }\end{array}$ & $\begin{array}{l}T S L E \geq 0 \\
\text { years and } \\
<2.5 \text { years }\end{array}$ \\
\hline $\begin{array}{l}\text { On \& Offsite Miss } \\
\text { Badge Cum Dose - }\end{array}$ & & -0.0804 & 0.3873 & 0.0596 & 0.0617 & -0.0150 & 0.0295 & 0.0129 \\
\hline Lagged 2 Years & 1.000 & 0.0540 & $<.0001$ & 0.1537 & 0.1394 & 0.7193 & 0.4806 & 0.7581 \\
\hline $\begin{array}{l}\text { Gender }(1=\text { Female, } \\
0=\text { Male })\end{array}$ & $\begin{array}{r}-0.0804 \\
0.0540\end{array}$ & 1.000 & $\begin{array}{r}-0.2076 \\
<.0001\end{array}$ & $\begin{array}{r}-0.0926 \\
0.0265\end{array}$ & $\begin{array}{r}-0.1883 \\
<.0001\end{array}$ & $\begin{array}{l}0.0578 \\
0.1664\end{array}$ & $\begin{array}{r}-0.0036 \\
0.9317\end{array}$ & $\begin{array}{l}0.0049 \\
0.9066\end{array}$ \\
\hline $\begin{array}{l}\text { Radiation Worker } \\
(1=\text { Yes, } 0=\text { No })\end{array}$ & $\begin{array}{l}0.3873 \\
<.0001\end{array}$ & $\begin{array}{r}-0.2076 \\
<.0001\end{array}$ & 1.000 & $\begin{array}{r}-0.0548 \\
0.1897\end{array}$ & $\begin{array}{l}0.2003 \\
<.0001\end{array}$ & $\begin{array}{l}0.0225 \\
0.5907\end{array}$ & $\begin{array}{l}0.0757 \\
0.0699\end{array}$ & $\begin{array}{r}-0.0533 \\
0.2018\end{array}$ \\
\hline $\begin{array}{l}\text { CASE IDENTIFIER } \\
(1=\text { CASE, } \\
0=\text { CONTROL })\end{array}$ & $\begin{array}{l}0.0596 \\
0.1537\end{array}$ & $\begin{array}{r}-0.0926 \\
0.0265\end{array}$ & $\begin{array}{r}-0.0548 \\
0.1897\end{array}$ & 1.000 & $\begin{array}{l}0.1208 \\
0.0037\end{array}$ & $\begin{array}{r}-0.0241 \\
0.5644\end{array}$ & $\begin{array}{l}0.0769 \\
0.0655\end{array}$ & $\begin{array}{r}-0.0359 \\
0.3902\end{array}$ \\
\hline $\begin{array}{l}\text { Solvent Duration } \\
\text { Exposed }\end{array}$ & $\begin{array}{l}0.0617 \\
0.1394\end{array}$ & $\begin{array}{r}-0.1883 \\
<.0001\end{array}$ & $\begin{array}{l}0.2003 \\
<.0001\end{array}$ & $\begin{array}{l}0.1208 \\
0.0037\end{array}$ & 1.000 & $\begin{array}{l}0.0034 \\
0.9349\end{array}$ & $\begin{array}{l}0.0046 \\
0.9120\end{array}$ & $\begin{array}{r}-0.0055 \\
0.8945\end{array}$ \\
\hline $\begin{array}{l}\text { TSLE is } \geq 5 \text { year and } \\
<10 \text { years }\end{array}$ & $\begin{array}{r}-0.0150 \\
0.7193\end{array}$ & $\begin{array}{l}0.0578 \\
0.1664\end{array}$ & $\begin{array}{l}0.0225 \\
0.5907\end{array}$ & $\begin{array}{r}-0.0241 \\
0.5644\end{array}$ & $\begin{array}{l}0.0034 \\
0.9349\end{array}$ & 1.000 & $\begin{array}{r}-0.1037 \\
0.0129\end{array}$ & $\begin{array}{r}-0.1591 \\
0.0001\end{array}$ \\
\hline $\begin{array}{l}\text { TSLE is } \geq 2.5 \text { years } \\
\text { and }<5 \text { years }\end{array}$ & $\begin{array}{l}0.0295 \\
0.4806\end{array}$ & $\begin{array}{r}-0.0036 \\
0.9317\end{array}$ & $\begin{array}{l}0.0757 \\
0.0699\end{array}$ & $\begin{array}{l}0.0769 \\
0.0655\end{array}$ & $\begin{array}{l}0.0046 \\
0.9120\end{array}$ & $\begin{array}{r}-0.1037 \\
0.0129\end{array}$ & 1.000 & $\begin{array}{r}-0.1209 \\
0.0037\end{array}$ \\
\hline $\begin{array}{l}\text { TSLE is } \geq 0 \text { years } \\
\text { and }<2.5 \text { years }\end{array}$ & $\begin{array}{l}0.0129 \\
0.7581 \\
\end{array}$ & $\begin{array}{l}0.0049 \\
0.9066 \\
\end{array}$ & $\begin{array}{r}-0.0533 \\
0.2018 \\
\end{array}$ & $\begin{array}{r}-0.0359 \\
0.3902 \\
\end{array}$ & $\begin{array}{r}-0.0055 \\
0.8945 \\
\end{array}$ & $\begin{array}{r}-0.1591 \\
0.0001 \\
\end{array}$ & $\begin{array}{r}-0.1209 \\
0.0037 \\
\end{array}$ & 1.000 \\
\hline
\end{tabular}




\begin{tabular}{|c|c|c|c|c|c|c|c|c|}
\hline Variable & DF & $\begin{array}{l}\text { Parameter } \\
\text { Estimate }\end{array}$ & $\begin{array}{l}\text { Standard } \\
\text { Error }\end{array}$ & $\begin{array}{l}\text { Chi- } \\
\text { Square }\end{array}$ & $\begin{array}{l}\text { Pr }> \\
\text { ChiSq }\end{array}$ & $\begin{array}{l}\text { Odds } \\
\text { Ratio }\end{array}$ & $\begin{array}{r}95 \\
\text { Conf } \\
\text { Lir }\end{array}$ & $\begin{array}{l}\% \\
\text { dence } \\
\text { iits }\end{array}$ \\
\hline \multirow[b]{2}{*}{$\begin{array}{l}\text { Badge Exposure - } \\
\text { Lagged } 2 \text { Years } \\
(1 \mathrm{mSv})\end{array}$} & & & & & \multicolumn{2}{|r|}{$\begin{array}{l}(10 \mathrm{mSv}) \\
1.08\end{array}$} & 1.01 & 1.16 \\
\hline & 1 & 0.0077 & 0.0035 & 4.847 & 0.0277 & $\begin{array}{l}(1 \mathrm{mSv}) \\
1.01\end{array}$ & 1.00 & 1.02 \\
\hline Gender & 1 & -1.1939 & 0.6112 & 3.816 & 0.0508 & 0.30 & 0.09 & 1.00 \\
\hline $\begin{array}{l}\text { Radiation Worker } \\
(1=\text { Yes, } 0=\text { No) }\end{array}$ & 1 & -0.7259 & 0.2625 & 7.645 & 0.0057 & 0.48 & 0.29 & 0.81 \\
\hline $\begin{array}{l}\text { Solvent Duration } \\
\text { Exposure - } \\
\text { Lagged } 2 \text { Years }\end{array}$ & 1 & 0.0323 & 0.0115 & 7.861 & 0.0051 & 1.03 & 1.01 & 1.06 \\
\hline
\end{tabular}




\begin{tabular}{|c|c|c|c|c|c|c|c|c|}
\hline \multirow{2}{*}{$\begin{array}{l}\text { Exposure Variable } \\
\qquad(1 \mathrm{mSv})\end{array}$} & \multirow{2}{*}{$\begin{array}{c}\text { DF } \\
1 \\
1\end{array}$} & \multirow{2}{*}{$\begin{array}{c}\begin{array}{c}\text { Parameter } \\
\text { Estimate }\end{array} \\
0.0057\end{array}$} & \multirow{2}{*}{$\begin{array}{c}\begin{array}{c}\text { Standard } \\
\text { Error }\end{array} \\
0.0041\end{array}$} & \multirow{2}{*}{$\begin{array}{l}\text { Odds } \\
\text { Ratio } \\
1.01\end{array}$} & \multicolumn{2}{|c|}{$\begin{array}{c}95 \% \\
\text { Confidence } \\
\text { Limits }\end{array}$} & \multirow{2}{*}{$\begin{array}{c}\begin{array}{c}\text { LR Test } \\
\text { Chi-Sq }\end{array} \\
1.820\end{array}$} & \multirow{2}{*}{$\begin{array}{c}\begin{array}{c}\text { Pr }> \\
\text { Chi-Sq }\end{array} \\
0.18\end{array}$} \\
\hline & & & & & 0.99 & 1.01 & & \\
\hline $\begin{array}{l}\text { Occupational Bone } \\
\text { Marrow Dose } \\
\text { Lagged } 2 \text { Years }\end{array}$ & 1 & 0.0059 & 0.0041 & 1.01 & 0.99 & 1.01 & 1.905 & 0.17 \\
\hline $\begin{array}{l}\text { Occupational Bone } \\
\text { Marrow Lagged } 5 \\
\text { Years }\end{array}$ & 1 & 0.0060 & 0.0043 & 1.01 & 0.99 & 1.01 & 1.798 & 0.18 \\
\hline $\begin{array}{l}\text { Occupational Bone } \\
\text { Marrow Dose } \\
\text { Lagged } 7 \text { Years }\end{array}$ & 1 & 0.0059 & 0.0044 & 1.01 & 0.99 & 1.02 & 1.703 & 0.19 \\
\hline
\end{tabular}


Table 9: Occupational Bone Marrow Dose Variable Combined with

Work-Related Medical X-Ray Dose with Zero, Two, Five, and Seven Year Lags

Exposure Variable

$$
\text { Parameter Standard Odds Confidence }
$$

LR Test Pr > (1 mSv)

DF Estimate Error Ratio

Limits

Chi-Sq Chi-Sq

Occupational Bone

Marrow Dose +

Medical X-Rays-

Lagged No Lag

$1 \quad 0.0061$

0.0039

1.01

$0.99 \quad 1.01$

2.214

0.14

Occupational Bone

Marrow Dose +

Medical X-Rays-

Lagged 2 Years

$1 \quad 0.0063$

0.0040

1.01

0.99

1.01

2.348

0.13

Occupational Bone

Marrow Dose +

Medical X-Rays-

Lagged 5 Years

$\begin{array}{llllll}1 & 0.0063 & 0.0041 & 1.01 & 0.99 & 1.01\end{array}$

2.159

0.14

Occupational Bone

Marrow Dose +

Medical X-Rays-

Lagged 7 Years

$1 \quad 0.006$

0.0042

1.01

0.99

1.02

1.971

0.16 
Table 10: Model Fit Statistics —Occupational Bone Marrow Dose Only

\begin{tabular}{|c|c|c|c|c|}
\hline Model & DF & $\begin{array}{l}\text {-2 LOG L } \\
\text { With } \\
\text { Covariates }\end{array}$ & $\begin{array}{l}\text {-2 LOG L } \\
\text { With } \\
\text { Covariates } \\
\text { Differences }\end{array}$ & $\begin{array}{c}\text { Critical } \\
\text { Value-Chi- } \\
\text { Sq }(0.05)\end{array}$ \\
\hline
\end{tabular}

A) Full model with 2-way, and main effects

$9 \quad 341.49$

B) Reduced model 2-way exposure interactions and main effects

$\begin{array}{ccc}8 & \text { B-A }=0.210 \\ & 341.706 & 1 \mathrm{df} \\ & & \mathrm{C}-\mathrm{B}=1.23 \\ 7 & 342.99 & 1 \mathrm{df}\end{array}$

C) Reduced model-main effects only

742.99 
Table 11: Model A—Full model with 2-Way, Interactions and Main EffectsOccupational Bone Marrow Dose Only-Two Year Lag

\begin{tabular}{|c|c|c|c|c|c|c|c|c|}
\hline \multirow{2}{*}{\begin{tabular}{|l}
\multicolumn{1}{||}{ Variable } \\
On \& Offsite \\
Occupational Dose \\
Lagged 2 Years \\
$(1 \mathrm{mSv})$
\end{tabular}} & \multirow{2}{*}{$\begin{array}{c}\text { DF } \\
\\
1 \\
1\end{array}$} & \multirow{2}{*}{$\begin{array}{c}\begin{array}{c}\text { Parameter } \\
\text { Estimate }\end{array} \\
0.0148\end{array}$} & \multirow{2}{*}{$\begin{array}{c}\begin{array}{c}\text { Standard } \\
\text { Error }\end{array} \\
0.0065\end{array}$} & \multirow{2}{*}{$\begin{array}{c}\begin{array}{c}\text { Chi- } \\
\text { Square }\end{array} \\
5.123\end{array}$} & \multirow{2}{*}{$\begin{array}{c}\begin{array}{c}\text { Pr }>\text { Chi } \\
\text { Sq }\end{array} \\
\\
0.0236\end{array}$} & \multirow{2}{*}{$\begin{array}{l}\text { Odds } \\
\text { Ratio }\end{array}$} & \multicolumn{2}{|c|}{$\begin{array}{c}95 \% \\
\text { Confidence } \\
\text { Limits }\end{array}$} \\
\hline & & & & & & & 1.00 & 1.03 \\
\hline $\begin{array}{l}\text { Gender }(1=\text { Female, } \\
0=\text { Male })\end{array}$ & 1 & -1.171 & 0.6186 & 3.585 & 0.0583 & 0.31 & 0.09 & 1.04 \\
\hline $\begin{array}{l}\text { Radiation Worker } \\
\text { (1=Yes, } 0=\text { No) Lagged } \\
2 \text { yrs }\end{array}$ & 1 & -0.7413 & 0.3559 & 4.340 & 0.0372 & 0.47 & 0.24 & 0.96 \\
\hline $\begin{array}{l}\text { Solvent Duration } \\
\text { Exposed - Lagged } 2 \\
\text { Years }\end{array}$ & 1 & 0.0436 & 0.0150 & 8.457 & 0.0036 & 1.05 & 1.01 & 1.08 \\
\hline $\begin{array}{l}\text { TSLE is } \geq 5 \text { year and } \\
<10 \text { years }\end{array}$ & 1 & -0.1644 & 0.3619 & 0.2063 & 0.6497 & 0.85 & 0.42 & 1.73 \\
\hline $\begin{array}{l}\text { TSLE is } \geq 2.5 \text { years } \\
\text { and }<5 \text { years }\end{array}$ & 1 & 0.6333 & 0.4078 & 2.412 & 0.1204 & 1.88 & 0.85 & 4.19 \\
\hline $\begin{array}{l}\text { TSLE is } \geq 0 \text { years and } \\
<2.5 \text { years }\end{array}$ & 1 & -0.5699 & 0.4152 & 1.884 & 0.1699 & 0.57 & 0.25 & 1.28 \\
\hline $\begin{array}{l}\text { On \& Offsite } \\
\text { Occupational Dose * } \\
\text { Solvent Duration } \\
\text { Exposure }\end{array}$ & 1 & -0.0004 & 0.0005 & 0.6404 & 0.4235 & 1.000 & 0.99 & 1.00 \\
\hline $\begin{array}{l}\text { Radiation Worker * } \\
\text { Solvent Duration } \\
\text { Exposed }\end{array}$ & 1 & -0.0122 & 0.0264 & 0.2124 & 0.6449 & 0.99 & 0.94 & 1.04 \\
\hline
\end{tabular}


Table 12: Model B-Reduced Model with 2-Way Dose Interactions and Main Effects-Occupational Bone Marrow Dose Only-Two Year Lag

\begin{tabular}{|c|c|c|c|c|c|c|c|c|}
\hline \multirow{2}{*}{\begin{tabular}{|l|}
\multicolumn{1}{|c}{ Variable } \\
On \& Offsite \\
Occupational Dose \\
Lagged 2 Years \\
$(1 \mathrm{mSv})$
\end{tabular}} & \multirow{2}{*}{$\begin{array}{c}\text { DF } \\
\\
1 \\
1\end{array}$} & \multirow{2}{*}{$\begin{array}{c}\begin{array}{c}\text { Parameter } \\
\text { Estimate }\end{array} \\
\\
0.0158\end{array}$} & \multirow{2}{*}{$\begin{array}{c}\begin{array}{c}\text { Standard } \\
\text { Error }\end{array} \\
0.0062\end{array}$} & \multirow{2}{*}{$\begin{array}{c}\begin{array}{c}\text { Chi- } \\
\text { Square }\end{array} \\
\\
6.538\end{array}$} & \multirow{2}{*}{$\begin{array}{c}\begin{array}{c}\text { Pr }>\text { Chi } \\
\mathbf{S q}\end{array} \\
\\
\\
0.0106\end{array}$} & \multirow{2}{*}{$\begin{array}{r}\text { Odds } \\
\text { Ratio } \\
\\
1.02\end{array}$} & \multicolumn{2}{|c|}{$\begin{array}{c}95 \% \\
\text { Confidence } \\
\text { Limits }\end{array}$} \\
\hline & & & & & & & 1.00 & 1.03 \\
\hline $\begin{array}{l}\text { Gender }(1=\text { Female, } \\
0=\text { Male })\end{array}$ & 1 & -1.195 & 0.6159 & 3.764 & 0.0524 & 0.30 & 0.09 & 1.01 \\
\hline $\begin{array}{l}\text { Radiation Worker } \\
(1=\text { Yes, } 0=\text { No }) \\
\text { Lagged } 2 \text { yrs }\end{array}$ & 1 & -0.8493 & 0.2731 & 9.675 & 0.0019 & 0.43 & 0.25 & 0.73 \\
\hline $\begin{array}{l}\text { Solvent Duration } \\
\text { Exposed - Lagged } 2 \\
\text { Years }\end{array}$ & 1 & 0.0398 & 0.0125 & 10.10 & 0.0015 & 1.04 & 1.02 & 1.07 \\
\hline $\begin{array}{l}\text { TSLE is } \geq 5 \text { year and } \\
<10 \text { years }\end{array}$ & 1 & -0.1673 & 0.3620 & 0.2136 & 0.6440 & 0.85 & 0.47 & 1.72 \\
\hline $\begin{array}{l}\text { TSLE is } \geq 2.5 \text { years } \\
\text { and }<5 \text { years }\end{array}$ & 1 & 0.6338 & 0.4075 & 2.419 & 0.1199 & 1.89 & 0.85 & 4.19 \\
\hline $\begin{array}{l}\text { TSLE is } \geq 0 \text { years and } \\
<2.5 \text { years }\end{array}$ & 1 & -0.5635 & 0.4152 & 1.842 & 0.1747 & 0.57 & 0.25 & 1.28 \\
\hline $\begin{array}{l}\text { On \& Offsite } \\
\text { Occupational Dose } \\
* \text { Solvent Duration } \\
\text { Exposure }\end{array}$ & 1 & -0.0005 & 0.0005 & 1.174 & 0.2785 & 0.99 & 0.99 & 1.00 \\
\hline
\end{tabular}


Table 13: Model C—Model with Main Effects Only—Occupational Bone Marrow Dose Only-Two Year Lag

\begin{tabular}{|c|c|c|c|c|c|c|c|c|}
\hline Variable & DF & $\begin{array}{l}\text { Parameter } \\
\text { Estimate }\end{array}$ & $\begin{array}{l}\text { Standard } \\
\text { Error }\end{array}$ & $\begin{array}{l}\text { Chi- } \\
\text { Square }\end{array}$ & $\begin{array}{c}\operatorname{Pr}>\text { Chi } \\
\text { Sq }\end{array}$ & $\begin{array}{l}\text { Odds } \\
\text { Ratio }\end{array}$ & \multicolumn{2}{|c|}{$\begin{array}{l}95 \% \\
\text { Confidence } \\
\text { Limits }\end{array}$} \\
\hline $\begin{array}{l}\text { Occupational Dose } \\
\text { Lagged } 2 \text { Years } \\
(1 \mathrm{mSv})\end{array}$ & 1 & 0.0112 & 0.0048 & 5.517 & 0.0188 & 1.01 & 1.00 & 1.02 \\
\hline $\begin{array}{l}\text { Gender }(1=\text { Female, } \\
0=\text { Male })\end{array}$ & 1 & -1.234 & 0.6140 & 4.042 & 0.0444 & 0.29 & 0.09 & 0.97 \\
\hline $\begin{array}{l}\text { Radiation Worker } \\
(1=\text { Yes, } 0=\text { No }) \\
\text { Lagged } 2 \text { yrs }\end{array}$ & 1 & -0.8289 & 0.2724 & 9.261 & 0.0023 & 0.44 & 0.26 & 0.74 \\
\hline $\begin{array}{l}\text { Solvent Duration } \\
\text { Exposed - Lagged } \\
2 \text { Years }\end{array}$ & 1 & 0.0348 & 0.0117 & 8.898 & 0.0029 & 1.04 & 1.01 & 1.06 \\
\hline $\begin{array}{l}\text { TSLE is } \geq 5 \text { year and } \\
<10 \text { years }\end{array}$ & 1 & -0.1670 & 0.3606 & 0.215 & 0.6433 & 0.85 & 0.42 & 1.72 \\
\hline $\begin{array}{l}\text { TSLE is } \geq 2.5 \text { years } \\
\text { and }<5 \text { years }\end{array}$ & 1 & 0.6650 & 0.4073 & 2.665 & 0.1026 & 1.94 & 0.88 & 4.32 \\
\hline $\begin{array}{l}\text { TSLE is } \geq 0 \text { years and } \\
<2.5 \text { years }\end{array}$ & 1 & -0.4937 & 0.4113 & 1.440 & 0.2301 & 0.61 & 0.27 & 1.37 \\
\hline
\end{tabular}


Table 14: Model Fit Statistics-Occupational Bone Marrow Dose Combined with Bone Marrow Dose from Medical X-Ray Examinations

\begin{tabular}{||ccccc|}
\hline \multicolumn{1}{|c|}{ Model } & DF & $\begin{array}{c}\mathbf{- 2} \text { LOG L } \\
\text { With } \\
\text { Covariates }\end{array}$ & $\begin{array}{c}\text {-2 LOG L } \\
\text { With } \\
\text { Covariates } \\
\text { Differences }\end{array}$ & $\begin{array}{c}\text { Critical } \\
\text { Value-Chi- } \\
\text { Sq (0.05) }\end{array}$ \\
\hline $\begin{array}{c}\text { A) Full model with 2-way, } \\
\text { 3-way and main effects }\end{array}$ & 12 & 343.94 & & \\
\begin{tabular}{|} 
B) Reduced model 2-way \\
exposure interactions and \\
main effects
\end{tabular} & 10 & 346.50 & $\begin{array}{c}\text { B-A }=2.56 \\
2 \mathrm{df}\end{array}$ & 5.99 \\
$\begin{array}{c}\text { C) Reduced model-main } \\
\text { effects only }\end{array}$ & 7 & 347.75 & $\begin{array}{c}\text { C-B }=1.25 \\
3 \mathrm{df}\end{array}$ & 7.81 \\
\hline
\end{tabular}




\begin{tabular}{|c|c|c|c|c|c|c|c|c|}
\hline Variable & DF & $\begin{array}{c}\text { Parameter } \\
\text { Estimate }\end{array}$ & $\begin{array}{c}\text { Standard } \\
\text { Error }\end{array}$ & $\begin{array}{c}\text { Chi- } \\
\text { Square }\end{array}$ & $\begin{array}{c}\mathrm{Pr}>\mathrm{Chi} \\
\quad \mathrm{Sq}\end{array}$ & $\begin{array}{l}\text { Odds } \\
\text { Ratio }\end{array}$ & $\begin{array}{r}95 \\
\text { Confi } \\
\text { Lin } \\
\end{array}$ & $\begin{array}{l}\% \\
\text { dence } \\
\text { its }\end{array}$ \\
\hline Lag 2 Years $(1 \mathrm{mSv})$ & 1 & -0.0528 & 0.0679 & 0.6045 & 0.4369 & 0.95 & 0.83 & 1.08 \\
\hline $\begin{array}{l}\text { Gender }(1=\text { Female, } \\
0=\text { Male })\end{array}$ & 1 & -2.081 & 1.089 & 3.654 & 0.0559 & 0.13 & 0.02 & 1.05 \\
\hline $\begin{array}{l}\text { Radiation Worker } \\
(1=\text { Yes, } 0=\text { No })\end{array}$ & 1 & -0.8946 & 0.4435 & 4.069 & 0.0437 & 0.41 & 0.17 & 0.98 \\
\hline $\begin{array}{l}\text { Solvent Duration } \\
\text { Exposed - Lagged } 2 \\
\text { Years }\end{array}$ & 1 & 0.0024 & 0.0323 & 0.0054 & 0.9413 & 1.00 & 0.94 & 1.07 \\
\hline $\begin{array}{l}\text { TSLE is } \geq 5 \text { year and } \\
<10 \text { years }\end{array}$ & 1 & -0.3091 & 0.3875 & 0.6364 & 0.4250 & 0.73 & 0.34 & 1.57 \\
\hline $\begin{array}{l}\text { TSLE is } \geq 2.5 \text { years } \\
\text { and }<5 \text { years }\end{array}$ & 1 & -0.0036 & 0.4464 & 0.0001 & 0.9935 & 0.99 & 0.425 & 2.39 \\
\hline $\begin{array}{l}\text { TSLE is } \geq 0 \text { years and } \\
<2.5 \text { years }\end{array}$ & 1 & -0.2003 & 0.4219 & 0.2255 & 0.6349 & 0.82 & 0.36 & 1.87 \\
\hline $\begin{array}{l}\text { On \& Offsite Occ + } \\
\text { Med X-Ray Dose * } \\
\text { Solv Dur Exp }\end{array}$ & 1 & 0.0069 & 0.0050 & 1.959 & 0.1616 & 1.01 & 0.99 & 1.02 \\
\hline $\begin{array}{l}\text { Rad Worker* Solv } \\
\text { Dur Exp }\end{array}$ & 1 & 0.0258 & 0.0404 & 0.4062 & 0.5239 & 1.03 & 0.95 & 1.11 \\
\hline $\begin{array}{l}\text { On \& Offsite Occ }+ \\
\text { Medical X-Ray Dose * } \\
\text { Rad Worker- Lag } 2 \text { yrs }\end{array}$ & 1 & 0.0657 & 0.0686 & 0.9160 & 0.3385 & 1.07 & 0.93 & 1.22 \\
\hline $\begin{array}{l}\text { On \& Offsite Occ }+ \\
\text { Medical X-Ray Dose * } \\
\text { Gender }\end{array}$ & 1 & 0.2343 & 0.1901 & 1.519 & 0.2178 & 1.26 & 0.87 & 1.84 \\
\hline $\begin{array}{l}\text { On \& Offsite Occ + } \\
\text { Med X-Ray Dose * } \\
\text { Rad Worker-Lag } 2 \text { yrs } \\
\text { * Solv Dur Exp }\end{array}$ & 1 & -0.0072 & 0.0050 & 2.085 & 0.1488 & 0.99 & 0.98 & 1.00 \\
\hline
\end{tabular}


Table 16: Model B-Reduced Model with 2-Way Exposure Interactions and Main Effects-Occupational Bone Marrow Dose Combined with Work-Related Medical XRay Dose-Two Year Lag

\begin{tabular}{|cccccccc|} 
& & Parameter & Standard & Chi- & Pr $>$ Chi & Odds & $\begin{array}{c}\text { O5\% } \\
\text { Confidence } \\
\text { Variable }\end{array}$ \\
DF & Estimate & Error & Square & Sq & Ratio & Limits \\
\hline
\end{tabular}

On \& Offsite Occ +

Med X-Ray Dose - Lag

2 Years $(1 \mathrm{mSv})$

\begin{tabular}{lllllll|l}
1 & 0.0130 & 0.0516 & 0.0636 & 0.8009 & 1.01 & 0.92 & 1.12
\end{tabular}

Gender $(1=$ Female,

$\begin{array}{lllllllll}0=\text { Male }) & 1 & -1.841 & 1.069 & 2.973 & 0.0850 & 0.16 & 0.02 & 1.29\end{array}$

Radiation Worker

$\begin{array}{lllllllll}(1=\text { Yes, } 0=\text { No }) & 1 & -0.7462 & 0.3682 & 4.108 & 0.0427 & 0.47 & 0.23 & 0.98\end{array}$

Solvent Duration

Exposed - Lagged 2

$\begin{array}{lllllllll}\text { Years } & 1 & 0.0367 & 0.0147 & 6.236 & 0.0125 & 1.04 & 1.01 & 1.07\end{array}$

TSLE is $\geq 5$ year and

\begin{tabular}{llllllll|l}
$<10$ years & 1 & -0.3269 & 0.3879 & 0.7103 & 0.3994 & 0.72 & 0.34 & 1.54
\end{tabular}

TSLE is $\geq 2.5$ years and

$\begin{array}{lllllllll}<5 \text { years } & 1 & -0.0242 & 0.4454 & 0.0029 & 0.9567 & 0.98 & 0.41 & 2.34\end{array}$

TSLE is $\geq 0$ years and

\begin{tabular}{llllllll|l}
$<2.5$ years & 1 & -0.2322 & 0.4223 & 0.3024 & 0.5824 & 0.79 & 0.35 & 1.81
\end{tabular}

On \& Offsite Occ Dose

+ Work-Related

Medical X-Ray Dose *

Radiation Worker-

$\begin{array}{lllllllll}\text { Lagged } 2 \text { yrs } & 1 & 0.0001 & 0.0526 & 0.0001 & 0.9983 & 1.00 & 0.90 & 1.11\end{array}$

On \& Offsite Occ Dose

+ Work-Related

Medical X-Ray Dose *

Gender

On \& Offsite Occ Dose

+ Work-Related

Medical X-Ray Dose *

Solvent Duration

Exposure

$1 \quad-0.0003$

0.0005

$0.4334 \quad 0.5103$

1.00

$0.99 \quad 1.00$ 
Table 17: Model C Main Effects Only_- Occupational Bone Marrow Dose Combined with Work-Related Medical X-Ray BMD- Two Year Lag

\begin{tabular}{|c|c|c|c|c|c|c|c|c|}
\hline \multirow{4}{*}{$\begin{array}{l}\text { On \& Offsite Occ } \\
+ \text { Med X-Ray }\end{array}$} & \multirow[t]{4}{*}{ DF } & \multirow[t]{4}{*}{$\begin{array}{c}\text { Parameter } \\
\text { Estimate }\end{array}$} & \multirow[t]{4}{*}{$\begin{array}{c}\text { Standard } \\
\text { Error }\end{array}$} & \multirow[t]{4}{*}{$\begin{array}{c}\text { Chi- } \\
\text { Sq }\end{array}$} & \multirow{3}{*}{$\begin{array}{c}\text { Pr }> \\
\text { ChiSq }\end{array}$} & \multirow{3}{*}{$\begin{array}{c}\begin{array}{c}\text { Odds } \\
\text { Ratio }\end{array} \\
(\mathbf{1 0} \mathbf{~ m S v}) \\
1.11\end{array}$} & \multicolumn{2}{|c|}{$\begin{array}{c}95 \% \\
\text { Confidence } \\
\text { Limits }\end{array}$} \\
\hline & & & & & & & & \\
\hline & & & & & & & 1.02 & 1.22 \\
\hline & & & & & & $(1 \mathrm{mSv})$ & & \\
\hline Dose - Lag 2 Years & 1 & 0.0107 & 0.0046 & 5.391 & 0.0202 & 1.01 & 1.00 & 1.02 \\
\hline Gender & 1 & -1.206 & 0.6119 & 3.884 & 0.0487 & 0.30 & 0.09 & 0.99 \\
\hline $\begin{array}{l}\text { Radiation Worker } \\
(1=\text { Yes, } 0=\mathrm{No})\end{array}$ & 1 & -0.7332 & 0.2692 & 7.418 & 0.0065 & 0.48 & 0.28 & 0.81 \\
\hline $\begin{array}{l}\text { Solvent Duration } \\
\text { Exp - Lagged } 2 \\
\text { Years }\end{array}$ & 1 & 315 & 1117 & 275 & 0.0070 & 5 & 1.01 & 1.06 \\
\hline $\begin{array}{l}\text { TSLE is } \geq 5 \text { year } \\
\text { and }<10 \text { years }\end{array}$ & 1 & -0.3057 & 0.3859 & 0.627 & 0.4282 & 0.74 & 0.35 & 1.57 \\
\hline $\begin{array}{l}\text { TSLE is } \geq 2.5 \\
\text { years and }<5 \text { years }\end{array}$ & 1 & -0.0510 & 0.4454 & 0.013 & 0.9088 & 0.95 & 0.40 & 2.28 \\
\hline $\begin{array}{l}\text { TSLE is } \geq 0 \text { years } \\
\text { and }<2.5 \text { years }\end{array}$ & 1 & -0.1707 & 0.4140 & 0.170 & 0.6801 & 0.84 & 0.37 & 1.90 \\
\hline
\end{tabular}


Table 18: Final Regression Model—On-Site BMD Only + Medical BMD—Two Year Lag

\begin{tabular}{|c|c|c|c|c|c|c|c|c|}
\hline \multirow{4}{*}{\begin{tabular}{l}
\multicolumn{1}{c}{ Variable } \\
On Site BMD + \\
Med BMD Cum \\
Dose - Lagged 2 \\
Years
\end{tabular}} & \multirow{4}{*}{$\begin{array}{c}\text { DF } \\
\\
1 \\
1\end{array}$} & \multirow{4}{*}{$\begin{array}{r}\begin{array}{c}\text { Parameter } \\
\text { Estimate }\end{array} \\
0.0109\end{array}$} & \multirow{4}{*}{$\begin{array}{c}\begin{array}{c}\text { Standard } \\
\text { Error }\end{array} \\
0.0046\end{array}$} & \multirow{4}{*}{$\begin{array}{c}\begin{array}{c}\text { Chi- } \\
\text { Square }\end{array} \\
\\
5.603\end{array}$} & \multirow{4}{*}{$\begin{array}{c}\begin{array}{c}\text { Pr }> \\
\text { ChiSq }\end{array} \\
0.0179\end{array}$} & \multirow{3}{*}{$\begin{array}{c}\begin{array}{c}\text { Odds } \\
\text { Ratio }\end{array} \\
(10 \mathrm{mSv}) \\
1.12\end{array}$} & \multicolumn{2}{|c|}{$\begin{array}{l}95 \% \\
\text { Confidence } \\
\text { Limits }\end{array}$} \\
\hline & & & & & & & & \\
\hline & & & & & & & 1.02 & 1.22 \\
\hline & & & & & & $\begin{array}{l}(1 \mathrm{mSv}) \\
1.01\end{array}$ & 1.00 & 1.02 \\
\hline Gender & 1 & -1.198 & 0.6110 & 3.844 & 0.0499 & 0.30 & 0.09 & 1.00 \\
\hline $\begin{array}{l}\text { Radiation Worker } \\
(1=\text { Yes, } 0=\text { No })\end{array}$ & 1 & -0.7559 & 0.2654 & 8.109 & 0.0044 & 0.47 & 0.28 & 0.79 \\
\hline $\begin{array}{l}\text { Solvent Duration } \\
\text { Exposure - Lagged } \\
2 \text { Years }\end{array}$ & 1 & 0.0312 & 0.0115 & 7.370 & 0.0066 & 1.03 & 1.01 & 1.06 \\
\hline
\end{tabular}

Table 19: Amount of Collective Cumulative Bone Marrow Dose and Whole Body Exposure Received from Estimated Missed Exposure, Onsite, and Offsite Sources for the 201 Radiation Monitored Cases and Controls

\begin{tabular}{|cccc|}
\hline Source & $\begin{array}{c}\text { Collective Bone } \\
\text { Marrow Dose } \\
\text { (person-mSv) }\end{array}$ & $\begin{array}{c}\text { Collective Whole } \\
\text { Body Exposure } \\
\text { (person-mSv) }\end{array}$ & $\begin{array}{c}\text { Difference } \\
\text { (person-mSv) }\end{array}$ \\
\hline Onsite Only & $3,429.50$ & $4,658.29$ & $1,228.79$ \\
Estimated Missed & 60.92 & 87.59 & 26.67 \\
Offsite Only & 7.63 & 10.92 & 3.29 \\
Total & $3,498.05$ & $4,756.80$ & $1,258.75$ \\
\hline
\end{tabular}




\section{Table 20: Formula for the Computation of Odds Ratio and 95\% Confidence Intervals for the Radiation Exposure * Time Since Last Exposed (TSLE) Category}

The relative risk at ( $1 \mathrm{mSv}$ and $10 \mathrm{mSv}$ ) exposure levels and TSLE category of interest

$e^{\hat{\beta}_{1}\left(f_{1}-f_{0}\right)+\hat{\beta}_{3} X\left(f_{1}-f_{0}\right)}$

Confidence Interval on Relative Risk at exposure $\mathrm{f}_{1}$ and TSLE category of interest

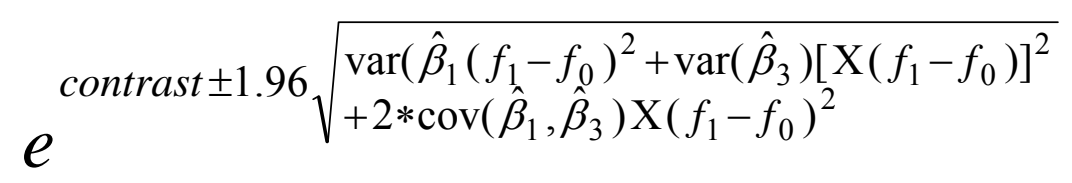

$\hat{\beta}_{1}=$ The estimated dose parameter

$\hat{\beta}_{3}=$ Estimated dose * TSLE category interaction parameter

$\operatorname{Cov}\left(\hat{\beta}_{1}, \hat{\beta}_{3}\right)=$ Covariance of the dose parameter and the dose $*$ TSLE category interaction parameter

$f_{1}=$ Exposure level of interest (eg. $1 \mathrm{mSv}$ or $10 \mathrm{mSv}$ )

$f_{0}=$ Comparison exposure level (eg. $\left.0 \mathrm{mSv}\right)$

$X=$ Dummy variable corresponding to the TSLE category $(\mathrm{X}=1)$

SAS Institute Inc., Survival Analysis Using the Proportional Hazards Model, SAS Institute Inc., Cary, NC. 2003. p. 171. 


\begin{tabular}{|c|c|c|c|c|}
\hline \multicolumn{5}{|c|}{ 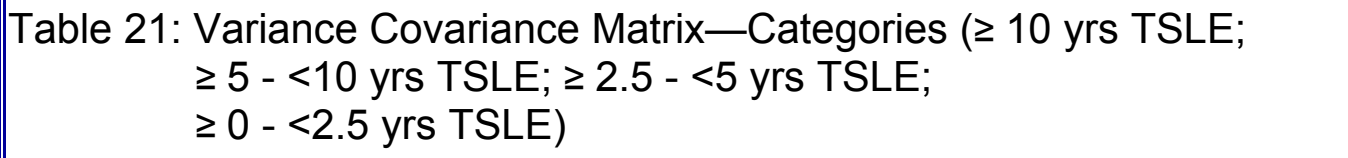 } \\
\hline $\begin{array}{c}\text { Rad Exposure } \\
(1 \mathrm{mSv})\end{array}$ & $\begin{array}{l}\text { Rad } \\
\text { Exposure * } \\
\geq 10 \text { years } \\
\text { TSLE }\end{array}$ & $\begin{array}{c}\text { Rad } \\
\text { Exposure * } \geq \\
5 \text { and }<10 \\
\text { years TSLE }\end{array}$ & $\begin{array}{c}\text { Rad } \\
\text { Exposure * } \\
\geq 2.5 \text { and } \\
<5 \text { years } \\
\text { TSLE }\end{array}$ & $\begin{array}{l}\text { Rad Exposure* } \\
\geq 0 \text { and }<2.5 \\
\text { years TSLE }\end{array}$ \\
\hline \multicolumn{5}{|l|}{ Parameter } \\
\hline Estimates & 0.00709 & $\mathbf{- 0 . 0 4 5 7 1}$ & 0.04330 & 0.00203 \\
\hline Rad Exposure * & (Variance) & $\begin{array}{c}\text { (Variance } \\
\text { Covariance) }\end{array}$ & $\begin{array}{l}\text { (Variance } \\
\text { Covariance) }\end{array}$ & $\begin{array}{l}\text { (Variance } \\
\text { Covariance) }\end{array}$ \\
\hline$\geq 10$ years TSLE & 0.000015657 & -0.000011 & -0.000012 & -0.000013 \\
\hline \multicolumn{5}{|c|}{$\begin{array}{l}\text { Rad Exposure * } \\
\geq 5 \text { and }<10 \text { years }\end{array}$} \\
\hline TSLE & -0.000011 & 0.001745 & 0.000030 & 0.000010566 \\
\hline $\begin{array}{l}\text { Rad Exposure * } \\
\geq 2.5 \text { and }<5 \\
\text { vears TSLF }\end{array}$ & -0.000012 & 0.000030 & $\begin{array}{r}\text { (Variance) } \\
0.000470\end{array}$ & 0.000017158 \\
\hline $\begin{array}{l}\text { Rad Exposure * } \\
\geq 0 \text { and }<2.5 \\
\text { years TSLE }\end{array}$ & -0.000013 & 0.000011 & 0.000017 & $\begin{array}{l}\text { (Variance) } \\
0.000075935\end{array}$ \\
\hline
\end{tabular}




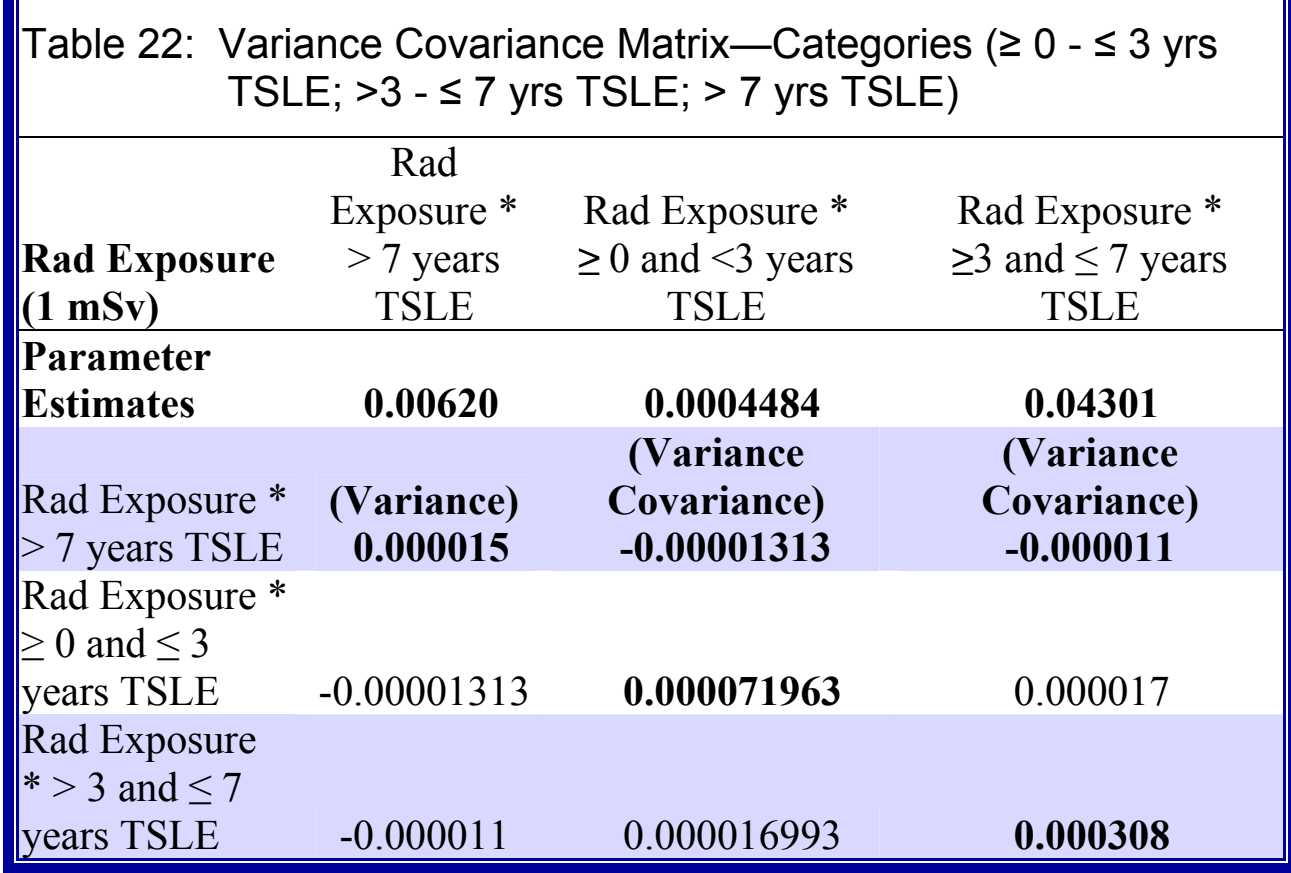




\begin{tabular}{|c|c|c|c|c|}
\hline \multicolumn{5}{|c|}{$\begin{array}{l}\text { Table 23: Variance Covariance Matrix-Categories ( } \geq 10 \text { yrs. TSLE; } \\
\quad \geq 5-<10 \text { yrs TSLE; } \geq 2.5-<5 \text { yrs TSLE; } \\
\quad \geq 0-<2.5 \text { yrs TSLE) }\end{array}$} \\
\hline $\begin{array}{l}\text { Rad Exposure } \\
(1 \mathrm{mSv})\end{array}$ & $\begin{array}{l}\text { Rad } \\
\text { Exposure * } \\
\geq 10 \text { years } \\
\text { TSLE }\end{array}$ & $\begin{array}{l}\text { Rad } \\
\text { Exposure* } \\
\geq \mathbf{5} \text { and }<10 \\
\text { years TSLE }\end{array}$ & $\begin{array}{l}\text { Rad } \\
\text { Exposure * } \\
\geq 2.5 \text { and }<5 \\
\text { years TSLE }\end{array}$ & $\begin{array}{l}\text { Rad Exposure } \\
* \geq 0 \text { and }<2.5 \\
\text { years TSLE }\end{array}$ \\
\hline $\begin{array}{l}\text { Parameter } \\
\text { Estimates }\end{array}$ & 0.00913 & 0.00991 & 0.00071 & 0.00153 \\
\hline $\begin{array}{l}\text { Rad Exposure* } \\
\geq 10 \text { years } \\
\text { TSLE }\end{array}$ & $\begin{array}{r}\text { (Variance) } \\
0.000034\end{array}$ & $\begin{array}{l}\text { (Variance } \\
\text { Covariance) } \\
\mathbf{- 0 . 0 0 0 0 3 0}\end{array}$ & $\begin{array}{l}\text { (Variance } \\
\text { Covariance) } \\
-\mathbf{0 . 0 0 0 0 3 1}\end{array}$ & $\begin{array}{c}\text { (Variance } \\
\text { Covariance) } \\
\mathbf{- 0 . 0 0 0 0 3 1}\end{array}$ \\
\hline $\begin{array}{l}\text { Rad Exposure } \\
* \geq 5 \text { and }<\mathbf{1 0} \\
\text { years TSLE }\end{array}$ & $-\mathbf{0 . 0 0 0 0 3 0}$ & $\begin{array}{r}\text { (Variance) } \\
\mathbf{0 . 0 0 0 2 0 4}\end{array}$ & 0.000031 & 0.000028 \\
\hline $\begin{array}{l}\text { Rad Exposure } \\
* \geq 2.5 \text { and }<5 \\
\text { years TSLE }\end{array}$ & -0.000031 & 0.000031 & $\begin{array}{c}\text { (Variance) } \\
0.000159\end{array}$ & 0.000027 \\
\hline $\begin{array}{l}\text { Rad Exposure } \\
* \geq 0 \text { and }<2.5 \\
\text { years TSLE }\end{array}$ & -0.000031 & 0.000028 & 0.000027 & $\begin{array}{c}\text { (Variance) } \\
0.000115\end{array}$ \\
\hline
\end{tabular}




\begin{tabular}{|c|c|c|c|}
\hline $\begin{array}{c}\text { Rad Exposure } \\
(1 \mathrm{mSv})\end{array}$ & $\begin{array}{c}\text { Rad Exposure } \\
*>7 \text { years } \\
\text { TSLE } \\
\end{array}$ & $\begin{array}{c}\text { Rad Exposure * } \\
\geq 0 \text { and }<3 \text { years } \\
\text { TSLE }\end{array}$ & $\begin{array}{c}\text { Rad Exposure * } \\
\geq 3 \text { and } \leq 7 \text { years } \\
\text { TSLE }\end{array}$ \\
\hline \begin{tabular}{|l} 
Parameter \\
Estimates
\end{tabular} & 0.01113 & -0.00139 & 0.00280 \\
\hline $\begin{array}{l}\text { Rad Exposure } \\
*>7 \text { years } \\
\text { TSLE }\end{array}$ & $\begin{array}{c}\text { (Variance) } \\
0.000030\end{array}$ & $\begin{array}{l}\text { (Variance } \\
\text { Covariance) } \\
\mathbf{- 0 . 0 0 0 0 2 6 4}\end{array}$ & $\begin{array}{l}\text { (Variance } \\
\text { Covariance) } \\
\mathbf{- 0 . 0 0 0 0 2 5 9}\end{array}$ \\
\hline $\begin{array}{l}\text { Rad Exposure } \\
* \geq 0 \text { and } \leq 3 \\
\text { years TSLE }\end{array}$ & -0.0000264 & $\begin{array}{l}\text { (Variance) } \\
0.000111\end{array}$ & 0.000024 \\
\hline $\begin{array}{l}\text { Rad Exposure } \\
*>3 \text { and } \leq 7 \\
\text { years TSLE }\end{array}$ & -0.0000259 & 0.000024 & $\begin{array}{l}\text { (Variance) } \\
0.000155\end{array}$ \\
\hline
\end{tabular}


Table 25: Model Fit Statistics —Badge Exposure with TSLE as a Continuous Variable

\begin{tabular}{|c|c|c|c|c|}
\hline Model & DF & $\begin{array}{l}-2 \text { LOG L } \\
\text { With } \\
\text { Covariates }\end{array}$ & $\begin{array}{l}\text {-2 LOG L } \\
\text { With } \\
\text { Covariates } \\
\text { Differences }\end{array}$ & $\begin{array}{c}\text { Critical } \\
\text { Value-Chi- } \\
\text { Sq }(0.05)\end{array}$ \\
\hline $\begin{array}{l}\text { del with } 2 \text {-way, and } \\
\text { fects }\end{array}$ & 12 & 347.32 & & \\
\hline $\begin{array}{l}\text { model 2-way } \\
\text { e interactions and } \\
\text { fects }\end{array}$ & 7 & 348.32 & $\begin{array}{c}\mathrm{B}-\mathrm{A}=1.01 \\
5 \mathrm{df}\end{array}$ & 11.07 \\
\hline model-main effects & 5 & 349.20 & $\begin{array}{c}C-B=0.88 \\
2 \mathrm{df}\end{array}$ & 5.99 \\
\hline
\end{tabular}


Table 26: Model A-Full Model with 2-Way Interactions and Main EffectsBadge Exposure-Two Year Lag-with TSLE as a Continuous Variable

\begin{tabular}{|c|c|c|c|c|c|c|c|c|}
\hline \multirow{3}{*}{\begin{tabular}{l}
\multicolumn{1}{c}{ Variable } \\
On/Offsite Badge \\
Cum Exp - Lag 2 \\
Years
\end{tabular}} & \multirow[t]{2}{*}{ DF } & \multirow[t]{2}{*}{$\begin{array}{c}\text { Parameter } \\
\text { Estimate }\end{array}$} & \multirow[t]{2}{*}{$\begin{array}{l}\text { Standard } \\
\text { Error }\end{array}$} & \multirow[t]{2}{*}{$\begin{array}{l}\text { Chi- } \\
\text { Square }\end{array}$} & \multirow[t]{2}{*}{$\begin{array}{r}\mathrm{Pr}> \\
\mathrm{Chi} \\
\mathrm{Sq}\end{array}$} & \multirow[t]{2}{*}{$\begin{array}{l}\text { Odds } \\
\text { Ratio }\end{array}$} & \multicolumn{2}{|c|}{$\begin{array}{c}95 \% \\
\text { Confidence } \\
\text { Limits }\end{array}$} \\
\hline & & & & & & & & \\
\hline & 1 & 0.0069 & 0.0080 & 0.7413 & 0.3892 & 1.01 & 0.99 & 1.02 \\
\hline Gender & 1 & -1.470 & 1.086 & 1.833 & 0.1758 & 0.23 & 0.03 & 1.93 \\
\hline $\begin{array}{l}\text { Radiation Worker } \\
\text { Lagged } 2 \text { yrs }\end{array}$ & 1 & -0.3699 & 0.5258 & 0.4951 & 0.4817 & 0.69 & 0.25 & 1.94 \\
\hline Solv Dur Exp - Lag & & & & & & & & \\
\hline 2 Years & 1 & 0.0300 & 0.0222 & 1.827 & 0.1765 & 1.03 & 0.99 & 1.08 \\
\hline TSLE & 1 & & & & 086 & & 0.97 & 1.03 \\
\hline $\begin{array}{l}\text { On/Off Badge } \\
\text { lag2*TSLE }\end{array}$ & 1 & 0.0002 & 0.0005 & 0.1484 & 0.7001 & 1.00 & 0.99 & 1.00 \\
\hline $\begin{array}{l}\text { On/Off Badge lag } 2 \\
* \text { Solv_Lag2 }\end{array}$ & 1 & -0.0002 & 008 & 0.0801 & 0.7772 & & 0.99 & 1.00 \\
\hline $\begin{array}{l}\text { On/Off Badge } \\
\text { lag2*Solv_lag2* } \\
\text { TSLE }\end{array}$ & 1 & & & & 0.9942 & & 1.00 & 1.00 \\
\hline $\begin{array}{l}\text { Rad worker } \\
\text { lag2*Solv_lag2 }\end{array}$ & 1 & -0.0117 & 0.0266 & 0.1933 & 0.6602 & 0.99 & 0.94 & 1.04 \\
\hline $\begin{array}{l}\text { Rad worker lag2 } \\
\text { *TSLE }\end{array}$ & 1 & -0.0 & 0.02 & 0.5 & 0.4765 & 0. & 0.93 & 1.04 \\
\hline Gender* TSLE & 1 & 0.0190 & 0.0468 & 0.16 & 0.6853 & 1.02 & 0.93 & 1.12 \\
\hline Solv_lag2*TSLE & 1 & 0.0007 & 0.0013 & 0.3063 & 0.5800 & 1.00 & 0.99 & 1.00 \\
\hline
\end{tabular}




\begin{tabular}{|c|c|c|c|c|c|c|c|c|}
\hline Variable & DF & $\begin{array}{c}\text { Parameter } \\
\text { Estimate }\end{array}$ & $\begin{array}{c}\text { Standard } \\
\text { Error }\end{array}$ & $\begin{array}{l}\text { Chi- } \\
\text { Square }\end{array}$ & $\begin{array}{l}\text { Pr }> \\
\text { Chi Sq }\end{array}$ & $\begin{array}{l}\text { Odds } \\
\text { Ratio }\end{array}$ & $\begin{array}{r}9 \\
\text { Conf } \\
\text { Li }\end{array}$ & $\begin{array}{l}\% \\
\text { lence } \\
\text { iits }\end{array}$ \\
\hline Lag 2 Years & 1 & 0.0100 & 0.0068 & 2.177 & 0.1401 & 1.01 & 0.99 & 1.02 \\
\hline Gender & 1 & -1.159 & 0.6129 & 3.577 & 0.0586 & 0.31 & 0.09 & 1.04 \\
\hline \begin{tabular}{|l} 
Rad Worker \\
Lag 2 yrs.
\end{tabular} & 1 & -0.7436 & 0.2634 & 7.967 & 0.0048 & 0.48 & 0.28 & 0.80 \\
\hline $\begin{array}{l}\text { Solv Dur Exp } \\
\text { Lag } 2 \text { Years } \\
\text { TSLE }\end{array}$ & $\begin{array}{l}1 \\
1\end{array}$ & $\begin{array}{c}0.0358 \\
-0.0012\end{array}$ & $\begin{array}{l}0.0127 \\
0.0120\end{array}$ & $\begin{array}{c}8.014 \\
0.0102\end{array}$ & $\begin{array}{l}0.0046 \\
0.9196\end{array}$ & $\begin{array}{l}1.04 \\
0.99\end{array}$ & $\begin{array}{l}1.01 \\
0.98\end{array}$ & $\begin{array}{l}1.06 \\
1.02\end{array}$ \\
\hline \begin{tabular}{|l} 
On/Off Badge \\
Lag2*Solv_lag2
\end{tabular} & 1 & -0.0003 & 0.0004 & 0.8450 & 0.3580 & 1.00 & 0.99 & 1.00 \\
\hline $\begin{array}{l}\text { On/Off Badge } \\
\text { Lag2*TSLE }\end{array}$ & 1 & 0.00003 & 0.0004 & 0.0047 & 0.9451 & 1.00 & 0.99 & 1.00 \\
\hline
\end{tabular}




\begin{tabular}{|c|c|c|c|c|c|c|c|c|}
\hline Variable & DF & $\begin{array}{c}\text { Parameter } \\
\text { Estimate }\end{array}$ & $\begin{array}{l}\text { Standard } \\
\text { Error }\end{array}$ & $\begin{array}{c}\text { Chi- } \\
\text { Square }\end{array}$ & $\begin{array}{l}\operatorname{Pr}> \\
\text { ChiSq }\end{array}$ & $\begin{array}{l}\text { Odds } \\
\text { Ratio }\end{array}$ & $\begin{array}{r}9 \\
\text { Con } \\
\mathrm{Li}\end{array}$ & $\begin{array}{l}\text { o } \\
\text { lence } \\
\text { its }\end{array}$ \\
\hline Badge Cum & & & & & & 1.08 & 1.01 & 1.16 \\
\hline $\begin{array}{l}\text { Exposure - } \\
\text { Lagged } 2 \text { Years }\end{array}$ & 1 & 0.0076 & 0.0035 & 4.769 & 0.0290 & 1.01 & 1.00 & 1.02 \\
\hline Gender & 1 & -1.193 & 0.6112 & 3.808 & 0.0510 & 0.30 & 0.09 & 1.01 \\
\hline $\begin{array}{l}\text { Radiation } \\
\text { Worker flag }\end{array}$ & 1 & -0.72819 & 0.2631 & 7.658 & 0.0057 & 0.48 & 0.29 & 0.81 \\
\hline $\begin{array}{l}\text { Solvent } \\
\text { Duration Exp - } \\
\text { Lagged } 2 \text { Years } \\
\text { TSLE }\end{array}$ & $\begin{array}{l}1 \\
1\end{array}$ & $\begin{array}{r}0.0318 \\
-0.0021\end{array}$ & $\begin{array}{l}0.0119 \\
0.0119\end{array}$ & $\begin{array}{c}7.150 \\
0.0317\end{array}$ & $\begin{array}{l}0.0075 \\
0.8587\end{array}$ & $\begin{array}{l}1.03 \\
0.99\end{array}$ & $\begin{array}{l}1.01 \\
0.98\end{array}$ & $\begin{array}{l}1.06 \\
1.02\end{array}$ \\
\hline
\end{tabular}

Table 29: Time Windows of Exposure Analysis

\begin{tabular}{|c|c|c|c|c|c|c|c|c|}
\hline Variable & DF & $\begin{array}{c}\text { Parameter } \\
\text { Estimate }\end{array}$ & $\begin{array}{c}\text { Standard } \\
\text { Error }\end{array}$ & $\begin{array}{c}\text { Chi- } \\
\text { Square }\end{array}$ & $\begin{array}{l}\text { Pr }> \\
\text { ChiSq }\end{array}$ & $\begin{array}{l}\text { Odds } \\
\text { Ratio }\end{array}$ & \multicolumn{2}{|c|}{$\begin{array}{c}\text { Confidence } \\
\text { Limits }\end{array}$} \\
\hline Gender & 1 & -1.1940 & 0.6105 & 3.825 & 0.0505 & 0.30 & 0.09 & 1.00 \\
\hline Rad_Worker & 1 & -0.7757 & 0.2694 & 8.291 & 0.0040 & 0.46 & 0.27 & 0.78 \\
\hline $\begin{array}{l}\text { Solvent } \\
\text { Exposure }\end{array}$ & 1 & 0.0320 & 0.0115 & 7.790 & 0.0053 & 1.03 & 1.01 & 1.06 \\
\hline $\begin{array}{l}0<2.5 \text { yrs. } \\
\text { Window }\end{array}$ & 1 & -0.1849 & 0.1941 & 0.9077 & 0.3407 & 0.83 & 0.57 & 1.22 \\
\hline $\begin{array}{l}2.5<5 \text { yrs. } \\
\text { Window }\end{array}$ & 1 & 0.0208 & 0.0438 & 0.2253 & 0.6350 & 1.02 & 0.94 & 1.11 \\
\hline $\begin{array}{l}5<10 \text { yrs. } \\
\text { Window }\end{array}$ & 1 & 0.03529 & 0.0161 & 4.758 & 0.0292 & 1.04 & 1.00 & 1.07 \\
\hline $\begin{array}{l}\geq 10 \text { yrs. } \\
\text { Window }\end{array}$ & 1 & 0.0064 & 0.0038 & 2.902 & 0.0885 & 1.01 & 0.99 & 1.01 \\
\hline
\end{tabular}


Table 30: Description of All Radiation Dose Metrics Used in the Regression Analysis in Order of Appearance or Reference in Report

\begin{tabular}{|c|c|c|c|}
\hline $\begin{array}{c}\text { Radiation dose metric } \\
\text { label }\end{array}$ & Table & Page & Radiation dose included in the metric \\
\hline Occupational Badge & & & Cumulative onsite and off site badge \\
\hline Exposure $0,2,5,7, \mathrm{Yr}$ & & & exposure and missed exposure \\
\hline Lags & 4.5 .1 & 33 & combined: $0,2,5$, and 7 year lag periods \\
\hline $\begin{array}{l}\text { Occupational Badge } \\
\text { Exposure Lagged } 2 \text { years }\end{array}$ & $\begin{array}{l}\text { 4.5.2.A., } \\
\text { 4.5.2.B. \& } \\
\quad 4.5 .3\end{array}$ & $\begin{array}{c}34,35 \\
37\end{array}$ & $\begin{array}{l}\text { Cumulative onsite and offsite } \\
\text { occupational badge exposure and } \\
\text { Missed Exposure combined with } 2 \text { yr } \\
\text { lag }\end{array}$ \\
\hline $\begin{array}{l}\text { On \& Offsite \& Missed } \\
\text { Badge Cumulative } \\
\text { Exposure - Lagged } 2 \\
\text { Years }\end{array}$ & $\begin{array}{l}\text { Appendix K } \\
\text { Tables 3, 4, } \\
\quad 5,6\end{array}$ & $148-151$ & $\begin{array}{l}\text { Cumulative onsite and offsite badge } \\
\text { exposure and Missed Exposure } \\
\text { combined with a } 2 \text { year lag }\end{array}$ \\
\hline $\begin{array}{l}\text { Onsite Badge Exposure - } \\
\text { Lagged } 2 \text { Years }\end{array}$ & $\begin{array}{l}\text { Appendix } \\
\text { KTable } 7\end{array}$ & 152 & $\begin{array}{l}\text { Cumulative onsite badge exposure } \\
\text { ONLY (Missed and Offsite are } \\
\text { excluded)-2 yr lag }\end{array}$ \\
\hline $\begin{array}{l}\text { Occupational Bone } \\
\text { Marrow Cum Dose } \\
0,2,5,7, \text { yr lags }\end{array}$ & $\begin{array}{l}\text { Appendix } \mathrm{K} \\
\text { Table } 8\end{array}$ & 153 & $\begin{array}{l}\text { Cumulative onsite and off site } \\
\text { Occupational badge exposure \& missed } \\
\text { exposure combined converted to } \\
\text { BMD- } 0,2,5,7 \text { year lag periods }\end{array}$ \\
\hline $\begin{array}{l}\text { Occupational Cumulative } \\
\text { BMD + Medical X-Ray } \\
\text { Dose Lagged } 0,2,5,7 \mathrm{yr}\end{array}$ & $\begin{array}{c}\text { Appendix K } \\
\text { Table } 9\end{array}$ & 154 & $\begin{array}{l}\text { Cumulative onsite and off site } \\
\text { Occupational badge exposure \& missed } \\
\text { exposure combined and converted to } \\
\text { BMD + Med X-Ray BMD- } 0,2,5,7 \text {, } \\
\text { year lag periods }\end{array}$ \\
\hline $\begin{array}{l}\text { Occupational Cumulative } \\
\text { Bone Marrow Dose } \\
\text { Only-2 yr lag }\end{array}$ & $\begin{array}{l}\text { Appendix K } \\
\text { Table } \\
10,11,12,13\end{array}$ & $155-158$ & $\begin{array}{l}\text { Cumulative onsite and off site } \\
\text { occupational badge exposure and } \\
\text { missed exposure combined \& } \\
\text { converted to BMD-2 year lag period }\end{array}$ \\
\hline $\begin{array}{l}\text { Occupational Cumulative } \\
\text { BMD + Medical X-Ray } \\
\text { Dose }\end{array}$ & $\begin{array}{l}\text { Appendix K } \\
\text { Table } \\
14,15,16,17\end{array}$ & $159-162$ & $\begin{array}{l}\text { Cumulative onsite and off site badge } \\
\text { exposure \& missed exposure combined } \\
\text { and converted to BMD }+ \text { Medical X- } \\
\text { Ray BMD Dose-lagged } 2 \text { years }\end{array}$ \\
\hline
\end{tabular}


Table 30: Description of All Radiation Dose Metrics Used in the Regression Analysis in Order of Appearance or Reference in Report

\begin{tabular}{|c|c|c|c|}
\hline $\begin{array}{l}\text { Radiation dose metric } \\
\text { label }\end{array}$ & Table & Page & Radiation dose included in the metric \\
\hline $\begin{array}{l}\text { Onsite BMD + Med } \\
\text { BMD Cum Dose Lag } 2 \\
\text { yrs }\end{array}$ & $\begin{array}{l}\text { Appendix K } \\
\text { Table } 18\end{array}$ & 163 & $\begin{array}{l}\text { Cumulative onsite badge exposure } \\
\text { converted to BMD (Missed Exposure } \\
\text { and offsite exposure are excluded) }+ \\
\text { Medical X-Ray BMD-2 year lag } \\
\text { period }\end{array}$ \\
\hline $\begin{array}{l}\text { Cum Rad Badge } \\
\text { Exposure }\end{array}$ & $\begin{array}{l}\text { Appendix K } \\
\text { Table 21-22 }\end{array}$ & $165-166$ & $\begin{array}{l}\text { Cumulative Onsite and Off site } \\
\text { occupational badge exposure } \\
\text { combined-No lag-(No Missed } \\
\text { Exposure) }\end{array}$ \\
\hline $\begin{array}{l}\text { Cum Rad Badge } \\
\text { Exposure }\end{array}$ & $\begin{array}{l}\text { Appendix K } \\
\text { Table 23-24 }\end{array}$ & $167-168$ & $\begin{array}{l}\text { Cumulative Onsite and Off site } \\
\text { occupational badge exposure combined } \\
\text { converted to BMD + Medical X-Ray } \\
\text { BMD-No lag-(No Missed Exposure) }\end{array}$ \\
\hline $\begin{array}{l}\text { Occupational Bone } \\
\text { Marrow Cum Dose } \\
\text { Lagged } 2 \text { Years }\end{array}$ & 4.5.4.1. & 38 & $\begin{array}{l}\text { BMD converted from onsite and offsite } \\
\text { badge exposure and missed exposure } \\
\text { combined-Lagged } 2 \text { Years }\end{array}$ \\
\hline $\begin{array}{l}\text { Occupational Cumulative } \\
\text { BMD + Medical X-Ray } \\
\text { BMD Lagged } 2 \text { yrs. }\end{array}$ & 4.5.4.2 & 39 & $\begin{array}{l}\text { Onsite and off site cumulative badge } \\
\text { exposure and missed exposure } \\
\text { converted to BMD }+ \text { Work-Related } \\
\text { Medical X-Rays given at PNS-lagged } \\
2 \text { years }\end{array}$ \\
\hline Cum Rad Exposure & $\begin{array}{l}\text { 4.5.5.A.,B,C, } \\
\text { \& D }\end{array}$ & $40-42$ & $\begin{array}{l}\text { Cumulative Onsite and Off site badge } \\
\text { exposure combined (No Missed } \\
\text { Exposure Included) - } 2 \text { yr. lag }\end{array}$ \\
\hline $\begin{array}{l}\text { Occupational Cumulative } \\
\text { BMD + Medical X-Ray } \\
\text { Dose Lagged } 2 \text { yrs. }\end{array}$ & 4.5.6.A. \& B & $43-44$ & $\begin{array}{l}\text { Onsite and off site cumulative badge } \\
\text { exposure converted to BMD + Work- } \\
\text { Related Medical X-Rays given at PNS } \\
\text { (No Missed Exposure Included) - } 2 \\
\text { year lag period }\end{array}$ \\
\hline $\begin{array}{l}\text { Badge Exposure with } \\
\text { TSLE as a Continuous } \\
\text { Variable }\end{array}$ & $\begin{array}{l}\text { Appendix K } \\
\text { Table } 25\end{array}$ & 169 & $\begin{array}{l}\text { Onsite and offsite cumulative badge } \\
\text { exposure and missed exposure-lagged } 2 \\
\text { years }\end{array}$ \\
\hline $\begin{array}{l}\text { On/Offsite Badge Cum } \\
\text { Exp - Lag } 2 \text { Years }\end{array}$ & $\begin{array}{l}\text { Appendix K } \\
\text { Table } 26\end{array}$ & 170 & $\begin{array}{l}\text { Onsite and offsite cumulative badge } \\
\text { exposure and missed exposure-lagged } 2 \\
\text { years }\end{array}$ \\
\hline
\end{tabular}


Table 30: Description of All Radiation Dose Metrics Used in the Regression Analysis in Order of Appearance or Reference in Report

\begin{tabular}{|c|c|c|c|}
\hline $\begin{array}{c}\text { Radiation dose metric } \\
\text { label }\end{array}$ & Table & Page & Radiation dose included in the metric \\
\hline $\begin{array}{l}\text { Badge Cum Exposure - } \\
\text { Lagged } 2 \text { Years }\end{array}$ & $\begin{array}{l}\text { Appendix K } \\
\text { Table } 27\end{array}$ & 171 & $\begin{array}{l}\text { Onsite and offsite cumulative badge } \\
\text { exposure and missed exposure-lagged } 2 \\
\text { years }\end{array}$ \\
\hline $\begin{array}{l}\text { Badge Cum Exposure - } \\
\text { Lagged } 2 \text { Years }\end{array}$ & $\begin{array}{c}\text { Appendix K } \\
\text { Table } 28\end{array}$ & 172 & $\begin{array}{l}\text { Onsite and offsite cumulative badge } \\
\text { exposure and missed exposure-lagged } 2 \\
\text { years }\end{array}$ \\
\hline $\begin{array}{l}\text { On \& off site Badge - } \\
\text { Win 0-2.5 yr } \\
\text { On \& off site badge - } \\
\text { Win } 2.5-5 \text { yr } \\
\text { On \& off site badge - } \\
\text { Win } 5-10 \text { yr } \\
\text { On \& off badge - Win } \\
>10 \text { yr }\end{array}$ & $\begin{array}{l}\text { Appendix K } \\
\text { Table } 29\end{array}$ & 172 & $\begin{array}{l}\text { For each exposure window-Onsite } \\
\text { and offsite cumulative badge exposure } \\
\text { no missed exposure no lag }\end{array}$ \\
\hline $\begin{array}{l}\text { Radiation Dose Category } \\
1-<1 \mathrm{mSv} \\
10-<50 \mathrm{mSv} \\
>50 \mathrm{mSv}\end{array}$ & $\begin{array}{c}\text { Appendix K } \\
\text { Table } 37\end{array}$ & 182 & $\begin{array}{c}\text { For each dose category-Onsite and } \\
\text { offsite cumulative badge and missed } \\
\text { exposure } 2 \text { yr lag }\end{array}$ \\
\hline
\end{tabular}


Table 31: Dose Distribution Radiation Monitored Cases

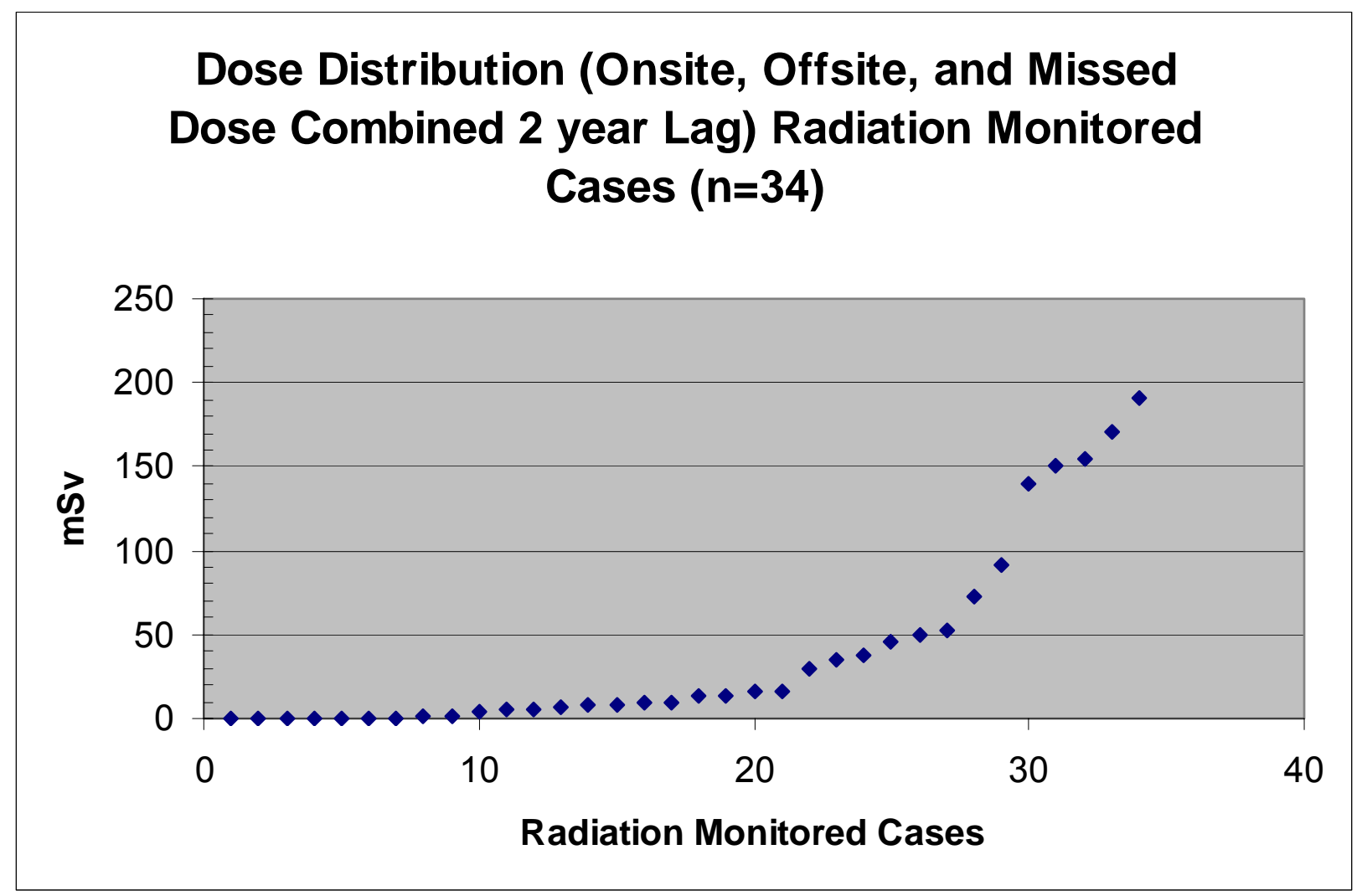


Table 32: Dose Distribution Radiation Monitored Controls

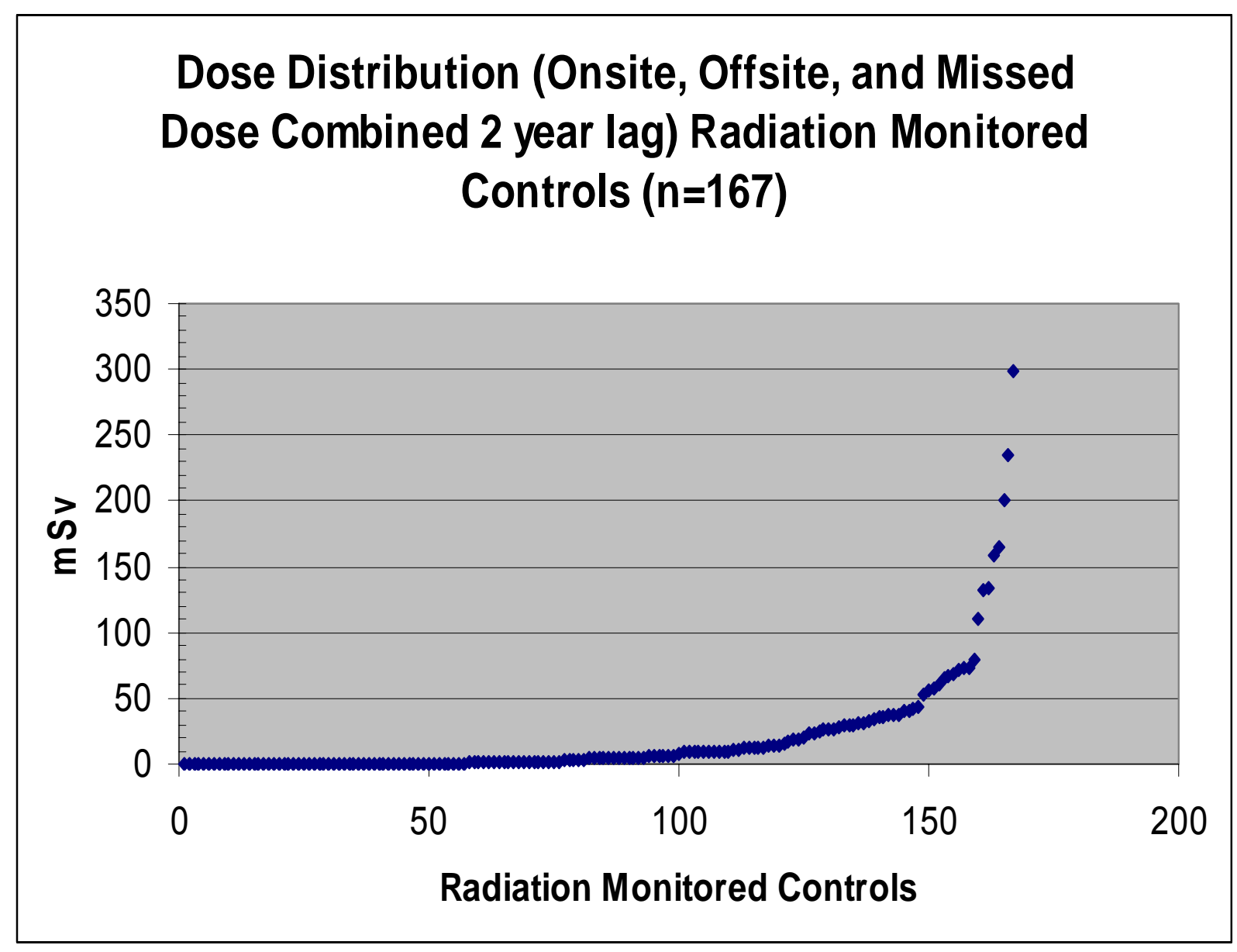


Table 33: Distribution of Solvent Duration (yrs) Radiation Monitored Cases

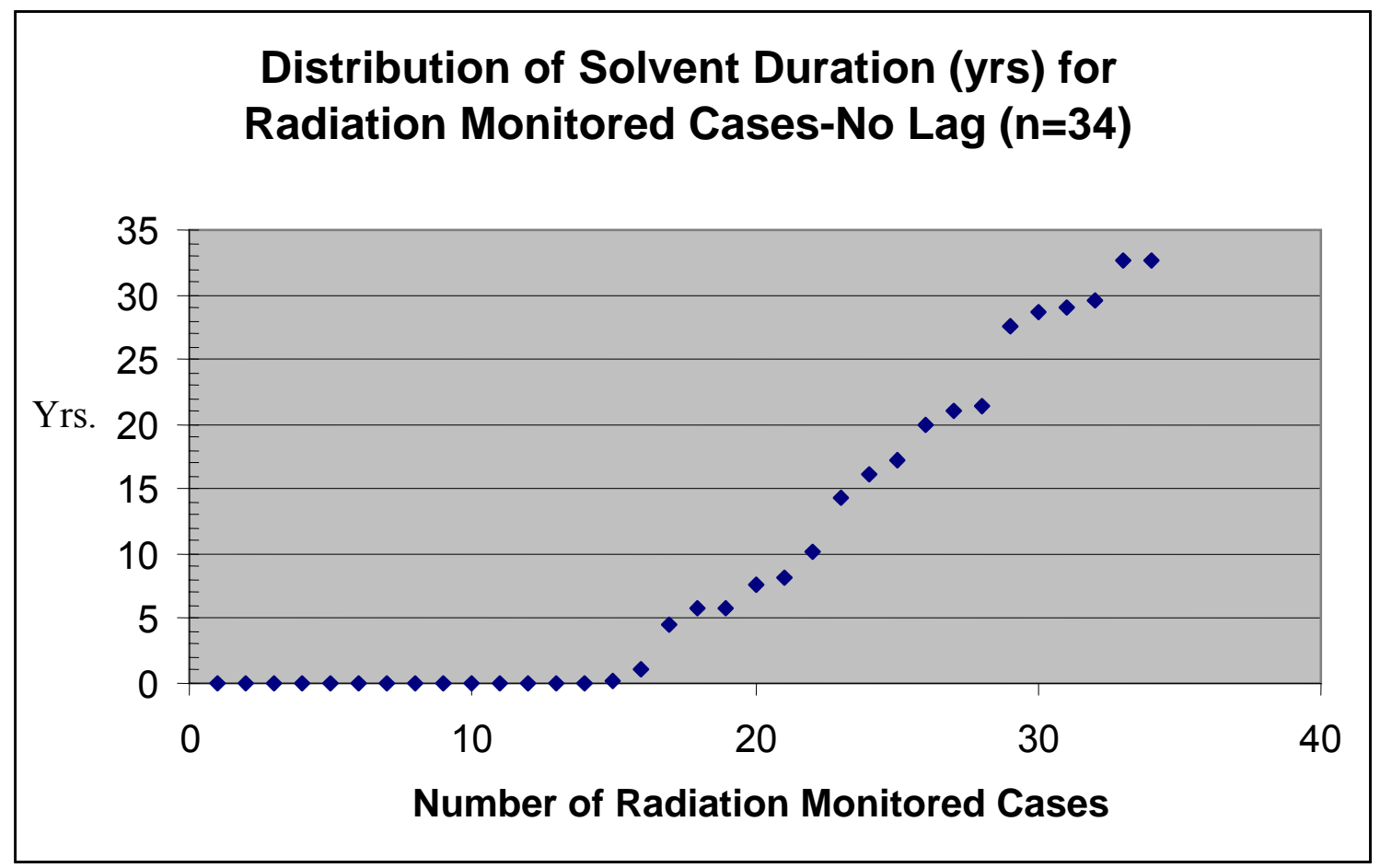


Table 34: Distribution of Solvent Duration (yrs) Non-Radiation Monitored Cases

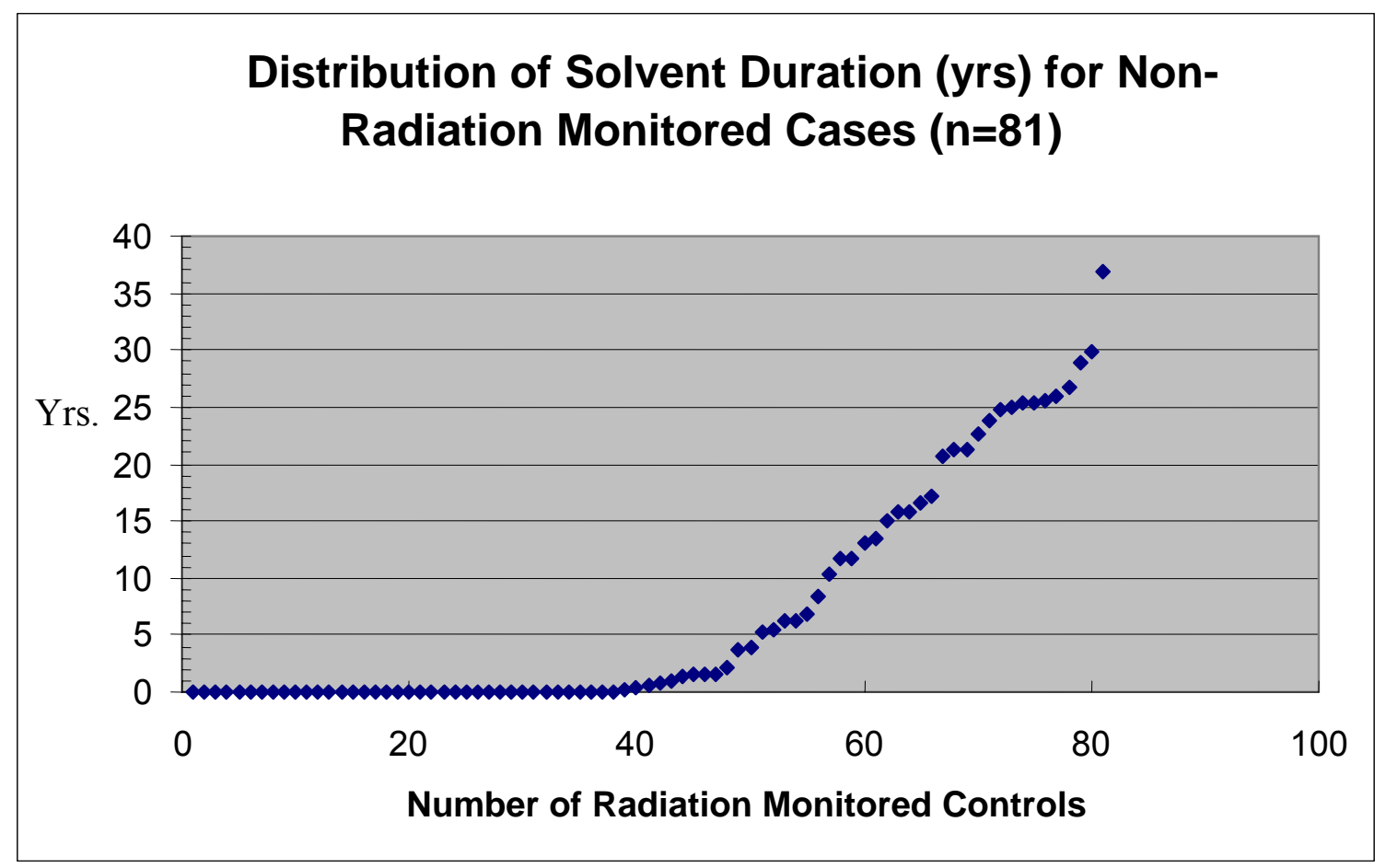


Table 35: Distribution of Solvent Duration (yrs) Radiation Monitored Controls

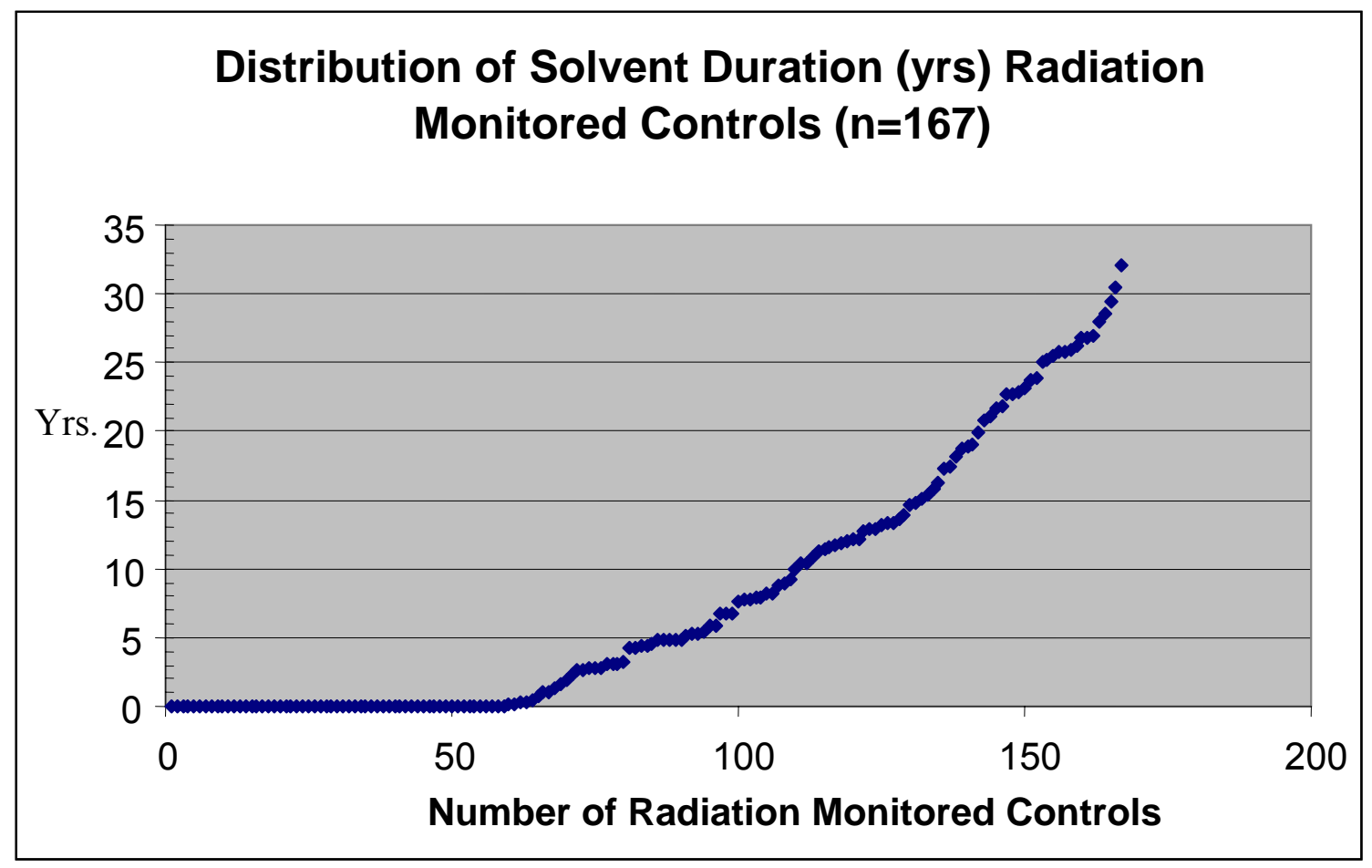


Table 36: Distribution of Solvent Duration (yrs) Non-Radiation Monitored Controls

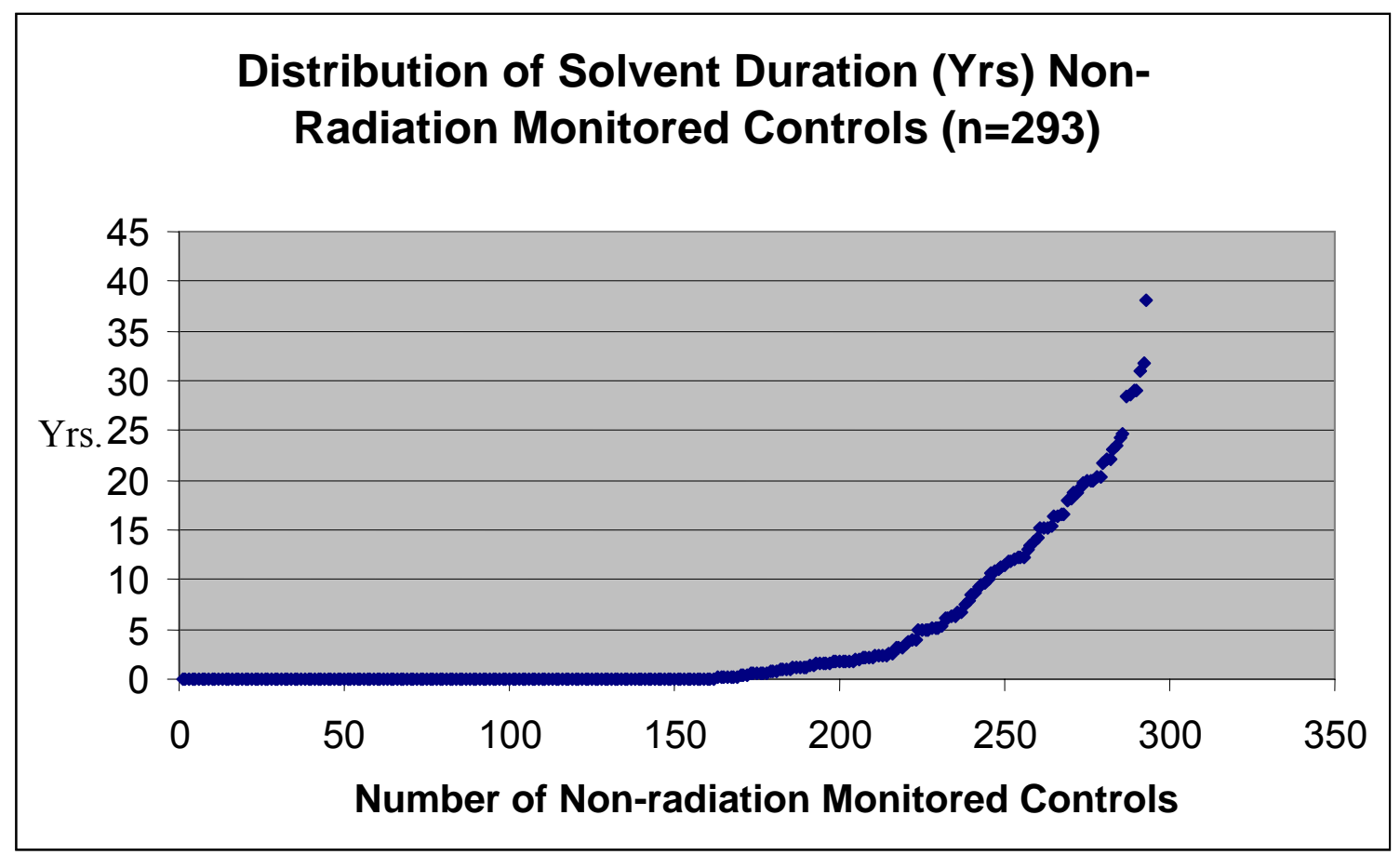




\begin{tabular}{||cccccccc||}
\hline Table 37: OR by Dose Category Onsite, Offsite, and Missed Badge Dose \\
Lagged Two years ( $=201$ Radiation Monitored Workers)
\end{tabular}




\section{DEPARTMENT OF HEALTH AND HUMAN SERVICES}

Centers for Disease Control and Prevention

National Institute for Occupational Safety and Health

4676 Columbia Parkway

Cincinnati, OH 45226-1998

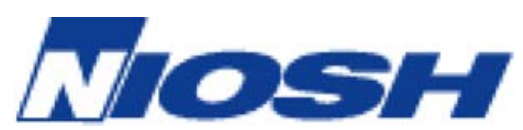

Delivering on the Nation's promise:

Safety and health at work for all people through research and prevention

To receive NIOSH documents or more information about occupational safety and health topics, contact NIOSH at

1-800-35-NIOSH (1-800-356-4674)

Fax: 513-533-8573

E-mail:pubstaft@cdc.gov

or visit the NIOSH Web site at

www.cdc.gov/niosh

DHHS (NIOSH) Publication No. 2005-104 